\title{
Brassica - Wildarten als neue genetische Ressource für die Rapszüchtung
}

\author{
Dissertation \\ zur Erlangung des Doktorgrades \\ der Fakultät für Agrarwissenschaften \\ der Georg-August-Universität Göttingen
}

\author{
vorgelegt von \\ Tobias Jesske \\ geboren in Wolfenbüttel
}

Göttingen, im Mai 2011 
D 7

1. Referent: Prof. Dr. Heiko C. Becker

2. Korreferent: PD Dr. Rod Snowdon

Tag der mündlichen Prüfung: 21. Juli 2011 
Meinen Eltern 



\section{Inhaltsverzeichnis}

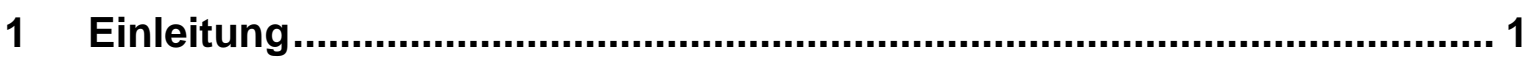





1.3 Wildarten der Brassica oleracea-Gruppe ........................................... 4



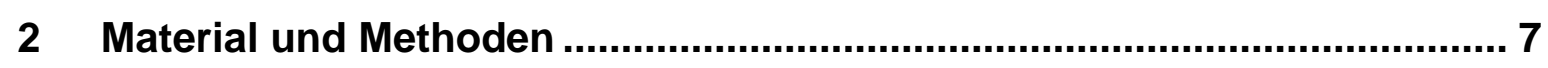

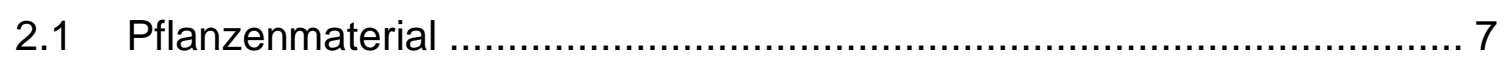

2.1.1 Brassica napus L. - Resynthesen und Zuchtmaterial .............................. 7

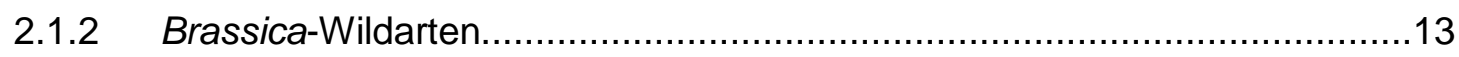

2.2 Anzucht der Pflanzen und Probenahme .......................................... 15

2.2.1 Resynthesen und Rapssorten für AFLP und Testkreuzungen....................15

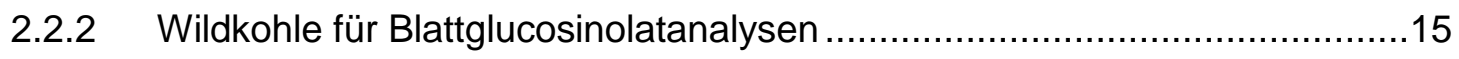





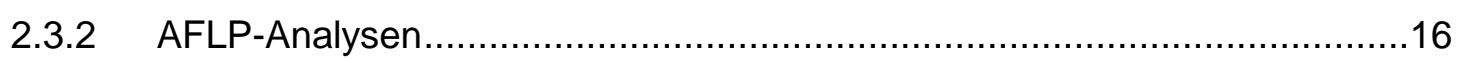

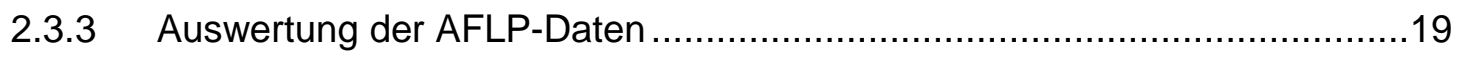



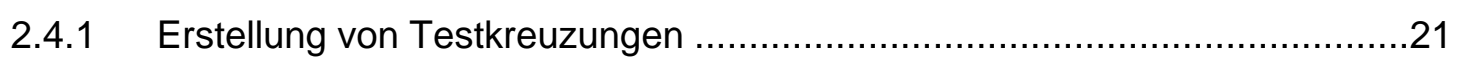

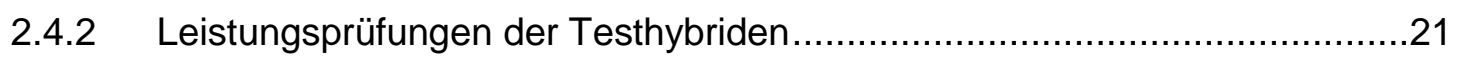

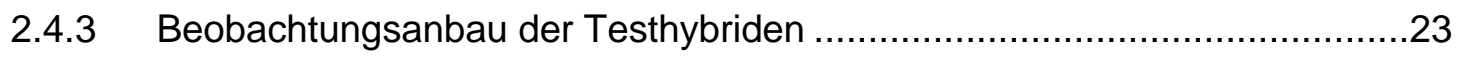

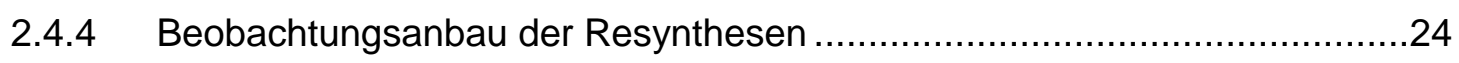

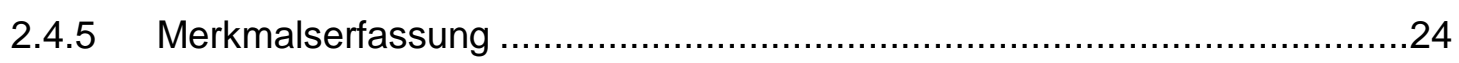

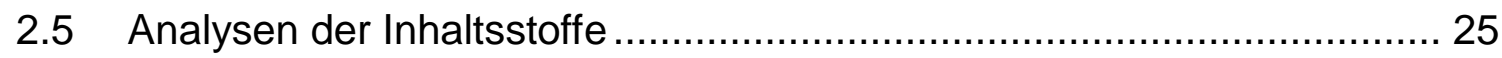

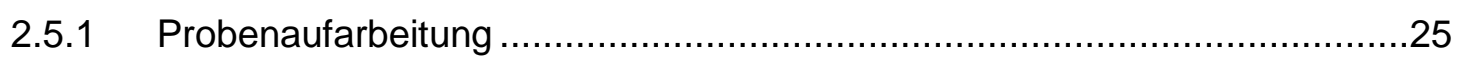



2.5.3 Gaschromatographie (GC) zur Bestimmung der Fettsäuremuster ..............26

2.5.4 HPLC (high performance liquid chromatography) zur Bestimmung der Glucosinolatgehalte und der Glucosinolatmuster .......................................27

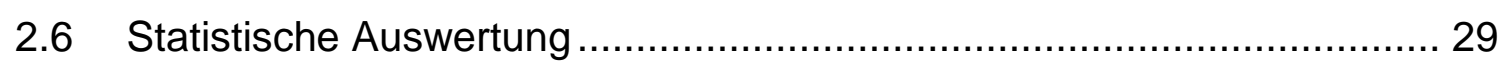









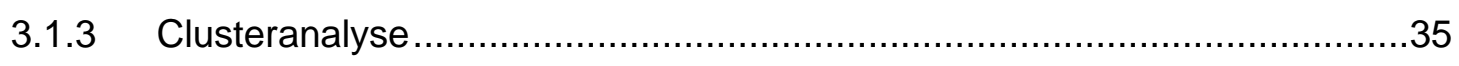

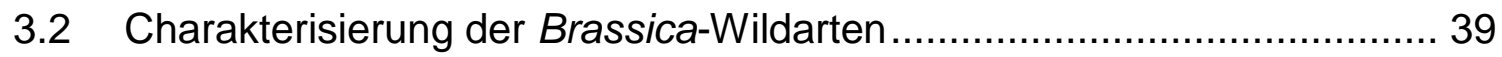

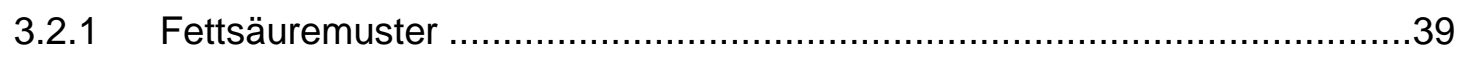

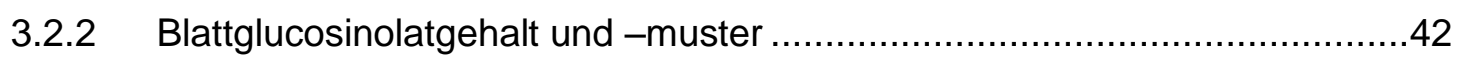


3.3 Agronomische Eigenschaften der Resynthesen................................. 46

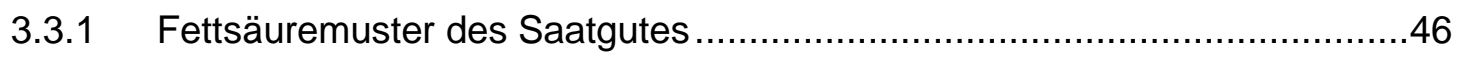

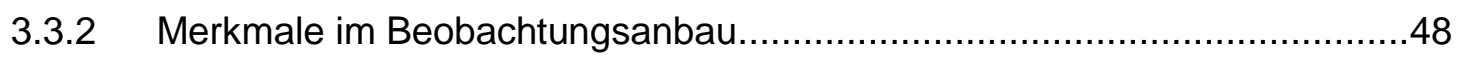

3.4 Agronomische Eigenschaften der Testkreuzungen .............................. 59

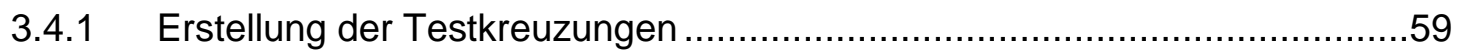



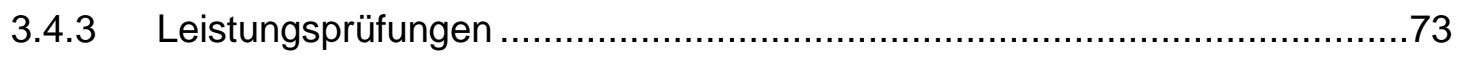

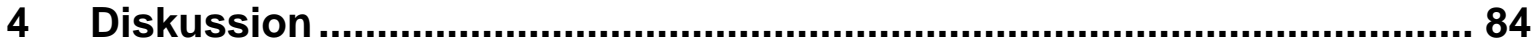



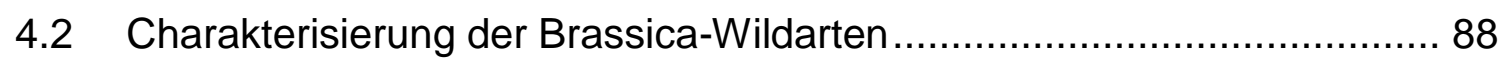

4.3 Agronomische Eigenschaften der Resynthesen.................................. 92

4.4 Agronomische Eigenschaften der Testkreuzungen .............................. 95

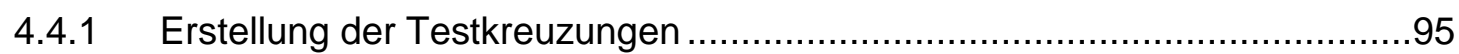

4.4.2 Beobachtungsanbau und Leistungsprüfungen der Testkreuzungen.............96







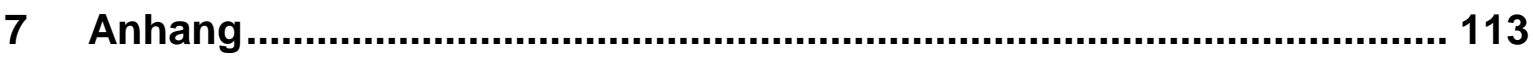




\section{$1 \quad$ Einleitung}

\subsection{Agronomische Bedeutung des Rapses}

Raps (Brassica napus) ist eine, im Vergleich mit anderen Kulturarten wie Mais (Zea mays) oder Weizen (Triticum aestivum), sehr junge Kulturpflanze aus der Familie der Kreuzblütler (Brassicaceae, ehemals Cruciferaceae). Die ältesten Hinweise der Nutzung von Raps zur Ölgewinnung stammen erst aus dem 16. Jhd. aus den Niederlanden (TOXOPEUS 1979, vgl. GIRKE 2002). Eine intensive züchterische Bearbeitung erfolgt aber erst seit wenigen Jahrzehnten. In dieser kurzen Zeit hat sich der Raps zu einer der wichtigsten Öl- und Eiweißpflanzen entwickelt. Mit einer weltweiten Produktion von 56,5 Mio. Tonnen im Jahr 2010 (FAO 2010) rangiert der Raps nach der Sojabohne (Glycine max) an zweiter Stelle der Ölsaaten. In Europa steht er mit einer Anbaufläche von 6,9 Mio. ha und einer Produktionsmenge von 28 Mio. Tonnen sogar an erster Stelle (BMELV 2010). Diese rasante Entwicklung war vor allem aufgrund der Züchtung des 00-Rapses möglich. Dieser enthält praktisch keine Erucasäure und weist einen sehr geringen Samenglucosinolatgehalt auf, wodurch ein großer Schritt in der Verwertbarkeit des Rapsöles als Nahrungsmittel sowie der Verwendbarkeit der Pressrückstände als Tierfutter gemacht wurde.

Einen weiteren Fortschritt in der Rapszüchtung erbrachte die Entwicklung stabiler Hybridsysteme. Die größte Bedeutung haben hierbei das Ogura/INRA cmsSystem, welches durch Protoplastenfusion von Ölrettich und Raps entwickelt wurde (RENARD et al. 1997) und das MSL-System, welches auf eine spontane Mutation und anschließende Selektion zurückzuführen ist (PAULMANN \& FraUEN 1998). Seit kurzem steht außerdem ein neues kerngenetisch vererbtes System von der Firma Syngenta mit dem Namen Safecross ${ }^{\mathrm{TM}}$ für die Entwicklung von Hybridsorten zur Verfügung. Im Gegensatz zum MSL- und Safecross ${ }^{{ }^{T M}}$-System, für die, soweit bekannt, alle Rapsformen als Restorer fungieren, werden für das Ogura/INRA cms-System spezielle Restorer-Linien als Bestäuber benötigt.

Um auf Dauer einen konstanten Fortschritt in der Pflanzenzüchtung gewährleisten zu können, ist jedoch ein möglichst divergentes Ausgangsmaterial unabdingbar. Dieses ist im Raps so nicht verfügbar. Das Zuchtmaterial weist hier einen hohen Verwandtschaftsgrad auf, wie in einer Reihe von Studien nachgewiesen wurde (vgl. Diers \& OSBORN 1993, BeCKER et al. 1995; KNAAK 1996; Voss et al. 1998; 
LOMBARD et al. 2000, PLIESKE \& StRUSS 2001; GIRKE 2002; HASAN et al. 2006). Zu erklären ist dies einerseits damit, dass die intensive Züchtung auf bestimmte Qualitätsmerkmale im Raps zu einer Einengung der genetischen Basis geführt hat (SEYIS et al. 2001 und 2005; HASAN et al. 2004), und andererseits das heutige Zuchtmaterial vermutlich auf wenige Ausgangspflanzen hybridogenen Ursprungs zurückgeht (BECKER et al. 1995).

\subsection{Resynthesen}

Erst 1833 wurde der Raps botanisch durch METZGER eindeutig vom Rübsen unterschieden. Dieser erkannte auch anhand morphologischer Merkmale, dass die Entstehung des Rapses (Brassica napus; AACC, $2 n=38$ ) auf eine Kreuzung von Rübsen (Brassica rapa; $A A, 2 n=20$ ) und Kohl (Brassica oleracea; $C C, 2 n=18$ ) zurückgehen muss. Cytogenetische Analysen ließen MoRINAGA (1934) ebenfalls zu dieser Schlussfolgerung kommen, die durch U (1935) bestätigt wurde. MORINAGA (1934) und $U$ (1935) belegten durch ihre cytogenetischen Untersuchungen und Kreuzungsstudien außerdem die amphidiploide Struktur des Genoms von Brassica napus (AACC, $2 n=18$ ) sowie den verwandten Arten Brassica juncea (AABB, $2 n=36$ ), die auf Hybridisation zwischen $B$. rapa (AA, $2 n=20$ ) und $B$. nigra ( $B B, 2 n=16$ ) zurückgeht, und $B$. carinata (BBCC, $2 n=34$ ), die ursprünglich aus einer Kreuzung zwischen $B$. nigra $(B B, 2 n=16)$ und B. oleracea $(C C, 2 n=18)$ entstanden ist.

Aufgrund dieser amphidiploiden Struktur des Rapses ist es möglich durch artifizielle Kreuzungen von Rübsen und Kohl neue Rapsformen, sogenannte Resynthesen zu erschaffen. Das diese zur Erweiterung der genetischen Variabilität des Rapsgenpools genutzt werden können, wurde in der Züchtungsforschung schnell erkannt (SEYIS et al. 2001). Dabei stand zunächst die Verbesserung agronomischer Merkmale wie Winterhärte, Öl- und Kornertrag und Krankheitstoleranz im Vordergrund (FRIEDT \& LÜHS 1994). Beispiele hierfür finden sich unter anderem bei Rudorf (1951, 1958), Hoffmann \& Peters (1958); OLSSON (1960) (vgl. FRIEDT \& LÜHS 1994). Später wurden Resynthesen auch erfolgreich in der Züchtung eingesetzt. So sind unter anderem die deutsche Sorte ,Rapol' sowie die schwedischen Sorten ,Panter' und ,Norde' aus Kreuzungen mit Resynthesen hervorgegangen (OLSSON 1986). Die Sorte ,Rapol' wurde in 
Deutschland sogar als Kreuzungselter in der Linienzüchtung eingesetzt (BECKER et al. 1999). Mit der Einführung des 00-Rapses ging die Bedeutung der Resynthesen als direkte Kreuzungspartner in der Sortenentwicklung zurück, da sie in der Regel hohe Glucosinolatgehalte und Erucasäure aufweisen. Dennoch behielten sie eine gewisse Bedeutung als Quelle von verschiedenen züchterisch interessanten Eigenschaften wie Krankheitsresistenzen z.B. gegen Kohlhernie (DIEDERICHSEN 1992) und Phoma (Mithen \& MAGRATH 1992) oder extreme Fettsäuremuster (z.B. hohe Erucasäuregehalte (LÜHS \& FRIEDT 1994). Eine umfangreiche Übersicht hierzu findet sich bei FRIEDT \& LÜHS (1994). Auch heutzutage stellen Resynthesen nach wie vor eine wichtige Quelle für Resistenzen gegen Schadorganismen dar. Dies zeigen unter anderem die Arbeiten von HAPPSTADIUS et al. (2003) und RYGULLA et al. (2007a und b, 2008). In diesen Studien wurden Brassica oleraceaAkzessionen auf ihre Resistenz gegenüber Verticillum longisporum untersucht. Anschließend wurden die gefundenen resistenten Kohlformen zu Erstellung von resynthetisiertem Raps genutzt, um die in den Kohlen vorhandenen Resistenzen in den für die Rapszüchtung zur Verfügung stehenden Genpool zu überführen.

Auch für die Hybridzüchtung werden die Resynthesen zunehmend interessant. GIRKE (2002) konnte zeigen, dass Resynthesen teilweise große genetische Distanzen zu derzeitigem Zuchtmaterial aufweisen, und dass Testhybriden aus angepasstem Winterrapszuchtmaterial und Resynthesen eine große Heterosis zeigen und hohe Erträge erbringen können. Auch SEYIS et al. (2005) konnten das hohe Ertragspotential solcher semisynthetischen Sorten auf Basis von Resyntheselinien aufzeigen.

Bisher wurden zur Erstellung von Resynthesen als Elter für das C-Genom fast ausschließlich Gemüseformen von Brassica oleracea verwendet. Durch ihre intensive züchterische Bearbeitung, weisen diese eine sehr große Formenvielfalt auf (vgl. Gladis \& HAMMER 1990 und 2003). Daneben gibt es aber auch eine ganze Reihe Brassica oleracea-Wildformen und nah verwandte BrassicaWildarten, die, wie verschiedene Studien gezeigt haben, für interspezifischen Kreuzungen mit Brassica rapa verwendet werden können (INOMATA 1993 und 2002). Ihr Potential für die Rapszüchtung ist bisher, mit Ausnahme einer Arbeit von MiTHEN \& MAGRATH (1992), nicht untersucht wurden. 


\subsection{Wildarten der Brassica oleracea-Gruppe}

Den Wildarten der Brassica oleracea-Formengruppen wird zunehmend eine große Bedeutung als Genreservoir für die Pflanzenzüchtung zugesprochen (SEYIS et al. 2001). Dies zeigt auch eine weltweite Umfrage bei Genbanknutzern, die ergab, dass es neben dem Interesse der Nutzer an den verschiedenen Sorten der wichtigsten Brassica-Arten auch ein großes Interesse an den verwandten Wildarten gibt (MCFERSON et al. 1996; vgl. BECKER 2001).

Nach Hanelt (2001) besteht die Gruppe der C-Genom tragenden BrassicaWildarten $(2 n=18)$ aus zehn Arten, die eine große morphologische Diversität aufweisen. Sie kommen mit Ausnahme von Brassica bourgeaui, dem KanarenKohl und Brassica oleracea, dem eigentlichen Wild-Kohl vor allem im Mittelmeergebiet vor (vgl. SNOGERUP et al. 1990. LANNÉR et al. 1997). Viele dieser Kohlarten sind endemisch in sehr kleinen Gebieten verbreitet. Hierzu gehören beispielsweise Brassica macrocarpa, die nur auf den Egadischen Inseln vorkommt oder auch Brassica hilarionis, die nur von wenigen Stellen auf der Insel Zypern bekannt ist.

Den absoluten Verbreitungsschwerpunkt stellt die Insel Sizilien dar, auf der insgesamt vier Arten vorkommen, während die meisten Arten keine überlappenden Verbreitungsgebiete aufweisen (vgl. SNOGERUP et al. 1990; LANNÉR et al. 1997).

Für einige Wildarten wird angenommen, dass sie an der Entwicklung der Brassica oleracea-Kulturformen beteiligt waren, so z.B. der Kretische Kohl (Brassica cretica) (HANELT 2001). Dies ist nicht weiter verwunderlich, da die Arten mehr oder weniger gut unter einander kreuzbar sind und anzunehmen ist, dass in ihren Verbreitungsgebieten auch Kohl-Kulturformen angebaut werden.

Wie verschiedenen Diversitätsstudien zeigen konnten, weisen die BrassicaWildarten aus der Brassica oleracea-Gruppe nicht nur eine große morphologische Variabilität auf, sondern auch eine große genetische Diversität (LANNÉR et al. 1997; LÁZARO \& AGUINAGALDE 1998; Mel et al. 2010). Diese große Diversität und die Tatsache, dass sie für die Herstellung von resynthetisierten Rapsformen genutzt werden können, macht sie für die Rapszüchtung äußerst interessant. Es ist zu erwarten, dass sie neben der von MITHEN \& MARGATH (1992) beschriebenen 
Resistenz gegen Phoma (aus Brassica insularis, syn. B. atlantica) viele weitere züchterisch interessante Eigenschaften aufweisen.

\subsection{Zielsetzung}

Wie bereits beschrieben, gibt es in der Brassica oleracea-Gruppe eine Reihe von Wildarten, die aufgrund ihrer großen phänotypischen (vgl. z.B. MithEN 1987; VeLASCO et al. 1998; VELASCO \& BECKER 2000) und genetischen Diversität (vgl. LANNÉR et al. 1997; LÁZARO \& AGUINAGALDE 1998; Mel et al. 2010) ein großes züchterisches Potential für die Rapszüchtung erwarten lassen.

Um zu überprüfen, wie groß dieses Potential tatsächlich ist, wurden WildResynthesen (Resynthesen mit Brassica oleracea-Wildformen oder verwandten Brassica-Wildarten), die im Rahmen eines vorhergehenden Projektes erstellt wurden, zusammen mit einer Reihe „klassischer" Resynthesen (Resynthesen mit Brassica oleracea-Kulturformen) und einem breitgefächertem Sortiment aus dem weltweiten Rapszuchtmaterial mittels molekularer Marker charakterisiert.

Des Weiteren wurden die agronomischen Eigenschaften der Wild-Resynthesen in Feldversuchen untersucht und die qualitätsbestimmenden Inhaltstoffe ihre Samen bestimmt.

$\mathrm{Da}$ von den Resynthesen hinsichtlich ihrer Ertragseigenschaften keine überragenden Leistungen erwartet werden konnte, wurden Testkreuzungen mit zwei Testern aus dem angepasstem Winterrapsmaterial angefertigt. Hierfür wurden zwei männlich sterile Linien verwendet. Von diesen trug eine das MSLSystem (,MSL 007', NPZ) und die andere das Safecross ${ }^{\mathrm{TM}}$-System (,RNX 4621', Syngenta). Diese beiden Systeme fanden Verwendung, da sie durch alle bekannten Rapsformen restauriert werden können. Das Ogura/INRA cms-System kam nicht zur Anwendung, da hier spezielle Restorer benötigt werden. Es ist somit für Versuche mit Resynthesen nur schlecht geeignet.

Aufgrund der hohen zu erwartenden genetischen Distanz der Wild-Resynthesen zum Zuchtmaterial war anzunehmen, dass die Testhybriden bei entsprechender Kombinationseignung der Wild-Resynthesen mit angepasstem Zuchtmaterial einen hohen Hybridertrag erbringen. Auch die Testhybriden wurden in mehrortigen Feldversuchen hinsichtlich ihrer agronomischen Eigenschaften geprüft. Außerdem 
wurden nach der Ernte die qualitätsbestimmenden Eigenschaften der Samen bestimmt.

Das Hauptziel dieser Arbeit war es somit, das bisher ungenutzte Potential der Wildarten durch ihre Verwendung als Elter für die Erstellung von Resynthesen für die Pflanzenzüchtung verfügbar zu machen, um auf diesem Wege den für die Rapszüchtung zur Verfügung stehenden Genpool zu erweitern. Die konkreten Fragestellungen, die sich dabei ergaben waren folgende:

(1) Zeigen Resynthesen die mit Brassica-Wildarten erstellt wurden im Vergleich zu klassischen Resynthesen eine größere genetische Distanz zum angepassten Zuchtmaterial und stellen sie eine Erweiterung des für die Rapszüchtung nutzbaren Genpools dar?

(2) Welche agronomischen Eigenschaften weisen derartige Resynthesen auf?

(3) Wie gut ist die Kombinationseignung derartiger Resynthesen in Kreuzungen mit angepasstem Winterrapszuchtmaterial? 


\section{Material und Methoden}

\subsection{Pflanzenmaterial}

\subsubsection{Brassica napus L. - Resynthesen und Zuchtmaterial}

Insgesamt wurden 71 resynthetisierte Rapslinien mittels AFLP-Analyse auf ihre genetische Verwandtschaft zum Zuchtmaterial untersucht. Das besondere Augenmerk lag dabei auf 44 „Wild“-Resynthesen, deren Abstammung auf Kreuzungen von Brassica rapa (A-Genom) mit insgesamt elf verschiedenen, das C-Genom tragenden, Brassica-Wildarten (B. bourgeaui, B. cretica, B. incana, B insularis, B. hilarionis, B. macrocarpa, B montana, B. oleracea, B. rupestris, $B$ taurica und $B$. villosa) zurückzuführen ist. Eine Übersicht über diese WildResynthesen sowie über ihre Abstammung ist in Tabelle 2-1 gegeben, weitere Angaben zu den einzelnen, für die Erstellung der Resynthesen verwendeten, Wildkohl-Akzessionen sind aus Tabelle 2-4 zu entnehmen.

Tab. 2-1: Übersicht über die Abstammung der Wild-Resynthesen

\begin{tabular}{|c|c|c|c|c|c|c|}
\hline \multirow{2}{*}{$\begin{array}{l}\text { Resynthese } \\
\begin{array}{l}\text { Bezeich- } \\
\text { nung }\end{array} \\
\end{array}$} & \multicolumn{6}{|c|}{ Ausgangselter } \\
\hline & Mutter & $\begin{array}{l}\text { Sorte / } \\
\text { Typ }^{1}\end{array}$ & $\begin{array}{l}\text { Akzes- } \\
\text { sion }\end{array}$ & Vater & $\begin{array}{l}\text { Sorte / } \\
\text { Typ }\end{array}$ & $\begin{array}{l}\text { Akzes- } \\
\text { sion }\end{array}$ \\
\hline BOY 1 & $\begin{array}{l}\text { B. rapa ssp. } \\
\text { trilocularis }\end{array}$ & $\begin{array}{l}\text { Yellow } \\
\text { Sarson }\end{array}$ & $\mathrm{RO} 18$ & B. bourgeaui & WS & $\begin{array}{l}\text { BRA 2998 } \\
(=\mathrm{K} 9825)\end{array}$ \\
\hline CRL 1 & $\begin{array}{l}\text { B. rapa ssp. } \\
\text { oleifera }\end{array}$ & 'Largo' & & $\begin{array}{l}\text { B. cretica } \\
\text { ssp. aegaea }\end{array}$ & WS & 6346 \\
\hline CRY 1 & $\begin{array}{l}\text { B. rapa ssp. } \\
\text { trilocularis }\end{array}$ & $\begin{array}{l}\text { Yellow } \\
\text { Sarson }\end{array}$ & $\mathrm{R} 018$ & B. cretica & WS & 5971 \\
\hline CRY 2 & $\begin{array}{l}\text { B. rapa ssp. } \\
\text { trilocularis }\end{array}$ & $\begin{array}{l}\text { Yellow } \\
\text { Sarson }\end{array}$ & R018 & $\begin{array}{l}\text { B. cretica } \\
\text { ssp aegaea }\end{array}$ & WS & 6021 \\
\hline HIL 1 & B. hilarionis & WS & $\begin{array}{l}\text { HRIGRU } \\
12483\end{array}$ & $\begin{array}{l}\text { B. rapa ssp. } \\
\text { oleifera }\end{array}$ & 'Largo' & \\
\hline HIY 1 & $\begin{array}{l}\text { B. rapa ssp. } \\
\text { trilocularis }\end{array}$ & $\begin{array}{l}\text { Yellow } \\
\text { Sarson }\end{array}$ & R018 & B. hilarionis & WS & 7344 \\
\hline HIY 2 & $\begin{array}{l}\text { B. rapa ssp. } \\
\text { trilocularis }\end{array}$ & $\begin{array}{l}\text { Yellow } \\
\text { Sarson }\end{array}$ & A59 & B. hilarionis & WS & $\begin{array}{l}\text { HRIGRU } \\
12483\end{array}$ \\
\hline INL 1 & $\begin{array}{l}\text { B. rapa ssp. } \\
\text { oleifera }\end{array}$ & 'Largo' & & B. incana & WS & 6570 \\
\hline INL 2 & $\begin{array}{l}\text { B. rapa ssp. } \\
\text { oleifera }\end{array}$ & 'Largo' & & B. incana & WS & 6572 \\
\hline INY 1 & $\begin{array}{l}\text { B. rapa ssp. } \\
\text { trilocularis }\end{array}$ & $\begin{array}{l}\text { Yellow } \\
\text { Sarson }\end{array}$ & RO18 & B. incana & WS & 6563 \\
\hline INY 3 & $\begin{array}{l}\text { B. rapa ssp. } \\
\text { trilocularis }\end{array}$ & $\begin{array}{l}\text { Yellow } \\
\text { Sarson }\end{array}$ & $\mathrm{RO} 18$ & B. incana & WS & 6569 \\
\hline INY 4 & $\begin{array}{l}\text { B. rapa ssp. } \\
\text { trilocularis }\end{array}$ & $\begin{array}{l}\text { Yellow } \\
\text { Sarson }\end{array}$ & $\mathrm{RO} 18$ & B. incana & WS & 6570 \\
\hline INY 5 & $\begin{array}{l}\text { B. rapa ssp. } \\
\text { trilocularis }\end{array}$ & $\begin{array}{l}\text { Yellow } \\
\text { Sarson }\end{array}$ & R018 & B. incana & WS & $\begin{array}{l}\text { BRA } 2918 \\
(=\mathrm{K} 8118)\end{array}$ \\
\hline
\end{tabular}

${ }^{1}$ WT $=$ Wildtyp (nur für B. oleracea verwendet), WS = Wildart/-spezies, TK = traditionelles Kultivar 
Tab. 2-1: Übersicht über die Abstammung der Wild-Resynthesen (Fortsetzung)

\begin{tabular}{|c|c|c|c|c|c|c|}
\hline Resynthese & Ausgangselter & & & & & \\
\hline $\begin{array}{l}\text { Bezeich- } \\
\text { nung }\end{array}$ & Mutter & $\begin{array}{l}\text { Sorte / } \\
\text { Typ }^{1}\end{array}$ & $\begin{array}{l}\text { Akzes- } \\
\text { sion }\end{array}$ & Vater & $\begin{array}{l}\text { Sorte / } \\
\text { Typ }{ }^{1}\end{array}$ & $\begin{array}{l}\text { Akzes- } \\
\text { sion }\end{array}$ \\
\hline INY 6 & $\begin{array}{l}\text { B. rapa ssp. } \\
\text { trilocularis }\end{array}$ & $\begin{array}{l}\text { Yellow } \\
\text { Sarson }\end{array}$ & RO18 & B. incana & WS & CGN18470 \\
\hline ISY 1 & $\begin{array}{l}\text { B. rapa ssp. } \\
\text { trilocularis }\end{array}$ & $\begin{array}{l}\text { Yellow } \\
\text { Sarson }\end{array}$ & RO18 & B. insularis & WS & 7356 \\
\hline ISY 2 & $\begin{array}{l}\text { B. rapa ssp. } \\
\text { trilocularis }\end{array}$ & $\begin{array}{l}\text { Yellow } \\
\text { Sarson }\end{array}$ & R018 & B. insularis & WS & $\begin{array}{l}\text { BRA } 2996 \\
(=\text { K 8934) }\end{array}$ \\
\hline J 104 & $\begin{array}{l}\text { B. rapa ssp. } \\
\text { trilocularis }\end{array}$ & $\begin{array}{l}\text { Yellow } \\
\text { Sarson }\end{array}$ & Syn 9 & $\begin{array}{l}\text { B. oleracea } \\
\text { ssp. oleracea }\end{array}$ & WT & BRA 259 \\
\hline J 112 & $\begin{array}{l}\text { B. rapa ssp. } \\
\text { trilocularis }\end{array}$ & $\begin{array}{l}\text { Yellow } \\
\text { Sarson }\end{array}$ & Syn 9 & $\begin{array}{l}\text { B. oleracea } \\
\text { ssp. oleracea }\end{array}$ & WT & BRA 101 \\
\hline J 134 & $\begin{array}{l}\text { B. oleracea } \\
\text { ssp. oleracea }\end{array}$ & WT & BRA 260 & B. rapa & ,NPZ 00‘ & \\
\hline J 154 & $\begin{array}{l}\text { B. oleracea } \\
\text { ssp. oleracea }\end{array}$ & WT & BRA 260 & $\begin{array}{l}\text { B. rapa ssp. } \\
\text { trilocularis }\end{array}$ & $\begin{array}{l}\text { Yellow } \\
\text { Sarson }\end{array}$ & Syn 9 \\
\hline J 161 & $\begin{array}{l}\text { B. rapa ssp. } \\
\text { trilocularis }\end{array}$ & $\begin{array}{l}\text { Yellow } \\
\text { Sarson }\end{array}$ & Syn 9 & $\begin{array}{l}\text { B. oleracea } \\
\text { ssp. oleracea }\end{array}$ & WT & BRA 259 \\
\hline J 166 & $\begin{array}{l}\text { B. oleracea } \\
\text { ssp. oleracea }\end{array}$ & WT & BRA 101 & $\begin{array}{l}\text { B. rapa ssp. } \\
\text { trilocularis }\end{array}$ & $\begin{array}{l}\text { Yellow } \\
\text { Sarson }\end{array}$ & Syn 9 \\
\hline J 32 & $\begin{array}{l}\text { B. rapa ssp. } \\
\text { trilocularis }\end{array}$ & $\begin{array}{l}\text { Yellow } \\
\text { Sarson }\end{array}$ & Syn 9 & $\begin{array}{l}\text { B. oleracea } \\
\text { ssp. oleracea }\end{array}$ & WT & BRA 259 \\
\hline J 400 & $\begin{array}{l}\text { B. oleracea } \\
\text { ssp. oleracea }\end{array}$ & WT & BRA 101 & B. rapa & ,NPZ 00‘ & \\
\hline J 401 & $\begin{array}{l}\text { B. oleracea } \\
\text { ssp. oleracea }\end{array}$ & WT & BRA 260 & B. rapa & ,NPZ 00‘ & \\
\hline J 408 & $\begin{array}{l}\text { B. oleracea } \\
\text { ssp. oleracea }\end{array}$ & WT & BRA 260 & $\begin{array}{l}\text { B. rapa ssp. } \\
\text { trilocularis }\end{array}$ & $\begin{array}{l}\text { Yellow } \\
\text { Sarson }\end{array}$ & Syn 9 \\
\hline J 410 & $\begin{array}{l}\text { B. rapa ssp. } \\
\text { trilocularis }\end{array}$ & $\begin{array}{l}\text { Yellow } \\
\text { Sarson }\end{array}$ & Syn 9 & $\begin{array}{l}\text { B. oleracea } \\
\text { ssp. oleracea }\end{array}$ & WT & BRA 101 \\
\hline J 45 & $\begin{array}{l}\text { B. rapa ssp. } \\
\text { trilocularis }\end{array}$ & $\begin{array}{l}\text { Yellow } \\
\text { Sarson }\end{array}$ & Syn 9 & $\begin{array}{l}\text { B. oleracea } \\
\text { ssp. oleracea }\end{array}$ & WT & BRA 108 \\
\hline MAY 1 & $\begin{array}{l}\text { B. rapa ssp. } \\
\text { trilocularis }\end{array}$ & $\begin{array}{l}\text { Yellow } \\
\text { Sarson }\end{array}$ & $\mathrm{RO} 18$ & $\begin{array}{l}\text { B. macro- } \\
\text { carpa }\end{array}$ & WS & 6584 \\
\hline MOL 1 & $\begin{array}{l}\text { B. rapa ssp. } \\
\text { oleifera }\end{array}$ & ,Largo' & & B. montana & WS & K 7220 \\
\hline MOL 2 & $\begin{array}{l}\text { B. rapa ssp. } \\
\text { oleifera }\end{array}$ & ,Largo‘ & & B. montana & WS & $\begin{array}{l}\text { BRA } 2946 \\
(=\text { K 8380) }\end{array}$ \\
\hline MOL 4 & $\begin{array}{l}\text { B. rapa ssp. } \\
\text { oleifera }\end{array}$ & ,Largo‘ & & B. montana & WS & 6816 \\
\hline MOY 1 & $\begin{array}{l}\text { B. rapa ssp. } \\
\text { trilocularis }\end{array}$ & $\begin{array}{l}\text { Yellow } \\
\text { Sarson }\end{array}$ & R018 & B. montana & WS & 6801 \\
\hline MOY 2 & $\begin{array}{l}\text { B. rapa ssp. } \\
\text { trilocularis }\end{array}$ & $\begin{array}{l}\text { Yellow } \\
\text { Sarson }\end{array}$ & $\mathrm{RO} 18$ & B. montana & WS & 6816 \\
\hline MOY 4 & $\begin{array}{l}\text { B. rapa ssp. } \\
\text { trilocularis }\end{array}$ & $\begin{array}{l}\text { Yellow } \\
\text { Sarson }\end{array}$ & R018 & B. montana & WS & 6835 \\
\hline MOY 5 & $\begin{array}{l}\text { B. rapa ssp. } \\
\text { trilocularis }\end{array}$ & $\begin{array}{l}\text { Yellow } \\
\text { Sarson }\end{array}$ & RO18 & B. montana & WS & $\begin{array}{l}\text { BRA } 2942 \\
(=\text { K } 7220)\end{array}$ \\
\hline MOY 6 & $\begin{array}{l}\text { B. rapa ssp. } \\
\text { trilocularis }\end{array}$ & $\begin{array}{l}\text { Yellow } \\
\text { Sarson }\end{array}$ & R018 & B. montana & WS & CGN18472 \\
\hline MOY 7 & $\begin{array}{l}\text { B. rapa ssp. } \\
\text { trilocularis }\end{array}$ & $\begin{array}{l}\text { Yellow } \\
\text { Sarson }\end{array}$ & $\mathrm{RO} 18$ & B. montana & WS & $\begin{array}{l}\text { BRA } 2993 \\
(=\text { K 7223) }\end{array}$ \\
\hline
\end{tabular}

${ }^{1}$ WT $=$ Wildtyp (nur für B. oleracea verwendet), WS = Wildart/-spezies, TK = traditionelles Kultivar 
Tab. 2-1: Übersicht über die Abstammung der Wild-Resynthesen (Fortsetzung)

\begin{tabular}{|c|c|c|c|c|c|c|}
\hline Resynthese & & & Aus & selter & & \\
\hline $\begin{array}{l}\text { Bezeich- } \\
\text { nung }\end{array}$ & Mutter & $\begin{array}{l}\text { Sorte / } \\
\text { Typ }\end{array}$ & $\begin{array}{l}\text { Akzes- } \\
\text { sion }\end{array}$ & Vater & $\begin{array}{l}\text { Sorte / } \\
\text { Typ }\end{array}$ & $\begin{array}{l}\text { Akzes- } \\
\text { sion }\end{array}$ \\
\hline OLL 1 & $\begin{array}{l}\text { B. rapa ssp. } \\
\text { oleifera }\end{array}$ & ,Largo“ & & $\begin{array}{l}\text { B. oleracea } \\
\text { ssp. oleracea }\end{array}$ & WT & BRA 258 \\
\hline OLY 1 & $\begin{array}{l}\text { B. rapa ssp. } \\
\text { trilocularis }\end{array}$ & $\begin{array}{l}\text { Yellow } \\
\text { Sarson }\end{array}$ & R018 & B. oleracea & WT & 7660 \\
\hline OLY 2 & $\begin{array}{l}\text { B. rapa ssp. } \\
\text { trilocularis }\end{array}$ & $\begin{array}{l}\text { Yellow } \\
\text { Sarson }\end{array}$ & R018 & $\begin{array}{l}\text { B. oleracea } \\
\text { var. selenisia }\end{array}$ & TK & $\begin{array}{l}\text { BRA 1668 } \\
(=\text { K 9344) }\end{array}$ \\
\hline RUY 1 & $\begin{array}{l}\text { B. rapa ssp. } \\
\text { trilocularis }\end{array}$ & $\begin{array}{l}\text { Yellow } \\
\text { Sarson }\end{array}$ & R018 & $\begin{array}{l}\text { B. rupestris } \\
\text { ssp. hispida }\end{array}$ & WS & 6580 \\
\hline TAY 1 & $\begin{array}{l}\text { B. rapa ssp. } \\
\text { trilocularis }\end{array}$ & $\begin{array}{l}\text { Yellow } \\
\text { Sarson }\end{array}$ & R018 & B. taurica & WS & $\begin{array}{l}\text { BRA 2947 } \\
(=\mathrm{K} 9238)\end{array}$ \\
\hline VIL 1 & $\begin{array}{l}\text { B. rapa ssp. } \\
\text { oleifera }\end{array}$ & ,Largo“ & & B. villosa & WS & $\begin{array}{l}\text { HRIGRU } \\
6848\end{array}$ \\
\hline
\end{tabular}

${ }^{1} \mathrm{WT}=$ Wildtyp (nur für $B$. oleracea verwendet), WS = Wildart/-spezies, TK = traditionelles Kultivar

Die übrigen 27 Resynthesen (siehe Tabelle 2-2.) basieren auf Kreuzungen diverser Brassica rapa-Formen mit sehr unterschiedlichen Brassica oleraceaKulturformen. Sie wurden zu Vergleichszwecken als Vertreter der „klassischen“ Resynthesen in das Untersuchungssortiment integriert. Mit Ausnahme der acht aus der Universität Gießen (JLU) stammenden Resynthesen und der Resynthese RS 8/6 die ursprünglich aus der Freien Universität Berlin (FUB) stammt, wurden all diese Genotypen in der Arbeit von GIRKE (2002) untersucht.

Tab. 2-2: Übersicht über die Abstammung der Resynthesen mit Brassica oleraceaKulturformen (vergl. GIRKE 2002)

\begin{tabular}{|c|c|c|c|c|c|c|}
\hline \multirow{2}{*}{$\begin{array}{l}\text { Resynthes } \\
\text { Bezeich- } \\
\text { nung }\end{array}$} & \multicolumn{6}{|c|}{ Ausgangselter } \\
\hline & Mutter & $\begin{array}{l}\text { Sorte / } \\
\text { Typ }\end{array}$ & $\begin{array}{l}\text { Akzes- } \\
\text { sion }\end{array}$ & Vater & $\begin{array}{l}\text { Sorte / } \\
\text { Typ }{ }^{1}\end{array}$ & $\begin{array}{l}\text { Akzes- } \\
\text { sion }\end{array}$ \\
\hline \multicolumn{7}{|c|}{ Resynthesen aus der GAU ${ }^{1}$} \\
\hline G 39 & $\begin{array}{l}\text { B. oler. conv. } \\
\text { capitata var. } \\
\text { capitata }\end{array}$ & 'Sun Up H' & & $\begin{array}{l}\text { B. rapa ssp. } \\
\text { oleifera }\end{array}$ & gelbsamig & \\
\hline G 50 & $\begin{array}{l}\text { B. olera. conv. } \\
\text { acephala var. } \\
\text { gongyloides }\end{array}$ & 'Erfordia' & & $\begin{array}{l}\text { B. rapa ssp. } \\
\text { oleifera }\end{array}$ & gelbsamig & \\
\hline H44 & $\begin{array}{l}\text { B. oler. conv. } \\
\text { capitata var. } \\
\text { sabauda }\end{array}$ & 'Eisenkopf' & & $\begin{array}{l}\text { B. rapa ssp. } \\
\text { pekinensis }\end{array}$ & ‘Ho46’ & \\
\hline H 149 & $\begin{array}{l}\text { B. oler. conv. } \\
\text { capitata var. } \\
\text { medullosa }\end{array}$ & $\begin{array}{l}\text { 'Cavalier } \\
\text { Rouge' }\end{array}$ & & $\begin{array}{l}\text { B. rapa ssp. } \\
\text { chinensis }\end{array}$ & Pak Choi & \\
\hline H 165 & $\begin{array}{l}\text { B. oler. conv. } \\
\text { capitata var. } \\
\text { sabauda }\end{array}$ & Wirsing & & $\begin{array}{l}\text { B. rapa ssp. } \\
\text { chinensis }\end{array}$ & Pak Choi & \\
\hline H 176 & $\begin{array}{l}\text { B. oler. conv. } \\
\text { capitata var. } \\
\text { sabauda }\end{array}$ & 'Praeco' & & $\begin{array}{l}\text { B. rapa ssp. } \\
\text { pekinensis var. } \\
\text { laxa }\end{array}$ & $\begin{array}{l}\text { 'Hsiao Pai } \\
\text { Kou Pai } \\
\text { Tsai' }\end{array}$ & \\
\hline
\end{tabular}

${ }^{1} \mathrm{GAU}=$ Georg-August-Universität Göttingen, FUB = Freie Universität Berlin, JLU = Justus-Liebig-Universität Gießen 
Tab. 2-2: Übersicht über die Abstammung der Resynthesen mit B. oleraceaKulturformen (vergl. GIRKE 2002) (Fortsetzung)

\begin{tabular}{|c|c|c|c|c|c|c|}
\hline \multirow{2}{*}{$\begin{array}{l}\text { Resynthese } \\
\text { Bezeich- } \\
\text { nung }\end{array}$} & \multicolumn{6}{|c|}{ Ausgangselter } \\
\hline & Mutter & $\begin{array}{l}\text { Sorte / } \\
\text { Typ }\end{array}$ & $\begin{array}{l}\text { Akzes- } \\
\text { sion }\end{array}$ & Vater & $\begin{array}{l}\text { Sorte / } \\
\text { Typ }\end{array}$ & $\begin{array}{l}\text { Akzes- } \\
\text { sion }\end{array}$ \\
\hline H355 & $\begin{array}{l}\text { B. oler. conv. } \\
\text { capitata var. } \\
\text { capitata }\end{array}$ & 'Hybrid 0' & & $\begin{array}{l}\text { B. rapa ssp. } \\
\text { pekinensis }\end{array}$ & $\begin{array}{l}\text { 'Spring } \\
\text { Giant' }\end{array}$ & \\
\hline R 53 & $\begin{array}{l}\text { B. oler. conv. } \\
\text { capitata var. } \\
\text { sabellica }\end{array}$ & $\begin{array}{l}\text { 'Winter- } \\
\text { kohl' }\end{array}$ & & $\begin{array}{l}\text { B. rapa ssp. } \\
\text { pekinensis }\end{array}$ & $\begin{array}{l}\text { 'Early } \\
\text { Hybrid G' }\end{array}$ & \\
\hline R 76 & $\begin{array}{l}\text { B. oler. conv. } \\
\text { botrytis var. } \\
\text { alboglabra }\end{array}$ & ‘966-1-4SI & & $\begin{array}{l}\text { B. rapa ssp. } \\
\text { oleifera }\end{array}$ & $\begin{array}{l}\text { 'Eskisehir } \\
\text { II' }\end{array}$ & \\
\hline R 99 & $\begin{array}{l}\text { B. oler. conv. } \\
\text { capitata var. } \\
\text { capitata }\end{array}$ & $\begin{array}{l}\text { 'Stone } \\
\text { Head' }\end{array}$ & & $\begin{array}{l}\text { B. rapa ssp. } \\
\text { pekinensis }\end{array}$ & $\begin{array}{l}\text { China } \\
\text { Kohl }\end{array}$ & \\
\hline S39 & $\begin{array}{l}\text { B. oler. conv. } \\
\text { capitata var. } \\
\text { capitata }\end{array}$ & $\begin{array}{l}\text { S-S Cross } \\
\text { Japan }\end{array}$ & & $\begin{array}{l}\text { B. rapa ssp. } \\
\text { chinensis }\end{array}$ & Pak Choi & \\
\hline \multicolumn{7}{|c|}{$\underline{\text { Resynthesen aus der FUB }}^{1}$} \\
\hline RS 4/2 & B. rapa & ‘ 85-326’ & & $\begin{array}{l}\text { B. oler. conv. } \\
\text { capitata var. } \\
\text { sabellica } x \\
\text { B. oler. conv. } \\
\text { gemmifera } \\
\text { B. oler. conv. }\end{array}$ & 'WS4' & \\
\hline RS 4/6 & $\begin{array}{l}\text { B. rapa ssp. } \\
\text { pekinensis }\end{array}$ & $\begin{array}{l}\text { ‘Tokyo } \\
\text { King' }\end{array}$ & & $\begin{array}{l}\text { capitata var. } \\
\text { sabellica } x \\
\text { B. oler. conv. } \\
\text { gemmifera }\end{array}$ & 'WS4' & \\
\hline RS 7/6 & $\begin{array}{l}\text { B. rapa ssp. } \\
\text { pekinensis }\end{array}$ & $\begin{array}{l}\text { 'Tokyo } \\
\text { King' }\end{array}$ & & $\begin{array}{l}\text { B. oler. conv. } \\
\text { capitata var. } \\
\text { medullosa } \\
\text { B. oler. conv. }\end{array}$ & 'WS14' & \\
\hline RS 8/6 & $\begin{array}{l}\text { B. rapa ssp. } \\
\text { pekinensis }\end{array}$ & $\begin{array}{l}\text { 'Tokyo } \\
\text { King' }\end{array}$ & & $\begin{array}{l}\text { capitata var. } \\
\text { medullosa x } B \text {. } \\
\text { oler. conv. } \\
\text { gemmifera }\end{array}$ & 'WS15' & \\
\hline RS 10/7 & $\begin{array}{l}\text { B. rapa ssp. } \\
\text { trilocularis }\end{array}$ & $\begin{array}{l}\text { Yellow } \\
\text { Sarson }\end{array}$ & & $\begin{array}{l}\text { B. oler. conv. } \\
\text { fructicosa }\end{array}$ & $\begin{array}{l}\text { Strauch- } \\
\text { kohl }\end{array}$ & \\
\hline RS $13 / 6$ & $\begin{array}{l}\text { B. rapa ssp. } \\
\text { pekinensis }\end{array}$ & China Kohl & & $\begin{array}{l}\text { B. oler. conv. } \\
\text { botrytis var. } \\
\text { alboglabra }\end{array}$ & $\begin{array}{l}\text { China } \\
\text { Brokkoli }\end{array}$ & \\
\hline RS 239 & $\begin{array}{l}\text { B. oler. ssp } \\
\text { botrytis var. } \\
\text { botrytis }\end{array}$ & $\begin{array}{l}\text { Blumen- } \\
\text { kohl }\end{array}$ & & $\begin{array}{l}\text { B. rapa ssp. } \\
\text { trilocularis }\end{array}$ & $\begin{array}{l}\text { Yellow } \\
\text { Sarson }\end{array}$ & \\
\hline S13 & $\begin{array}{l}\text { B. rapa ssp } \\
\text { oleifera } 4 x\end{array}$ & Ölrübsen & & $\begin{array}{l}\text { B. oler. conv. } \\
\text { capitata var. } \\
\text { medullosa }\end{array}$ & $\begin{array}{l}\text { Mark- } \\
\text { stammkohl }\end{array}$ & \\
\hline \multicolumn{7}{|c|}{$\underline{\text { Resynthesen aus der JLU }}{ }^{1}$} \\
\hline B $1 / 3.3$ & $\begin{array}{l}\text { B. rapa ssp. } \\
\text { oleifera }\end{array}$ & 'Asko' & CR 1469 & $\begin{array}{l}\text { B. oler. conv. } \\
\text { capitata var. } \\
\text { capitata }\end{array}$ & $\begin{array}{l}\text { 'Kashirka } \\
\text { 202' }\end{array}$ & $\begin{array}{l}50220- \\
1428\end{array}$ \\
\hline FS 94.3 & $\begin{array}{l}\text { B. rapa ssp. } \\
\text { oleifera }\end{array}$ & $\begin{array}{l}\text { Blüten- } \\
\text { blattloser } \\
\text { Ölrübsen }\end{array}$ & & $\begin{array}{l}\text { B. oler. conv. } \\
\text { capitata var. } \\
\text { capitata }\end{array}$ & $\begin{array}{l}\text { 'Kashirka } \\
\text { 202' }\end{array}$ & $\begin{array}{l}50220- \\
1428\end{array}$ \\
\hline K 160.1.1 & $\begin{array}{l}\text { B. rapa ssp. } \\
\text { pekinensis }\end{array}$ & China Kohl & 13444 & $\begin{array}{l}\text { B. olera. conv. } \\
\text { acephala }\end{array}$ & Futterkohl & $\begin{array}{l}\text { HRIGRU } \\
8207\end{array}$ \\
\hline K 199.16.2 & $\begin{array}{l}\text { B. rapa ssp. } \\
\text { chinensis }\end{array}$ & Pak Choi & 56515 & $\begin{array}{l}\text { B. oler. conv. } \\
\text { botrytis var. botrytis }\end{array}$ & 'Maxima' & $\begin{array}{l}\text { BRA } \\
1398\end{array}$ \\
\hline
\end{tabular}

${ }^{1} \mathrm{GAU}=$ Georg-August-Universität Göttingen, FUB = Freie Universität Berlin, JLU = Justus-Liebig-Universität Gießen 
Tab. 2-2: Übersicht über die Abstammung der Resynthesen mit B. oleraceaKulturformen (vergl. GIRKE 2002) (Fortsetzung)

\begin{tabular}{|c|c|c|c|c|c|c|}
\hline \multirow{2}{*}{$\begin{array}{l}\text { Resynthese } \\
\text { Bezeich- } \\
\text { nung }\end{array}$} & \multicolumn{6}{|c|}{ Ausgangselter } \\
\hline & Mutter & $\begin{array}{l}\text { Sorte / } \\
\text { Typ }\end{array}$ & $\begin{array}{l}\text { Akzes- } \\
\text { sion }\end{array}$ & Vater & $\begin{array}{l}\text { Sorte / } \\
\text { Typ }^{1}\end{array}$ & $\begin{array}{l}\text { Akzes- } \\
\text { sion }\end{array}$ \\
\hline K 199.16.2 & $\begin{array}{l}\text { B. rapa ssp. } \\
\text { chinensis }\end{array}$ & Pak Choi & 56515 & $\begin{array}{l}\text { B. oler. conv. } \\
\text { botrytis var. botrytis }\end{array}$ & 'Maxima' & $\begin{array}{l}\text { BRA } \\
1398\end{array}$ \\
\hline S 108.1.1 & $\begin{array}{l}\text { B. rapa ssp. } \\
\text { oleifera }\end{array}$ & $\begin{array}{l}\text { Hoch- } \\
\text { Ölsäure } \\
\text { Rübsen }\end{array}$ & $98-39157$ & $\begin{array}{l}\text { B. oler. conv. } \\
\text { botrytis var. } \\
\text { alboglabra }\end{array}$ & ‘Kailan' & $\begin{array}{l}\text { CGN } \\
14044\end{array}$ \\
\hline S 228.8.1 & $\begin{array}{l}\text { B. rapa ssp. } \\
\text { chinensis }\end{array}$ & Pak Choi & 56515 & $\begin{array}{l}\text { B. oler. conv. } \\
\text { acephala }\end{array}$ & Futterkohl & $\begin{array}{l}\text { HRIGRU } \\
8207\end{array}$ \\
\hline S 237.20.1 & $\begin{array}{l}\text { B. rapa ssp. } \\
\text { pekinensis }\end{array}$ & China Kohl & 13444 & $\begin{array}{l}\text { B. oler. conv. } \\
\text { botrytis var. botrytis }\end{array}$ & 'Maxima' & $\begin{array}{l}\text { BRA } \\
1398\end{array}$ \\
\hline S 45.2.2 & $\begin{array}{l}\text { B. rapa ssp. } \\
\text { oleifera }\end{array}$ & $\begin{array}{l}\text { Hoch- } \\
\text { Ölsäure } \\
\text { Rübsen }\end{array}$ & $\begin{array}{l}98- \\
39188-9\end{array}$ & $\begin{array}{l}\text { B. oler. conv. } \\
\text { botrytis var. italica }\end{array}$ & Brokkoli & $\begin{array}{l}\text { HRIGRU } \\
7518\end{array}$ \\
\hline
\end{tabular}

${ }^{1} \mathrm{GAU}=$ Georg-August-Universität Göttingen, FUB = Freie Universität Berlin, JLU = Justus-Liebig-Universität Gießen

Neben den 71 Resynthesen wurden außerdem 55 Brassica napus-Zuchtformen (Tabelle. 2-3) mit in die AFLP-Analysen einbezogen. Diese Sorten decken ein breites Spektrum des bekannten Zuchtmaterials ab. Es finden sich darunter sowohl aktuellere Winter- und Sommerrapssorten wie ,Favorite' und ,Siesta', die eine 00-Qualität aufweisen, wie auch zum Teil sehr alte Sorten, die in der Regel einen hohen Anteil an Erucasäure und Glucosinolaten im Samen (++ -Qualität) aufweisen, wie z.B. ,Mansholts Hamburger oder die alte polnische Sommerrapssorte ,Zachodni'. Auch die polnische Sommerrapssorte ,Bronowski", auf die der niedrige Samenglucosinolatgehalt der heutigen 00-Sorten zurückzuführen ist, wurde berücksichtigt. Desweiteren beinhaltet das Sortiment Rapssorten aus China und der Türkei sowie Gemüseformen, beispielsweise die ,Wilhelmsburger Steckrübe‘ oder den Schnittkohl ,Goldgelber Zarter Butter‘.

Tab. 2-3: Übersicht über die in der AFLP-Analyse untersuchten Rapssorten

\begin{tabular}{lllllll}
\hline Sorte & $\begin{array}{l}\text { Akzes- } \\
\text { sion (IPK) }\end{array}$ & Form $^{1}$ & $\begin{array}{l}\text { Qua- } \\
\text { lität }\end{array}$ & Züchter $^{2}$ & Land $^{3}$ & $\begin{array}{l}\text { Zulas- } \\
\text { sung }\end{array}$ \\
\hline Aphid Resistant Rape & CR 167 & W,Ge & & & NZ & \\
Alesi & & W & 00 & KWS & DE & 2004 \\
Billy & & W & 00 & DSV & DE & 2005 \\
Campari & & W, F & 00 & NPZ & DE & 1996 \\
Digger & & W & 00 & KWS & DE & \\
Emerald & CR 312 & W, F & 00 & DA & IE & 1973 \\
\hline
\end{tabular}

${ }^{1} \mathrm{~W}=$ Winterraps, $\mathrm{S}=$ Sommerraps, $\mathrm{T}=$ Türkische Sorte, $\mathrm{C}=$ Chinesische Sorte, $\mathrm{mS}=$ männlich sterile Linie, $\mathrm{F}=$ Futterraps, $\mathrm{G}(\mathrm{K})=$ Gemüseform (Kohlrübe), $\mathrm{G}(\mathrm{Sch})=$ Gemüseform (Schnittkohl); ${ }^{2}$ siehe Tab. I im Anhang; ${ }^{3}$ Abkürzung entsprechend der international verwendeten Länderkürzel, ${ }^{4} \mathrm{DH}$-Linie der entsprechenden Sorte 
Tab. 2-3: Übersicht über die in der AFLP-Analyse untersuchten Rapssorten (Fortsetzung)

\begin{tabular}{|c|c|c|c|c|c|c|}
\hline Sorte & $\begin{array}{l}\text { Akzes- } \\
\text { sion (IPK) }\end{array}$ & Form $^{1}$ & $\begin{array}{l}\text { Qua- } \\
\text { lität }\end{array}$ & Züchter $^{2}$ & Land $^{3}$ & $\begin{array}{l}\text { Zulas- } \\
\text { sung }\end{array}$ \\
\hline Express 617 & & W & 00 & NPZ & $\mathrm{DE}$ & 1993 \\
\hline Favorite & & W & 00 & DSV & $\mathrm{DE}$ & 2006 \\
\hline Gießener Höhenraps & CR 579 & W & ++ & & $\mathrm{DE}$ & \\
\hline Jet Neuf & CR 662 & W & $0+$ & Serasem & FR & 1977 \\
\hline Ladoga & & W & 00 & Limagrain & $\mathrm{DE}$ & 2005 \\
\hline Lembkes Normal & & W & ++ & NPZ & $\mathrm{DE}$ & \\
\hline Mansholt $54^{4}$ & & W & ++ & & $\mathrm{DE}$ & \\
\hline Mansholts Hamburger & CR 754 & W & ++ & Mansholt & $\mathrm{NL}$ & 1899 \\
\hline Mosa & & $W, F$ & 00 & Joordens & $\mathrm{NL}$ & 2001 \\
\hline Nikos & & $W, F$ & 00 & Euro Grass & & \\
\hline Norde & CR 3104 & W & ++ & Svalöv & SE & 1968 \\
\hline Oase & & W & 00 & DSV & $\mathrm{DE}$ & 2004 \\
\hline Samourai $11.4^{4}$ & & W & 00 & & & \\
\hline Samourai & CR 176 & W & 00 & INRA/Serasem & FE & 1989 \\
\hline Sollux & CR 952 & W & ++ & Lüsewitz & $\mathrm{DE}$ & 1973 \\
\hline Viking & & W & 00 & NPZ & $\mathrm{DE}$ & 2002 \\
\hline MSL 007 & & $\mathrm{~W}, \mathrm{mS}$ & 00 & NPZ & $\mathrm{DE}$ & 1999 \\
\hline RNX 4621 & & $\mathrm{~W}, \mathrm{mS}$ & 00 & Syngenta & $\mathrm{DE}$ & 2009 \\
\hline Bronowski & CR 270 & $\mathrm{~s}$ & +0 & IHAR & $\mathrm{PL}$ & $\sim 1945$ \\
\hline Golden & CR 3141 & $\mathrm{~S}$ & ++ & AG Cda & CA & 1954 \\
\hline Heros & & $S$ & 00 & Raps Gbr & $\mathrm{DE}$ & 2000 \\
\hline Licosmos & & $\mathrm{S}$ & 00 & DSV & $\mathrm{DE}$ & 1996 \\
\hline Mazowieki & CR3165 & $\mathrm{S}$ & ++ & IHAR & $\mathrm{PL}$ & $\sim 1945$ \\
\hline Mlochowski & CR 3117 & $\mathrm{~S}$ & ++ & IHAR & $P L$ & $\sim 1945$ \\
\hline Nugget & CR 3133 & $S$ & ++ & AG Cda & CA & 1961 \\
\hline Petranova & CR 3231 & $\mathrm{~S}$ & ++ & Petkus & $\mathrm{DE}$ & 1963 \\
\hline Regina, & CR 882 & $S$ & ++ & Svalöv & SE & 1942 \\
\hline Siesta & & $\mathrm{s}$ & 00 & NPZ & $\mathrm{DE}$ & 2003 \\
\hline Svaloefs Gulle & CR 3283 & $S$ & ++ & Svalöv & SE & 1969 \\
\hline Tanka & CR 1011 & $S$ & ++ & U. of Man. & CA & 1963 \\
\hline Tira & CR 1016 & $\mathrm{~S}$ & ++ & Borries & $\mathrm{DE}$ & 1972 \\
\hline Topas & CR 3086 & $S$ & 00 & Svalöv & SE & 1981 \\
\hline Westar & CR 1054 & $\mathrm{~S}$ & 00 & AG Cda & $\mathrm{CA}$ & 1982 \\
\hline Zachodni & CR 1170 & $\mathrm{~S}$ & ++ & ZNRio & $\mathrm{PL}$ & $\sim 1945$ \\
\hline Eskisehir & & $\mathrm{T}$ & & & TR & \\
\hline Turhal & & $\mathrm{T}$ & & & TR & \\
\hline Yenisehir & & $\mathrm{T}$ & & & TR & \\
\hline Ganyu 3 & & C & ++ & CAAS & $\mathrm{CN}$ & 1977 \\
\hline Italy & & C & ++ & HAU & CN & \\
\hline Linyou 5 & & C & ++ & JAAS & $\mathrm{CN}$ & \\
\hline Zhenyou 11 & & C & ++ & ZAU & CN & \\
\hline Xiangyou 11 & & C & 00 & HAAS & $\mathrm{CN}$ & \\
\hline $87-50182$ & & C & ++ & WIAS & CN & \\
\hline Brauner Schnittkohl & BRA 175 & $\mathrm{G}(\mathrm{Sch})$ & & & $\mathrm{DE}$ & vor 1945 \\
\hline Goldgelber Zarter Butter & BRA 176 & G(Sch) & & & $\mathrm{DE}$ & vor 1945 \\
\hline Grüner Schnittkohl & BRA 177 & $\mathrm{G}(\mathrm{Sch})$ & & & $\mathrm{DE}$ & vor 1945 \\
\hline Mecklenburger Weiße & BRA 1787 & $G(K)$ & & & $\mathrm{DE}$ & \\
\hline MB6-BRS-039 & & $\mathrm{G}(\mathrm{Sch})$ & & & ES & \\
\hline Wilhelmsb. Steckrübe & & $G(K)$ & & & $\mathrm{DE}$ & \\
\hline
\end{tabular}

${ }^{1} \mathrm{~W}=$ Winterraps, $\mathrm{S}=$ Sommerraps, $\mathrm{T}=$ Türkische Sorte, $\mathrm{C}=$ Chinesische Sorte, $\mathrm{mS}=$ männlich sterile Linie, $\mathrm{F}=$ Futterraps, $\mathrm{G}(\mathrm{K})=$ Gemüseform (Kohlrübe), $\mathrm{G}(\mathrm{Sch})=$ Gemüseform (Schnittkohl); ${ }^{2}$ siehe Tab. I im Anhang; ${ }^{3}$ Abkürzung entsprechend der international verwendeten Länderkürzel, ${ }^{4} \mathrm{DH}$-Linie der entsprechenden Sorte 
Um die Kombinationseignung der mit den Brassica-Wildarten erstellten Resynthesen mit angepasstem Rapszuchtmaterials zu prüfen, wurden Testhybriden hergestellt. Hierzu wurden insgesamt 65 Resyntheselinien als Pollenspender ausgewählt. In diesem Sortiment waren, mit Ausnahme der Genotypen ,HIL 1', ,HIY 2', ,ISY 2', ,MOL 4' und ,MOY 7', alle in Tabelle 2-1 aufgeführten Genotypen enthalten. Komplettiert wurde die Auswahl durch die in Tabelle 2-2 aufgeführten klassischen Resynthesen (ohne ,RS 239'). Als Tester für die Erstellung der Testhybriden wurden die männlich sterilen Linien ,MSL 007‘ und ,RNX 4621' verwendet. Die Linie ,MSL 007' stellt eine männlich sterile Variante der Sorte ,Express' dar und wurde von der NPZ zur Verfügung gestellt. Die Linie ,RNX 4621' wurde von Syngenta zur Verfügung gestellt. Beide Linien nutzen Sterilitätssysteme für die, soweit bekannt, alle Rapsgenotypen als Restorer wirken. Die zwei männlich sterilen Linien wurden außerdem in den AFLP-Analysen mit getestet (siehe Tabelle 2-3).

\subsubsection{Brassica-Wildarten}

Im Herbst bzw. Winter 2009/2010 wurden 40 Wildkohl-Akzessionen von zehn verschiedenen Arten aus der näheren Brassica oleracea-Verwandtschaft hinsichtlich ihres Blattglucosinolatgehaltes und -musters untersucht. Die Analysen wurden von Julia Rudloff im Rahmen ihrer Bachelorarbeit durchgeführt. Die Untersuchten Akzessionen sind zusammen mit den für die Herstellung der WildResynthesen verwendeten Akzessionen, in Tabelle 2-4 aufgelistet. Zwanzig der in den Glucosinolatanalysen getesteten 40 Akzessionen dienten auch als Elter für die Resyntheseherstellung.

Tab. 2-4: Übersicht über die Herkunft und Nutzung der Brassica-Wildarten

\begin{tabular}{lllll}
\hline Art & Akzession & Quelle $^{3}$ & ursprüngliche Herkunft & Nutzung \\
\hline B. bourgeaui Kuntze & BRA 2998 $(=$ K 9825) & IPK & La Palma, Spanien & RS, GSL \\
\hline B. cretica Lam. & 5971 & ESP & Griechenland & RS, GSL \\
\hdashline B.cretica Lam. ssp. & BRA 2997 $(=$ K 9689) & IPK & Kälamaki-Äydin, Türkei & RSS, GSL \\
aegaea (Heldr. \& Hal.) & 6021 & ESP & Evia, Griechenland & RS, GSL \\
Snogerup et al. & 6344 & ESP & Limnos, Griechenland & GSL \\
& 6346 & ESP & Kusadasi-Aydin, Türkei & RS, GSL \\
\hline
\end{tabular}

${ }^{1+2}$ Duplikate der selben Akzession; ${ }^{3} \mathrm{CGN}=$ Centre for Genetic Resources, Wageningen, Niederlande, ESP = Banco de Germoplasma, Universidad Politécnica de Madrid, Spanien, IPK = Genbank des Leibniz-Institut für Pflanzengenetik und Kulturpflanzenforschung Gatersleben, Deutschland, GBR = Warwick HRI Genetic Resources Unit, University of Warwick, Groß Britannien; ${ }^{4} \mathrm{RS}=$ für Erstellung von Resynthesen, GSL = für Analyse der Blattglucosinolate 
Tab. 2-4: Übersicht über die Herkunft und Nutzung der Brassica-Wildarten (Fortsetzung)

\begin{tabular}{|c|c|c|c|c|}
\hline Art & Akzession & Quelle $^{3}$ & ursprüngliche Herkunft & Nutzung $^{4}$ \\
\hline \multirow{2}{*}{ B. hilarionis G.E.Post } & 7344 & ESP & Kyrenia-Berge, Zypern & RS \\
\hline & HRIGRU 12483 & GBR & Kyrenia-Berge, Zypern & RS \\
\hline \multirow{13}{*}{ B. incana Ten. } & ${\text { BRA } 1166^{1}}^{1}$ & IPK & k.A. & GSL \\
\hline & BRA 1262 & IPK & k.A. & GSL \\
\hline & BRA 2918 (= K 8118) & IPK & Sizilien, Italien & RS \\
\hline & 5974 & ESP & Krim, Ukraine & GSL \\
\hline & 6558 & ESP & Capri, Italien & GSL \\
\hline & 6560 & ESP & Capri, Italien & GSL \\
\hline & 6563 & ESP & Sorrento, Italien & RS, GSL \\
\hline & 6564 & ESP & Sorrento, Italien & GSL \\
\hline & 6569 & ESP & Sizilien, Italien & RS, GSL \\
\hline & 6570 & ESP & Sizilien, Italien & RS, GSL \\
\hline & 6572 & ESP & Sizilien, Italien & RS, GSL \\
\hline & HRIGRU 6691 & GBR & Sorrento, Italien & GSL \\
\hline & CGN $18470^{1}$ & CGN & k.A. & RS, GSL \\
\hline \multirow{7}{*}{ B. insularis Moris } & 1952 & ESP & Türkei & GSL \\
\hline & BRA $2996(=$ K 8934) & IPK & Sardinien, Italien & RS, GSL \\
\hline & BRA $3050(=\mathrm{K} 9321)$ & IPK & Sardinien, Italien & GSL \\
\hline & BRA $3051(=\mathrm{K} 9338)$ & IPK & Sardinien, Italien & GSL \\
\hline & 7346 & ESP & Sardinien, Italien & GSL \\
\hline & 7347 & ESP & Sardinien, Italien & GSL \\
\hline & 7356 & ESP & Korsika, Frankreich & RS, GSL \\
\hline \multirow{2}{*}{ B. macrocarpa Guss. } & 3819 & ESP & Egadische Inseln, Italien & GSL \\
\hline & 6584 & ESP & Egadische Inseln, Italien & RS \\
\hline \multirow{9}{*}{ B. montana Pourr. } & BRA 1644 (= K 5457) & IPK & k.A. & GSL \\
\hline & BRA $2942(=$ K 7220) & IPK & k.A. & RS, GSL \\
\hline & BRA $2946(=$ K 8380) & IPK & k.A. & \\
\hline & BRA $2993(=\mathrm{K} 7223)$ & IPK & k.A. & RS, GSL \\
\hline & BRA $3047(=\mathrm{K} 6675)^{2}$ & IPK & Italien & GSL \\
\hline & 6801 & ESP & Toscana, italien & \\
\hline & 6816 & ESP & Toulon, Frankreich & RS, GSL \\
\hline & 6835 & ESP & Gerona, Spanien & RS \\
\hline & CGN $18472^{2}$ & CGN & Italien & RS, GSL \\
\hline \multirow{4}{*}{ B. oleracea L. } & 6824 & ESP & Gran Ville, Frankreich & GSL \\
\hline & 7660 & ESP & Spanien & RS, GSL \\
\hline & 7681 & ESP & Frankreich & GSL \\
\hline & 7694 & ESP & Groß Britannien & GSL \\
\hline \multirow{5}{*}{$\begin{array}{l}\text { B. oleracea L. ssp. } \\
\text { oleracea }\end{array}$} & $B R A 101$ & IIPK & k.A. & RS \\
\hline & BRA 108 & IPK & Gallodoro, Italien & RS \\
\hline & BRA 258 & IPK & k.A. & RS \\
\hline & BRA 259 & IPK & k.A. & RS \\
\hline & BRA 260 & IPK & k.A. & RS \\
\hline $\begin{array}{l}\text { B. rupestris Raf. ssp. } \\
\text { hispida }\end{array}$ & 6580 & ESP & Sizilien, Italien & RS, GSL \\
\hline B. taurica Tzelv. & BRA 2947 (= K 9238) & IPK & k.A. & RS, GSL \\
\hline B. villosa Biv. & $\begin{array}{l}3821 \\
\text { HRIGRU } 6848\end{array}$ & $\begin{array}{l}\text { ESP } \\
\text { GBR }\end{array}$ & $\begin{array}{l}\text { Italien } \\
\text { Sizilien, Italien }\end{array}$ & $\begin{array}{l}\text { GSL } \\
\text { RS, GSL }\end{array}$ \\
\hline $\begin{array}{l}\text { B. villosa Biv. ssp. } \\
\text { bivoniana }\end{array}$ & 6581 & ESP & Sizilien, Italien & GSL \\
\hline
\end{tabular}

${ }^{1+2}$ Duplikate der selben Akzession; ${ }^{3}$ CGN = Centre for Genetic Resources, Wageningen, Niederlande, ESP = Banco de Germoplasma, Universidad Politécnica de Madrid, Spanien, IPK = Genbank des Leibniz-Institut für Pflanzengenetik und Kulturpflanzenforschung Gatersleben, Deutschland, GBR = Warwick HRI Genetic Resources Unit, University of Warwick, Groß Britannien; ${ }^{4} \mathrm{RS}=$ für Erstellung von Resynthesen, GSL $=$ für Analyse der Blattglucosinolate 


\subsection{Anzucht der Pflanzen und Probenahme}

\subsubsection{Resynthesen und Rapssorten für AFLP und Testkreuzungen}

Die Anzucht der Rapssorten (Tab. 2-3) und der in den Tabellen 2-1 und 2-2 aufgelisteten Resynthesen erfolgte im Winter 2008/2009 im Gewächshaus. Dazu wurden jeweils sechs Samen von jedem Genotyp in Multitopfplatten in Anzuchterde ausgesät und nach erfolgter Keimung für vier Wochen im Gewächshaus kultiviert (Bedingungen: $16 \mathrm{~h}$ Licht bei $18^{\circ} \mathrm{C}$ tagsüber und $15^{\circ} \mathrm{C}$ nachts). Nach den vier Wochen wurden für die AFLP-Analysen von jedem Genotyp $100 \mathrm{mg}$ frisches Blattmaterial geerntet und jeweils in ein $1,5 \mathrm{ml}$ Reaktiongefäß (Eppendorf) überführt und in flüssigem Stickstoff bei $-196^{\circ} \mathrm{C}$ tiefgefroren. Bis zur weiteren Aufarbeitung wurden die Proben anschließend bei $20^{\circ} \mathrm{C}$ in einer Tiefkühltruhe gelagert. Nach der Beprobung wurden die ResyntheseJungpflanzen für 8 Wochen in einem Kühlcontainer unter Kurztagbedingungen (10 h Tag, $14 \mathrm{~h}$ Nacht) bei $4^{\circ} \mathrm{C}$ vernalisiert. Nach erfolgter Vernalisation wurden die Pflanzen aus den Multitopfplatten entnommen, in $13 \mathrm{~cm}$ Töpfe mit aufbereiteter Komposterde gepflanzt und im Gewächshaus, unter oben genannten Bedingungen, für die Herstellung von Testkreuzungen und zur Samenproduktion für die Feldversuche weiterkultiviert. Parallel zur Anzucht der Pflanzen für die AFLP-Analysen wurden außerdem je 200 Pflanzen der beiden männlich sterilen Tester MSL 007 und RNX 4621 für die Erstellung der Testkreuzungen in der gleichen Weise angezogen.

\subsubsection{Wildkohle für Blattglucosinolatanalysen}

Für die Blattglucosinolatanalysen wurden im Sommer 2009 Stecklinge von $40^{\circ}$ Wildkohlakzessionen, die als adulte blühfähige Pflanzen vorhanden waren, genommen. Hierzu wurden von jeweils einer Pflanze pro Akzession drei junge Seitentriebe entnommen. Diese wurden an ihrem unteren Ende schräg angeschnitten und anschließend in mit Anzuchterde befülte Multitopfplatten gesteckt und im Gewächshaus solange kultiviert, bis sie nach ca. 6 Wochen zu kräftigen Jungpflanzen herangewachsen waren. Es folgte eine 11 wöchige Vernalisation unter Kurztagbedingungen (10 h Tag, $14 \mathrm{~h}$ Nacht) bei $4^{\circ} \mathrm{C}$. Nach erfolgter Vernalisation wurden die Kohlpflanzen in $13 \mathrm{~cm}$ Töpfe die mit Komposterde gefüllt wurden gepflanzt und für 14 Tage im Gewächshaus (Bedingungen: $16 \mathrm{~h} \mathrm{Licht} \mathrm{bei} 18^{\circ} \mathrm{C}$ tagsüber und $15^{\circ} \mathrm{C}$ nachts) weiterkultiviert. Am 
14. bzw. 15. Tag nach dem Topfen (die ersten Pflanzen begannen zu schossen) wurden von jeder Akzession zwei Pflanzen beprobt. Die genommenen Blattproben bestanden jeweils aus einem jungen, einem älteren und einem alten stielfreien Blatt. Es wurde darauf geachtet, dass keines der Blätter beschädigt oder vergilbt war. Die entnommenen Blattproben wurden umgehend in einen mit flüssigem Stickstoff befüllten Mörser überführt und dort mit einem Pistill zu einem homogenen Pulver zerrieben. Dieses Pulver wurde unter ständiger Kühlung in ein vorgekühltes Plastikprobenröhrchen mit Schraubdeckel überführt und für einige Tage bei $-20^{\circ} \mathrm{C}$ gelagert. Anschließend wurden die tiefgefrorenen Proben gefriergetrocknet (Gefriertrocknung Christ Delta 1A). Die gefriergetrockneten Proben wurden bei Raumtemperatur unter Lichtausschluss bis zur Weiterverarbeitung aufbewahrt.

\subsection{AFLP-Markeranalysen}

\subsubsection{DNA-Extraktion}

Die Extraktion der genomischen DNA erfolgte aus jeweils $100 \mathrm{mg}$ tiefgefrorenem Blattmaterial mit dem Nucleon PhytoPure plant extraction Kit (GE Healthcare, Illustra ${ }^{T M}$ ) unter genauer Beachtung der Gebrauchsanweisung. Die Bestimmung der DNA-Konzentration erfolgte mit dem Fluorescent DNA Quantification Kit (BioRad Laboratories CA, USA).

\subsubsection{AFLP-Analysen}

Die Durchführung der AFLP erfolgte nach dem Protokoll von Vos et al. (1995) mit den bei ECKE et al. (2010) beschriebenen Modifikationen für die Multiplex-PCR.

Dabei wurden insgesamt 20 Primerkombinationen verwendet, von denen viele eine hohe Anzahl Polymorphismen erbrachten. Für die Auswertung wurden aufgrund des hohen Polymorphiegrades nur die besten drei Kombinationen (M50/E37, M50/E40 und M50/E42, Tab. 2-5) berücksichtigt.

Restriktion: $250 \mathrm{ng}$ genomischer DNA wurden in einem Gesamtvolumen von $30 \mu \mathrm{l}$, bestehend aus 1x Restriktions-Ligationspuffer (RL-Puffer; $10 \mathrm{mM}$ Tris HAc, $10 \mathrm{mM}$ MgAc, $50 \mathrm{mM} \mathrm{KAc,} 5 \mathrm{mM}$ DTT, pH 7,5) zusammen mit jeweils $4 \mathrm{U}$ der Enzyme EcoRI (Fermentas) und Msel (New England Biolabs) für $1,5 \mathrm{~h}$ bei $37^{\circ} \mathrm{C}$ verdaut. 
Ligation: $\mathrm{Zu}$ den $30 \mu \mathrm{l}$ Restriktionsprodukt wurden $10 \mu \mathrm{l}$ eines Ligationsmixes hinzugegeben. Dieser bestand aus 1x RL-Puffer mit 5 pmol EcoRI-Adapter, $50 \mathrm{pmol}$ Msel-Adapter (siehe Tab. 2-5), $1 \mathrm{mM}$ ATP und $1 \mathrm{U}$ T4-DNA-Ligase (Promega). Die Ligation erfolgte nach folgendem Programm: $3 \mathrm{~h} 10 \mathrm{~min}$ bei $37^{\circ} \mathrm{C}$ gefolgt von $33,5^{\circ} \mathrm{C}$ für $3 \mathrm{~min}, 26^{\circ} \mathrm{C}$ für 4 min und $22^{\circ} \mathrm{C}$ für $15 \mathrm{~min}$.

Tab. 2-5: Übersicht über die in den AFLP-Analysen verwendeten Primer

\begin{tabular}{|c|c|c|}
\hline Primer & Name & Sequenz \\
\hline \multicolumn{3}{|l|}{ Adapter Paare (Eurofins MWG Operon) } \\
\hline $\begin{array}{l}\text { EcoRI } \\
\text { Msel }\end{array}$ & $\begin{array}{l}\text { EA } 1 \\
\text { EA } 2 \\
\text { MA1 } \\
\text { MA2 }\end{array}$ & $\begin{array}{l}\text { 5'-CTCGTA GAC TGC GTA CC-3“ } \\
\text { 5'-AAT TGG TAC GCA GTC-3‘ } \\
\text { 5'-GAC GAT GAG TCC TGA G-3" } \\
\text { 5'-TAC TCA GGA CTC AT-3’” }\end{array}$ \\
\hline $\begin{array}{l}\text { selektive Primer (Eurofins MWG Operon } \\
\text { EcoRI+A } \\
\text { Msel+C }\end{array}$ & $\begin{array}{l}\text { E01 } \\
\text { M02 }\end{array}$ & $\begin{array}{l}\text { 5'-CTG CGT ACC AAT TCA-3' } \\
\text { 5'-GAT GAG TCC TGA GTA AAC-3' }\end{array}$ \\
\hline $\begin{array}{l}\text { Msel+3-Primer (Eurofins MWG Operon) } \\
\text { Msel+CAT }\end{array}$ & M50 & 5'-GAT GAG TCC TGA GTA ACA T-3' \\
\hline \multicolumn{3}{|c|}{ EcoRI+3-Primer, fluoreszenzmarkiert (Applied Biosystems) } \\
\hline $\begin{array}{l}\text { EcoRI+ACG, markiert mit PET }{ }^{\mathrm{TM}} \text { (rot) } \\
\text { EcoRI+AGC, markiert mit 6-Fam }{ }^{\mathrm{TM}}{ }_{\text {(blau) }} \text { (blarkiert mit NED }{ }^{\mathrm{MM}} \text { (gelb) }\end{array}$ & $\begin{array}{l}\text { E37 } \\
\text { E40 } \\
\text { E42 }\end{array}$ & $\begin{array}{l}\text { 5'- CTG CGT ACC AAT TCA CG-3' } \\
\text { 5'- CTG CGT ACC AAT TCA GC-3' } \\
\text { 5'- CTG CGT ACC AAT TCA GT-3' }\end{array}$ \\
\hline
\end{tabular}

Präamplifikation: Für die Präamplifikation wurde das Restriktions-Ligationsprodukt 1:5 mit HPLC- $\mathrm{H}_{2} \mathrm{O}$ verdünnt. $8 \mu \mathrm{l}$ dieser Verdünnung wurden zu $12 \mu \mathrm{l}$ des Präamplifikationsmixes, bestehend aus 1x PCR-Puffer (10 mM Tris-HCL, $50 \mathrm{mM}$ $\mathrm{KCL}, \mathrm{pH}$ 8), 3,125 mM MgCl $2,0,45 \mathrm{mM}$ dNTPs, $10 \mathrm{pmol}$ EcoRl+1 Primer, 9 pmol Msel+1 Primer (Tab. 2-5), und 2,5 U Taq DNA-Polymerase (FIREpol, Solis Biodyne) gegeben, so dass ein Gesamtreaktionsvolumen von $30 \mu$ entsteht. Die PCR-Reaktion wurde in einem Biometra T1 Thermocycler (Biometra GmbH) durchgeführt. Das verwendete PCR-Programm geht aus Tabelle 2-6 hervor.

Tab. 2-6: PCR-Programm für die Präamplifikation

\begin{tabular}{llll}
\hline Schritt & Temperatur & Zeit & Wiederholungen \\
\hline Start & $94^{\circ} \mathrm{C}$ & $30 \mathrm{~s}$ & \\
\hline Denaturierung & $94^{\circ} \mathrm{C}$ & $30 \mathrm{~s}$ & \\
Annealing & $56^{\circ} \mathrm{C}$ & $30 \mathrm{~s}$ & 20 Zyklen \\
Elongation & $72^{\circ} \mathrm{C}$ & $1 \mathrm{~min}$ & \\
\hline Ende & $72^{\circ} \mathrm{C}$ & $5 \mathrm{~min}$ & \\
Aufbewahrung & $4^{\circ} \mathrm{C}$ & $\infty$ & \\
\hline
\end{tabular}


Hauptamplifikation: Für die Hauptamplifikation wurden EcoRI-Primer und MselPrimer mit jeweils 3 selektiven Basen (Tab. 2-5) verwendet. Insgesamt wurden 20 verschiedene Primerkombinationen gescreent, von denen letztlich drei Kombinationen (M50/E37, M50/E40 und M50/E42, siehe Tab. 2-5) für die Analysen genutzt wurden. Die PCR-Reaktion fand in einem Gesamtvolumen von $20 \mu \mathrm{l}$, bestehend aus $6 \mu \mathrm{l}$ des mit HPLC-Wasser 1:10 verdünnten Präamplifikationsproduktes und $14 \mu \mathrm{l}$ des Hauptamplifikationsmixes statt. Der Hauptamplifikationsmix bestand aus 1x PCR-Puffer (10 mM Tris-HCL, $50 \mathrm{mM}$ $\mathrm{KCL}, \mathrm{pH}$ 8), 3,125 mM MgCl $2,0,36 \mathrm{mM}$ dNTPs, 8 pmol des Msel-Primers M50, 2 pmol des mit dem Fluoreszensfarbstoff $\mathrm{PET}^{\mathrm{TM}}$ markierten EcoRI+3 Primers E37, 4 pmol des mit dem Fluoreszensfarbstoff $6-\mathrm{Fam}^{\mathrm{TM}}$ markierten EcoRI+3 Primers E40 und 2 pmol des mit dem Fluoreszensfarbstoff NED ${ }^{\mathrm{TM}}$ markierten EcoRI+3 Primers E42 sowie 1U Taq DNA-Polymerase (FIREpol, Solis Biodyne). Das verwendete PCR-Programm ist in Tabelle 2-7 beschrieben.

Detektion: Die Auftrennung und Detektion der AFLP-Fragmente erfolgte mit einem ABI PRISM 3130 Genetic Analyser $(A B I)$ mit einem $36 \mathrm{~cm}$ Kapillar-Array. Als Größenstandard wurde GeneScan-500 LIZ (Applied Biosystems) verwendet. Das Maker Scoring erfolgte als halbautomatisches Scoring mit dem Programm GeneMapper v.4.0 (Applied Biosystems). Vorhandene Fragmente wurden mit 1, nicht vorhandene mit 0 gekennzeichnet. 
Tab 2-7: PCR-Programm für die Hauptamplifikation

\begin{tabular}{llllllll}
\hline Schritt & Temp. & Zeit & Temp & Zeit & Temp & Zeit & Wiederholungen \\
\hline Denaturierung & $94^{\circ} \mathrm{C}$ & $30 \mathrm{~s}$ & & & & & \\
& $94^{\circ} \mathrm{C}$ & $30 \mathrm{~s}$ & $65,0^{\circ} \mathrm{C}$ & $30 \mathrm{~s}$ & $72^{\circ} \mathrm{C}$ & $1 \mathrm{~min}$ & \\
& $94^{\circ} \mathrm{C}$ & $30 \mathrm{~s}$ & $64,3^{\circ} \mathrm{C}$ & $30 \mathrm{~s}$ & $72^{\circ} \mathrm{C}$ & $1 \mathrm{~min}$ & \\
& $94^{\circ} \mathrm{C}$ & $30 \mathrm{~s}$ & $63,6^{\circ} \mathrm{C}$ & $30 \mathrm{~s}$ & $72^{\circ} \mathrm{C}$ & $1 \mathrm{~min}$ & \\
& $94^{\circ} \mathrm{C}$ & $30 \mathrm{~s}$ & $62,9^{\circ} \mathrm{C}$ & $30 \mathrm{~s}$ & $72^{\circ} \mathrm{C}$ & $1 \mathrm{~min}$ & \\
High & $94^{\circ} \mathrm{C}$ & $30 \mathrm{~s}$ & $62,2^{\circ} \mathrm{C}$ & $30 \mathrm{~s}$ & $72^{\circ} \mathrm{C}$ & $1 \mathrm{~min}$ & \\
to & $94^{\circ} \mathrm{C}$ & $30 \mathrm{~s}$ & $61,5^{\circ} \mathrm{C}$ & $30 \mathrm{~s}$ & $72^{\circ} \mathrm{C}$ & $1 \mathrm{~min}$ & \\
Low & $94^{\circ} \mathrm{C}$ & $30 \mathrm{~s}$ & $60,8^{\circ} \mathrm{C}$ & $30 \mathrm{~s}$ & $72^{\circ} \mathrm{C}$ & $1 \mathrm{~min}$ & \\
Temp. & $94^{\circ} \mathrm{C}$ & $30 \mathrm{~s}$ & $60,1^{\circ} \mathrm{C}$ & $30 \mathrm{~s}$ & $72^{\circ} \mathrm{C}$ & $1 \mathrm{~min}$ & \\
& $94^{\circ} \mathrm{C}$ & $30 \mathrm{~s}$ & $59,4^{\circ} \mathrm{C}$ & $30 \mathrm{~s}$ & $72^{\circ} \mathrm{C}$ & $1 \mathrm{~min}$ & \\
& $94^{\circ} \mathrm{C}$ & $30 \mathrm{~s}$ & $58,7^{\circ} \mathrm{C}$ & $30 \mathrm{~s}$ & $72^{\circ} \mathrm{C}$ & $1 \mathrm{~min}$ & \\
& $94^{\circ} \mathrm{C}$ & $30 \mathrm{~s}$ & $58,0^{\circ} \mathrm{C}$ & $30 \mathrm{~s}$ & $72^{\circ} \mathrm{C}$ & $1 \mathrm{~min}$ & \\
& $94^{\circ} \mathrm{C}$ & $30 \mathrm{~s}$ & $57,3^{\circ} \mathrm{C}$ & $30 \mathrm{~s}$ & $72^{\circ} \mathrm{C}$ & $1 \mathrm{~min}$ & \\
\hline Denaturierung & $94^{\circ} \mathrm{C}$ & $30 \mathrm{~s}$ & $56,6^{\circ} \mathrm{C}$ & $30 \mathrm{~s}$ & $72^{\circ} \mathrm{C}$ & $1 \mathrm{~min}$ & \\
Annealing & $56^{\circ} \mathrm{C}$ & $30 \mathrm{~s}$ & & & & & \\
Elongation & $72^{\circ} \mathrm{C}$ & $1 \mathrm{~min}$ & & & & & \\
\hline Ende & $72^{\circ} \mathrm{C}$ & $5 \mathrm{~min}$ & & & & & \\
Aufbewahrung & $4^{\circ} \mathrm{C}$ & $\infty$ & & & & &
\end{tabular}

\subsubsection{Auswertung der AFLP-Daten}

Für die statistische Auswertung wurden die Daten in eine 0-1 Matrix umgewandelt, dabei wurden nur polymorphe Marker berücksichtigt. Die genetische Ähnlichkeit (GA) aller möglichen Paarvergleiche wurde, wie für dominante Marker empfohlen (LINK et al. 1995), nach dem Jaccard-Koeffizienten (JACCARD 1908) berechnet:

$$
G A_{\text {Jaccard }}=\frac{n_{i j}}{\left(n_{i}+n_{i}+n_{i j}\right)}
$$

dabei entspricht:
$\mathrm{n}_{\mathrm{i}}$
der Anzahl der Banden die nur bei Genotyp i vorhanden sind
$\mathrm{n}_{\mathrm{j}}$ der Anzahl der Banden die nur bei Genotyp j vorhanden sind
$n_{i j}$ der Anzahl der Banden die sowohl bei Genotyp i wie auch bei Genotyp j vorhanden sind 
Die genetischen Distanzen (GD) wurden aus den genetischen Ähnlichkeiten (GA) wie folgt errechnet:

$$
G D_{\text {Jaccard }}=1-G A_{\text {Jaccard }}
$$

Die graphische Darstellung der Ergebnisse als Dendrogramm basiert auf der UPGMA (Unweighted Pair Group Method with Arithmetic mean) -Clusteranalyse. Zur Überprüfung des gefundenen Dendrogramms wurde die cophenetische Korrelation nach SNEATH \& SOKAL (1973) berechnet. Weiterhin wurde für die gefundenen genetischen Ähnlichkeitswerte eine Hauptkoordinatenanalyse (BACKHAUS ET AL. 1990) durchgeführt. Die Ergebnisse dieser Hauptkoordinatenanalyse werden als Plot der ersten drei Hauptkoordinaten dargestellt.

Alle statistischen Analysen wurden mit den Softwareprogrammen FreeTree (HAMPL et al. 2001) und NTSYSpc 2.1 (Exeter Software, ROHLF 2000) durchgeführt. Die Darstellung und die graphische Aufarbeitung des Dendrogramms erfolgten mit dem Programm TreeView (PAGE, 1996). Die statistische Absicherung der mit der UPGMA-Clusterung gefundenen Cluster erfolgte mit der Bootstrap-Analyse nach FELSENSTEIN (1985). Nach HILLIS \& BULL (1993) können Äste im Dendrogramm die im Bootstrap einen Wert größer 70 \% erhalten, als statistisch gut abgesichert gelten. 


\subsection{Feldversuche}

\subsubsection{Erstellung von Testkreuzungen}

Die Erstellung von Testkreuzungen erfolgte im Versuchsjahr 2008/2009 in Isolierkabinen bei den Zuchtfirmen NPZ und Syngenta sowie in kleinem Umfang im Gewächshaus der Abteilung Pflanzenzüchtung der Universität Göttingen. Dabei wurden die Testkreuzungen mit dem Tester MSL 007 bei der NPZ in Malchow und die mit dem Tester RNX 4621 bei Syngenta in Biemsen erstellt. Im Gewächshaus in Göttingen wurden Testkreuzungen mit beiden Testern hergestellt.

Bei den Züchtern wurden die Tester für die Testkreuzungen zur Aussaat 2008 in jeweils zwei Doppelreihen ausgesät, während die für die Kreuzungen vorgesehenen 65 Resyntheselinien (siehe 2.1.1 Brassica napus L. - Resynthesen und Zuchtmaterial) im Winter 2008/2009 im Gewächshaus angezogen und, nach erfolgter achtwöchiger Vernalisation, im März 2009 zwischen den entsprechenden Testern ausgepflanzt wurden. Um Fremdbestäubungen zu vermeiden wurde zu Blühbeginn über jeder Kreuzungsparzelle (bestehend aus vier Reihen des männlich sterilen Testers und den dazwischen gepflanzten Resynthesen) ein engmaschiges Gazezelt aufgebaut. Um den Bestäubungserfolg innerhalb der Zelte zu erhöhen, wurden bei der NPZ Rote Mauerbienen und bei Syngenta Fliegen als Bestäuber eingesetzt. Im Gewächshaus in Göttingen wurden für jede vorgesehene Testkreuzung jeweils drei Pflanzen pro Resynthese-Genotyp mit drei Pflanzen des jeweiligen Testers zusammengestellt. Bei Blühbeginn wurde dann, um unerwünschte Fremdbestäubungen zu vermeiden, jeweils eine ResynthesePflanze zusammen mit einer Tester-Pflanze mit einer Crispack-Tüte überzogen. In regelmäßigen Abständen wurden die Tüten geschüttelt um den Bestäubungserfolg zu erhöhen. In einigen wenigen Fällen wurden auch Handkreuzungen durchgeführt.

\subsubsection{Leistungsprüfungen der Testhybriden}

Die Leistungsprüfungen der Testhybriden erfolgten während der Anbauperiode 2009/2010 an insgesamt neun Standorten (siehe Tab. 2-8) von denen zwei außerhalb Deutschlands in wintermilderen Regionen lagen. Diese Standorte waren Ressons sur Matz (nördlich von Paris) und Impington in der Nähe von Cambridge in Groß Britannien. Bei der NPZ in Hohenlieth gab es zwei 
Leistungsprüfungsorte, von denen einer im Herbst 2009 mit dem Fungizid Folicur® (Bayer CropScience $\mathrm{GmbH}$ ) behandelt wurde, um die Winterfestigkeit zu erhöhen.

Tab. 2-8: Übersicht über die Versuchsstandorte

\begin{tabular}{lllccc}
\hline & Züchter & Standort & $\begin{array}{l}\text { LP }^{1} \\
\text { Testhybriden }\end{array}$ & $\begin{array}{l}\text { BA }^{2} \\
\text { Testhybriden }\end{array}$ & $\begin{array}{l}\text { BA }^{2} \\
\text { Resynthesen }\end{array}$ \\
\hline I. & DSV & Thüle & $\mathrm{x}$ & $\mathrm{x}$ & $\mathrm{x}$ \\
II. & Uni-Gö & Reinshof & $\mathrm{x}$ & $\mathrm{x}$ & $\mathrm{x}$ \\
III. & KWS & Einbeck & $\mathrm{x}$ & $\mathrm{x}$ & $\mathrm{x}$ \\
IV. & KWS (UK) & Thriplow & $\mathrm{x}$ & $\mathrm{x}$ & $\mathrm{x}$ \\
V. & Limagrain & Rosenthal & $\mathrm{x}$ & $\mathrm{x}$ & $\mathrm{x}$ \\
VI. & NPZ (1+2) & Hohenlieth & $\mathrm{x}$ & - & - \\
VII. & NPZ (3) & Groß Lüsewitz & - & $\mathrm{x}$ & $\mathrm{x}$ \\
VIII. & NPZ (UK) & Impington & - & $\mathrm{x}$ & $\mathrm{x}$ \\
IX. & Syngenta & Biemsen & $\mathrm{x}$ & $\mathrm{x}$ & $\mathrm{x}$ \\
X. & Syngenta (F) & Ressons sur Matz & $\mathrm{x}$ & - & - \\
\hline
\end{tabular}

${ }^{1} \mathrm{LP}=$ Leistungsprüfungen, ${ }^{2} \mathrm{BA}=$ Beobachtungsanbau, ${ }^{3}(1+2)=$ am Standort NPZ Hohenlieth gab es zwei Leistungsprüfungen

Der Versuch wurde an allen Orten randomisiert und ohne Wiederholung angelegt. Insgesamt konnten 42 Prüfglieder (39 Testhybriden plus 3 Standards) an allen neun Standorten angebaut werden; 25 weitere Testhybriden konnten, aufgrund geringerer vorhandener Saatgutmengen, nur an vier Orten (Einbeck, Hohenlieth 1, Reinshof, und Resson sur Matz) ausgesät werden, so dass an diesen Standorten insgesamt 67 Prüfglieder (64 Testhybriden plus 3 Standards) geprüft werden konnten. Als Standards für die Leistungsprüfungen dienten die Hybridsorte ,Visby (NPZ, Zulassungsjahr 2007, Qualität: 00), die fertile Form des Testers MSL 007 (Tab. 2-3) sowie eine als, Tester Syngenta' bezeichnete Mischung aus $70 \%$ der männlich sterilen RNX 4621(Tab. 2-3) und 30\% der zur Rückkreuzung verwendeten fertilen Sorte, die als Bestäuber zugesetzt wurde. Die Eigenschaften der einzelnen Versuchsstandorte lassen sich aus Tab. 2-9 entnehmen. 
Tab 2-9 : Eigenschaften der einzelnen Versuchsstandorte

\begin{tabular}{|c|c|c|c|c|c|c|c|c|c|c|}
\hline Eigenschaft & $\begin{array}{c}\text { I } \\
\text { DSV }\end{array}$ & $\begin{array}{c}\text { II } \\
\text { Uni- } \\
\text { Gö }\end{array}$ & $\begin{array}{c}\text { III } \\
\text { KWS }\end{array}$ & $\begin{array}{c}\text { IV } \\
\text { KWS } \\
\text { UK }\end{array}$ & $\begin{array}{c}V \\
\text { Lim }\end{array}$ & $\begin{array}{c}\mathrm{VI} \\
\mathrm{NPZ} \\
(1+2)^{2}\end{array}$ & $\begin{array}{c}\text { VII } \\
\text { NPZ } \\
(3)\end{array}$ & $\begin{array}{l}\text { VIII } \\
\text { NPZ } \\
\text { UK }\end{array}$ & $\begin{array}{c}\text { IX } \\
\text { Syn }\end{array}$ & $\begin{array}{c}X \\
\text { Syn } \\
F\end{array}$ \\
\hline $\begin{array}{l}\text { Höhe über NN } \\
\text { [m] } \\
\text { lanaiähriaes }\end{array}$ & 100 & 150 & 120 & 30 & 70 & 30 & - & 20 & 139 & 83 \\
\hline $\begin{array}{l}\text { Temp.-Mittel } \\
{\left[\mathbf{C}^{\circ}\right]}\end{array}$ & 8,4 & 8,7 & 8,8 & 10,5 & - & 8,8 & - & 10,5 & 8,6 & 10,8 \\
\hline $\begin{array}{l}\varnothing \text { Temp. }\left[C^{\circ}\right] \\
2009 / 2010\end{array}$ & 8,2 & 8,7 & 8,6 & 10,5 & - & 8,6 & - & 10,5 & 8,5 & 10,7 \\
\hline $\begin{array}{l}\text { langjähriges } \\
\text { NS-Mittel [mm] }\end{array}$ & 850 & 645 & 681 & 593 & - & 809 & - & 593 & 852 & 662 \\
\hline $\begin{array}{l}\varnothing \text { NS [mm] } \\
2009 / 2010\end{array}$ & 870 & 652 & 630 & 599 & - & 891 & - & 599 & 798 & 598 \\
\hline $\begin{array}{l}\text { Parzellengröße } \\
{\left[\mathrm{m}^{2}\right]}\end{array}$ & 15,00 & 11,25 & 18,00 & 17,28 & 16,25 & 12,80 & - & - & 15,00 & 13,50 \\
\hline $\begin{array}{l}\text { Aussaatstärke } \\
\text { [Samen } / \mathbf{m}^{2} \text { ) }\end{array}$ & 55 & 80 & 55 & 83 & 55 & - & - & - & 50 & 40 \\
\hline $\begin{array}{l}\text { Reihenabstand } \\
\text { [cm] }\end{array}$ & 22,0 & 20,0 & 21 & 24,0 & 25 & - & - & - & 30,0 & 37,5 \\
\hline Bodenart $^{1}$ & $s L$ & $\mathrm{~L}$ & $\mathrm{~L}$ & $\mathrm{~kL}$ & $s L$ & $s L$ & - & $\mathrm{kL}$ & $s L$ & $\mathrm{~kL}$ \\
\hline
\end{tabular}

${ }^{1} \mathrm{~L}=\mathrm{Lehm}, \mathrm{sL}=$ sandiger Lehm, $\mathrm{kL}=$ kalkiger $\mathrm{Lehm} ;{ }^{2}(1+2)=$ am Standort NPZ Hohenlieth gab es zwei Leistungsprüfungen

\subsubsection{Beobachtungsanbau der Testhybriden}

Neben den Leistungsprüfungen der Testhybriden fand außerdem ein Beobachtungsanbau der Testhybriden statt. Dieser wurde zur Aussaat im August 2009 an insgesamt acht Standorten (siehe Tab. 2-8) angelegt, von denen später aber zwei Standorte (Groß Lüsewitz, NPZ und Thriplow, KWS UK) ausfielen, so dass nur sechs Standorte in die Versuchsauswertung eingingen. Der Versuch wurde an allen Standorten als randomisierter Blockanalage mit zwei Wiederholungen angelegt. Ausnahmen bildeten die Orte Thüle (DSV) und Rosenthal (Limagrain) an denen der Versuch ohne Wiederholungen durchgeführt wurde. Die Aussaat der Genotypen erfolgte als Doppelreihe in Kleinparzellen. Pro Wiederholung wurden in der Regel 100 Korn in zwei Reihen angesät. An den Orten Biemsen (Syngenta), Rosenthal (Limagrain) und Thüle (DSV) wurden pro Genotyp und Wiederholung 200 Korn in vier Reihen ausgesät.

Insgesamt konnten 70 Prüfglieder (67 Testhybriden plus 3 Standards) an allen sechs verbliebenen Standorten geprüft werden; 27 weitere konnten aufgrund geringer Saatgutmengen zum Aussaattermin nur an vier der sechs Standorte (Biemsen, Syngenta; Einbeck, KWS; Impington (NPZ UK) und Reinshof, Uni-Gö) angebaut werden. An den Standorten Einbeck und Reinshof konnten zusätzlich 8 
weitere Testhybriden getestet werden. Als Standards wurden die gleichen drei Sorten wie bei den Leistungsprüfungen verwendet.

\subsubsection{Beobachtungsanbau der Resynthesen}

Der Beobachtungsanbau der Resynthesen wurde an den gleichen acht Orten (siehe Tabelle 2-8) wie der Beobachtungsanbau der Testhybriden angelegt. Auch hier fielen die Standorte Groß Lüsewitz (NPZ) und Thriplow (KWS UK) aus. Das Versuchsdesign entsprach dem für den Beobachtungsanbau der Testhybriden beschriebenen.

Insgesamt konnten 48 Prüfglieder (38 Resynthesen + 10 Standards) an allen sechs verbliebenen Standorten geprüft werden, 32 weitere konnten, aufgrund geringer Saatgutmengen nur am Standort Reinshof (Uni-Gö) angebaut werden. Als Standards dienten die fertile Form des Testers MSL 007 (NPZ), eine als ,Tester Syngenta' bezeichnete Mischung aus 70\% der männlich sterilen RNX 4621 und $30 \%$ der zur Rückkreuzung verwendeten fertilen Sorte sowie die WinterrapsLiniensorten ,Alesi‘ (KWS, 2004), ,Favorite‘ (DSV, 2006), ,Ladoga‘ (Limagrain, 2005), ,Lorenz' (NPZ, 2005), ,Oase‘ (DSV, 2004) und die Winterraps-Hybridsorten ,Elektra‘ (RAPS GbR, 2002), ,Trabant' (NPZ, 2004) und ,Visby‘ (NPZ, 2007).

\subsubsection{Merkmalserfassung}

Folgende Merkmale wurden während der Vegetationsperiode 2009/2010 in den Feldversuchen bonitiert:

Entwicklung vor Winter (VW)

Entwicklung nach Winter (NW)

Blühbeginn (BB)

Wuchshöhe (Höhe)

Lager
Boniturnote 1 = schlecht, 9 = gut

Boniturnote 1 = schlecht, 9 = gut

als Tag im Jahr

in $\mathrm{cm}$, gemessen nach Blühende in der Parzellenmitte

nur für die Leistungsprüfungen,

Boniturnote 1 = gut, 9 = schlecht

Zur Ernte wurde für die Leistungsprüfungen außerdem der Kornertrag durch Mähdruschernte erfasst. Die Angabe der ermittelten Werte erfolgt in Dezitonnen pro Hektar [dt/ha] bei $91 \%$ Trockenmasseanteil. Weiterhin wurde für alle 
Feldversuche nach der Ernte das Tausendkorngewicht (TKG) ermittelt. Die Angabe erfolgt in Gramm [g].

Die Boniturnoten für „Entwicklung vor Winter“ (VW) und „Entwicklung nach Winter" (NW) wurden selber nicht in die Auswertungen aufgenommen, aus Ihnen wurde aber das Merkmal Winterfestigkeit (WF) als Differenz errechnet.

Umso kleiner die errechnete Zahl für die Winterfestigkeit ausfällt, desto winterfester ist der entsprechende Genotyp.

\subsection{Analysen der Inhaltsstoffe}

\subsubsection{Probenaufarbeitung}

Für die Qualitätsanalysen der Samen wurden ausschließlich Mischproben verwendet. Hierzu wurden im Juli 2010 von jedem Prüfglied der Beobachtungsanbauten der Resynthesen und der Testhybriden zehn offen abgeblühte Haupttriebe pro Prüfglied geerntet. Diese wurden gedroschen, und das gewonnene Saatgut gereinigt und für die NIR-Spektroskopie für einen Tag bei $40^{\circ} \mathrm{C}$ im Trockenschrank getrocknet. Die Parzellen der Leistungsprüfungen wurden mit Parzellenmähdreschern beerntet. Auch hier wurden Saatgutproben für die NIRS gezogen.

Für die Bestimmung der Glucosinolat- und Fettsäuremuster mittels HPLC (high performance liquid chromatography) bzw. GC (Gaschromatographie) wurde jeweils $1 \mathrm{~g}$ Samenmaterial mit einer Ika®-Mühle feingemahlen. Das entstandene Rapsmehl wurde anschließend in Schnappdeckelgläschen gefüllt und bis zur weiteren Verwendung unter Ausschluss von Licht bei Raumtemperatur gelagert.

\subsubsection{Nahinfrarotspektroskopie (NIRS)}

Der größte Teil der Qualitätsanalytik erfolgte mittels NIRS-Messung (REINHARD 1992) auf einem NIRS 6500-Gerät (Foss GmbH). Dabei wurde zur Bestimmung von Öl-, Protein-, Glucosinolat-, Linolensäure- und Erucasäure-Gehalt die von der VDLUFA herausgegebene Kalibrierung für 2010 verwendet. Zur Bestimmung des Gesamtphytosterolgehaltes sowie der Anteile der einzelnen Phytosterole (Avenasterol, Brassicasterol, Campesterol, Sitosterol, Stigmasterol) wurde die von AMAR et al. (2009) entwickelte Kalibrierung verwendet. Die Gehalte der Sinapoylverbindungen im Samen wurden unter Nutzung der von ZUM FELDE et al. 
(2007) entwickelte Kalibrierung ermittelt. Eine Übersicht über alle mit NIRS ermittelten Merkmale findet sich in Tab. 2-10.

Tab. 2-10: Übersicht über die mit NIRS ermittelten Merkmale und die Einheiten in denen sie angegeben werden

\begin{tabular}{ll}
\hline Merkmal & Einheit \\
\hline Ölgehalt & in \% bei einen Trockenmasseanteil von $91 \%$ \\
Linolensäure (C 18:3) & in \% des Gesamtfettsäuregehalts \\
Erucasäure (C 22:1) & in \% des Gesamtfettsäuregehalts \\
Proteingehalt & in \% bei einen Trockenmasseanteil von $91 \%$ \\
Glucosinolatgehalt & $\mu \mathrm{mol} / \mathrm{g}$ bei einen Trockenmasseanteil von $91 \%$ \\
\hline Avenasterol & $\mathrm{mg} / \mathrm{kg}$ Samen \\
Brassicasterol & $\mathrm{mg} / \mathrm{kg}$ Samen \\
Campesterol & $\mathrm{mg} / \mathrm{kg}$ Samen \\
Sitosterol & $\mathrm{mg} / \mathrm{kg}$ Samen \\
Stigmasterol & $\mathrm{mg} / \mathrm{kg}$ Samen \\
Gesamtphytosterolgehalt & $\mathrm{mg} / \mathrm{kg}$ Samen \\
\hline Sinapin & $\mathrm{mg} / \mathrm{g}$ \\
Sinapoylglucose & $\mathrm{mg} / \mathrm{g}$ \\
andere Sinapinsäureester & $\mathrm{mg} / \mathrm{g}$ (berechnet als Sinapinsäureäquivalente) \\
Gesamtsinapinsäuregehalt & $\mathrm{mg} / \mathrm{g}$ (berechnet als Sinapinsäureäquivalente) \\
\hline
\end{tabular}

\subsubsection{Gaschromatographie (GC) zur Bestimmung der Fettsäuremuster}

Vor der Erstellung der Testhybriden wurde das Fettsäuremuster der für die Testkreuzungen vorgesehenen Resynthesen (siehe Tab. 2-1 und 2-2) mittels Einzelkorn-GC überprüft. Hierzu wurde je ein Samenkorn von jedem Genotyp in eine Vertiefung einer 96 Well Mikrotiterplatte (Greiner) gelegt und unter Zugabe von $50 \mu \mathrm{l}$ Iso-Oktan:Iso-Propanol (9:1, v:v) mit einem Metallkamm zermahlen. Nach abdampfen des Lösungsmittels bei Raumtemperatur wurden $100 \mu \mathrm{l}$ NatriumMethylat $(0,5 \mathrm{~mol} / \mathrm{l} \mathrm{MeOH})$ hinzugegeben. Es folgte eine 20 minütigen Inkubationszeit. Danach wurden zu jeder Probe $150 \mu$ Iso-Oktan pipettiert. Nach einer 20 minütigen Extraktionsszeit wurde die fettsäuremethylesterhaltige IsoOktanfraktion in Probengläschen (Septum-Vials) für den Autosampler der GC überführt.

Weiterhin wurde, zusätzlich zur Ölgehalts- und Fettsäurebestimmung der Ernteproben aus den Feldversuchen mittels NIRS, für die Samenproben aus dem 
Beobachtungsanbau der Testkreuzungen in Göttingen sowie für den Beobachtungsanbau der Resynthesen in Impington (UK) eine gaschromatographische Analyse der Fettsäuremuster durchgeführt. Für Genotypen von denen für diese Standorte keine Samenproben vorhanden waren, wurden im Fall der Testkreuzungen Samenproben vom Standort Einbeck, im Fall der Resynthesen Samenproben vom Standort Göttingen analysiert.

Die Proben wurden für die Analysen wie folgt aufgearbeitet:

$200 \mathrm{mg}$ feingemahlener Rapssamen wurden in ein $3 \mathrm{ml}$ Probenröhrchen eingewogen. Anschließend wurde $1 \mathrm{ml}$ Natrium-Methylat $(0,5 \mathrm{~mol} / \mathrm{l} \mathrm{MeOH})$ hinzugegeben und gut mit dem Rapsmehl vermischt. Es folgte eine 20 minütige Inkubation, wobei die Proben nach 10 min erneut aufgeschüttelt wurden. Danach wurden jeder Probe $500 \mu \mathrm{l}$ Iso-Oktan sowie $200 \mu \mathrm{l}$ 5\%ige $\mathrm{NaHSO}_{4}$-Lösung hinzugegeben und das Ganze für 3 min auf dem Schüttler geschüttelt. Es folgte eine kurze Zentrifugation. Anschließend wurden $450 \mu \mathrm{l}$ der Iso-Oktanfraktion in ein Septum-Vial überführt. Die gaschromatographische Analyse aller Proben erfolgte mit einem Perkin-Elmer 8600 Gaschromatographen unter folgenden technischen Bedingungen: $25 \mathrm{~m} \times 0,25 \mathrm{~mm}$ Säule I.D. FFAP (Machery - Nagel), 0,25 $\mu \mathrm{m}$ Filmdicke; Säulentemperatur $210^{\circ} \mathrm{C}$; Split 1:70; Trägergas: Wasserstoff, Druck 120 $\mathrm{kPa}$, Injektor- und Detektortemperatur $230^{\circ} \mathrm{C}$; FID (Flammenionisationsdetektor).

\subsubsection{HPLC (high performance liquid chromatography) zur Bestimmung der Glucosinolatgehalte und der Glucosinolatmuster}

Neben der NIRS-Bestimmung der Gesamtglucosinolatgehalte der Samenproben aus den Feldversuchen, erfolgte für die Samenproben aus dem Beobachtungsanbau der Testkreuzungen in Göttingen sowie für den Beobachtungsanbau der Resynthesen in Impington (UK) zusätzlich eine Bestimmung der Gesamtglucosinolatgehalte sowie der Glucosinolatmuster mittels HPLC. Für Genotypen für die von diesen Standorten keine Samenproben vorhanden waren, wurden im Fall der Testkreuzungen Samenproben vom Standort Einbeck, im Fall der Resynthesen Samenproben vom Standort Göttingen analysiert. Desweiteren wurden im Rahmen der Bachelorarbeit von Julia Rudloff die Blattglucosinolatgehalte und die Blattglucosinolatmuster einer Reihe verschiedener Brassica-Wildarten (siehe Tab. 2-4) unter Nutzung der HPLC analysiert. Dazu wurden die Proben wie folgt aufgearbeitet: 
Jeweils $200 \mathrm{mg}$ feingemahlener Samen bzw. feingemahlenes und gefriergetrocknetes Blattmaterial wurden in ein $13 \mathrm{ml}$ Probenröhrchen $(100 \times 16 \mathrm{~mm}, \mathrm{PP})$ eingewogen. Dann wurden die Probenröhrchen in ein auf $75^{\circ} \mathrm{C}$ erwärmtes Wasserbad überführt und dort für eine Minute erhitzt. Anschließend wurden die Proben mit je $3 \mathrm{ml}$ 70\%igem Methanol (Roth) und $200 \mu \mathrm{l}$ des internen Standards Glucotropaeolin (Glucotropaeolin TMA-Salz, isoliert aus Lepidium sativum) versetzt und gründlich gemischt. Es folgte eine zehnminütige Extraktion bei $75^{\circ} \mathrm{C}$ im Wasserbad, wobei die Proben mehrfach aufgeschüttelt wurden. Im Anschluss daran wurden die Proben für fünf Minuten bei $2400 \mathrm{~g}$ zentrifugiert (Varifuge F, Heraeus Sepatech). Der Überstand wurde jeweils in ein $5 \mathrm{ml}$ Reagenzröhrchen $(70 \times 12 \mathrm{~mm}$, PP) dekantiert und die Pellets mit je $2 \mathrm{ml}$ $10 \%$ igem Methanol aufgeschüttelt und für weitere $10 \mathrm{~min}$ bei $75^{\circ} \mathrm{C}$ im Wasserbad inkubiert. Nach erneuter fünf minütiger Zentrifugation bei $2400 \mathrm{~g}$ wurden die erhaltenen Überstände vereinigt und durch Schütteln gemischt. Die Pellets wurden verworfen. Je $500 \mu \mathrm{l}$ der erhaltenen glucosinolathaltigen Lösung wurden auf eine $20 \mathrm{mg}$ DEAE-Sephadex®A-25-Säule (Pharmacia) gegeben und mit $2 \times 1 \mathrm{ml}$ entionisiertem $\mathrm{H}_{2} \mathrm{O}$ auf die Säule gespült. Anschließend wurden $100 \mu \mathrm{l}$ einer 1:2,5 verdünnten Sulfatase-Stammlösung (0,33\%ige Lösung von Sulfatase Typ H1 aus Helix pomatia; Sigma( ${ }^{\circledR}$ ) hinzugegeben und die Proben für $16 \mathrm{~h}$ bei $39^{\circ} \mathrm{C}$ in einem Trockenschrank (Memmert) inkubiert. Die desulfatisierten Glucosinolate wurden mit je $3 \times 500 \mu \mathrm{l} \mathrm{HPLC}$-Wasser von den Säulen eluiert und der Durchfluss in $5 \mathrm{ml}$ Probenröhrchen aufgefangen. Je Probe wurden $700 \mu \mathrm{l}$ dieses Eluats in ein $0,8 \mathrm{ml}$ HPLC-Vial mit Deckel (Gilson) pipettiert. Die Auftrennung der so aufgereinigten Glucosinolate erfolgte mittels Gradienten HPLC und anschließender UV-Detektion. Als Eluenten wurden Acetonitril (AppliChem) und HPLC-Wasser verwendet.

Die HPLC-Analytik wurde unter folgenden technischen Bedingungen durchgeführt: Gradient: $0-19 \mathrm{~min}=1-19 \%$ Acetonitril in Wasser, $19-22 \mathrm{~min} 19 \%-1 \%$ Acetonitril in Wasser, 22 - 30 min equalibrien der Säule; Fließgeschwindigkeit: 0,6 ml/min. (Gradientenpumpe Techlab LCP 4100); Autosampler: Waters 717 plus; Säule: $125 \times 3 \mathrm{~mm}$ NUCLEODUR 100-3 C18 ec (Machery-Nagel) ; Säulenofen K4, Techlab $35^{\circ} \mathrm{C}$; Detektionswellenlänge: $\lambda=229 \mathrm{~nm}$ (UV-VIS Detector L4250 Merck Hitachi) Integrator: C-R 3A, Shimadzu.

Die Benennung der bei den Analysen nachgewiesenen Glucosinolate erfolgt, wie in Tabelle 2-11 dargestellt. 
Tab. 2-11: Abkürzungen der Glucosinolate und ihre Bedeutung

\begin{tabular}{lll}
\hline Abkürzung & Trivialname & Seitenkette (chemischer Rest) \\
\hline IBE & Glucoiberin & 3-Methylsulfinylpropyl \\
PRO & Progoitrin & 2-Hydroxy-3-butenyl \\
SIN & Sinigrin & 2-Propenyl \\
GNL & Gluconapoleiferin & 2-Hydroxy-4-Pentenyl \\
RAA & Glucoraphanin & 4-Methylsulfinylbutyl \\
RAE & Glucoraphenin & 4-Methylsulfinyl-3-butenyl \\
GNA & Gluconapin & 3-Butenyl \\
4OH & 4-Hydroxiglucobrassicin & 4-OH-3-indolylmethyl \\
GBN & Glucobrassicanapin & 4-Pentenyl \\
GBC & Glucobrassicin & 3-Indolylmethyl \\
NAS & Gluconasturtiin & 2-Phenethyl, 2-Phenylethyl \\
4ME & 4-Methoxyglucobrassicin & 4-Methoxy-3-indolylmethyl \\
NEO & Neoglucobrassicin & 1-Methoxy-3-indolylmethyl \\
\hline
\end{tabular}

\subsection{Statistische Auswertung}

Die statistische Auswertung der in den Feldversuchen und bei den Inhaltstoffanalysen ermittelten Daten erfolgte mit dem Softwareprogramm PLABSTAT (UTZ 2007). Bei Versuchen, die an den einzelnen Versuchsorten ohne Wiederholung angelegt wurden, wurde folgendes Model für die Analyse der Varianz (ANOVA) genutzt:

$$
x_{i j}=\mu+g_{i}+l_{j}+g l_{i j}
$$

dabei entspricht:

$x_{i j} \quad$ dem Merkmalswert des Genotyps $i$ am Standort $j$

$\mu \quad$ dem Versuchsmittelwert

$g_{i} \quad$ dem Effekt des $i$-ten Genotyps

$l_{j} \quad$ dem Effekt des $j$-ten Ortes

$g l_{i j} \quad$ der Interaktion zwischen dem $i$-ten Genotyp und dem Ort $j$

Die Genotypen wurden bei den Analysen als fixiert angesehen, wohingegen die Orte als zufällige Faktoren in die Analysen einflossen. Der Versuchsfehler $\varepsilon$ ist bei Analysen von einjährigen Versuchen ohne Wiederholungen in der Interaktion von Genotypen und Orten $g l_{i j}$ enthalten. 
Bei Versuchen die an einzelnen Standorten mit Wiederholung und an anderen ohne Wiederholungen durchgeführt wurden, wurde zuerst für jeden Ort mit Wiederholung einzeln eine Varianzanalyse mit folgendem Modell durchgeführt:

$$
x_{i j}=\mu+g_{i}+w_{j}+g w_{i j}
$$

dabei entspricht:

$x_{i j} \quad$ dem Merkmalswert des Genotyps $i$ am Standort $j$

$\mu \quad$ dem Versuchsmittelwert,

$g_{i} \quad$ dem Effekt des $i$-ten Genotyps

$w_{j} \quad$ dem Effekt der $j$-ten Wiederholung

$g w_{i j} \quad$ der Interaktion zwischen dem $i$-ten Genotyp und der Wiederholung $j$

Die Genotypen wurden auch in diesem Fall bei den Analysen als fixiert angesehen, die Wiederholungen hingegen wurden als zufällige Faktoren angesehen.

Die bei der ANOVA berechneten Mittelwerte der Genotypen für die einzelnen Merkmale an den einzelnen Orten wurden anschließend genutzt um eine Varianzanalyse über alle Versuchsorte zu rechnen. Diese entsprach dem oben beschriebenem Modell für Versuche ohne Wiederholungen. Der Versuchsfehler $\varepsilon$ für die Gesamt-ANOVA wurde aus den Einzel-Varianzanalysen der Orte mit Wiederholung geschätzt.

Korrelationen zwischen den verschiedenen Merkmalen wurden als Pearson Korrelationen berechnet. Ihre Berechnung erfolgte mit PLABSTAT (UTZ 2007). 


\section{Ergebnisse}

\subsection{AFLP-Markeranalysen}

Die AFLP-Analysen wurden mit Proben von 126 verschiedenen Rapsgenotypen durchgeführt. Dabei wurden drei Primerkombinationen (M50/E37, M50/E40 und M50/E42) genutzt. Bei der Auswertung dieser drei Primerkombinationen konnten insgesamt 471 polymorphe Banden identifiziert werden, welche anschließend zur Bestimmung der genetischen Distanzen verwendet wurden.

\subsubsection{Genetische Distanzen}

Die aus insgesamt 15.750 Paarvergleichen errechnete mittlere genetische Distanz (GD) über alle untersuchten Genotypen beträgt 0,54. Dabei ist eine Spannweite der GD zwischen den einzelnen Genotypen von 0,09 bis 0,81 zu beobachten (Tab. 3-1). Der kleinste Wert $(0,09)$ liegt innerhalb der Materialgruppe der klassischen Resynthesen (Resynthesen, die mit B. oleracea-Kulturformen erstellt wurden) zwischen den Genotypen , J 166“ und ,J 400'. Der größte Wert ist zwischen der Gruppe der klassischen Resynthesen und der Gruppe der WildResynthesen (Resynthesen, die das C-Genom einer Brassica-Wildart/Wildform tragen) zu beobachten. Er findet sich zwischen den Genotypen ,FS 94.3' und ,MOY 2'.

Die geringsten mittleren genetischen Distanzen sind innerhalb des Zuchtmaterials zu beobachten (Tab. 3-1). So beträgt die GD innerhalb des Winterrapses im Mittel 0,29 und innerhalb des Sommerrapses 0,28. Die Variation reicht im Winterraps von 0,12 zwischen den Sorten "Billy' und ,Oase' bis 0,42 zwischen der Sorte ,Campari“ und der DH-Linie ,Mansholt 54'. Ähnlich sieht es beim Sommerraps aus. Die Variation liegt hier zwischen 0,19 für die Sorten ,Golden' und ,Licosmos' und 0,44 zwischen den Sorten ,Bronowski' und ,Zachodni'. Innerhalb der chinesischen Sorten liegt der mittlere GD-Wert bei 0,37 mit einer Spannweite von 0,29 (zwischen ,Italy“ und ,Xiangyou 11') bis 0,43 (zwischen ,Linyou 5“ und ,Ganyu 3"). Bei den Gemüseformen reicht die Spanne von 0,23 zwischen den beiden Schnittkohlen ,Brauner Schnittkohl ' und ,Goldgelber Zarter Butter und 0,50 zwischen dem ,Grünen Schnittkohl' und der ,Wilhelmsburger Steckrübe'. Die mittlere GD liegt hier bei 0,41.

Die beobachtete mittlere GD zwischen den verschiedenen Materialgruppen fält in der Regel höher aus, als die innerhalb der Gruppen. 
Tab. 3-1: Mittlere genetische Distanz und Spannweite der genetischen Distanz innerhalb und zwischen den verschiedenen Materialgruppen

\begin{tabular}{|c|c|c|c|c|}
\hline Material & $\mathrm{n}^{1}$ & MW & Min & Max \\
\hline Winterraps x Winterraps & 506 & 0,29 & 0,12 & 0,42 \\
\hline Winterraps $\mathrm{x}$ Sommerraps & 437 & 0,37 & 0,22 & 0,51 \\
\hline Winterraps x Chin. Rapssorten & 138 & 0,39 & 0,26 & 0,52 \\
\hline Winterraps x Gemüseformen & 161 & 0,34 & 0,19 & 0,54 \\
\hline Winterraps $x$ klassische Resynthesen & 621 & 0,50 & 0,26 & 0,71 \\
\hline Winterraps $\mathrm{x}$ Wild-Resynthesen & 1012 & 0,61 & 0,44 & 0,79 \\
\hline Winterraps x Resynthesen gesamt & 1633 & 0,57 & 0,26 & 0,79 \\
\hline Sommerraps $\mathrm{x}$ Sommerraps & 342 & 0,28 & 0,19 & 0,44 \\
\hline Sommerraps $\mathrm{x}$ chin. Rapssorten & 114 & 0,46 & 0,33 & 0,54 \\
\hline Sommerraps x Gemüseformen & 133 & 0,38 & 0,26 & 0,50 \\
\hline Sommerraps x klassische Resynthesen & 513 & 0,53 & 0,33 & 0,71 \\
\hline Sommerraps $\mathrm{x}$ Wild-Resynthesen & 836 & 0,61 & 0,44 & 0,76 \\
\hline Sommerraps $\mathrm{x}$ Resynthesen ${ }_{\text {gesamt }}$ & 1349 & 0,58 & 0,33 & 0,75 \\
\hline chin. Rapssorten x chin. Rapssorten & 30 & 0,37 & 0,29 & 0,43 \\
\hline chin. Rapssorten x Gemüseformen & 42 & 0,41 & 0,39 & 0,52 \\
\hline chin. Rapssorten x klassische Resynthesen & 162 & 0,45 & 0,35 & 0,69 \\
\hline chin. Rapssorten x Wild-Resynthesen & 264 & 0,62 & 0,49 & 0,79 \\
\hline chin. Rapssorten x Resynthesen gesamt & 426 & 0,59 & 0,35 & 0,79 \\
\hline Gemüseformen x Gemüseformen & 42 & 0,41 & 0,23 & 0,50 \\
\hline Gemüseformen x klassische Resynthesen & 189 & 0,51 & 0,28 & 0,70 \\
\hline Gemüseformen $\mathrm{x}$ Wild-Resynthesen & 308 & 0,61 & 0,44 & 0,78 \\
\hline Gemüseformen x Resynthesen $_{\text {gesamt }}$ & 497 & 0,57 & 0,28 & 0,78 \\
\hline Zuchtmaterial x Zuchtmaterial & 2970 & 0,35 & 0,12 & 0,54 \\
\hline Zuchtmaterial x klassische Resynthesen & 1485 & 0,52 & 0,26 & 0,71 \\
\hline Zuchtmaterial x Wild-Resynthesen & 2420 & 0,61 & 0,44 & 0,79 \\
\hline Zuchtmaterial x Resynthesen $n_{\text {gesamt }}$ & 3905 & 0,58 & 0,26 & 0,79 \\
\hline klassische Resynthesen x klassische Resynthesen & 702 & 0,55 & 0,18 & 0,75 \\
\hline Wild-Resynthesen $x$ Wild-Resynthesen & 1892 & 0,59 & 0,09 & 0,79 \\
\hline klassische Resynthesen x Wild-Resynthesen & 1188 & 0,61 & 0,35 & 0,81 \\
\hline Resynthesen $_{\text {gesamt }}$ x Resynthesen gesamt $_{\text {g }}$ & 4970 & 0,59 & 0,09 & 0,81 \\
\hline
\end{tabular}

${ }^{1}$ Anzahl der Paarvergleiche

Die geringste mittlere Distanz lässt sich mit 0,34 zwischen der Winterrapsgruppe und der Gruppe der Gemüseformen finden. Die größten mittleren genetischen Distanzen von 0,61 bis 0,62 treten bei den Gruppenvergleichen unter Beteiligung der Wild-Resynthesen auf (Tab. 3-1). Auch die beobachteten Minimal- und Maximalwerte liegen im Schnitt höher als diejenigen der anderen Vergleiche.

Die Vergleiche zwischen den Gruppen des Zuchtmaterials und der Gruppe der klassischen Resynthesen erbringen ebenfalls mittlere genetische Distanzen, die in 
den meisten Fällen höher ausfallen, als die zwischen den Gruppenvergleichen innerhalb des Zuchtmaterials. Sie liegen zwischen 0,45 und 0,53.

Die größte Variationsbreite zeigt sich innerhalb der Wild-Resynthesen. Sie reicht hier von 0,09 zwischen den Resyntheselinien , J 166' und , J 400' bis 0,79 zwischen den Linien ,MAY 1' und ,MOL 2'. Die mittlere GD liegt bei 0,59. Auch die Spanne der GD bei den klassischen Resynthesen ist groß. Sie umfasst einen Bereich von 0,18 zwischen den Genotypen ,RS 7/6، und ,H44' bis 0,75 zwischen ,S 39، und ,RS 10/7‘ bei einer mittleren GD von 0,55.

Für die Gruppe der 65 Resynthesen, die für die Testkreuzungen verwendet wurden, wurde eine mittlere GD zu dem Tester ,MSL 007 von 0,56 und zu ,RNX 4621' von 0,57 geschätzt. Die GD zwischen den beiden Testern liegt bei 0,27. Vergleicht man die GD der Resynthesen zu ,MSL 007 und zu ,RNX 4621', so erhält man eine sehr hohe signifikante Korrelation (Abb. 3-1).



Abb. 3-1: Genetische Distanzen der 65 für die Produktion von Testhybriden verwendeten Resynthesen zu den männlich sterilen Testern ,MSL 007' und ,RNX 4621'; ** $=$ hochsignifikant $(P=0,01)$

Teilt man die Resynthesen in klassische Resynthesen und Wild-Resynthesen auf, lässt sich für die klassischen Resynthesen eine mittlere GD zu den beiden Testern 
von jeweils 0,50 beobachten. Für die Wild-Resynthesen liegt sie bei 0,61 zu ,MSL 007، und bei 0,62 zu ,RNX 4621‘.

\subsubsection{Hauptkoordinatenanalyse}

Für die aus den Markeranalysen ermittelten genetischen Distanzen wurde eine Hauptkoordinatenanalyse durchgeführt. Diese ermöglicht es zu überprüfen, inwieweit sich die unterschiedlichen für die Untersuchung verwendeten Materialgruppen genetisch tatsächlich voneinander abgrenzen lassen. Das Ergebnis ist in Abbildung 3-2 graphisch für die ersten drei Hauptkoordinaten dargestellt. Sie erklären zusammen $21,8 \%$ der vorhandenen genetischen Variation.

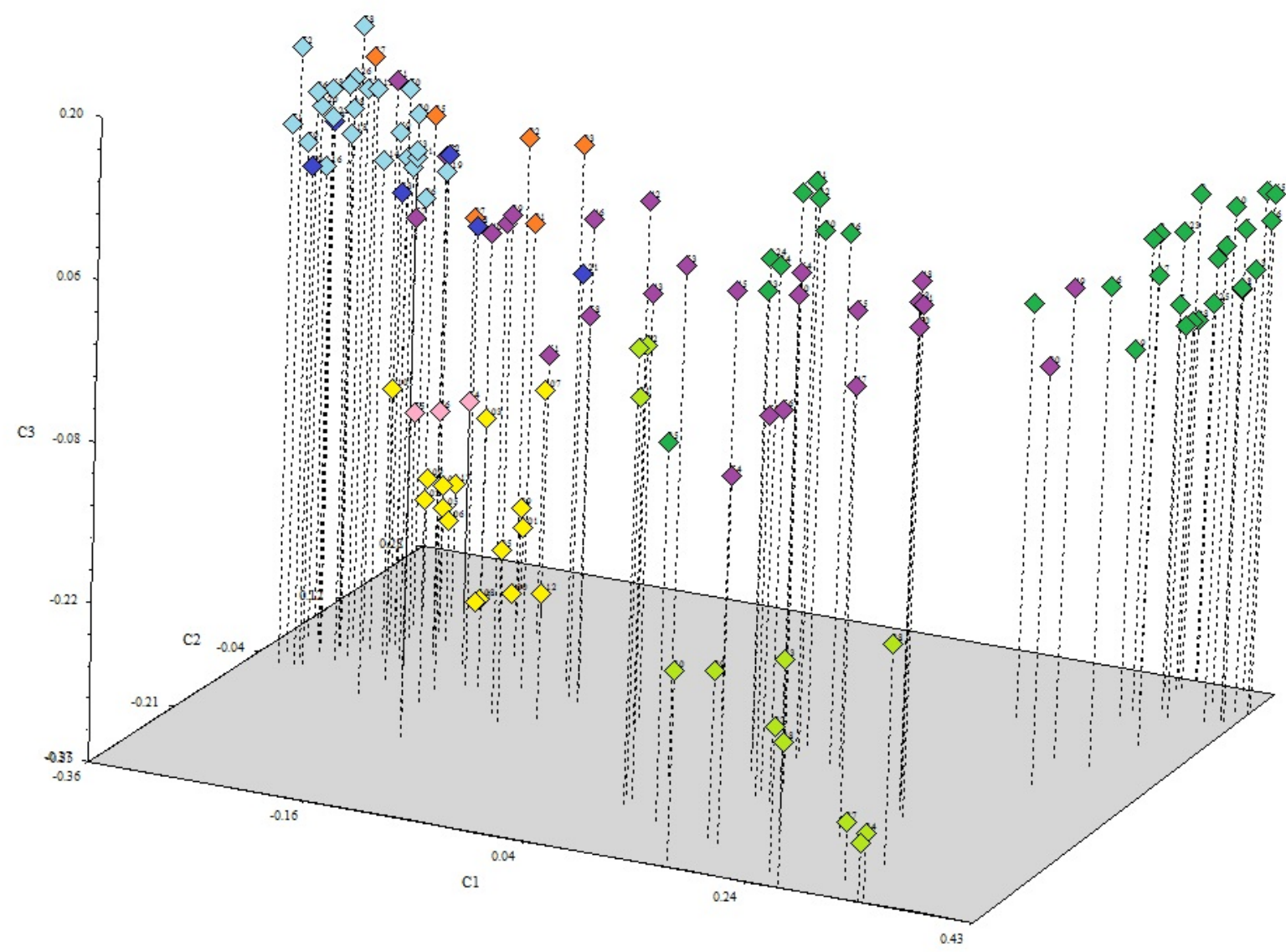

Abb. 3-2: Hauptkoordinatenanalyse der Verwandtschaftsbeziehungen zwischen 55 Rapssorten und 71 Resynthesen. Hellblau = Winterraps, blau = Gemüseformen, gelb = Sommerraps, orange = chinesische Sorten, rosa $=$ türkische Sorten, violett $=$ klassische Resynthesen, hellgrün $=$ Resynthesen mit $B$. oleraceaWildtypen, grün = Resynthesen mit Brassica-Wildarten

Anhand des Ergebnisses der Hauptkoordinatenanalyse (Abb. 3-2) kann das Untersuchungsmaterial in mehrere klar abgrenzbare Gruppen eingeteilt werden. Die hellblau gekennzeichnete Gruppe am linken oberen Rand entspricht den 
untersuchten Winterrapssorten. Die Sommerrapssorten (gelb) bilden zusammen mit den türkischen Sorten (rosa) eine eigene Gruppe. Weiterhin lassen sich zwei in grün markierte und zwei in hellgrün markierte Gruppen identifizieren. Die grün markierte Gruppe im mittleren Bereich der Grafik enthält die Wild-Resynthesen, die aus Kreuzungen der Winterrübsensorte ,Largo' und verschiedenen BrassicaWildarten erstellt wurden. In der zweiten grünen Gruppe, am rechten oberen Rand, finden sich Wild-Resynthesen, die auf Kreuzungen zwischen der Sommerrübsenform ,Yellow Sarson' und diversen Brassica-Wildarten basieren. Die beiden hellgrünen Gruppierungen bestehen aus Wild-Resynthesen, die mit Wildformen von Brassica oleracea hergestellt wurden, wobei die Genotypen der kleineren hellgrünen Gruppe (in der Mitte der Abbildung) auf Kreuzungen mit Winterrübsen zurückgehen und die der größere Gruppe (im vorderen rechten Bereich) auf Kreuzungen mit der Sommerrübsenform ,Yellow Sarson“ zurückzuführen sind. Für die chinesischen Sorten (orange) ist nur ansatzweise eine Gruppenbildung zu erkennen. Sie liegen in der Nähe der Winterrapsgruppe (hellblau). Die Gemüseformen (blau) und die klassischen Resynthesen (violett) bilden keine eindeutigen Gruppierungen. Die Gemüseformen (blau) gruppieren mehrheitlich zusammen mit den Winterrapssorten, während die klassischen Resynthesen fast über den gesamten Bereich streuen. Die verschiedenen Gruppen des Zuchtmaterials (Winter- und Sommerraps, chinesische und türkische Sorten sowie Gemüseformen) liegen in der Hauptkoordinatenanalyse im linken Teil der Abbildung nah beieinander. Die verschiedenen Gruppierungen der WildResynthesen sind von denen des Zuchtmaterials deutlich abgesetzt und finden sich im mittleren bzw. rechten Teil der Grafik.

\subsubsection{Clusteranalyse}

Um die Verwandtschaftsbeziehungen zwischen den einzelnen Linien der 126 untersuchten Rapsgenotypen aufzuzeigen, wurde auf Grundlage der geschätzten genetischen Distanzen eine Clusteranalyse durchgeführt. Das Ergebnis ist als Dendrogramm in Abbildung 3-3 dargestellt. Um die Übereinstimmung dieses Verwandtschaftsbaumes mit der Distanzmatrix zu überprüfen, wurde die cophenetische Korrelation zwischen den mittleren genetischen Distanzen der Clusteranalyse und den genetischen Distanzen für die einzelnen Paarvergleiche berechnet. Die Berechnung ergab eine Wert von $r=0,92$. Zur statistischen 
Absicherung der in der Clusteranalyse gefundenen Gruppierungen wurde außerdem ein Bootstrapping durchgeführt. Die Ergebnisse dafür werden in Abbildung I im Anhang gezeigt.

Innerhalb des Dendrogramms (Abb. 3-3) lässt sich eine Reihe von klar identifizierbaren Gruppierungen beobachten. Zur besseren Übersicht wurden diese mit verschiedenen Buchstaben gekennzeichnet. Die ersten drei Cluster von oben, gekennzeichnet mit den Buchstaben , W', ,S' und ,C', bilden zusammen ein größeres Cluster. In diesem sind alle Genotypen des Rapszuchtmaterials mit Ausnahme der ,Wilhelmsburger Steckrübe' eingegliedert. Das mit ,W' bezeichnete Cluster enthält sämtliche Winterrapsorten sowie fast alle Gemüseformen und mit den Linien ,S 13', ,B 1/3.3' und ,S 108.1.1' auch drei klassische Resynthesen. Cluster ,S' vereinigt alle Sommerrapssorten sowie die drei türkischen Rapssorten, und Cluster ,C' beinhaltet die Sorten chinesischen Ursprungs. Die Trennung dieser drei Gruppierungen voneinander erfolgt im Dendrogramm bei einer mittleren GD von 0,37 für die Cluster , $W$ ' und , $S$ ' bzw. bei einer mittleren GD von $~ 0,41$ für das Cluster , $C^{\prime}$ zu den Clustern ,W' und , $S^{\prime}$.

Die größten genetischen Distanzen zu den drei Gruppierungen des angepassten Zuchtmaterials weisen die drei mit ,WS' bezeichneten Cluster auf. Ihre Abtrennung erfolgt bei mittleren GD-Werten von $\sim 0,60$ für Cluster ,WS $a^{\prime}, \sim 0,63$ für Cluster ,WS b' bzw. bei $\sim 0,65$ für das Cluster ,WS c'. Diese drei Gruppierungen enthalten sämtliche Wild-Resynthesen, die das C-Genom einer Brassica-Wildart in sich tragen. Cluster ,WS a' beinhaltet neben den Wild-Resynthesen außerdem zwei klassische Resynthesen (,FS 94.3' und ,R 76'). In Cluster ,WS b' sind drei klassische Resynthesen (,RS 4/6', ,RS 10/7 ' und ,RS 239') enthalten. Desweiteren finden sich hier zwei Wild-Resynthesen (, OLY $1^{\prime}$ und ,OLY $2^{\prime}$ ), die mit Wildformen von Brassica oleracea erstellt wurden. Die meisten der untersuchten klassischen Resyntheselinien gruppieren sich zwischen den Clustern des angepassten Zuchtmaterials (,W', , $S^{\prime}$ und , C') und den Wild-Resynthese-Clustern (,WS') ein. Für die klassischen Resynthese lassen sich meist nur kleinere Cluster von 3 bis maximal 5 Genotypen finden. Viele der klassischen Resynthesen stehen im Dendrogramm mehr oder weniger separiert. Dennoch lassen sich zwei Gruppen klassischer Resynthesen identifizieren. Diese sind im Dendrogramm mit den Buchstaben ,RS a' und ,RS b' gekennzeichnet. In der Gruppe ,RS a' ist zusätzlich zu den Resynthesen noch die Gemüseform ,Wilhelmsburger Steckrübe‘ enthalten. 


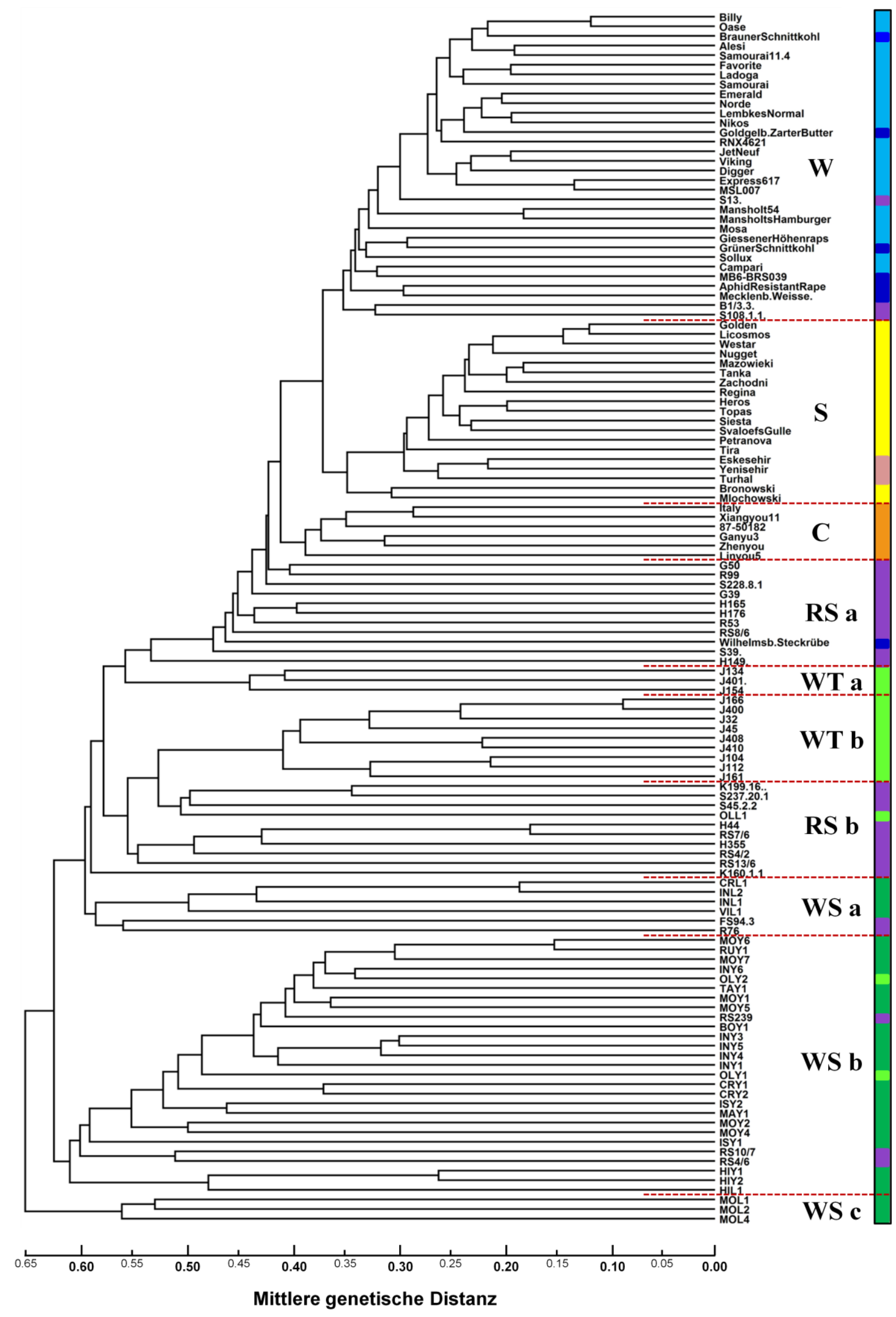

Abb. 3-3.: UPGMA Dendrogramm der Verwandtschaftsbeziehungen zwischen 55 Rapssorten und 71 Resynthesen. Die Berechnung der genetischen Distanzen erfolgte mit dem Jaccard-Koeffizienten. Hellblau = Winterraps $\left(, W^{\prime}\right)$, blau = Gemüseformen, gelb = Sommerraps (,S'), orange = chinesische Sorten $\left(, C^{\prime}\right)$, rosa $=$ türkische Sorten, violett $=$ klassische Resynthesen $\left(, \mathrm{RS}^{\prime}\right)$, hellgrün $=$ Resynthesen mit $B$. oleracea-Wildtypen (,WT'), grün = Resynthesen mit Brassica-Wildarten 
Sie clustert als einzige Zuchtform nicht mit dem übrigen Zuchtmaterial. Die Trennung der Resynthesen der Gruppe ,RS a' vom angepassten Zuchtmaterial erfolgt in einem Bereich der mittleren GD von $\sim 0,43$ (für die Genotypen ,G 50، und ,$R 9^{\circ}$ ) bis $\sim 0,53$ (für die Linie,$H 1^{\circ} 9^{\prime}$ ). Die Gruppe ,RS b` enthält neben den klassischen Resynthesen auch eine Wild-Resynthese (,OLL 1') die das C-Genom von einer B. oleracea-Wildform beinhaltet.

Zwischen den beiden Gruppen der klassischen Resynthesen liegen zwei weitere Cluster (markiert mit ,WT'), die Wild-Resynthesen beinhalten, welche aus Kreuzungen mit Wildformen von B. oleracea hervorgegangen sind. Das Cluster ,WT a' trennt sich vom Zuchtmaterial bei einer mittleren GD von 0,55. Das zweite Cluster (,WT b') bildet zusammen mit den klassischen Resynthesen des Clusters ,RS b' ein größeres Cluster, welches eine mittlere GD von $\sim 0,58$ zum züchterisch bearbeiteten Rapszuchtmaterial aufweist. 


\subsection{Charakterisierung der Brassica-Wildarten}

\subsubsection{Fettsäuremuster}

Für insgesamt 56 Brassica-Wildart-Akzessionen wurden im Zuge von EinzelkornGC Untersuchungen der Wild-Resynthesen die Fettsäuremuster analysiert.

Da für jede Akzession (im Folgenden mit AZ abgekürzt) jeweils nur ein Samenkorn analysiert wurde, wurde von einer statistischen Auswertung der Daten abgesehen. Die Ergebnisse der Einzelkorn-GC sind in Tabelle 3-2 dargestellt. Für die meisten Fettsäuren lassen sich sowohl innerhalb der einzelnen untersuchten Arten wie auch artübergreifend große Variationen beobachten.

Für Palmitinsäure (C 16:0) lässt sich zum Beispiel eine Spanne von 2,56\% für die B. villosa-AZ 6568 bis zu 7,3\% für die B. oleracea-AZ 6824 beobachten. Der Mittelwert beträgt 4,5\%. Auch für Ölsäure (C 18:1), Linolsäure (C 18:2) und Linolensäure (C 18:3) sind große Variationen festzustellen. Im Mittel erreichen diese drei Fettsäuren ähnliche Prozentanteile (Ölsäure 14,7\%, Linolsäure 14,4\% und Linolensäure 12,6\%). Welche dieser drei Ölsäuren den höchsten Anteil (nach Erucasäure (C22:1)) aufweist, variiert zwischen den einzelnen Akzessionen stark. Während es bei den $B$. cretica-Akzessionen in der Regel die Ölsäure ist, dominiert in anderen Fällen die Linolsäure (z.B. bei der B. oleracea-AZ 6824) oder die Linolensäure (z.B. bei der B. hilarionis-AZ 7344).

Den höchsten prozentualen Anteil weist bei allen Akzessionen die Erucasäure auf. Die Spannbreite reicht hier von 27,1\% für die B. insularis AZ-BRA 3050/2 bis zu $57 \%$ bei der B. villosa-AZ 6589

Tendenziell scheinen die B. villosa-Akzessionen und die B. rupestris-Akzessionen im Mittel die höchsten Erucasäuregehalte und die geringsten Palmitinsäuregehalte aufzuweisen. 
Tab. 3-2: Ergebnisse der Einzelkorn-GC der Fettsäuren für 56 Brassica-Wildart-Akzessionen

\begin{tabular}{|c|c|c|c|c|c|c|c|c|c|c|c|c|}
\hline Spezies & Akzession $^{1}$ & $16: 0$ & $16: 1$ & $16: 2$ & $18: 0$ & $18: 1$ & $18: 2$ & $18: 3$ & $20: 0$ & $20: 1$ & $22: 0$ & $22: 1$ \\
\hline B. bourgeaui & BRA 2998 & 6,04 & 0,83 & 0,00 & 0,68 & 11,26 & 11,00 & 16,40 & 0,53 & 4,02 & 0,59 & 47,72 \\
\hline B. cretica & BRA 3092 & 5,04 & 0,00 & 0,00 & 1,20 & 17,38 & 15,03 & 15,56 & 0,94 & 7,75 & 1,07 & 36,00 \\
\hline B. cretica & BRA 2997 & 4,87 & 0,00 & 0,00 & 1,34 & 18,49 & 13,19 & 7,86 & 0,92 & 5,15 & 1,13 & 47,00 \\
\hline B. cretica & 6343 & 4,79 & 0,51 & 0,00 & 1,09 & 13,32 & 11,46 & 13,11 & 0,82 & 4,12 & 1,00 & 49,61 \\
\hline B. cretica & 5971 & 4,67 & 0,68 & 0,00 & 1,83 & 19,99 & 10,51 & 8,85 & 1,25 & 1,95 & 1,45 & 48,81 \\
\hline B. cretica aegea & 6021 & 2,77 & 0,34 & 0,20 & 1,01 & 19,63 & 12,07 & 4,03 & 0,81 & 6,74 & 0,70 & 51,55 \\
\hline B. cretica aegea & 6344 & 3,34 & 0,40 & 0,00 & 0,99 & 14,80 & 8,98 & 12,10 & 0,71 & 6,98 & 0,78 & 50,45 \\
\hline B. cretica aegea & 6346 & 3,30 & 0,37 & 0,14 & 1,19 & 20,38 & 8,82 & 6,42 & 0,91 & 6,32 & 1,12 & 51,00 \\
\hline B. hilarionis & HRIGRU 12483 & 4,39 & 0,00 & 0,00 & 1,11 & 21,11 & 12,56 & 9,50 & 0,94 & 6,24 & 1,06 & 43,08 \\
\hline B. hilarionis & 7344 & 5,17 & 0,00 & 0,00 & 0,88 & 17,69 & 13,94 & 19,53 & 0,50 & 5,34 & 0,84 & 35,48 \\
\hline B. incana & 6570 & 4,66 & 0,00 & 0,00 & 1,06 & 13,13 & 14,30 & 13,63 & 0,64 & 2,41 & 0,82 & 48,92 \\
\hline B. incana & BRA 2918 & 4,16 & 0,51 & 0,00 & 1,12 & 16,56 & 11,64 & 9,19 & 0,67 & 3,11 & 0,76 & 52,14 \\
\hline B. incana & 6563 & 5,10 & 0,57 & 0,00 & 0,76 & 10,53 & 11,17 & 14,18 & 0,55 & 4,99 & 0,65 & 50,89 \\
\hline B. incana & 6564 & 5,34 & 0,00 & 0,00 & 0,82 & 14,64 & 14,43 & 13,90 & 0,54 & 1,53 & 0,32 & 48,34 \\
\hline B. incana & 6569 & 3,51 & 0,42 & 0,00 & 0,85 & 12,92 & 11,75 & 8,87 & 0,59 & 4,87 & 0,72 & 54,86 \\
\hline B. incana & 6572 & 4,87 & 0,69 & 0,00 & 0,88 & 11,50 & 13,64 & 7,91 & 0,61 & 4,87 & 0,81 & 53,45 \\
\hline B. incana & CGN 18470 & 5,12 & 0,00 & 0,00 & 1,12 & 15,27 & 13,16 & 16,74 & 0,98 & 2,65 & 0,23 & 43,98 \\
\hline B. incana & 6558 & 5,73 & 0,00 & 0,00 & 1,30 & 19,63 & 17,45 & 11,34 & 0,66 & 2,97 & 0,45 & 40,33 \\
\hline B. incana & 6560 & 5,80 & 0,00 & 0,00 & 1,11 & 17,21 & 17,85 & 16,01 & 0,78 & 2,67 & 0,58 & 37,45 \\
\hline B. incana & 5974 & 6,48 & 0,00 & 0,00 & 0,95 & 18,54 & 16,44 & 11,17 & 0,94 & 3,48 & 1,20 & 40,33 \\
\hline B. incana & BRA 1166 & 6,98 & 0,00 & 0,00 & 1,29 & 20,03 & 20,45 & 12,19 & 0,65 & 2,31 & 0,47 & 35,22 \\
\hline B. incana & BRA 1262 & 6,86 & 0,00 & 0,00 & 1,45 & 13,99 & 21,22 & 20,83 & 0,98 & 3,57 & 1,60 & 29,10 \\
\hline B. insularis & BRA 2996 & 3,80 & 0,46 & 0,00 & 1,13 & 14,48 & 17,38 & 8,45 & 0,92 & 5,17 & 1,14 & 46,20 \\
\hline B. insularis & BRA 3050 & 4,14 & 0,00 & 0,00 & 1,16 & 16,16 & 13,33 & 12,23 & 0,73 & 3,14 & 1,03 & 47,91 \\
\hline B. insularis & BRA $3051 / 1$ & 4,74 & 0,62 & 0,00 & 0,95 & 13,74 & 14,32 & 9,11 & 0,71 & 2,74 & 1,64 & 51,28 \\
\hline B. insularis & BRA $3051 / 2$ & 3,66 & 0,40 & 0,00 & 1,05 & 18,92 & 18,55 & 15,87 & 0,78 & 12,81 & 0,61 & 27,13 \\
\hline B. insularis & 7346 & 4,52 & 0,00 & 0,00 & 1,09 & 16,54 & 14,31 & 12,46 & 0,79 & 8,45 & 0,65 & 41,12 \\
\hline B. macrocarpa & 6584 & 3,43 & 0,00 & 0,00 & 1,03 & 14,20 & 12,29 & 10,82 & 0,68 & 7,25 & 0,70 & 49,56 \\
\hline B. montana & 6816 & 2,98 & 0,00 & 0,00 & 0,78 & 17,30 & 14,57 & 18,00 & 0,42 & 10,58 & 0,40 & 34,60 \\
\hline B. montana & 6817 & 3,75 & 0,00 & 0,00 & 1,06 & 9,80 & 16,98 & 17,30 & 1,05 & 9,93 & 2,14 & 38,01 \\
\hline
\end{tabular}

${ }^{1}$ Akzessionen ohne Buchstabenkürzel entstammen der Banco de Germoplasma, Madrid (ES); CGN steht für Centre for Genetic Resources, Wageningen (NL), BRA für das IPK

(D) und HRIGRU für Warwick HRI Genetic Resources Unit, University of Warwick (GB) 
Tab. 3-2: Ergebnisse der Einzelkorn-GC der Fettsäuren für 56 Brassica-Wildart-Akzessionen (Fortsetzung)

\begin{tabular}{|c|c|c|c|c|c|c|c|c|c|c|c|c|}
\hline Spezies & Akzession $^{1}$ & $16: 0$ & 16:1 & $16: 2$ & $18: 0$ & 18:1 & $18: 2$ & $18: 3$ & $20: 0$ & 20:1 & $22: 0$ & $22: 1$ \\
\hline B. montana & 6801 & 3,96 & 0,00 & 0,00 & 0,96 & 11,41 & 15,06 & 11,62 & 0,81 & 3,14 & 0,87 & 52,09 \\
\hline B. montana & 6835 & 3,52 & 0,00 & 0,00 & 1,13 & 15,38 & 15,56 & 10,88 & 0,90 & 9,57 & 1,01 & 41,56 \\
\hline B. montana & CGN 18472 & 4,97 & 0,00 & 0,00 & 1,04 & 16,76 & 13,96 & 13,49 & 0,66 & 4,32 & 0,81 & 43,97 \\
\hline B. montana & BRA 2946 & 3,15 & 0,00 & 0,00 & 0,99 & 18,68 & 13,64 & 10,25 & 0,70 & 10,65 & 0,72 & 41,05 \\
\hline B. montana & BRA 2993 & 4,25 & 0,00 & 0,00 & 0,86 & 12,05 & 12,70 & 16,17 & 0,40 & 3,06 & 0,96 & 49,23 \\
\hline B. montana & BRA 2942 & 4,60 & 0,00 & 0,00 & 0,86 & 11,89 & 18,84 & 15,91 & 0,50 & 7,05 & 0,49 & 39,68 \\
\hline B. montana & BRA 3074 & 6,47 & 0,88 & 0,00 & 0,98 & 18,08 & 15,86 & 13,44 & 0,64 & 4,78 & 0,58 & 38,01 \\
\hline B. oleracea & 6824 & 7,32 & 0,71 & 0,00 & 1,02 & 15,01 & 21,07 & 16,20 & 1,00 & 7,29 & 1,08 & 29,25 \\
\hline B. oleracea & 7694 & 6,99 & 0,00 & 0,00 & 1,35 & 15,72 & 18,53 & 17,86 & 0,56 & 6,58 & 0,89 & 31,44 \\
\hline B. oleracea & BRA 141 & 4,57 & 0,00 & 0,00 & 0,88 & 8,68 & 18,53 & 17,15 & 0,60 & 2,70 & 1,27 & 45,60 \\
\hline B. oleracea & BRA 258 & 4,62 & 0,00 & 0,00 & 1,31 & 20,65 & 15,83 & 10,50 & 0,86 & 6,55 & 0,86 & 38,80 \\
\hline B. oleracea & 7681 & 4,28 & 0,36 & 0,17 & 1,08 & 14,79 & 13,50 & 13,49 & 0,72 & 10,56 & 0,50 & 40,12 \\
\hline B. oleracea & 7660 & 4,07 & 0,47 & 0,00 & 0,70 & 8,40 & 12,74 & 11,78 & 0,55 & 5,45 & 0,80 & 54,50 \\
\hline B. oleracea selenisia & BRA 1668 & 5,36 & 0,61 & 0,00 & 1,01 & 21,21 & 16,58 & 7,18 & 0,59 & 8,20 & 0,68 & 37,99 \\
\hline B. rupestris hispida & 6580 & 3,24 & 0,12 & 0,00 & 0,69 & 12,99 & 11,25 & 10,66 & 0,50 & 1,91 & 1,04 & 56,11 \\
\hline B. rupestris hispida & 6575 & 3,13 & 0,00 & 0,00 & 0,74 & 9,65 & 12,25 & 13,40 & 0,61 & 3,41 & 1,42 & 54,70 \\
\hline B. rupestris & 6579 & 4,75 & 0,00 & 0,00 & 1,12 & 14,41 & 17,09 & 12,12 & 0,88 & 4,57 & 1,61 & 43,41 \\
\hline B. rupestris & 6594 & 2,64 & 0,00 & 0,00 & 0,64 & 8,74 & 13,13 & 11,57 & 0,60 & 3,90 & 1,65 & 56,45 \\
\hline B- rupestris & BRA 2992 & 4,30 & 0,00 & 0,00 & 1,12 & 7,36 & 16,93 & 12,47 & 0,87 & 3,25 & 1,18 & 52,23 \\
\hline B. taurica & BRA 2947 & 4,64 & 0,55 & 0,00 & 1,02 & 11,79 & 19,06 & 11,47 & 0,67 & 2,80 & 0,77 & 47,08 \\
\hline B. villosa bivoniana & 6589 & 2,56 & 0,00 & 0,00 & 0,93 & 10,47 & 10,06 & 13,72 & 0,84 & 2,90 & 1,42 & 57,00 \\
\hline B. villosa bivoniana & 6581 & 2,83 & 0,13 & 0,00 & 0,70 & 9,83 & 14,42 & 10,16 & 0,67 & 4,62 & 1,41 & 55,10 \\
\hline B. villosa drepanensis & 6926 & 4,36 & 0,00 & 0,00 & 1,17 & 11,96 & 13,96 & 13,63 & 0,81 & 4,23 & 1,48 & 47,81 \\
\hline B. villosa & 6595 & 3,28 & 0,00 & 0,00 & 0,69 & 8,12 & 15,39 & 14,79 & 0,69 & 2,15 & 1,20 & 53,47 \\
\hline B. villosa & 6848 & 2,79 & 0,00 & 0,00 & 1,28 & 22,40 & 8,24 & 5,12 & 0,77 & 5,63 & 1,34 & 52,42 \\
\hline \multirow[t]{4}{*}{ B. villosa } & 6691 & 3,55 & 0,56 & 0,00 & 0,55 & 9,93 & 9,67 & 15,31 & 0,53 & 4,15 & 0,45 & 55,54 \\
\hline & Mittelwert & 4,47 & 0,20 & 0,01 & 1,02 & 14,74 & 14,40 & 12,57 & 0,73 & 5,13 & 0,95 & 45,47 \\
\hline & Min. & 2,56 & 0,00 & 0,00 & 0,55 & 7,36 & 8,24 & 4,03 & 0,40 & 1,53 & 0,23 & 27,13 \\
\hline & Max. & 7,32 & 0,88 & 0,20 & 1,83 & 22,40 & 21,22 & 20,83 & 1,25 & 12,81 & 2,14 & 57,00 \\
\hline
\end{tabular}

${ }^{1}$ Akzessionen ohne Buchstabenkürzel entstammen der Banco de Germoplasma, Madrid (ES); CGN steht für Centre for Genetic Resources, Wageningen (NL), BRA für das IPK (D) und HRIGRU für Warwick HRI Genetic Resources Unit, University of Warwick (GB) 


\subsubsection{Blattglucosinolatgehalt und -muster}

Im Rahmen einer Bachelorarbeit (Julia Rudloff (2010): „Charakterisierung von Brassica-Wildarten und deren Verwendung für Resynthesen“) wurden die Blattglucosinolatgehalte und Blattglucosinolatmuster von 40 Brassica-WildartAkzessionen aus 10 Arten mittels HPLC analysiert. Die dabei erarbeiteten Ergebnisse werden im Folgenden präsentiert.

Bei den HPLC-Analysen der Blattglucosinolate konnten insgesamt 12 unterschiedliche Glucosinolate nachgewiesen werden. Für annähernd alle gefundenen Glucosinolate sowie für den Gesamtglucosinolatgehalt der Blätter konnten in der Varianzanalyse hochsignifikante Unterschiede bestätigt werden (Tab. 3-3). Auch die errechneten Heritabilitäten erreichten in der Regel sehr hohe Werte von $\mathrm{h}^{2} \geq 0,90$ (Tab. 3-3). Ausnahmen bildeten die seltener bzw. nur in geringen Mengen vorkommenden Glucosinolate Glucobrassicanapin (GBN), 4-Methoxyglucobrassicin (4OH) und Neoglucobrassicin (NEO) für die keine signifikanten bzw. keine hochsignifikanten Unterschiede und nur sehr geringe Heritabilitäten vorlagen. Für Gluconapoleiferin (GNL) konnten zwar eine hochsignifikante genotypische Variation nachgewiesen werden, die Heritabilität ist aber mit $h^{2}=0,60$ eher niedrig.

Tab. 3-3: Ergebnisse der ANOVA für die HPLC-Analyse der Blattglucosinolatgehalte und -muster der Brassica-Wildarten. Gezeigt sind die Varianzkomponenten und die Heritabilität der einzelnen Merkmale

\begin{tabular}{lcrrr}
\hline Varianzursache $^{\text {a }}$ & Genotyp & $\mathbf{W}$ & $\mathbf{G x W}$ & $\mathbf{h}^{\mathbf{2}}$ \\
\hline Glucoiberin (IBE) & $15,7901^{* *}$ & $-0,0232$ & 1,4846 & 0,96 \\
Progoitrin (PRO) & $223,2595^{\star *}$ & $-0,1700$ & 7,2290 & 0,98 \\
Sinigrin (SIN) & $135,1271^{* *}$ & 0,0226 & 1,7599 & 0,99 \\
Gluconapoleiferin (GNL) & $0,0016^{* *}$ & $-0,0001$ & 0,0022 & 0,60 \\
Glucoraphanin (RAA) & $41,9859^{* *}$ & $-0,0324$ & 1,3745 & 0,98 \\
Gluconapin (GNA) & $560,0122^{* *}$ & $-0,4849$ & 28,3942 & 0,98 \\
4-Hydroxiglucobrassicin (4OH) & $12,1021^{* *}$ & $-0,0028$ & 0,1746 & 0,99 \\
Glucobrassicanapin (GBN) & 0,1162 & $-0,0136$ & 0,6114 & 0,28 \\
Glucobrassicin (GBC) & $20,6402^{* *}$ & 0,0131 & 2,8462 & 0,94 \\
Gluconasturtiin (NAS) & $7,5785^{* *}$ & $-0,0049$ & 0,1985 & 0,99 \\
4-Methoxyglucobrassicin (4ME) & 0,0000 & 0,0000 & 0,0007 & 0,12 \\
Neoglucobrassicin (NEO) & $0,0674^{+}$ & 0,0008 & 0,2360 & 0,36 \\
GSL gesamt & $616,6710^{* *}$ & $-0,2453$ & 48,4547 & 0,96 \\
\hline
\end{tabular}

${ }^{a} \mathrm{~W}=$ Wiederholung, $\mathrm{GxW}=$ Interaktion zwischen Genotyp und Wiederholung; $\mathrm{h}^{2}=$ Heritabilität;

${ }^{* *},{ }^{*},{ }^{+}$signifikant bei $p=0,01, p=0,05$ bzw. $p=0,1$ 
Die Ergebnisse für die Blattglucosinolatmuster und den Blattglucosinolatgehalt sind in Abbildung 3-4 graphisch dargestellt. Die genauen Einzelwerte sind Tabelle II im Anhang zu entnehmen.

Der Gesamtglucosinolatgehalt der Blätter zeigt eine große Spannweite sowohl zwischen den einzelnen Arten wie auch zwischen den Akzessionen innerhalb einer Art. Die ermittelte Grenzdifferenz $(p=0,05)$ für den Gesamtglucosinolatgehalt beträgt $14,1 \mu \mathrm{mol} / \mathrm{g}$. Der niedrigste Blattglucosinolatgehalt wurde mit 10,1 $\mu \mathrm{mol} / \mathrm{g}$ für die B. montana-Akzession (AZ) BRA 2993 ermittelt, der höchste Wert mit 117,5 $\mu \mathrm{mol} / \mathrm{g}$ zeigte sich bei der AZ 6816, die ebenfalls der Art B. montana angehört. B. montana weist damit auch die größte beobachtete Spanne innerhalb einer Art auf. Auch bei den Akzessionen der Arten $B$. cretica, $B$. incana und $B$. insularis lassen sich große Variationsbreiten innerhalb der Arten beobachten, wohingegen es zwischen den vier Akzessionen von B. oleracea keine signifikanten Unterschiede im Blattglucosinolatgehalt gibt. Sie liegen alle zwischen $31,9 \mu \mathrm{mol} / \mathrm{g}$ und $39,3 \mu \mathrm{mol} / \mathrm{g}$.

Betrachtet man die Glucosinolatmuster der einzelnen Akzessionen (Abb. 3-4), so fällt die große Variation auf. Bei den Akzessionen von B. cretica ist Gluconapin (GNA) mit Prozentanteilen zwischen 64,3\% (AZ 6344) und 95,2\% (AZ 6021) des Gesamtglucosinolatgehaltes das Hauptglucosinolat, alle anderen Glucosinolate kommen gar nicht oder nur in geringeren Anteilen vor. Die Akzessionen von B. insularis zeichnen sich durch relativ hohe Anteile von Gluconapin (GNA) (bis $>90 \%$, AZ BRA 3050) und Progoitrin (PRO) (bis 67\%, AZ 7356) aus. Auch Guconasturtiin (NAS) ist mit Prozentanteilen bis 21\% (AZ BRA 2996) vorhanden. Einen Sonderfall innerhalb der B. insularis-Akzessionen stellt die AZ 1952 dar. Sie weist als Hauptglucosinolat Sinigrin (SIN) mit $97 \%$ auf, andere Glucosinolate sind nur in Spuren enthalten. Die übrigen Akzessionen weisen zum Teil sehr heterogene Glucosinolatmuster innerhalb der Arten wie auch zwischen den Arten auf. So ähneln sich bei B. incana die Muster der Akzessionen BRA 1262, 5974 und CGN 18470. Sie enthalten jeweils größere Anteile Iberin (IBE) und Sinigrin. Auch die AZ BRA 1166 zeigt ein ähnliches Muster, enthält aber anstatt Iberin mehr Progoitrin. Die übrigen $B$. incana Akzessionen enthalten nur wenig oder gar kein Iberin und Sinigrin. Bei innen sind vor allem Glucoraphanin (RAA), Gluconapin und Glucobrassicin (GBC) zu finden. Bei B. montana ist Gluconapin das Hauptglucosinolat der meisten Akzessionen mit Anteilen von 52\% (AZ BRA 2942) 


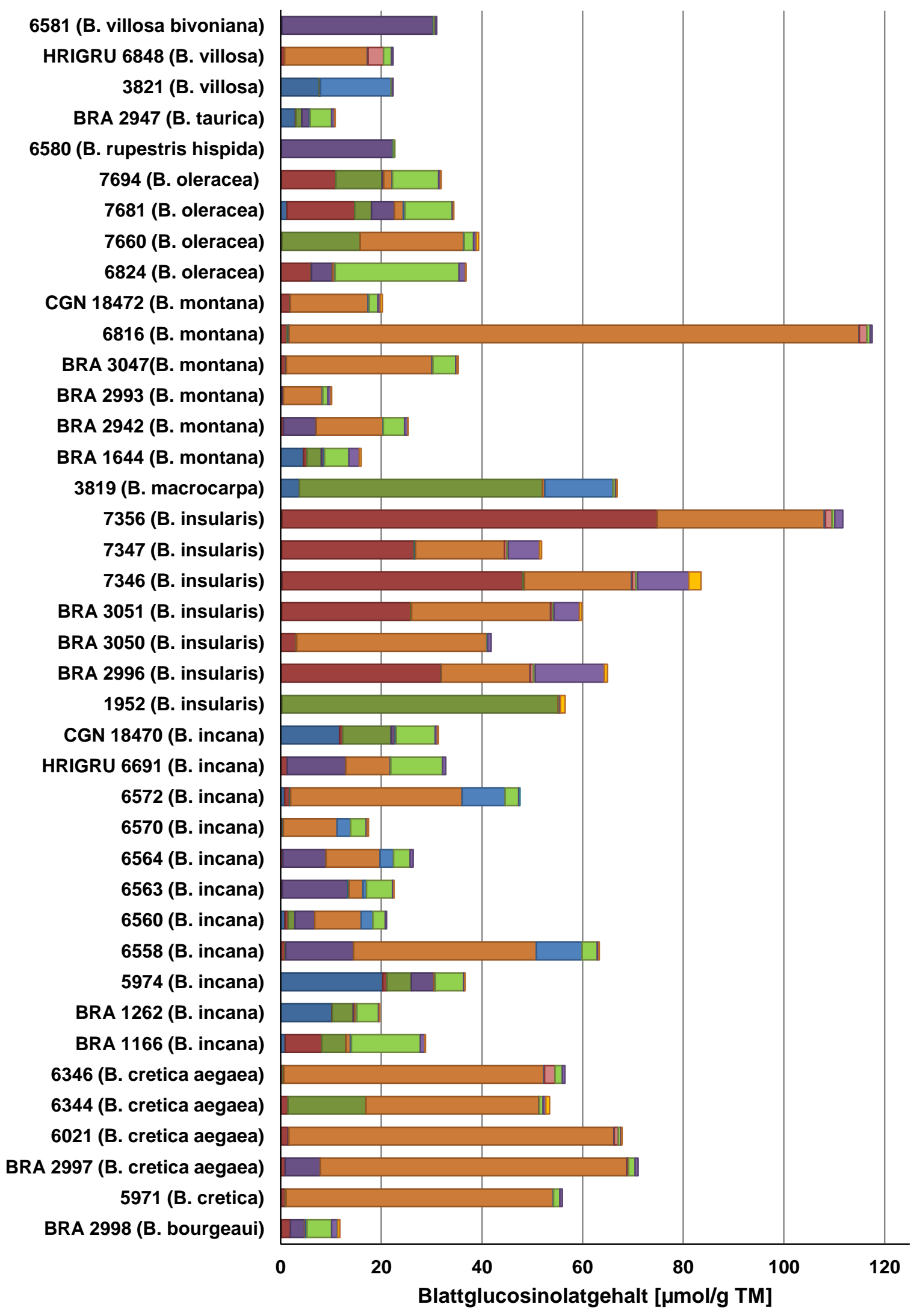

$\square$ IBE $\square$ PRO $\square$ SIN $\square$ RAA $\square$ GNL $\square$ GNA $\square 4 \mathrm{OH} \square$ GBN $\square$ GBC $\square$ NAS $\square 4 M E \square$ NEO

Abb. 3-4: Blattglucosinolatgehalt und -muster der Brassica-Wildarten 
bis 96\% (AZ 6816). Hier fällt nur die AZ BRA 1644 heraus, die kein Gluconapin enthält. Besonders große Unterschiede zwischen den einzelnen Akzessionen lassen sich bei den drei untersuchten $B$. villosa-Akzessionen feststellen. Während bei AZ3821 annähernd nur die beiden Glucosinolate Iberin (34\%) und 4-Methoxyglucobrassicin (63\%) enthält, stellt bei AZ HRIGRU 6848 Gluconapin mit $74 \%$ das Hauptglucosinolat. Weiterhin sind Glucobrassicanapin (GNA) mit 14\% und Glucobrassicin mit 7\% enthalten. Die dritte AZ 6581 beinhaltet zu 97\% Glucoraphanin und zeigt damit ein nahezu identisches Muster wie die B. rupestris AZ 6580. 


\subsection{Agronomische Eigenschaften der Resynthesen}

\subsubsection{Fettsäuremuster des Saatgutes}

Im Vorfeld der Testkreuzungsproduktion wurde jeweils ein Samenkorn der für die Kreuzungen vorgesehenen Resynthesen hinsichtlich des Fettsäuremusters untersucht. Dies geschah mittels Einzelkorn-GC. Die verwendeten Samen stammten aus Gewächshausvermehrungen. Die Ergebnisse dieser Analyse sind in Tabelle 3-4 dargestellt.

Tab. 3-4: Ergebnisse der Einzelkorn-GC der Fettsäuren für die, für die Testkreuzungen vorgesehenen Resynthesen

\begin{tabular}{|c|c|c|c|c|c|c|c|c|c|c|c|}
\hline Genotyp & $\begin{array}{c}16: 0 \\
{[\%]}\end{array}$ & $\begin{array}{c}16: 1 \\
{[\%]}\end{array}$ & $\begin{array}{c}16: 2 \\
{[\%]}\end{array}$ & $\begin{array}{c}18: 0 \\
{[\%]}\end{array}$ & $\begin{array}{c}18: 1 \\
{[\%]}\end{array}$ & $\begin{array}{c}18: 2 \\
{[\%]}\end{array}$ & $\begin{array}{l}18: 3 \\
{[\%]}\end{array}$ & $\begin{array}{c}20: 0 \\
{[\%]}\end{array}$ & $\begin{array}{c}20: 1 \\
{[\%]}\end{array}$ & $\begin{array}{c}22: 0 \\
{[\%]}\end{array}$ & $\begin{array}{c}22: 1 \\
{[\%]}\end{array}$ \\
\hline B 1/3.3 & 2,7 & 0,2 & 0,0 & 1,1 & 25,0 & 13,1 & 10,7 & 0,7 & 16,7 & 0,5 & 28,6 \\
\hline BOY 1 & 2,5 & 0,3 & 0,0 & 0,8 & 11,4 & 16,1 & 6,8 & 0,7 & 4,9 & 1,1 & 53,7 \\
\hline CRL 1 & 4,0 & 0,5 & 0,0 & 1,6 & 18,9 & 13,8 & 10,8 & 1,0 & 11,0 & 0,8 & 37,5 \\
\hline CRY 1 & 2,5 & 0,3 & 0,1 & 1,5 & 15,5 & 14,8 & 3,2 & 1,3 & 5,4 & 1,5 & 52,9 \\
\hline CRY 2 & 2,2 & 0,2 & 0,0 & 0,8 & 12,8 & 14,9 & 7,6 & 0,7 & 5,6 & 0,8 & 52,6 \\
\hline FS 94.3 & 10,2 & 0,9 & 0,0 & 1,3 & 34,0 & 31,3 & 13,6 & 0,7 & 3,2 & 0,5 & 4,3 \\
\hline G 39 & 4,9 & 0,0 & 0,0 & 1,4 & 17,4 & 23,4 & 8,9 & 0,7 & 14,8 & 1,2 & 26,9 \\
\hline G 50 & 4,2 & 0,0 & 0,0 & 1,9 & 59,7 & 20,4 & 9,8 & 0,8 & 1,7 & 0,5 & 1,1 \\
\hline H 149 & 3,1 & 0,0 & 0,0 & 0,7 & 13,7 & 12,5 & 8,6 & 0,7 & 9,2 & 0,7 & 50,2 \\
\hline H 165 & 3,4 & 0,0 & 0,0 & 1,2 & 19,0 & 17,2 & 5,9 & 0,9 & 15,1 & 0,8 & 36,2 \\
\hline H 176 & 3,7 & 0,0 & 0,0 & 1,0 & 21,1 & 15,6 & 9,3 & 0,8 & 14,2 & 0,5 & 33,5 \\
\hline H 355 & 2,8 & 0,0 & 0,0 & 1,0 & 14,1 & 15,0 & 7,6 & 0,8 & 6,8 & 0,8 & 51,2 \\
\hline H44 & 3,4 & 0,0 & 0,0 & 1,2 & 23,6 & 14,7 & 7,2 & 1,0 & 9,2 & 1,0 & 38,0 \\
\hline HIY 1 & 2,9 & 0,3 & 0,0 & 0,9 & 19,4 & 14,2 & 3,7 & 0,8 & 8,2 & 0,8 & 48,1 \\
\hline INL 1 & 2,7 & 0,3 & 0,2 & 1,0 & 22,4 & 17,1 & 8,8 & 0,6 & 11,5 & 0,4 & 35,0 \\
\hline INL 2 & 3,3 & 0,0 & 0,0 & 1,3 & 21,5 & 18,2 & 10,6 & 0,9 & 10,0 & 1,0 & 32,6 \\
\hline INY 1 & 4,2 & 0,0 & 0,0 & 1,3 & 16,0 & 20,6 & 5,8 & 1,0 & 7,7 & 1,6 & 40,1 \\
\hline INY 4 & 2,8 & 0,4 & 0,0 & 1,2 & 15,4 & 17,2 & 5,6 & 1,0 & 4,1 & 1,5 & 49,6 \\
\hline INY 5 & 2,5 & 0,4 & 0,0 & 0,7 & 9,2 & 16,9 & 6,1 & 0,6 & 3,5 & 1,1 & 58,5 \\
\hline INY 6 & 3,5 & 0,0 & 0,0 & 0,8 & 16,7 & 10,5 & 11,0 & 0,7 & 3,3 & 1,0 & 52,3 \\
\hline ISY 1 & 3,9 & 0,0 & 0,0 & 1,6 & 21,8 & 15,8 & 5,5 & 1,3 & 8,9 & 1,4 & 39,0 \\
\hline J 104 & 3,1 & 0,0 & 0,0 & 1,1 & 11,9 & 12,9 & 8,2 & 0,9 & 4,0 & 1,6 & 54,5 \\
\hline J 11 \& & 2,1 & 0,0 & 0,0 & 1,0 & 10,6 & 12,9 & 7,0 & 0,8 & 2,4 & 1,0 & 62,2 \\
\hline J 134 & 4,2 & 0,6 & 0,0 & 1,7 & 26,9 & 24,0 & 5,2 & 1,1 & 12,1 & 0,8 & 23,4 \\
\hline J 154 & 2,7 & 0,0 & 0,0 & 1,0 & 17,8 & 13,1 & 7,7 & 0,8 & 11,1 & 0,8 & 44,5 \\
\hline J 16 & 2,7 & 0,0 & 0,0 & 0,8 & 10,8 & 14,6 & 8,0 & 0,7 & 5,7 & 1,3 & 54,7 \\
\hline J 166 & 3,3 & 0,4 & 0,0 & 1,0 & 12,5 & 17,6 & 5,7 & 0,8 & 6,4 & 1,4 & 50,5 \\
\hline J 32 & 3,0 & 0,0 & 0,0 & 0,8 & 9,7 & 15,0 & 8,7 & 0,6 & 3,9 & 1,4 & 56,0 \\
\hline J 4 & 3,7 & 0,0 & 0,0 & 1,3 & 29,4 & 16,5 & 6,3 & 0,8 & 13,7 & 0,8 & 27,5 \\
\hline $\mathrm{J} 4 \mathrm{C}$ & 2,6 & 0,0 & 0,0 & 1,3 & 15,9 & 13,6 & 5,2 & 1,1 & 7,5 & 1,7 & 50,6 \\
\hline J 410 & 2,9 & 0,0 & 0,0 & 1,1 & 12,9 & 13,6 & 7,8 & 1,0 & 4,6 & 1,3 & 53,5 \\
\hline J 45 & 5,7 & 1,2 & 0,0 & 2,4 & 22,4 & 18,7 & 7,3 & 1,8 & 4,2 & 2,1 & 34,4 \\
\hline & - & - & - & - & - & - & - & - & - & - & - \\
\hline K 160.1.1 & 4,1 & 0,0 & 0,0 & 1,3 & 11,0 & 15,7 & 10,7 & 0,6 & 6,5 & 1,8 & 48,3 \\
\hline
\end{tabular}


Tab. 3-4: Ergebnisse der Einzelkorn-GC der Fettsäuren für die, für die Testkreuzungen vorgesehenen Resynthesen (Fortsetzung)

\begin{tabular}{|c|c|c|c|c|c|c|c|c|c|c|c|}
\hline Genotyp & $\begin{array}{c}16: 0 \\
{[\%]}\end{array}$ & $\begin{array}{c}16: 1 \\
{[\%]}\end{array}$ & $\begin{array}{c}16: 2 \\
{[\%]}\end{array}$ & $\begin{array}{c}18: 0 \\
{[\%]}\end{array}$ & $\begin{array}{c}18: 1 \\
{[\%]}\end{array}$ & $\begin{array}{c}18: 2 \\
{[\%]}\end{array}$ & $\begin{array}{c}18: 3 \\
{[\%]}\end{array}$ & $\begin{array}{c}20: 0 \\
{[\%]}\end{array}$ & $\begin{array}{c}20: 1 \\
{[\%]}\end{array}$ & $\begin{array}{c}22: 0 \\
{[\%]}\end{array}$ & $\begin{array}{c}22: 1 \\
{[\%]}\end{array}$ \\
\hline K 199.16.2 & 2,8 & 0,2 & 0,1 & 0,8 & 12,6 & 12,3 & 10,3 & 0,7 & 3,7 & 1,1 & 54,8 \\
\hline MAY 1 & 3,0 & 0,3 & 0,1 & 0,8 & 13,6 & 20,3 & 4,1 & 0,7 & 8,5 & 0,8 & 46,5 \\
\hline MOL 1 & 3,6 & 0,0 & 0,0 & 1,4 & 31,3 & 18,6 & 6,6 & 2,5 & 11,5 & 1,2 & 21,8 \\
\hline MOL 2 & 3,7 & 0,0 & 0,0 & 2,2 & 37,9 & 15,0 & 3,5 & 1,2 & 12,8 & 1,0 & 22,8 \\
\hline MOY 1 & 2,2 & 0,4 & 0,0 & 0,6 & 9,1 & 16,3 & 8,0 & 0,6 & 2,1 & 0,9 & 59,0 \\
\hline MOY 2 & 4,1 & 0,7 & 0,0 & 2,4 & 26,4 & 16,7 & 4,8 & 1,9 & 8,2 & 1,6 & 32,6 \\
\hline MOY 4 & 2,4 & 0,0 & 0,0 & 1,0 & 16,3 & 15,0 & 5,1 & 0,9 & 9,9 & 1,2 & 48,3 \\
\hline MOY 5 & 2,7 & 0,0 & 0,0 & 1,8 & 20,6 & 15,2 & 2,7 & 1,6 & 11,1 & 1,5 & 42,6 \\
\hline MOY 6 & 3,0 & 0,0 & 0,0 & 2,0 & 21,0 & 12,8 & 3,6 & 1,7 & 5,1 & 2,6 & 48,3 \\
\hline OLL 1 & 3,8 & 0,0 & 0,0 & 1,3 & 29,8 & 12,4 & 8,2 & 0,7 & 14,6 & 0,5 & 28,8 \\
\hline OLY 1 & 4,1 & 0,8 & 0,0 & 1,9 & 21,6 & 12,7 & 2,9 & 1,7 & 3,9 & 2,9 & 47,7 \\
\hline OLY 2 & 2,9 & 0,0 & 0,0 & 1,4 & 20,4 & 14,0 & 3,5 & 1,2 & 8,6 & 1,6 & 45,2 \\
\hline R 53 & 3,5 & 0,0 & 0,0 & 1,2 & 23,0 & 14,7 & 8,5 & 0,9 & 13,2 & 0,6 & 34,1 \\
\hline R 76 & 3,6 & 0,0 & 0,0 & 1,5 & 29,6 & 14,8 & 6,7 & 1,0 & 11,2 & 0,9 & 30,6 \\
\hline R 99 & 3,6 & 0,1 & 0,0 & 1,3 & 22,9 & 14,8 & 9,5 & 0,8 & 20,0 & 0,4 & 26,1 \\
\hline RS $10 / 7$ & 1,9 & 0,0 & 0,0 & 0,6 & 11,6 & 11,4 & 7,6 & 0,6 & 5,2 & 0,6 & 59,7 \\
\hline RS 13/6 & 2,7 & 0,0 & 0,0 & 2,4 & 31,2 & 9,8 & 2,9 & 1,7 & 10,8 & 1,1 & 37,6 \\
\hline RS $4 / 2$ & 2,3 & 0,0 & 0,0 & 1,2 & 14,4 & 10,5 & 7,3 & 1,1 & 7,5 & 1,2 & 54,2 \\
\hline RS $4 / 6$ & 2,8 & 0,2 & 0,0 & 0,9 & 18,7 & 12,1 & 5,7 & 0,8 & 10,2 & 0,9 & 47,6 \\
\hline RS $7 / 6$ & 3,1 & 0,0 & 0,0 & 1,2 & 24,9 & 12,2 & 4,2 & 0,9 & 10,2 & 1,0 & 41,7 \\
\hline RS $8 / 6$ & 3,4 & 0,0 & 0,0 & 1,3 & 28,2 & 14,6 & 6,8 & 0,8 & 17,4 & 0,7 & 26,8 \\
\hline RUY 1 & 2,7 & 0,2 & 0,0 & 1,1 & 13,7 & 17,1 & 6,1 & 1,0 & 3,9 & 1,5 & 51,4 \\
\hline S 108.1.1 & 4,4 & 0,5 & 0,0 & 3,3 & 36,2 & 18,2 & 9,1 & 1,4 & 10,7 & 0,8 & 15,2 \\
\hline S 228.8.1 & 3,8 & 0,0 & 0,0 & 1,4 & 17,2 & 17,6 & 11,5 & 1,0 & 13,8 & 1,1 & 32,4 \\
\hline S 237.20.1 & 3,8 & 0,5 & 0,3 & 1,2 & 20,6 & 12,9 & 5,6 & 0,8 & 6,2 & 1,3 & 46,4 \\
\hline S 39 & 3,7 & 0,3 & 0,2 & 2,5 & 69,5 & 13,4 & 4,9 & 0,9 & 1,9 & 0,5 & 2,3 \\
\hline S 45.2 .2 & 2,7 & 0,0 & 0,0 & 1,3 & 18,8 & 14,2 & 9,8 & 0,8 & 11,9 & 0,7 & 38,9 \\
\hline S13 & 3,0 & 0,0 & 0,0 & 0,8 & 14,1 & 11,4 & 8,5 & 0,8 & 6,0 & 0,8 & 54,1 \\
\hline TAY 1 & 3,2 & 0,0 & 0,0 & 1,1 & 10,5 & 17,5 & 5,6 & 1,2 & 3,0 & 3,0 & 54,0 \\
\hline VIL 1 & 3,0 & 0,4 & 0,0 & 0,8 & 13,5 & 16,9 & 13,9 & 0,6 & 9,0 & 0,5 & 40,5 \\
\hline Min. & 1,9 & 0,0 & 0,0 & 0,6 & 9,1 & 9,8 & 2,7 & 0,6 & 1,7 & 0,4 & 1,1 \\
\hline Max. & 10,2 & 1,2 & 0,3 & 3,3 & 69,5 & 31,3 & 13,9 & 2,5 & 20,0 & 3,0 & 62,2 \\
\hline Mittelwert & 3,3 & 0,2 & 0,0 & 1,3 & 20,6 & 15,5 & 7,2 & 1,0 & 8,4 & 1,1 & 40,9 \\
\hline
\end{tabular}

Für fast alle Fettsäuren lässt sich eine große Variabilität zwischen den einzelnen Resynthesen beobachten. So reicht z.B. die Spanne für Palmitinsäure (C 16:0) von $1,9 \%$ bei ,RS $10 / 7^{`}$ bis $5,7 \%$ bei,$J 45^{`}$ bzw. $10,2 \%$ bei,$F S 94.3^{‘}$. Die Variationsbreiten für Ölsäure (C 18:1) liegt zwischen 9,1\% (,MOY $1^{\prime}$ ) und 69,5\% (,S 39') und die für Linolsäure (C 18:2) zwischen 9,8\% und 31,3\%. Bei einer ganzen Reihe Resynthesen liegt der Linolsäuregehalt über dem Ölsäuregehalt. Dies ist vor allem bei den Wildresynthesen zu beobachten (z.B. bei ,MAY 1' mit 13,6\% Ölsäure und 20,3\% Linolsäure). Auch für Linolensäure (C 18:3) und Icosensäure (C 20:1) sind große Spannbreiten zu beobachten. Die Variationsbreite der Erucasäure (C 22:1) reicht von 1,1\% (,G50) bis 62,2\% 
(,J $\left.112^{\circ}\right)$. Bis auf wenige Ausnahmen, für die bekannt war, dass sie annähernd erucasäurefrei sein sollten, wiesen alle Resynthesen einen mittleren bis hohen Erucasäuregehalt auf.

\subsubsection{Merkmale im Beobachtungsanbau}

Im Beobachtungsanbau konnten insgesamt 70 Resynthesen zusammen mit 10 Standards getestet werden. Dabei konnte beobachtet werden, dass insbesondere viele der mit Brassica-Wildarten bzw. Wildformen erstellten Resynthesen an allen Versuchsstandorten in Deutschland ausgewintert sind. Auch einige klassische Resynthesen haben den Winter 2009/2010 in Deutschland nicht überlebt. Viele weitere erlitten deutliche Winterschäden. Lediglich am Standort Impington (GB) haben alle 48 dort angebauten Resynthesen den Winter überstanden. Die dort geprüften Genotypen sind aus der GC- Ergebnistabelle (Tabelle 3-7) zu entnehmen.

Insgesamt konnten nur 23 Resyntheselinien identifiziert werden, die den Winter an allen sechs auswertbaren Standorten mehr oder weniger gut überstanden haben (siehe Tab. 3-6, Merkmal Winterfestigkeit (WF)). Die Auswertung der erfassten agronomischen Merkmale für diese Resynthesen ist zusammen mit denen der zehn als Standard verwendeten Winterrapssorten in Tab. 3-6 dargestellt. Für die mittels NIRS erfassten Phytosterole und Sinapoylverbindungen werden in Tab. 3-6 jeweils nur die Gesamtgehalte dargestellt. Die Werte für die einzelnen enthaltenen Phytosterole und Sinapoylverbindungen sind den Tabellen III und IV im Anhang zu entnehmen. Des weiteren sind zur Vervollständigung am Ende der Tab. 3-6 14 Genotypen aufgeführt, die nur am Standort Impington (GB) überlebt haben. Sie sind nicht mit in die Varianzanalyse der agronomischen Merkmale über sechs Standorte (Tab. 3-5) eingeflossen. Die Ergebnisse der Varianzanalyse für die agronomischen Merkmale für den Standort Impington werden daher im Anhang in Tab. $\vee$ gezeigt.

Für alle erfassten Merkmale zeigen sich hochsignifikante genotypische Variationen (Tab. 3-5). Die Heritabilitäten (Tab. 3-5) für die einzelnen Merkmale erreichen sehr hohe Werte. Sie liegen in fast allen Fällen bei $\geq 0,90$. Eine Ausnahme bilden die durch Bonituren erfassten Merkmale Winterfestigkeit $\left(h^{2}=0,62\right)$, Blühbeginn $\left(h^{2}=0,83\right)$ und Lager $\left(h^{2}=0,74\right)$ sowie die durch Messung erfasste Wuchshöhe $\left(h^{2}=0,82\right)$ deren Werte etwas niedriger liegen. 
Die beobachtete Spanne für den Ölgehalt reicht bei den Resynthesen von 35,6\% (,G 39') bis 43,1\% ( , H 176' und ,K 199.16.2'), und bei den Standards von 42,1\% (,Tester Syngenta') bis 45,6\% (,Oase') (Tab. 3-6). Im Mittel liegt der Ölgehalt der Resynthesen bei $40,4 \%$, der der Standards bei $44,2 \%$. Bei den Merkmalen Erucasäure (C 22:1) und Glucosinolatgehalt (GSL) weisen die Resynthesen deutlich höhere Gehalte als die Standardsorten auf. Während die Standards erucasäurefrei sind, reicht die Spanne bei den Resynthesen von 2,0\% bei ,G 50" bis $33,3 \%$ bei ,S 13 . Beim GSL-Gehalt erreichen die Standards maximal $19,7 \mu \mathrm{mol} / \mathrm{g}$, bei den Resynthesen reicht die Spanne von $41,2 \mu \mathrm{mol} / \mathrm{g}$ für, $\mathrm{H} 176^{\circ}$ bis $96,9 \mu \mathrm{mol} / \mathrm{g}$ bei ,H 165. Für die in der Tabelle aufgeführten Resynthesen vom Standort Impington (GB) liegen die GSL-Werte zum Teil noch deutlich höher.

Tab. 3-5: Ergebnisse der ANOVA für den 6-ortigen Beobachtungsanbau der Resynthesen, gezeigt sind die Varianzkomponenten und die Heritabilität der einzelnen Merkmale

\begin{tabular}{|c|c|c|c|c|c|c|}
\hline & Varianzursache $^{a}$ & Genotyp & Ort & GxO & Fehler $^{b}$ & $h^{2}$ \\
\hline & TKG & $0,37^{* *}$ & $0,23^{* *}$ & $0,25^{* *}$ & 0,12 & 0,90 \\
\hline & Wuchshöhe & $139,46^{\star *}$ & $128,83^{\star *}$ & $112,58^{* *}$ & 21,28 & 0,83 \\
\hline & Blühbeginn & $6,84^{* *}$ & $1,15^{\star *}$ & $4,46^{* *}$ & 0,91 & 0,82 \\
\hline & Winterfestigkeit & $1,24^{\star *}$ & $0,38^{* *}$ & $3,89^{* \star}$ & 0,71 & 0,62 \\
\hline & Lager & $1,34^{\star *}$ & $0,39^{* *}$ & $1,43^{\star *}$ & 0,65 & 0,74 \\
\hline & ÖL & $6,01^{* *}$ & $3,82^{* *}$ & $1,53^{\star *}$ & 0,64 & 0,96 \\
\hline & C22:1 & $111,76^{* *}$ & 0,16 & $18,44^{* *}$ & 2,94 & 0,97 \\
\hline & Protein & $4,50^{* *}$ & $3,26^{* *}$ & $1,05^{* *}$ & 0,40 & 0,96 \\
\hline & Glucosinolate & $677,71^{* *}$ & $15,01^{* *}$ & $57,55^{\star *}$ & 15,73 & 0,99 \\
\hline \multirow{6}{*}{ 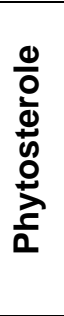 } & Brassicasterol & $954,09^{* *}$ & $258,89 * *$ & $319,07^{* *}$ & 129,49 & 0,95 \\
\hline & Camposterol & $27503,76^{* *}$ & $2277,42^{\star *}$ & $5808,06^{* *}$ & 1273,35 & 0,97 \\
\hline & Stigmasterol & $0,33^{* *}$ & $0,20^{* *}$ & $0,11^{* *}$ & 0,05 & 0,95 \\
\hline & Sitosterol & $15069,74^{\star *}$ & $156,25^{\star \star}$ & $4230,38^{\star *}$ & 790,19 & 0,96 \\
\hline & Avenasterol & $493,25^{\star *}$ & $178,06^{\star *}$ & $111,36^{* *}$ & 37,69 & 0,96 \\
\hline & Phytosterol gesamt & $112787,91^{\star *}$ & $4237,71^{\star *}$ & $25178,18^{\star *}$ & 3942,35 & 0,96 \\
\hline \multirow{4}{*}{ 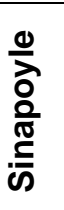 } & Sinapoylglucose & $0,55^{\star *}$ & $0,01^{* *}$ & $0,16^{* *}$ & 0,08 & 0,95 \\
\hline & Sinapin & $0,37^{\star *}$ & $0,03^{* *}$ & $0,22^{* *}$ & 0,10 & 0,91 \\
\hline & andere $\mathrm{SE}^{\mathrm{c}}$ & $0,19^{* *}$ & $0,02^{* *}$ & $0,04^{* *}$ & 0,02 & 0,96 \\
\hline & Sinapinsäure gesamt & $0,54^{\star *}$ & $0,05^{* *}$ & $0,29^{* *}$ & 0,14 & 0,92 \\
\hline
\end{tabular}

${ }^{\mathrm{a}} \mathrm{GxO}=$ Interakttion zwischen Genotyp und Ort, $\mathrm{h}^{2}=$ Heritabilität; ${ }^{\mathrm{b}}$ Fehler geschätzt aus 4 Orten mit je 2 Wiederholungen; ${ }^{c} \mathrm{SE}=$ Sinapinsäureester; ${ }^{+},{ }^{*},{ }^{* *}$ signifikant bei $p=0,1, p=0,05$ bzw. bei $p=0,01$ 
Tab. 3-6: Agronomische Merkmale der Resynthesen aus dem 6-ortigen Beobachtungsanbau

\begin{tabular}{|c|c|c|c|c|c|c|c|c|c|c|c|}
\hline Genotyp & $\begin{array}{c}\text { Öl } \\
{[\%]}\end{array}$ & $\begin{array}{c}\text { C22:1 } \\
{[\%]}\end{array}$ & $\begin{array}{c}\text { Protein } \\
{[\%]}\end{array}$ & $\begin{array}{c}\text { GSL } \\
{[\mu \mathrm{mol} / \mathrm{g}]}\end{array}$ & $\begin{array}{c}\text { Phytosterol } \\
\text { gesamt [mg } / \mathrm{kg}]\end{array}$ & $\begin{array}{c}\text { Sinapinsäure } \\
\text { gesamt }[\mathrm{mg} / \mathrm{g}]^{\mathrm{b}}\end{array}$ & $\begin{array}{c}\text { TKG } \\
{[g]}\end{array}$ & $\begin{array}{l}\text { Höhe } \\
\text { [cm] }\end{array}$ & WF & BB & Lager \\
\hline B1/3.3 & 40,7 & 7,9 & 20,9 & 61,3 & 3573,4 & 6,9 & 5,4 & 157,4 & 1,9 & 117,4 & 3,4 \\
\hline FS94.3 & 39,0 & 21,9 & 23,9 & 73,8 & 3294,5 & 6,6 & 5,1 & 178,7 & 3,5 & - & 1,3 \\
\hline G39 & 35,6 & 13,4 & 25,0 & 89,4 & 3291,0 & 6,1 & 4,7 & - & 5,6 & - & - \\
\hline G50 & 40,0 & 2,0 & 20,8 & 44,0 & 3553,4 & 7,9 & 4,3 & 118,2 & 4,5 & 122,6 & - \\
\hline H149 & 40,3 & 23,6 & 21,4 & 62,6 & 3193,3 & 6,2 & 5,3 & 121,5 & 2,0 & 116,6 & 7,3 \\
\hline H165 & 37,0 & 24,2 & 24,9 & 96,9 & 3207,2 & 5,8 & 5,0 & - & 6,5 & - & - \\
\hline H176 & 43,1 & 22,7 & 20,0 & 41,2 & 3354,2 & 7,3 & 5,7 & 132,5 & 1,4 & 117,7 & 1,7 \\
\hline H355 & 42,7 & 32,1 & 20,9 & 89,0 & 3164,7 & 7,1 & 5,9 & 138,9 & 2,0 & 121,2 & 2,0 \\
\hline H44 & 38,4 & 15,8 & 23,5 & 61,1 & 3228,8 & 6,6 & 5,9 & 130,4 & 5,2 & 121,2 & 1,8 \\
\hline INL2 & 40,8 & 10,4 & 21,7 & 61,1 & 3507,6 & 7,9 & 5,7 & 159,8 & 3,4 & 118,1 & 2,0 \\
\hline INY1 & 38,1 & 28,4 & 23,6 & 96,8 & 3279,8 & 6,0 & 7,6 & 126,9 & 3,0 & 118,8 & - \\
\hline J134 & 41,6 & 15,1 & 21,0 & 45,9 & 3306,8 & 6,9 & 5,1 & 134,5 & 4,2 & 118,2 & 1,4 \\
\hline K160.1.1 & 40,8 & 8,5 & 21,7 & 54,7 & 3552,4 & 6,3 & 4,6 & 129,4 & 1,8 & 117,8 & 4,5 \\
\hline K199.16.2 & 43,1 & 25,9 & 21,5 & 58,5 & 3144,7 & 7,4 & 4,8 & 122,3 & 3,3 & 119,7 & 2,8 \\
\hline OLL1 & 40,9 & 15,1 & 21,3 & 59,0 & 3444,5 & 7,3 & 6,1 & 138,9 & 4,2 & 115,4 & 3,3 \\
\hline R53 & 41,7 & 24,8 & 22,4 & 57,3 & 3162,6 & 7,3 & 5,2 & 120,6 & 2,5 & 118,9 & 1,3 \\
\hline R99 & 42,7 & 15,2 & 20,6 & 46,9 & 3381,5 & 6,9 & 4,3 & 136,9 & 1,9 & 115,7 & 3,5 \\
\hline RS10/7 & 37,3 & 15,6 & 23,9 & 91,3 & 3292,2 & 6,9 & 4,6 & 136,4 & 6,1 & 125,2 & 2,4 \\
\hline $\mathrm{RS} 7 / 6$ & 40,8 & 19,2 & 22,1 & 81,6 & 3288,6 & 6,9 & 5,3 & 161,3 & 4,0 & 121,8 & 3,0 \\
\hline $\mathrm{RS} 8 / 6$ & 40,3 & 15,1 & 21,9 & 62,7 & 3418,2 & 8,0 & 5,7 & 145,0 & 3,1 & 119,0 & 3,3 \\
\hline S108.1.1 & 40,1 & 7,8 & 21,6 & 57,2 & 3551,9 & 7,8 & 6,0 & 136,3 & 4,2 & 110,3 & 4,0 \\
\hline S13 & 42,7 & 33,3 & 21,0 & 96,2 & 3142,8 & 7,1 & 6,1 & 134,4 & 3,1 & 120,0 & 3,3 \\
\hline S228.8.1 & 40,7 & 16,8 & 21,7 & 61,8 & 3396,5 & 7,1 & 5,5 & 131,9 & 3,2 & 118,5 & 1,7 \\
\hline Tester Syngenta & 42,1 & 0,3 & 19,7 & 25,9 & 3870,9 & 7,8 & 5,7 & 145,0 & 3,3 & 124,7 & 3,3 \\
\hline MSL 007 & 44,0 & 0,1 & 19,4 & 22,7 & 3984,3 & 8,0 & 5,3 & 136,9 & 1,5 & 118,7 & 1,7 \\
\hline
\end{tabular}

${ }^{\text {a }}$ Resynthesen, die nur am Standort Impington (GB) überlebt haben und daher nicht mit in die Auswertung eingeflossen sind; ${ }^{\mathrm{b}}$ berechnet als Sinapinsäureäquivalente 
Tab. 3-6: Agronomische Merkmale der Resynthesen aus dem 6-ortigen Beobachtungsanbau (Fortsetzung)

\begin{tabular}{|c|c|c|c|c|c|c|c|c|c|c|c|}
\hline Genotyp & $\begin{array}{c}\text { Öl } \\
{[\%]}\end{array}$ & $\begin{array}{c}\text { C22:1 } \\
{[\%]}\end{array}$ & $\begin{array}{c}\text { Protein } \\
{[\%]}\end{array}$ & $\begin{array}{c}\mathrm{GSL} \\
{[\mu \mathrm{mol} / \mathrm{g}]}\end{array}$ & $\begin{array}{c}\text { Phytosterol } \\
\text { gesamt [mg/kg] }\end{array}$ & $\begin{array}{c}\text { Sinapinsäure } \\
\text { gesamt }[\mathrm{mg} / \mathrm{g}]^{\mathrm{b}}\end{array}$ & $\begin{array}{c}\text { TKG } \\
\text { [g] }\end{array}$ & $\begin{array}{l}\text { Höhe } \\
{[\mathrm{cm}]}\end{array}$ & WF & BB & Lager \\
\hline Alesi & 43,4 & 0,1 & 18,2 & 20,5 & 3936,8 & 7,4 & 5,0 & 140,0 & 1,3 & 120,7 & 1,7 \\
\hline Elektra & 44,4 & 0,0 & 18,2 & 20,5 & 4067,7 & 8,5 & 5,9 & 143,1 & 2,0 & 115,3 & 1,8 \\
\hline Favorite & 44,9 & 0,0 & 18,2 & 18,5 & 3894,9 & 7,6 & 5,7 & 141,3 & 2,7 & 120,3 & 1,7 \\
\hline Ladoga & 44,2 & 0,0 & 17,0 & 20,6 & 4093,4 & 8,3 & 5,9 & 140,0 & 1,3 & 118,2 & 1,7 \\
\hline Lorenz & 45,4 & 0,0 & 17,5 & 22,8 & 4164,4 & 8,1 & 5,6 & 138,1 & 2,9 & 118,7 & 1,7 \\
\hline Oase & 45,6 & 0,3 & 18,2 & 21,5 & 3911,3 & 8,5 & 5,3 & 145,6 & 1,7 & 120,5 & 1,7 \\
\hline Trabant & 43,9 & 0,0 & 18,9 & 21,5 & 4022,5 & 8,3 & 5,7 & 148,1 & 1,8 & 116,8 & 1,7 \\
\hline Visby & 43,5 & 0,0 & 17,7 & 18,7 & 4178,1 & 8,6 & 6,1 & 150,6 & 1,3 & 117,5 & 1,3 \\
\hline $\operatorname{LSD}(p=0,05)$ & 1,4 & 4,9 & 1,2 & 8,7 & 181,2 & 0,6 & 0,6 & 15,0 & 2,5 & 3,47 & 2,0 \\
\hline Min. & 35,6 & 0,00 & 17,0 & 18,5 & 3142,8 & 5,8 & 4,3 & 118,2 & 1,3 & 110,3 & 1,3 \\
\hline Max. & 45,6 & 33,26 & 25,0 & 96,9 & 4178,1 & 8,6 & 7,6 & 178,7 & 6,5 & 125,2 & 7,3 \\
\hline MW Resynthesen & 40,4 & 18,03 & 22,1 & 67,4 & 3336,1 & 7,0 & 5,4 & 137,7 & 3,5 & 118,7 & 2,8 \\
\hline MW Standards & 44,2 & 0,09 & 18,3 & 21,3 & 4012,4 & 8,1 & 5,6 & 142,9 & 2,0 & 119,1 & 1,8 \\
\hline BOY1 $^{a}$ & 37,0 & 27,4 & 24,8 & 116,6 & 2943,1 & 5,9 & 6,3 & - & - & - & - \\
\hline $\operatorname{CRL1}^{\mathrm{a}}$ & 35,6 & 13,9 & 26,0 & 82,3 & 3316,9 & 6,4 & 6,5 & - & - & - & - \\
\hline $\mathrm{CRY}^{\mathrm{a}}$ & 37,7 & 25,0 & 24,7 & 101,4 & 3208,1 & 4,9 & 11,8 & - & - & - & - \\
\hline HIY1 ${ }^{a}$ & 37,7 & 27,7 & 25,4 & 104,6 & 3067,5 & 5,2 & 8,7 & - & - & - & - \\
\hline INY3 $^{a}$ & 34,2 & 25,1 & 23,2 & 90,1 & 3389,8 & 2,8 & 8,7 & - & - & - & - \\
\hline INY4 ${ }^{a}$ & 37,6 & 28,5 & 25,6 & 112,7 & 3053,3 & 4,8 & 6,2 & - & - & - & - \\
\hline INY5 ${ }^{a}$ & 40,0 & 31,4 & 23,0 & 100,4 & 3209,6 & 6,4 & 6,3 & - & - & - & - \\
\hline MOY $^{a}$ & 38,4 & 31,3 & 24,3 & 103,9 & 3177,0 & 6,4 & 7,0 & - & - & - & - \\
\hline MOY5 $^{\text {a }}$ & 38,2 & 21,7 & 24,6 & 102,1 & 3350,3 & 5,3 & 5,6 & - & - & - & - \\
\hline
\end{tabular}

${ }^{\mathrm{a}}$ Resynthesen, die nur am Standort Impington (GB) überlebt haben und daher nicht mit in die Auswertung eingeflossen sind; ${ }^{\mathrm{b}}$ berechnet als Sinapinsäureäquivalente 
Tab. 3-6: Agronomische Merkmale der Resynthesen aus dem 6-ortigen Beobachtungsanbau (Fortsetzung)

\begin{tabular}{|c|c|c|c|c|c|c|c|c|c|c|c|}
\hline Genotyp & $\begin{array}{c}\text { Öl } \\
\text { [\%] }\end{array}$ & $\begin{array}{c}\text { C22:1 } \\
{[\%]}\end{array}$ & $\begin{array}{c}\text { Protein } \\
{[\%]}\end{array}$ & $\begin{array}{c}\text { GSL } \\
{[\mu \mathrm{mol} / \mathrm{g}]}\end{array}$ & $\begin{array}{c}\text { Phytosterol } \\
\text { gesamt [mg/kg] }\end{array}$ & $\begin{array}{c}\text { Sinapinsäure } \\
\text { gesamt [mg/g] }\end{array}$ & $\begin{array}{c}\text { TKG } \\
{[\mathrm{g}]}\end{array}$ & $\begin{array}{l}\text { Höhe } \\
{[\mathrm{cm}]}\end{array}$ & WF & BB & Lager \\
\hline OLY2 ${ }^{a}$ & 35,8 & 24,7 & 25,1 & 67,6 & 3189,2 & 5,5 & 6,9 & - & - & - & - \\
\hline RUY1 ${ }^{a}$ & 36,3 & 26,5 & 24,2 & 93,4 & 3207,2 & 4,3 & 9,1 & - & - & - & - \\
\hline S237.20.1 ${ }^{\mathrm{a}}$ & 39,2 & 25,4 & 23,9 & 76,1 & 3133,8 & 5,6 & 8,5 & - & - & - & - \\
\hline $\mathrm{S} 39^{\mathrm{a}}$ & 37,4 & 12,5 & 23,2 & 78,0 & 3510,7 & 6,4 & 4,3 & - & - & - & - \\
\hline $\mathrm{S} 45.2 .2^{\mathrm{a}}$ & 40,9 & 20,5 & 22,7 & 72,7 & 3316,0 & 7,4 & 4,9 & - & - & - & - \\
\hline
\end{tabular}

${ }^{\text {a }}$ Resynthesen, die nur am Standort Impington (GB) überlebt haben und daher nicht mit in die Auswertung eingeflossen sind; ${ }^{b}$ berechnet als Sinapinsäureäquivalente 
Für die Resynthesen vom Standort Impington (GB) wurden zusätzlich zu den NIRS-Analysen Samenproben mittels GC-Analysen hinsichtlich ihrer Fettsäuremuster sowie mittels HPLC-Analysen hinsichtlich ihres Glucosinolatgehaltes und -musters untersucht. Um möglichst viele Resynthesen charakterisieren zu können, wurden einige weitere Genotypen, die nicht am Standort Impington geprüft werden konnten, vom Standort Göttingen mit in die Analysen einbezogen. Die Ergebnisse dieser Genotypen sind natürlich nicht direkt mit den übrigen Genotypen vergleichbar, sie sind daher in den Ergebnisdarstellungen extra gekennzeichnet und sind nicht mit in die statistische Auswertung der Teilversuche eingeflossen. Die Ergebnisse der GC- Analyse der Fettsäuremuster sind in Tabelle 3-7 dargestellt.

Tab. 3-7 : Ergebnisse der GC-Analyse der Fettsäuremuster für die Samenproben aus dem Beobachtungsanbau der Resynthesen in Impington (GB)

\begin{tabular}{lrrrrrrrrrrr}
\hline Genotyp & $\mathbf{1 6 : 0}$ & $\mathbf{1 6 : 1}$ & $\mathbf{1 6 : 2}$ & $\mathbf{1 8 : 0}$ & $\mathbf{1 8 : 1}$ & $\mathbf{1 8 : 2}$ & $\mathbf{1 8 : 3}$ & $\mathbf{2 0 : 0}$ & $\mathbf{2 0 : 1}$ & $\mathbf{2 2 : 0}$ & $\mathbf{2 2 : 1}$ \\
& {$[\%]$} & {$[\%]$} & {$[\%]$} & {$[\%]$} & {$[\%]$} & {$[\%]$} & {$[\%]$} & {$[\%]$} & {$[\%]$} & {$[\%]$} & {$[\%]$} \\
\hline B1/3.3 & 3,4 & 0,3 & 0,0 & 1,7 & 64,2 & 16,7 & 9,3 & 0,4 & 2,0 & 0,2 & 1,2 \\
BOY1 & 3,2 & 0,3 & 0,1 & 0,9 & 15,5 & 16,6 & 7,8 & 0,6 & 8,2 & 0,7 & 45,4 \\
CRL1 & 4,2 & 0,3 & 0,2 & 1,6 & 29,0 & 17,0 & 12,2 & 0,7 & 13,3 & 0,3 & 20,7 \\
CRY1 & 3,5 & 0,3 & 0,1 & 1,0 & 20,3 & 17,3 & 8,9 & 0,7 & 10,6 & 0,5 & 36,5 \\
FS94.3 & 4,3 & 0,3 & 0,1 & 1,4 & 41,0 & 18,0 & 11,2 & 0,5 & 7,1 & 0,3 & 15,3 \\
G39 & 4,8 & 0,3 & 0,2 & 1,2 & 25,3 & 21,1 & 10,4 & 0,5 & 16,6 & 0,2 & 18,6 \\
G50 & 4,7 & 0,3 & 0,2 & 1,4 & 27,1 & 21,6 & 10,7 & 0,5 & 15,4 & 0,2 & 17,2 \\
H149 & 4,0 & 0,4 & 0,2 & 1,1 & 20,7 & 13,7 & 7,9 & 0,7 & 12,3 & 0,5 & 38,1 \\
H165 & 4,0 & 0,4 & 0,2 & 1,2 & 23,7 & 20,8 & 7,1 & 0,7 & 14,6 & 0,5 & 26,7 \\
H176 & 4,4 & 0,3 & 0,2 & 1,8 & 25,8 & 16,8 & 9,4 & 0,7 & 13,1 & 0,4 & 26,8 \\
H355 & 5,2 & 0,2 & 0,1 & 0,9 & 13,6 & 13,7 & 11,0 & 0,6 & 8,1 & 0,3 & 45,5 \\
H44 & 4,2 & 0,3 & 0,2 & 1,4 & 28,7 & 20,0 & 9,3 & 0,6 & 15,6 & 0,3 & 18,9 \\
HIY1 & 3,3 & 0,2 & 0,2 & 1,0 & 17,7 & 19,7 & 8,3 & 0,7 & 9,1 & 0,8 & 38,7 \\
INL2 & 3,6 & 0,2 & 0,1 & 1,3 & 37,6 & 17,7 & 11,2 & 0,5 & 13,7 & 0,2 & 13,8 \\
INY1 & 4,1 & 0,2 & 0,1 & 0,8 & 18,2 & 20,3 & 9,7 & 0,6 & 10,3 & 0,4 & 35,2 \\
INY3 & 5,2 & 0,0 & 0,1 & 0,4 & 30,0 & 20,2 & 9,2 & 0,5 & 6,2 & 0,2 & 27,5 \\
INY4 & 3,9 & 0,1 & 0,1 & 0,7 & 17,6 & 18,9 & 9,7 & 0,6 & 9,2 & 0,4 & 38,6 \\
INY5 & 3,2 & 0,2 & 0,1 & 0,9 & 18,4 & 17,9 & 8,2 & 0,7 & 10,7 & 0,4 & 39,2 \\
J134 & 3,8 & 0,3 & 0,4 & 1,5 & 36,6 & 19,1 & 7,9 & 0,6 & 13,2 & 0,3 & 15,7 \\
K160.1.1 & 5,1 & 0,3 & 0,1 & 1,7 & 32,2 & 18,5 & 12,3 & 0,5 & 8,3 & 0,3 & 20,3 \\
K199.16.2 & 4,9 & 0,3 & 0,1 & 1,6 & 32,2 & 18,2 & 12,4 & 0,5 & 8,7 & 0,3 & 20,7 \\
MOY4 & 3,4 & 0,3 & 0,3 & 1,1 & 17,3 & 19,0 & 8,7 & 0,7 & 10,2 & 0,7 & 37,5 \\
MOY5 & 3,9 & 0,3 & 0,4 & 1,2 & 21,7 & 19,3 & 9,3 & 0,7 & 14,1 & 0,5 & 27,9 \\
OLL1 & 3,7 & 0,2 & 0,2 & 1,3 & 32,3 & 16,8 & 10,9 & 0,5 & 14,2 & 0,3 & 19,4 \\
OLY2 & 3,5 & 0,3 & 0,1 & 0,9 & 15,3 & 18,7 & 7,4 & 0,6 & 9,2 & 0,9 & 42,5 \\
R53 & 3,5 & 0,3 & 0,2 & 1,0 & 22,1 & 13,3 & 8,6 & 0,8 & 12,8 & 0,6 & 36,3 \\
R99 & 4,1 & 0,4 & 0,1 & 1,1 & 36,0 & 16,3 & 8,8 & 0,6 & 13,7 & 0,3 & 18,1 \\
\hline
\end{tabular}


Tab. 3-7 : Ergebnisse der GC-Analyse der Fettsäuremuster für die Samenproben aus dem Beobachtungsanbau der Resynthesen in Impington (GB) (Fortsetzung)

\begin{tabular}{|c|c|c|c|c|c|c|c|c|c|c|c|}
\hline Genotyp & $\begin{array}{r}16: 0 \\
{[\%]}\end{array}$ & $\begin{array}{r}16: 1 \\
{[\%]}\end{array}$ & $\begin{array}{r}16: 2 \\
{[\%]}\end{array}$ & $\begin{array}{r}18: 0 \\
{[\%]}\end{array}$ & $\begin{array}{r}18: 1 \\
{[\%]}\end{array}$ & $\begin{array}{r}18: 2 \\
{[\%]}\end{array}$ & $\begin{array}{r}18: 3 \\
{[\%]}\end{array}$ & $\begin{array}{r}20: 0 \\
{[\%]}\end{array}$ & $\begin{array}{r}20: 1 \\
{[\%]}\end{array}$ & $\begin{array}{r}22: 0 \\
{[\%]}\end{array}$ & $\begin{array}{r}22: 1 \\
{[\%]}\end{array}$ \\
\hline RS10/7 & 4,7 & 0,3 & 0,2 & 1,8 & 27,6 & 18,0 & 9,8 & 0,6 & 15,9 & 0,3 & 20,4 \\
\hline RS7/6 & 5,5 & 0,2 & 0,1 & 1,5 & 36,6 & 20,4 & 13,5 & 0,5 & 5,8 & 0,3 & 15,0 \\
\hline $\mathrm{RS} 8 / 6$ & 5,9 & 0,2 & 0,1 & 0,8 & 39,8 & 21,0 & 14,2 & 0,5 & 6,0 & 0,3 & 11,0 \\
\hline RUY1 & 2,9 & 0,3 & 0,5 & 0,9 & 15,1 & 18,3 & 8,4 & 0,6 & 8,6 & 0,8 & 43,2 \\
\hline S108.1.1 & 6,6 & 0,2 & 0,1 & 2,6 & 45,9 & 14,5 & 8,4 & 0,5 & 8,1 & 0,3 & 12,0 \\
\hline S13 & 3,6 & 0,3 & 0,1 & 1,0 & 12,7 & 13,9 & 10,3 & 0,7 & 9,7 & 0,4 & 46,9 \\
\hline S228.8.1 & 5,0 & 0,2 & 0,2 & 2,0 & 32,9 & 16,4 & 9,8 & 0,6 & 12,2 & 0,3 & 19,7 \\
\hline S237.20.1 & 6,2 & 0,2 & 0,1 & 1,7 & 24,7 & 14,4 & 8,5 & 0,8 & 12,0 & 0,6 & 30,6 \\
\hline S39 & 5,2 & 0,2 & 0,1 & 1,4 & 34,9 & 19,6 & 12,6 & 0,5 & 6,1 & 0,3 & 18,4 \\
\hline S45.2.2 & 4,9 & 0,3 & 0,1 & 1,5 & 30,2 & 18,7 & 12,6 & 0,5 & 8,8 & 0,3 & 21,4 \\
\hline VIL1 & 3,4 & 0,3 & 0,3 & 1,4 & 24,6 & 19,2 & 9,7 & 0,6 & 11,2 & 0,6 & 28,7 \\
\hline Tester Syngenta & 7,3 & 0,1 & 0,0 & 1,1 & 57,9 & 16,2 & 9,7 & 0,4 & 3,4 & 0,2 & 3,3 \\
\hline MSL007 & 4,3 & 0,1 & 0,0 & 0,7 & 65,2 & 17,9 & 9,3 & 0,4 & 1,2 & 0,3 & 0,3 \\
\hline Alesi & 5,5 & 0,1 & 0,0 & 0,7 & 66,4 & 16,8 & 8,3 & 0,4 & 1,1 & 0,2 & 0,3 \\
\hline Elektra & 6,0 & 0,2 & 0,0 & 0,7 & 60,8 & 20,2 & 9,0 & 0,4 & 1,3 & 0,3 & 1,1 \\
\hline Favorite & 6,4 & 0,1 & 0,0 & 0,7 & 65,9 & 16,3 & 8,1 & 0,4 & 1,3 & 0,2 & 0,4 \\
\hline Ladoga & 4,6 & 0,2 & 0,0 & 0,4 & 62,5 & 21,7 & 8,5 & 0,4 & 1,2 & 0,2 & 0,2 \\
\hline Lorenz & 4,2 & 0,2 & 0,0 & 1,1 & 62,7 & 19,4 & 9,5 & 0,3 & 1,3 & 0,2 & 0,9 \\
\hline Oase & 4,2 & 0,2 & 0,0 & 0,0 & 68,7 & 17,5 & 7,3 & 0,4 & 1,1 & 0,3 & 0,1 \\
\hline Trabant & 5,4 & 0,1 & 0,0 & 0,6 & 63,2 & 18,9 & 9,4 & 0,4 & 1,2 & 0,2 & 0,3 \\
\hline Visby & 6,7 & 0,2 & 0,0 & 0,0 & 59,0 & 21,4 & 10,0 & 0,3 & 1,4 & 0,2 & 0,8 \\
\hline $\operatorname{LSD}(p=0,05)$ & 1,5 & 0,1 & 0,2 & 1,0 & 9,6 & 2,5 & 2,0 & 0,1 & 3,1 & 0,2 & 9,5 \\
\hline Min. & 2,9 & 0,0 & 0,0 & 0,0 & 12,7 & 13,3 & 7,1 & 0,3 & 1,1 & 0,2 & 0,1 \\
\hline Max. & 7,3 & 0,4 & 0,5 & 2,6 & 68,7 & 21,7 & 14,2 & 0,8 & 16,6 & 0,9 & 46,9 \\
\hline MW Resynthesen & 4,3 & 0,3 & 0,2 & 1,3 & 27,5 & 17,9 & 9,9 & 0,6 & 10,7 & 0,4 & 26,6 \\
\hline MW Standards & 5,5 & 0,1 & 0,0 & 0,6 & 63,2 & 18,6 & 8,9 & 0,4 & 1,5 & 0,2 & 0,8 \\
\hline $\mathrm{J} 112^{1}$ & 3,6 & 0,2 & 0,3 & 1,2 & 23,9 & 18,5 & 11,0 & 0,7 & 10,4 & 0,5 & 29,3 \\
\hline $\mathrm{J} 154^{1}$ & 3,7 & 0,2 & 0,1 & 1,3 & 27,1 & 17,9 & 9,7 & 0,6 & 13,3 & 0,4 & 25,1 \\
\hline $\mathbf{J} 161^{1}$ & 3,1 & 0,2 & 0,1 & 1,7 & 19,2 & 19,3 & 10,5 & 0,6 & 10,9 & 0,5 & 33,6 \\
\hline $\mathrm{RS} 4 / \mathbf{2}^{1}$ & 3,8 & 0,3 & 0,2 & 1,4 & 15,6 & 17,1 & 9,8 & 0,9 & 10,6 & 0,7 & 39,0 \\
\hline $\mathrm{RS} 13 / 6^{1}$ & 3,6 & 0,2 & 0,1 & 2,4 & 36,2 & 20,9 & 8,8 & 0,7 & 11,1 & 0,3 & 15,2 \\
\hline
\end{tabular}

${ }^{1}$ Ergebnisse für diese Resynthesen stammen vom Standort Göttingen und wurden daher nicht zusammen mit den übrigen aufgeführten Resynthesen vom Standort Impington (UK) verrechnet.

Für alle Fettsäuren liegt eine hochsignifikante genotypische Varianz vor (Tab.3-8). Die Resynthesen weisen in der Regel niedrige Ölsäuregehalte (C 18:1) und mittlere bis hohe Erucasäuregehalte (C 22:1) auf (Tab.3-7). Die Spanne für Ölsäure reicht von 12,7\% (,S 13`) bis 45,9\% (,S 108.1.1'), bei Erucasäure von $11,0 \%$ (,RS 8/6') bis 46,9\% (,S 13`). Eine Ausnahme bildet die Resynthese ,B 1/3.3‘ die einen hohen Ölsäuregehalt (64,2\%) und einen sehr niedrigen 
Erucasäuregehalt $(1,2 \%)$ zeigt. Eine hohe Variationsbreite kann auch für Linolsäure (C 18:2), Linolensäure (C 18:3) und Icosensäure (C 20:1) festgestellt werden (Tab. 3-7). Bei einigen Resynthesen (vor allem Wild-Resynthesen) übertrifft der Linolsäuregehalt (C 18:2) den Ölsäuregehalt (C 18:1). Beispiele hierfür sind die Genotypen ,BOY 1', ,HIY 1', ,INY 1', ,INY 4', ,OLY 2‘ und ,RUY 1'. Die Variation der einzelnen Fettsäuren innerhalb der Standards fällt deutlich geringer aus. Sie weisen alle hohe Ölsäuregehalte und sehr niedrige Erucasäuregehalte auf.

Die in der statistischen Auswertung errechnete Heritabilität (Tab.3-8) erreicht für alle Fettsäuren mit Ausnahme der Stearinsäure (C 18:0) hohe Werte von $\geq 0,74$. Für Ölsäure, Icosensäure und Erucasäure werden sogar sehr hohe Werte $\geq 0,95$ erreicht.

Tab. 3-8: Ergebnisse der ANOVA für die GC-Analyse der Fettsäuren der Resynthesen vom Standort Impington (GB). Gezeigt sind die Varianzkomponenten und die Heritabilität der einzelnen Merkmale

\begin{tabular}{lrrrr}
\hline Varianzursache $^{\text {a }}$ & Genotyp & Wdh. & GxW & $\mathbf{h}^{\mathbf{2}}$ \\
\hline 16:0 Palmitinsäure & $0,82^{* *}$ & 0,00 & 0,57 & 0,74 \\
16:1 Palmitoleinsäure & $0,00^{\star *}$ & 0,00 & 0,02 & 0,77 \\
16:2 & $0,01^{* *}$ & $0,00^{*}$ & 0,00 & 0,77 \\
18:0 Stearinsäure & $0,12^{* *}$ & 0,00 & 0,24 & 0,50 \\
18:1 Ölsäure & $291,98^{\star *}$ & 0,27 & 22,92 & 0,96 \\
18:2 Linolsäure & $4,06^{* *}$ & $-0,03$ & 1,53 & 0,84 \\
18:3 Linolensäure & $2,25^{\star *}$ & $-0,02$ & 1,01 & 0,82 \\
20:0 Arachinsäure & $0,01^{* *}$ & 0,00 & 0,00 & 0,87 \\
20:1 Icosensäure & $22,03^{\star *}$ & $-0,04$ & 2,40 & 0,95 \\
22:0 Behensäure & $0,03^{* *}$ & 0,00 & 0,01 & 0,80 \\
22:1 Erucasäure & $205,72^{* *}$ & 0,01 & 22,25 & 0,95 \\
\hline
\end{tabular}

${ }^{a}$ Wdh. = Wiederholung, GxW = Interaktion zwischen Genotyp und Wiederholung, $\mathrm{h}^{2}=$ Heritabilität;

**, * signifikant bei $p=0,01$ bzw. bei $p=0,05$

In der HPLC der Samenglucosinolate konnten insgesamt 12 verschiedene Glucosinolate nachgewiesen werden. Auch hier konnte in der Varianzanalyse (Tab. 3-9) für alle Merkmale eine hohe genotypische Variation festgestellt werden.

Der Gesamtglucosinolatgehalt sowie die Glucosinolatmuster der einzelnen Genotypen sind in Abbildung 3-5 graphisch dargestellt. Die genauen Einzelwerte sind Tabelle VI im Anhang zu entnehmen. Der Gesamtglucosinolatgehalt zeigt 




$\square \mathrm{PRO} \square \mathrm{SIN} \square \mathrm{GNL} \square \mathrm{RAA} \square \mathrm{RAE} \square \mathrm{GNA} \square 4 \mathrm{OH} \square \mathrm{GBN} \square \mathrm{GBC} \square \mathrm{NAS} \square 4 \mathrm{ME} \square \mathrm{NEO}$

Abb. 3-5: Samenglucosinolatgehalt und -muster der Resynthesen des Beobachtungsanbaus am Standort Impington (GB). ${ }^{*}=$ Standards, ${ }^{*}=$ Samenproben vom Standort Göttingen 
eine sehr große Variationsbreite. Er reicht bei den Resynthesen von $43,9 \mu \mathrm{mol} / \mathrm{g}$ (,OLY 2') bis $182 \mu \mathrm{mol} / \mathrm{g}$ (,BOY 1') (Abb. 3-5) und liegt im Mittel bei 93,4 $\mu \mathrm{mol} / \mathrm{g}$. Bei den Standardsorten ist die Variationsbreite deutlich geringer. Die Spanne liegt


Mittelwert beträgt $21,5 \mu \mathrm{mol} / \mathrm{g}$. Die höchsten Glucosinolatgehalte $(\geq 120 \mu \mathrm{mol} / \mathrm{g})$ werden ausschließlich von Wild-Resynthesen erreicht.

Betrachtet man die Glucosinolatmuster, so ist festzustellen, dass das Hauptsamenglucosinolat der Standardsorten und annähernd aller klassischen Resynthesen Progoitrin (PRO) ist, während es bei den meisten Wild-Resynthesen Gluconapin (GNA) ist. Bei vielen der Wild-Resynthesen hat GNA einen Anteil von mehr als 90\% am Gesamtglucosinolatgehalt. Ausnahmen bilden die Genotypen ,BOY 1', J134' und ,OLL 1' deren Hauptglucosinolat Progoitrin ist und ,OLY 2' deren Hauptglucosinolate Sinigrin (SIN) mit 38,6\% und Gluconapoleiferin (GNL) mit 37,2\% vom Gesamtglucosinolatgehalt sind. Weiterhin fallen die drei klassischen Resynthesen ,G 39', ,RS 10/7' und ,S 39' auf, die einen relativ hohen Anteil (> 20\%) an GNL aufweisen sowie die Wild-Resynthese 'CRL 1' und die Resynthese ,G 50' bei denen Glucobrassicanapin (GBN) deutlich mehr als 10\% des Gesamtclucosinolatgehaltes ausmacht. Auch 4-Hydroxiglucobrassicin $(4 \mathrm{OH})$ ist in fünf der klassischen Resynthesen (,B 1/3.3', ,G 50', ,H 176', ,K 199.16.2' und ,R 99') mit Prozentanteilen $>10 \%$ vertreten. Alle weiteren gefundenen Glucosinolate kommen in den Resynthesen nur in geringen Prozentanteilen $<10 \%$ meist sogar $<5 \%$ vor.

Zwischen den Standards gibt es nur geringe Unterschiede in den Glucosinolatmustern. Hauptglucosinolat ist bei allen PRO mit einem mittleren Prozentanteil von $45 \%$, an zweiter Stelle folgt $4 \mathrm{OH}$ mit durchschnittlich $23 \%$ und an dritter Stelle GNA mit 21\%. Alle anderen Glucosinolate sind in den Standards nur in geringen Mengen enthalten.

Teilt man die Glucosinolatgehalte nach ihrer chemischen Gruppenzugehörigkeit in die Gruppen Alkenylglucosinolate, Indolglucosinolate und phenolische Glucosinolate auf, so beträgt der prozentuale Anteil der Alkenyle bei den Resynthesen im Mittel 92,1\%. Die Indole sind mit 6,6\% vertreten und die phenolischen Glucosinolate mit 1,3\%. Bei den Standards ist der prozentuale Anteil der Alkenyle mit 72,2\% deutlich geringer, der der Indole hingegen mit 25,5\% deutlich höher. Die phenolischen Glucosinolate sind hier mit 1,8\% vertreten. 
Tab. 3-9: Ergebnisse der ANOVA für die HPLC-Analyse der Samenglucosinolatgehalte und -muster für die Resynthesen vom Standort Impington (GB). Gezeigt sind die Varianzkomponenten und die Heritabilität der einzelnen Merkmale

\begin{tabular}{|c|c|c|c|c|}
\hline Varianzursache $^{a}$ & Genotyp & Wdh. & GxW & $\mathrm{h}^{2}$ \\
\hline Progoitrin (PRO) & $602,4291^{\star *}$ & 0,2025 & 37,2433 & 0,97 \\
\hline Sinigrin (SIN) & $9,8225^{\star *}$ & 0,0086 & 1,8279 & 0,91 \\
\hline Gluconapoleiferin (GNL) & $43,9648^{\star *}$ & $-0,0187$ & 4,0691 & 0,96 \\
\hline Glucoraphanin (RAA) & $0,8777^{* *}$ & $-0,0078$ & 0,3731 & 0,82 \\
\hline Glucoraphenin (RAE) & $3,2025^{\star *}$ & $-0,0021$ & 0,5251 & 0,92 \\
\hline Gluconapin (GNA) & $1923,4874^{\star *}$ & $-0,6113$ & 44,6259 & 0,99 \\
\hline 4-Hydroxiglucobrassicin (4OH) & $2,7886^{* *}$ & 0,0215 & 0,6803 & 0,89 \\
\hline Glucobrassicanapin (GBN) & $10,0558^{* *}$ & $-0,0134$ & 0,6506 & 0,97 \\
\hline Glucobrassicin (GBC) & $0,0359^{* *}$ & 0,0001 & 0,0251 & 0,74 \\
\hline Gluconasturtiin (NAS) & $0,5028^{\star *}$ & $-0,0006$ & 0,0517 & 0,95 \\
\hline 4-Methoxyglucobrassicin (4ME) & $0,0030^{\star *}$ & 0,0000 & 0,0007 & 0,90 \\
\hline Neoglucobrassicin (NEO) & $0,0014^{* *}$ & 0,0000 & 0,0006 & 0,82 \\
\hline GSL gesamt $_{\text {t }}$ & $1713,1915^{\star \star}$ & $-0,2639$ & 61,2472 & 0,98 \\
\hline
\end{tabular}

${ }^{a}$ Wdh. = Wiederholung, GxW = Interaktion zwischen Genotyp und Wiederholung, $\mathrm{h}^{2}=$ Heritabilität;

** Signifikant bei $p=0,01$

Die statistische Auswertung der Ergebnisse der HPLC-Analyse erbrachte für alle Glucosinolate hohe Heritabilitäten (Tab. 3-9). Lediglich für Glucoraphanin (RAA), Glucobrassicin (GBC) und Neoglucobrassicin (NEO) liegen die Heritabilitätswerte etwas niedriger. 


\subsection{Agronomische Eigenschaften der Testkreuzungen}

\subsubsection{Erstellung der Testkreuzungen}

Die Erstellung der Testhybriden aus Kreuzungen der 65 Resyntheselinien mit den beiden Testern ,MSL 007' und ,RNX 4621' bei den Züchtern erbrachte für die meisten Hybridkombinationen nur geringe Saatgutmengen, für einige der geplanten Hybridkombinationen auch gar kein Saatgut.

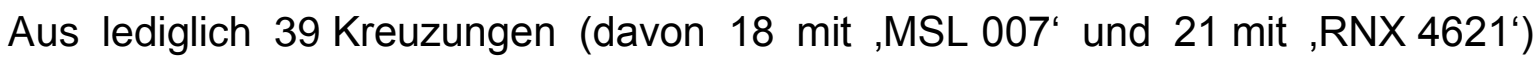
konnte ausreichend Saatgut für alle Versuchsteile und -standorte (Leistungsprüfungen: 9 Standorte, Beobachtungsanbau: 8 Standorte) gewonnen werden. Bei 25 weiteren Testhybriden (12 mit ,MSL 007', 13 mit ,RNX 4621') reichten die produzierten Saatgutmengen für vier Leistungsprüfungsstandorte und den Beobachtungsanbau, so dass in den Leistungsprüfungen insgesamt 64 Hybridkombinationen (30 mit ,MSL 007' und 34 mit ,RNX 4621') geprüft werden konnten.

Von 36 ,MSL'-Hybriden und 31 ,RNX'-Hybriden gab es außerdem ausreichend Saatgut für alle Standorte des Beobachtungsanbaus. Zusätzlich gab es von

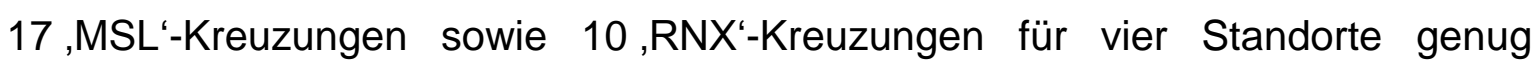
Saatgut. Bei weiteren acht,MSL'- sowie zwei ,RNX'-Kombinationen reichte die erzielte Saatgutmenge nur für einen bzw. zwei Standorte des Beobachtungsanbaus aus. Insgesamt waren somit 104 Testhybriden in den Beobachtungsanbau integriert.

Bei der Durchführung der Testkreuzungen im Gewächshaus konnte mit Ausnahme von drei Kombinationen (eine mit ,MSL 007' und zwei mit ,RNX 4621') von allen der vorgesehenen Kreuzungen Saatgut geerntet werden. Aufgrund des geringen Umfangs der Testkreuzungsproduktion im Gewächshaus konnten hier jedoch nur geringe Saatgutmengen produziert werden. 


\subsubsection{Merkmale im Beobachtungsanbau}

Im Beobachtungsanbau der Testkreuzungen konnten insgesamt 70 Genotypen an sechs Standorten geprüft werden. Weitere 27 konnten nur an vier Standorten geprüft werden, so dass an diesen vier Standorten insgesamt 97 Genotypen angebaut wurden.

Im Folgenden werden daher nur die Ergebnisse des umfangreicheren 4-ortigen Beobachtungsanbaus präsentiert. Die Ergebnisse des 6-ortigen Beobachtungsanbaus sind den Tabellen IX bis XII im Anhang zu entnehmen.

Annähernd alle Testkreuzungen haben den Winter 2009/2010 gut überdauert, einige wenige wiesen eine geringere Winterfestigkeit auf. Dies zeigt sich auch in den Bonituren für die Winterfestigkeit (WF) in Tab.3-10. Die meisten Genotypen zeigen hier niedrige Werte und somit eine akzeptable Winterfestigkeit. Es gibt aber auch Ausnahmen wie z.B. die Kreuzungen ,MSL 007 x J 166", ,MSL 007 x J 410;, ,MSL $007 \times$ J 45' und ,RNX $4621 \times \mathrm{J} 104^{\prime}$, die Werte $>5$ aufweisen und damit entsprechend große Auswinterungserscheinungen zeigten.

In Tabelle 3-10 sind neben den Werten für die Winterfestigkeit auch alle weiteren erfassten agronomischen Merkmale dargestellt. Für die Phytosterole und Sinapoylverbindungen werden an dieser Stelle nur die Gesamtgehalte aufgeführt. Die Werte für die einzelnen enthaltenen Phytosterole und Sinapoylverbindungen sind den Tabellen VII und VIII im Anhang zu entnehmen.

Für alle erfassten Merkmale zeigt die Varianzanalyse (Tab. 3-11) eine hochsignifikante genotypisch bedingte Variation. Des Weiteren werden für alle Merkmale hohe bis sehr hohe Heritabilitäten ausgegeben. Ausnahmen bilden hier nur die Merkmale Winterfestigkeit $\left(h^{2}=0,56\right)$ und Wuchshöhe $\left(h^{2}=0,71\right)$.

Der Ölgehalt der Testhybriden weist eine Spanne von 37,5\% (,MSL 007 x MOY 6') bis $45,3 \%$ (,MSL $007 \times \mathrm{RS} 7 / 6^{\circ}$ ) auf und liegt im Mittel bei $42,4 \%$. Die drei Standards liegen leicht höher mit einem Mittelwert von 43,8\%. Für den Erucasäuregehalt (C 22:1) reicht die Spanne von 0,1\% (,RNX $4621 \times$ G 50) bis 22,5\% (,MSL $007 \times$ CRY 1'). Der Mittelwert liegt bei knapp 13\%. Die Standards sind annähernd erucasäurefrei. Der Gesamtglucosinolatgehalt zeigt zwischen den Testhybriden eine große Spannbreite. Er reicht von 29,5 $\mu \mathrm{mol} / \mathrm{g}, \mathrm{MSL} \times \mathrm{H} 176$ ' bis $94,7 \mu \mathrm{mol} / \mathrm{g}$ bei ,MSL $007 \times$ MOY $6^{\prime}$ und liegt im Mittel bei $51,6 \mu \mathrm{mol} / \mathrm{g}$. Die Standards liegen mit einem Mittelwert von 22,5 $\mu \mathrm{mol} / \mathrm{g}$ deutlich darunter. Auch für die anderen Merkmale lassen sich deutliche Variationen beobachten. 
Tab.3-10: Agronomische Merkmale der Testhybriden aus dem 4-ortigen Beobachtungsanbau

\begin{tabular}{|c|c|c|c|c|c|c|c|c|c|c|c|}
\hline Genotyp & $\begin{array}{c}\text { Öl } \\
{[\%]}\end{array}$ & $\begin{array}{c}\text { C22:1 } \\
{[\%]}\end{array}$ & $\begin{array}{l}\text { Protein } \\
\text { [\%] }\end{array}$ & $\begin{array}{c}\text { GSL } \\
{[\mu \mathrm{mol} / \mathrm{g}]}\end{array}$ & $\begin{array}{c}\text { Phytosterol } \\
\text { gesamt [mg/kg] }\end{array}$ & $\begin{array}{l}\text { Sinapinsäure } \\
\text { gesamt [mg/g] }\end{array}$ & $\begin{array}{c}\text { TKG } \\
\text { [g] }\end{array}$ & $\begin{array}{l}\text { Höhe } \\
{[\mathrm{cm}]}\end{array}$ & WF & BB & Lager \\
\hline MxB1/3.3 & 42,8 & 7,6 & 20,2 & 63,1 & 3663,1 & 7,6 & 5,2 & 155,8 & 1,3 & 118,5 & 1,5 \\
\hline MxBOY1 & 40,7 & 20,7 & 21,9 & 79,2 & 3365,5 & 7,5 & 6,4 & 142,0 & 2,4 & 119,0 & - \\
\hline MxCRY1 & 40,5 & 17,4 & 22,5 & 83,2 & 3446,2 & 7,2 & 10,9 & - & - & - & - \\
\hline MxFS94.3 & 42,9 & 1,7 & 19,1 & 43,7 & 3885,7 & 7,9 & 5,5 & 166,7 & 1,3 & 119,0 & 1,5 \\
\hline MxG39 & 42,4 & 8,8 & 20,2 & 61,3 & 3697,7 & 7,6 & 5,1 & 163,3 & 2,8 & 119,8 & 2,5 \\
\hline MxG50 & 43,4 & 0,4 & 19,0 & 44,5 & 3976,8 & 8,6 & 5,5 & 143,3 & 1,3 & 119,0 & 1,5 \\
\hline MxH149 & 44,4 & 20,2 & 19,0 & 54,4 & 3456,1 & 7,1 & 5,2 & 155,0 & 1,2 & 113,8 & 2,0 \\
\hline MxH165 & 43,7 & 12,1 & 19,7 & 44,5 & 3640,4 & 7,9 & 5,0 & 140,7 & 1,8 & 118,9 & 1,5 \\
\hline MxH176 & 45,3 & 13,5 & 18,5 & 29,5 & 3651,1 & 8,1 & 5,7 & 150,0 & 1,3 & 117,8 & 1,5 \\
\hline MxH355 & 43,5 & 22,2 & 21,0 & 61,6 & 3336,2 & 8,0 & 5,5 & 136,6 & 2,7 & 116,5 & 1,4 \\
\hline MxH44 & 44,5 & 19,7 & 20,0 & 41,9 & 3427,5 & 7,1 & 5,8 & 143,3 & 1,0 & 113,8 & 1,5 \\
\hline MxHIY1 & 40,4 & 20,2 & 22,4 & 85,8 & 3326,6 & 7,0 & 8,0 & 142,3 & 3,6 & 116,8 & 1,5 \\
\hline MxINL1 & 41,4 & 9,5 & 20,9 & 41,2 & 3663,5 & 7,9 & 6,5 & 152,5 & 1,2 & 118,4 & 1,5 \\
\hline MxINL2 & 41,4 & 11,1 & 21,1 & 52,9 & 3569,3 & 7,7 & 5,7 & 151,7 & 1,3 & 114,5 & 1,5 \\
\hline MxINY1 & 38,2 & 20,5 & 23,8 & 83,4 & 3351,5 & 6,3 & 9,4 & - & - & - & - \\
\hline MxINY4 & 39,6 & 19,5 & 22,9 & 83,1 & 3437,4 & 7,5 & 8,3 & - & - & - & - \\
\hline MxINY6 & 40,7 & 9,8 & 21,0 & 61,2 & 3661,7 & 7,8 & 7,1 & 151,7 & 1,3 & 118,7 & 1,6 \\
\hline MxJ104 & 41,0 & 18,4 & 20,3 & 57,1 & 3368,9 & 7,5 & 5,3 & 127,8 & 4,3 & 118,1 & 1,5 \\
\hline MxJ112 & 42,8 & 7,9 & 20,1 & 39,8 & 3840,6 & 7,8 & 6,1 & 142,3 & 1,0 & 116,8 & 1,5 \\
\hline MxJ134 & 42,6 & 9,7 & 19,5 & 36,6 & 3590,0 & 7,4 & 5,6 & 137,6 & 2,7 & 116,4 & 1,5 \\
\hline MxJ154 & 42,0 & 13,7 & 20,4 & 61,7 & 3579,5 & 7,6 & 6,3 & 136,0 & 2,8 & 109,1 & 1,5 \\
\hline MxJ161 & 42,8 & 18,0 & 19,8 & 51,6 & 3378,7 & 7,9 & 5,1 & 127,0 & 4,9 & 119,5 & - \\
\hline MxJ166 & 41,3 & 16,6 & 20,9 & 61,6 & 3458,8 & 7,9 & 6,4 & 135,5 & 5,1 & 115,6 & 1,5 \\
\hline MxJ32 & 41,8 & 9,3 & 20,4 & 51,1 & 3657,7 & 7,8 & 6,1 & 143,3 & 3,7 & 117,8 & 1,5 \\
\hline MxJ400 & 40,5 & 16,3 & 20,5 & 52,8 & 3497,8 & 7,8 & 5,8 & 136,7 & 5,0 & 118,5 & 1,5 \\
\hline
\end{tabular}

aberechnet als Sinapinsäureäquivalente 
Tab.3-10: Agronomische Merkmale der Testhybriden aus dem 4-ortigen Beobachtungsanbau (Fortsetzung)

\begin{tabular}{|c|c|c|c|c|c|c|c|c|c|c|c|}
\hline Genotyp & $\begin{array}{l}\text { Öl } \\
{[\%]}\end{array}$ & $\begin{array}{c}\text { C22:1 } \\
{[\%]}\end{array}$ & $\begin{array}{l}\text { Protein } \\
{[\%]}\end{array}$ & $\begin{array}{c}\text { GSL } \\
{[\mu \mathrm{mol} / \mathrm{g}]}\end{array}$ & $\begin{array}{c}\text { Phytosterol } \\
\text { gesamt [mg/kg] }\end{array}$ & $\begin{array}{l}\text { Sinapinsäure } \\
\text { gesamt }[\mathrm{mg} / \mathrm{g}]^{\mathrm{a}}\end{array}$ & $\begin{array}{l}\text { TKG } \\
\text { [g] }\end{array}$ & $\begin{array}{l}\text { Höhe } \\
\text { [cm] }\end{array}$ & WF & BB & Lager \\
\hline MxJ401 & 42,3 & 10,0 & 19,7 & 44,6 & 3643,5 & 7,7 & 6,0 & 150,8 & 2,2 & 115,8 & 1,5 \\
\hline MxJ408 & 42,7 & 17,7 & 19,7 & 51,5 & 3562,4 & 7,6 & 5,5 & 143,0 & 2,2 & 115,9 & 1,6 \\
\hline MxJ410 & 41,6 & 21,0 & 20,5 & 57,2 & 3407,6 & 7,8 & 5,6 & 129,2 & 5,3 & 114,8 & 1,5 \\
\hline MxJ45 & 41,8 & 17,0 & 19,8 & 54,7 & 3442,2 & 7,6 & 5,2 & 144,0 & 3,8 & 118,0 & 1,5 \\
\hline MxK199.16.2 & 44,0 & 19,4 & 20,7 & 56,8 & 3389,6 & 7,7 & 5,3 & 145,0 & 2,7 & 120,0 & 1,5 \\
\hline MxMOL1 & 41,5 & 10,4 & 20,6 & 65,3 & 3634,6 & 8,0 & 5,6 & 150,8 & 1,5 & 117,3 & 1,5 \\
\hline MxMOL2 & 40,6 & 8,0 & 21,6 & 66,6 & 3687,3 & 7,2 & 6,0 & 165,8 & 1,0 & 119,0 & 1,5 \\
\hline MxMOY2 & 43,5 & 8,1 & 19,5 & 37,2 & 3692,8 & 7,8 & 5,3 & 147,3 & 2,3 & 117,5 & 1,5 \\
\hline MxMOY4 & 44,0 & 5,6 & 18,4 & 39,5 & 3779,4 & 7,8 & 5,3 & 148,6 & 1,9 & 116,6 & 1,5 \\
\hline MxMOY5 & 41,2 & 15,7 & 21,7 & 67,3 & 3421,3 & 6,8 & 7,8 & 151,1 & 2,5 & 118,0 & - \\
\hline MxMOY6 & 37,5 & 20,7 & 23,7 & 94,7 & 3302,7 & 6,5 & 5,8 & - & - & - & - \\
\hline MxOLL1 & 42,6 & 8,7 & 19,8 & 33,8 & 3634,7 & 8,1 & 5,9 & 141,7 & 2,2 & 113,5 & 1,5 \\
\hline MxOLY2 & 42,4 & 6,8 & 20,2 & 47,9 & 3653,3 & 7,3 & 4,9 & 148,0 & 4,3 & 117,9 & - \\
\hline MxR53 & 44,9 & 19,5 & 19,9 & 41,9 & 3439,0 & 7,8 & 5,4 & 151,5 & 1,5 & 117,8 & 1,5 \\
\hline MxR99 & 44,2 & 6,9 & 18,9 & 37,0 & 3741,2 & 7,7 & 5,0 & 146,5 & 1,3 & 117,6 & 1,5 \\
\hline MxRS10/7 & 43,2 & 18,9 & 20,8 & 67,8 & 3496,9 & 7,4 & 6,1 & 140,8 & 2,2 & 118,3 & 1,5 \\
\hline MxRS13/6 & 43,6 & 17,3 & 20,2 & 55,5 & 3327,9 & 7,2 & 6,1 & 140,8 & 2,5 & 109,0 & 1,5 \\
\hline MxRS4/2 & 43,6 & 18,7 & 20,3 & 52,0 & 3403,2 & 7,7 & 5,5 & 155,0 & 3,0 & 118,3 & 1,5 \\
\hline MxRS4/6 & 44,2 & 15,9 & 20,4 & 45,7 & 3481,0 & 7,1 & 5,4 & 154,2 & 2,0 & 115,5 & 1,5 \\
\hline MxRS7/6 & 45,3 & 16,4 & 19,0 & 37,1 & 3539,7 & 7,3 & 5,5 & 145,8 & 1,7 & 114,0 & 1,5 \\
\hline MxRS8/6 & 44,7 & 19,9 & 19,8 & 49,8 & 3380,2 & 7,9 & 5,7 & 164,2 & 2,3 & 118,8 & 1,5 \\
\hline MxRUY1 & 40,1 & 16,5 & 21,9 & 71,7 & 3539,4 & 6,9 & 6,8 & 139,4 & 1,5 & 117,3 & 1,6 \\
\hline MxS108.1.1 & 42,3 & 6,8 & 19,9 & 45,6 & 3669,9 & 7,9 & 5,6 & 144,8 & 1,3 & 112,5 & 1,5 \\
\hline MxS13 & 44,9 & 21,4 & 19,5 & 65,9 & 3444,0 & 7,5 & 5,3 & 148,3 & 1,3 & 117,3 & 1,5 \\
\hline MxS228.8.1 & 42,7 & 11,5 & 20,4 & 53,8 & 3605,6 & 7,7 & 5,4 & 150,1 & 2,5 & 117,1 & 1,5 \\
\hline
\end{tabular}

${ }^{a}$ berechnet als Sinapinsäureäquivalente 
Tab.3-10: Agronomische Merkmale der Testhybriden aus dem 4-ortigen Beobachtungsanbau (Fortsetzung)

\begin{tabular}{|c|c|c|c|c|c|c|c|c|c|c|c|}
\hline Genotyp & $\begin{array}{c}\text { Öl } \\
{[\%]}\end{array}$ & $\begin{array}{c}\text { C22:1 } \\
{[\%]}\end{array}$ & $\begin{array}{l}\text { Protein } \\
\text { [\%] }\end{array}$ & $\begin{array}{c}\text { GSL } \\
{[\mu \mathrm{mol} / \mathrm{g}]}\end{array}$ & $\begin{array}{c}\text { Phytosterol } \\
\text { gesamt [mg/kg] }\end{array}$ & $\begin{array}{c}\text { Sinapinsäure } \\
\text { gesamt [mg/g] }\end{array}$ & $\begin{array}{c}\text { TKG } \\
{[\mathrm{g}]}\end{array}$ & $\begin{array}{l}\text { Höhe } \\
{[\mathrm{cm}]}\end{array}$ & WF & BB & Lager \\
\hline MxS237.20.1 & 42,5 & 19,9 & 20,5 & 53,1 & 3488,0 & 8,1 & 5,5 & 140,8 & 2,2 & 118,0 & 1,5 \\
\hline MxS45.2.2 & 42,5 & 11,5 & 21,0 & 52,8 & 3648,1 & 8,1 & 5,3 & 141,7 & 2,7 & 113,5 & 1,5 \\
\hline MxVIL1 & 42,3 & 8,6 & 19,9 & 47,6 & 3681,4 & 8,0 & 6,2 & 144,2 & 1,3 & 117,3 & 1,5 \\
\hline $\mathrm{RxB1/3.3}$ & 43,2 & 6,1 & 18,9 & 51,4 & 3776,4 & 7,9 & 5,6 & 158,5 & 1,7 & 117,4 & 1,5 \\
\hline RxBOY1 & 41,6 & 17,9 & 20,1 & 63,2 & 3514,2 & 7,4 & 6,2 & 141,9 & 1,5 & 119,1 & 1,6 \\
\hline RxG39 & 42,0 & 4,9 & 19,5 & 47,0 & 3827,1 & 8,6 & 5,4 & 157,5 & 1,8 & 118,8 & 1,5 \\
\hline RxG50 & 43,9 & 0,1 & 17,7 & 39,7 & 4016,5 & 8,7 & 5,2 & 146,7 & 1,5 & 119,0 & 1,5 \\
\hline RxH149 & 43,7 & 18,6 & 18,8 & 50,3 & 3495,5 & 7,5 & 5,1 & 157,5 & 1,7 & 114,8 & 1,5 \\
\hline RxH165 & 42,7 & 11,0 & 19,6 & 38,9 & 3658,0 & 7,5 & 4,9 & 138,3 & 3,2 & 119,5 & 2,0 \\
\hline RxH176 & 43,1 & 11,9 & 19,6 & 35,3 & 3686,8 & 7,2 & 6,0 & 147,5 & 1,3 & 118,3 & 1,5 \\
\hline RxH355 & 42,1 & 15,6 & 20,5 & 52,7 & 3474,9 & 8,3 & 5,7 & 142,5 & 1,7 & 117,8 & 1,5 \\
\hline RxH44 & 44,3 & 18,7 & 19,8 & 36,1 & 3518,2 & 7,2 & 5,9 & 146,7 & 1,5 & 114,3 & 1,5 \\
\hline RxINL1 & 41,0 & 7,5 & 20,2 & 39,8 & 3754,9 & 7,6 & 6,5 & 162,5 & 1,5 & 118,3 & 1,5 \\
\hline RxINL2 & 41,4 & 8,0 & 20,5 & 51,4 & 3667,9 & 8,1 & 5,9 & 154,2 & 1,3 & 116,5 & 1,5 \\
\hline RxINY1 & 42,5 & 4,4 & 19,3 & 39,0 & 3820,9 & 7,8 & 5,6 & 153,1 & 1,1 & - & 1,4 \\
\hline RxJ104 & 41,8 & 13,9 & 19,0 & 41,9 & 3728,3 & 8,1 & 5,5 & 123,5 & 5,2 & 119,9 & 1,4 \\
\hline RxJ112 & 40,9 & 17,6 & 20,2 & 59,8 & 3381,2 & 7,8 & 6,3 & 140,7 & 3,6 & 118,8 & 1,5 \\
\hline RxJ134 & 42,9 & 9,2 & 18,6 & 34,2 & 3656,8 & 7,9 & 5,6 & 131,7 & 2,2 & 116,5 & 2,5 \\
\hline RxJ154 & 41,6 & 12,1 & 19,9 & 53,2 & 3615,4 & 8,1 & 6,4 & 144,2 & 1,7 & 114,5 & 1,5 \\
\hline RxJ161 & 41,2 & 16,1 & 20,3 & 49,1 & 3393,6 & 7,7 & 4,9 & 131,9 & 1,2 & 118,4 & 2,5 \\
\hline RxJ166 & 40,3 & 12,4 & 20,7 & 53,8 & 3563,9 & 8,0 & 6,3 & 135,2 & 3,9 & 117,2 & 1,5 \\
\hline RxJ32 & 41,2 & 16,5 & 19,3 & 49,8 & 3512,6 & 8,2 & 5,5 & 144,4 & 1,5 & 118,1 & 1,6 \\
\hline RxJ400 & 41,8 & 11,9 & 19,0 & 41,9 & 3614,4 & 7,9 & 6,2 & 141,7 & 3,2 & 117,2 & 1,5 \\
\hline RxJ408 & 40,7 & 15,7 & 20,6 & 51,3 & 3481,2 & 7,8 & 5,6 & 133,0 & 3,8 & 116,0 & 1,5 \\
\hline RxJ410 & 42,2 & 15,4 & 18,9 & 49,4 & 3652,8 & 8,0 & 5,6 & 135,0 & 3,3 & 117,8 & 1,5 \\
\hline
\end{tabular}

${ }^{a}$ berechnet als Sinapinsäureäquivalente 
Tab.3-10: Agronomische Merkmale der Testhybriden aus dem 4-ortigen Beobachtungsanbau (Fortsetzung)

\begin{tabular}{|c|c|c|c|c|c|c|c|c|c|c|c|}
\hline Genotyp & $\begin{array}{c}\text { Öl } \\
{[\%]}\end{array}$ & $\begin{array}{c}\text { C22:1 } \\
{[\%]}\end{array}$ & $\begin{array}{c}\text { Protein } \\
{[\%]}\end{array}$ & $\begin{array}{c}\text { GSL } \\
{[\mu \mathrm{mol} / \mathrm{g}]}\end{array}$ & $\begin{array}{c}\text { Phytosterol } \\
\text { gesamt [mg/kg] }\end{array}$ & $\begin{array}{c}\text { Sinapinsäure } \\
\text { gesamt }[\mathrm{mg} / \mathrm{g}]^{\mathrm{a}}\end{array}$ & $\begin{array}{c}\text { TKG } \\
{[g]}\end{array}$ & $\begin{array}{l}\text { Höhe } \\
\text { [cm] }\end{array}$ & WF & BB & Lager \\
\hline RxJ45 & 42,5 & 14,0 & 18,7 & 51,5 & 3945,0 & 8,0 & 5,1 & 146,7 & 2,2 & 118,5 & 1,5 \\
\hline RxK160.1.1 & 42,7 & 7,5 & 19,2 & 40,8 & 3743,9 & 8,2 & 5,7 & 156,2 & 1,7 & 116,5 & 1,6 \\
\hline RxMAY1 & 41,6 & 6,2 & 19,5 & 66,3 & 3850,4 & 7,9 & 6,9 & - & - & - & - \\
\hline RxMOL1 & 40,9 & 4,7 & 20,4 & 55,0 & 3748,9 & 8,3 & 5,6 & 162,2 & 1,7 & 117,8 & 1,6 \\
\hline RxMOL2 & 40,0 & 7,3 & 21,3 & 61,3 & 3789,4 & 7,5 & 6,0 & 149,8 & 0,9 & 119,1 & 1,5 \\
\hline RxMOY5 & 44,5 & 9,0 & 18,2 & 50,5 & 3740,0 & 8,6 & 4,9 & - & - & - & - \\
\hline RxOLL1 & 41,5 & 7,1 & 19,8 & 37,1 & 3643,4 & 8,4 & 6,4 & 148,3 & 2,3 & 116,0 & 1,5 \\
\hline RxR53 & 43,7 & 19,3 & 20,0 & 41,9 & 3419,1 & 7,9 & 5,6 & 150,0 & 1,3 & 118,5 & 1,5 \\
\hline RxR76 & 41,4 & 12,7 & 20,5 & 54,8 & 3601,8 & 7,1 & 5,7 & 144,1 & 1,2 & - & 1,4 \\
\hline RxR99 & 44,3 & 4,2 & 17,8 & 33,5 & 3847,9 & 7,8 & 5,2 & 151,7 & 0,8 & 117,3 & 1,5 \\
\hline RxRS10/7 & 42,8 & 12,1 & 19,7 & 56,0 & 3709,9 & 7,7 & 6,2 & 145,8 & 1,3 & 118,0 & 1,5 \\
\hline RxRS13/6 & 42,4 & 15,3 & 20,1 & 51,4 & 3495,1 & 7,6 & 6,0 & 143,3 & 2,2 & 116,0 & 1,5 \\
\hline RxRS4/2 & 43,5 & 13,0 & 18,6 & 42,2 & 3685,5 & 7,8 & 5,2 & 164,7 & 1,2 & 118,2 & 1,5 \\
\hline RxRS7/6 & 44,1 & 17,6 & 19,1 & 37,8 & 3596,0 & 7,5 & 5,8 & 150,0 & 1,5 & 114,3 & 1,5 \\
\hline RxRS8/6 & 42,7 & 6,5 & 19,2 & 37,4 & 3826,6 & 8,6 & 5,9 & 158,5 & 1,0 & 118,9 & 1,5 \\
\hline RxS108.1.1 & 41,6 & 3,8 & 19,8 & 44,8 & 3762,5 & 7,9 & 5,9 & 144,2 & 1,0 & 110,0 & 1,5 \\
\hline $\mathrm{RxS13}$ & 44,8 & 19,0 & 17,9 & 62,0 & 3571,9 & 7,6 & 5,5 & 149,2 & 1,2 & 117,0 & 1,5 \\
\hline RxS45.2.2 & 42,2 & 7,4 & 20,1 & 39,6 & 3700,7 & 7,8 & 5,2 & 138,3 & 1,5 & 117,5 & 1,5 \\
\hline RxVIL1 & 42,5 & 3,2 & 19,1 & 34,0 & 3894,5 & 7,9 & 6,0 & 147,5 & 1,0 & 116,9 & 1,5 \\
\hline MSL 007 & 44,4 & 0,0 & 19,1 & 23,0 & 3990,1 & 7,8 & 5,5 & 135,8 & 0,8 & 119,5 & 1,5 \\
\hline $\begin{array}{l}\text { Tester Syngenta } \\
\text { Visby }\end{array}$ & $\begin{array}{l}43,0 \\
44,1 \\
\end{array}$ & $\begin{array}{l}0,7 \\
0,0\end{array}$ & $\begin{array}{l}19,0 \\
17,4 \\
\end{array}$ & $\begin{array}{l}25,1 \\
19,5 \\
\end{array}$ & $\begin{array}{l}3974,5 \\
4219,3 \\
\end{array}$ & $\begin{array}{l}7,7 \\
8,3 \\
\end{array}$ & $\begin{array}{l}6,1 \\
6,1 \\
\end{array}$ & $\begin{array}{l}144,2 \\
140,8 \\
\end{array}$ & $\begin{array}{l}1,0 \\
1,0 \\
\end{array}$ & $\begin{array}{l}125,1 \\
118,3 \\
\end{array}$ & $\begin{array}{l}3,0 \\
1,5 \\
\end{array}$ \\
\hline $\operatorname{LSD}(p=0,05)$ & 1,3 & 4,6 & 1,2 & 9,3 & 149,7 & 0,5 & 0,6 & 13,5 & 2,2 & 2,8 & 0,8 \\
\hline Min. & 37,5 & 0,0 & 17,4 & 19,5 & 3302,7 & 6,3 & 4,9 & 123,5 & 0,8 & 109,0 & 1,4 \\
\hline Max. & 45,3 & 22,2 & 23,8 & 94,7 & 4219,3 & 8,7 & 10,9 & 166,7 & 5,3 & 125,1 & 3,0 \\
\hline MW Testhybriden & 42,4 & 12,7 & 20,0 & 51,6 & 3600,5 & 7,7 & 5,9 & 146,3 & 2,1 & 117,0 & 1,6 \\
\hline MW Standards & 43,8 & 0,2 & 18,5 & 22,5 & 4061,3 & 7,9 & 5,9 & 140,3 & 0,9 & 120,9 & 2,0 \\
\hline
\end{tabular}

aberechnet als Sinapinsäureäquivalente 
So ist der Phytosterolgehalt der Testhybriden im Mittel gut $450 \mathrm{mg} / \mathrm{kg}$ geringer als der der Standards, während der Proteingehalt bei den Testhybriden mit 20\% leicht höher liegt.

Tab. 3-11: Ergebnisse der ANOVA für den 4-ortigen Beobachtungsanbau der Testhybriden, gezeigt sind die Varianzkomponenten und die Heritabilität der einzelnen Merkmale

\begin{tabular}{|c|c|c|c|c|c|c|}
\hline & Varianzursache $^{a}$ & Genotyp & Ort & GxO & Fehler $^{b}$ & $h^{2}$ \\
\hline & TKG & $0,73^{* *}$ & $0,23^{* *}$ & $0,21^{\star \star}$ & 0,09 & 0,93 \\
\hline & Wuchshöhe & $56,69^{* *}$ & $23,62^{* *}$ & $69,52^{* *}$ & 33,28 & 0,71 \\
\hline & Blühbeginn & $4,59^{* *}$ & $2,22^{* *}$ & $1,91^{* *}$ & 0,81 & 0,83 \\
\hline & Winterfestigkeit & $0,77^{\star *}$ & $1,63^{* *}$ & $1,78^{* *}$ & 0,58 & 0,56 \\
\hline & ÖL & $1,99^{\star *}$ & $4,30^{* *}$ & $0,91^{* *}$ & 0,58 & 0,90 \\
\hline & C22:1 & $32,84^{\star *}$ & $0,57^{* *}$ & $11,04^{\star *}$ & 4,73 & 0,92 \\
\hline & Protein & $1,13^{\star *}$ & $4,57^{\star \star}$ & $0,78^{\star *}$ & 0,50 & 0,85 \\
\hline & Glucosinolate & $177,72^{* *}$ & $28,84^{* *}$ & $44,70^{* *}$ & 18,99 & 0,94 \\
\hline \multirow{6}{*}{ 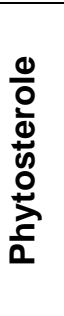 } & Brassicasterol & $363,41^{* *}$ & $525,80^{* *}$ & $174,80^{\star *}$ & 119,61 & 0,89 \\
\hline & Camposterol & $5918,32^{\star *}$ & $2098,23^{* *}$ & $2366,42^{\star *}$ & 1558,15 & 0,91 \\
\hline & Stigmasterol & $0,08^{* *}$ & $0,13^{* *}$ & $0,03^{* *}$ & 0,02 & 0,89 \\
\hline & Sitosterol & $5583,65^{\star *}$ & $437,26^{* *}$ & $1937,53^{* *}$ & 1296,42 & 0,92 \\
\hline & Avenasterol & $128,59^{* *}$ & $141,25^{\star *}$ & $68,10^{* *}$ & 37,06 & 0,88 \\
\hline & Phytosterol gesamt & $29799,15^{\star \star}$ & $3580,27^{\star \star}$ & $11543,88^{\star *}$ & 7600,75 & 0,91 \\
\hline \multirow{4}{*}{$\begin{array}{l}\frac{0}{2} \\
\frac{0}{0} \\
\frac{0}{\omega}\end{array}$} & Sinapoylglucose & $0,37^{* *}$ & $0,08^{* *}$ & $0,12^{* *}$ & 0,09 & 0,93 \\
\hline & Sinapin & $0,39^{* *}$ & $0,20^{* *}$ & $0,13^{\star \star}$ & 0,12 & 0,92 \\
\hline & andere $S E^{c}$ & $0,07^{\star *}$ & $0,02^{* *}$ & $0,02^{+}$ & 0,02 & 0,92 \\
\hline & Sinapinsäure gesamt & $0,15^{\star *}$ & $0,02^{* *}$ & 0,12 & 0,13 & 0,83 \\
\hline
\end{tabular}

${ }^{\mathrm{a}} \mathrm{GxO}=$ Interaktion zwischen Genotyp und Ort, $\mathrm{h}^{2}=$ Heritabilität; ${ }^{\mathrm{b}}$ Fehler geschätzt aus 4 Orten mit je 2 Wiederholungen; ${ }^{c} \mathrm{SE}=$ Sinapinsäureester; ${ }^{+,},{ }^{* *}{ }^{* *}$ signifikant bei $p=0,1, p=0,05$ bzw. bei $p=0,01$

Für die Samenproben der Testhybriden vom Standort Göttingen wurden zusätzlich zu den NIRS-Analysen GC-Analysen der Fettsäuremuster und HPLC-Analysen des Glucosinolatgehaltes und -musters durchgeführt. Um möglichst viele der Testhybriden charakterisieren zu können, wurden von einigen weiteren Genotypen, von denen keine Samenproben vom Standort Göttingen zur Verfügung standen, Proben vom Standort Einbeck mit in die Analysen einbezogen. Die Ergebnisse dieser Genotypen sind natürlich nicht direkt mit den übrigen Genotypen vergleichbar, sie sind daher in den Ergebnisdarstellungen gekennzeichnet und sind nicht mit in die statistische Auswertung der Teilversuche eingeflossen. Die Ergebnisse der GC- Analyse der Fettsäuremuster sind in Tabelle 3-12 dargestellt. 
Tab. 3-12: Ergebnisse der GC-Analyse der Fettsäuremuster für die Samenproben aus dem Beobachtungsanbau der Testhybriden in Göttingen

\begin{tabular}{|c|c|c|c|c|c|c|c|c|c|c|c|}
\hline Genotyp & 16:0 & $16: 1$ & $16: 2$ & $18: 0$ & $18: 1$ & $18: 2$ & $18: 3$ & $20: 0$ & $20: 1$ & $22: 0$ & 22:1 \\
\hline MxB1/3.3 & 4,7 & 0,2 & 0,0 & 1,3 & 51,0 & 15,5 & 10,0 & 0,5 & 8,8 & 0,2 & 7,7 \\
\hline MxBOY1 & 4,4 & 0,4 & 0,1 & 1,7 & 35,5 & 18,4 & 9,9 & 0,5 & 9,2 & 0,6 & 18,6 \\
\hline MxCRL1 & 4,6 & 0,2 & 0,0 & 1,2 & 42,3 & 16,7 & 11,1 & 0,4 & 11,7 & 0,2 & 11,6 \\
\hline MxCRY2 & 4,0 & 0,3 & 0,0 & 1,8 & 36,5 & 17,8 & 8,7 & 0,7 & 11,4 & 0,5 & 17,5 \\
\hline MxFS94.3 & 5,2 & 0,1 & 0,0 & 1,5 & 53,8 & 15,4 & 9,7 & 0,4 & 6,9 & 0,2 & 6,7 \\
\hline MxG39 & 4,9 & 0,2 & 0,0 & 1,0 & 42,3 & 20,2 & 10,3 & 0,4 & 11,7 & 0,3 & 8,6 \\
\hline MxG50 & 4,8 & 0,2 & 0,0 & 1,5 & 59,2 & 19,3 & 10,7 & 0,4 & 2,5 & 0,1 & 1,3 \\
\hline MxH149 & 4,9 & 0,2 & 0,0 & 1,0 & 32,6 & 16,7 & 10,7 & 0,4 & 12,4 & 0,3 & 20,1 \\
\hline MxH165 & 4,9 & 0,2 & 0,0 & 1,0 & 42,5 & 19,9 & 9,6 & 0,4 & 11,1 & 0,3 & 10,1 \\
\hline MxH176 & 5,0 & 0,1 & 0,0 & 1,0 & 40,1 & 18,1 & 11,2 & 0,5 & 10,6 & 0,3 & 13,0 \\
\hline MxH355 & 4,0 & 0,3 & 0,7 & 1,4 & 31,7 & 15,6 & 11,8 & 0,6 & 13,3 & 0,3 & 20,4 \\
\hline xH44 & 4,3 & 0,1 & 0,0 & 1,0 & 33,1 & 16,9 & 9,5 & 0,4 & 13,5 & 0,3 & 20,9 \\
\hline MxHIY1 & 4,1 & 0,3 & 0,1 & 1,5 & 34,8 & 18,2 & 8,7 & 0,6 & 11,7 & 0,6 & 18,7 \\
\hline MxINL1 & 4,6 & 0,3 & 0,1 & 1,7 & 45,1 & 20,2 & 11,1 & 0,5 & 8,3 & 0,4 & 7,5 \\
\hline MxINL2 & 4,8 & 0,1 & 0,2 & 1,4 & 44,7 & 19,8 & 11,0 & 0,4 & 8,6 & 0,4 & 8,3 \\
\hline MxINY1 & 5,0 & 0,2 & 0,1 & 1,7 & 50,8 & 20,0 & 11,0 & 0,4 & 4,1 & 0,3 & 6,0 \\
\hline MxINY3 & 4,1 & 0,3 & 1,0 & 1,4 & 36,6 & 16,8 & 9,6 & 0,7 & 10,9 & 0,2 & 17,6 \\
\hline MxISY1 & 6,0 & 0,3 & 0,2 & 1,8 & 34,2 & 20,4 & 10,8 & 0,6 & 9,8 & 0,6 & 14,8 \\
\hline MxJ104 & 4,7 & 0,1 & 0,0 & 1,1 & 32,7 & 18,1 & 9,8 & 0,4 & 10,7 & 0,3 & 21,7 \\
\hline MxJ134 & 4,5 & 0,2 & 0,0 & 1,0 & 45,8 & 18,0 & 9,3 & 0,3 & 10,9 & 0,2 & 9,5 \\
\hline MxJ154 & 5,9 & 0,3 & 0,2 & 1,5 & 39,2 & 18,8 & 10,6 & 0,5 & 10,0 & 0,4 & 11,8 \\
\hline MxJ161 & 5,0 & 0,2 & 0,0 & 2,8 & 30,3 & 17,5 & 10,2 & 1,1 & 10,9 & 1,5 & 20,3 \\
\hline MxJ32 & 5,0 & 0,0 & 0,2 & 1,4 & 43,6 & 18,8 & 11,1 & 0,4 & 8,9 & 0,3 & 9,9 \\
\hline MxJ400 & 5,1 & 0,2 & 0,0 & 1,0 & 28,1 & 19,0 & 10,7 & 0,4 & 11,7 & 0,5 & 22,6 \\
\hline MxJ401 & 4,8 & 0,2 & 0,0 & 1,0 & 41,6 & 17,7 & 10,0 & 0,3 & 11,9 & 0,2 & 12,2 \\
\hline MxJ408 & 5,2 & 0,2 & 0,0 & 1,1 & 34,0 & 17,9 & 9,7 & 0,3 & 9,2 & 0,3 & 18,6 \\
\hline MxJ410 & 4,6 & 0,1 & 0,0 & 1,1 & 26,4 & 17,6 & 10,9 & 0,5 & 12,6 & 0,2 & 25,8 \\
\hline MxJ45 & 4,6 & 0,1 & 0,0 & 1,0 & 26,2 & 18,5 & 10,0 & 0,4 & 11,9 & 0,3 & 26,4 \\
\hline MxK160.1.1 & 5,0 & 0,2 & 0,0 & 0,9 & 35,2 & 15,5 & 11,6 & 0,4 & 13,0 & 0,2 & 17,8 \\
\hline MxK199.16.2 & 4,7 & 0,1 & 0,0 & 0,9 & 32,5 & 15,9 & 10,9 & 0,5 & 13,3 & 0,2 & 20,8 \\
\hline MxMAY1 & 4,6 & 0,3 & 0,1 & 1,9 & 37,2 & 18,4 & 8,8 & 0,6 & 11,0 & 0,5 & 16,1 \\
\hline MxMOL1 & 5,0 & 0,3 & 0,2 & 1,6 & 40,0 & 19,6 & 11,1 & 0,5 & 10,5 & 0,3 & 10,5 \\
\hline MxMOL2 & 4,5 & 0,3 & 0,2 & 1,5 & 43,9 & 21,1 & 11,5 & 0,4 & 9,1 & 0,4 & 7,0 \\
\hline MxMOY1 & 4,3 & 0,4 & 0,1 & 2,1 & 35,2 & 19,6 & 9,3 & 0,6 & 10,5 & 0,6 & 15,6 \\
\hline MxMOY4 & 4,7 & 0,3 & 0,1 & 1,5 & 51,6 & 19,6 & 11,1 & 0,5 & 4,3 & 0,2 & 5,6 \\
\hline MxMOY5 & 4,6 & 0,1 & 0,0 & 1,2 & 43,0 & 19,7 & 9,0 & 0,4 & 8,3 & 0,2 & 13,2 \\
\hline MxOLL1 & 5,1 & 0,0 & 0,2 & 1,4 & 43,0 & 19,1 & 11,5 & 0,4 & 9,8 & 0,4 & 8,8 \\
\hline MxOLY1 & 5,5 & 0,3 & 0,2 & 1,5 & 37,0 & 21,0 & 10,3 & 0,5 & 9,6 & 0,4 & 13,0 \\
\hline MxOLY2 & 4,7 & 0,2 & 0,1 & 1,8 & 46,8 & 19,6 & 9,5 & 0,5 & 9,5 & 0,3 & 6,7 \\
\hline MxR53 & 4,3 & 0,2 & 0,0 & 0,9 & 35,1 & 15,0 & 10,8 & 0,4 & 13,2 & 0,2 & 19,8 \\
\hline MxR76 & 4,0 & 0,3 & 0,3 & 1,3 & 32,3 & 17,7 & 10,8 & 0,6 & 12,7 & 0,3 & 18,9 \\
\hline MxR99 & 5,1 & 0,2 & 0,0 & 1,4 & 54,8 & 15,5 & 9,9 & 0,4 & 6,9 & 0,2 & 5,6 \\
\hline MxRS10/7 & 4,2 & 0,1 & 0,0 & 0,8 & 35,7 & 17,1 & 11,1 & 0,4 & 10,2 & 0,2 & 19,9 \\
\hline
\end{tabular}


Tab. 3-12: Ergebnisse der GC-Analyse der Fettsäuremuster für die Samenproben aus dem Beobachtungsanbau der Testhybriden in Göttingen (Fortsetzung)

\begin{tabular}{|c|c|c|c|c|c|c|c|c|c|c|c|}
\hline Genotyp & $16: 0$ & $16: 1$ & $\begin{array}{ll}16: 2 \\
\end{array}$ & $18: 0$ & $\begin{array}{l}18: 1 \\
\end{array}$ & $18: 2$ & $18: 3$ & $20: 0$ & $20: 1$ & $22: 0$ & $22: 1$ \\
\hline MxRS13/6 & 4,5 & 0,2 & 0,0 & 1,0 & 39,9 & 14,5 & 8,6 & 0,5 & 12,3 & 0,2 & 18,4 \\
\hline MxRS4/2 & 5,3 & 0,2 & 0,0 & 1,1 & 46,6 & 15,7 & 10,4 & 0,5 & 8,6 & 0,2 & 11,1 \\
\hline MxRS4/6 & 4,4 & 0,2 & 0,0 & 0,9 & 38,2 & 18,3 & 11,3 & 0,5 & 10,2 & 0,2 & 15,6 \\
\hline MxRS7/6 & 4,5 & 0,2 & 0,9 & 1,4 & 31,5 & 16,7 & 11,1 & 0,6 & 12,8 & 0,4 & 19,9 \\
\hline MxRS8/6 & 4,7 & 0,3 & 0,2 & 1,2 & 28,4 & 19,3 & 9,7 & 0,5 & 12,3 & 0,5 & 22,0 \\
\hline MxS108.1.1 & 5,1 & 0,1 & 0,0 & 1,4 & 56,7 & 14,9 & 9,8 & 0,5 & 6,4 & 0,3 & 4,3 \\
\hline MxS13 & 5,0 & 0,2 & 0,0 & 0,8 & 29,6 & 14,9 & 11,3 & 0,4 & 16,1 & 0,2 & 21,1 \\
\hline MxS228.8.1 & 5,2 & 0,2 & 0,0 & 1,5 & 53,0 & 15,6 & 9,6 & 0,4 & 7,0 & 0,2 & 7,3 \\
\hline MxS237.20.1 & 4,7 & 0,3 & 0,2 & 1,4 & 44,1 & 19,7 & 10,5 & 0,6 & 10,1 & 0,2 & 7,4 \\
\hline MxS39 & 4,6 & 0,2 & 0,0 & 1,0 & 44,2 & 14,0 & 11,1 & 0,5 & 11,9 & 0,3 & 12,2 \\
\hline MxS45.2.2 & 4,5 & 0,3 & 0,2 & 1,3 & 33,8 & 16,6 & 11,6 & 0,5 & 11,5 & 0,4 & 18,8 \\
\hline MxVIL1 & 5,0 & 0,1 & 0,2 & 1,4 & 42,8 & 19,4 & 10,8 & 0,4 & 9,6 & 0,3 & 9,5 \\
\hline RxB1/3.3 & 4,6 & 0,3 & 0,4 & 1,3 & 47,5 & 18,4 & 12,0 & 0,6 & 10,8 & 0,2 & 7,1 \\
\hline RxBOY1 & 5,1 & 0,2 & 0,2 & 2,8 & 45,4 & 17,9 & 10,8 & 0,5 & 6,3 & 0,2 & 9,6 \\
\hline RxCRL1 & 5,6 & 0,2 & 0,0 & 1,1 & 50,0 & 14,4 & 13,5 & 0,2 & 5,2 & 0,3 & 9,3 \\
\hline RxCRY2 & 4,9 & 0,2 & 0,1 & 1,6 & 41,1 & 16,7 & 11,0 & 0,5 & 10,9 & 0,2 & 12,2 \\
\hline RxG39 & 5,3 & 0,2 & 0,0 & 1,1 & 45,8 & 17,8 & 11,5 & 0,4 & 9,8 & 0,3 & 7,9 \\
\hline RxG50 & 5,6 & 0,2 & 0,0 & 1,3 & 55,9 & 20,8 & 12,1 & 0,4 & 2,1 & 0,3 & 1,3 \\
\hline RxH149 & 5,3 & 0,2 & 0,0 & 1,1 & 36,3 & 15,5 & 10,3 & 0,3 & 12,8 & 0,2 & 17,9 \\
\hline RxH165 & 5,2 & 0,2 & 0,0 & 1,5 & 39,5 & 18,8 & 10,4 & 0,5 & 11,9 & 0,4 & 11,2 \\
\hline RxH176 & 6,0 & 0,2 & 0,0 & 0,9 & 38,6 & 18,1 & 12,5 & 0,3 & 10,7 & 0,3 & 12,4 \\
\hline RxH355 & 4,4 & 0,3 & 0,2 & 1,4 & 37,3 & 16,6 & 11,5 & 0,5 & 11,1 & 0,6 & 15,5 \\
\hline RxH44 & 4,7 & 0,1 & 0,0 & 1,3 & 40,0 & 15,9 & 11,9 & 0,4 & 10,2 & 0,3 & 13,9 \\
\hline RxINL1 & 5,5 & 0,2 & 0,0 & 0,9 & 44,6 & 18,4 & 11,9 & 0,3 & 8,9 & 0,3 & 8,9 \\
\hline RxINL2 & 5,0 & 0,2 & 0,1 & 1,6 & 46,5 & 19,2 & 10,6 & 0,5 & 8,2 & 0,2 & 7,5 \\
\hline RxINY3 & 4,1 & 0,3 & 0,1 & 1,6 & 30,8 & 16,0 & 10,5 & 0,6 & 12,6 & 0,4 & 22,4 \\
\hline RxJ104 & 5,8 & 0,2 & 0,2 & 1,5 & 30,9 & 17,2 & 10,4 & 0,6 & 11,7 & 0,5 & 20,6 \\
\hline RxJ112 & 4,9 & 0,1 & 0,2 & 1,4 & 30,6 & 17,6 & 10,4 & 0,6 & 12,3 & 0,4 & 20,8 \\
\hline RxJ134 & 5,0 & 0,1 & 0,2 & 1,6 & 45,0 & 17,5 & 10,9 & 0,5 & 10,3 & 0,2 & 8,3 \\
\hline RxJ154 & 5,6 & 0,1 & 0,2 & 1,3 & 36,8 & 19,3 & 11,6 & 0,4 & 10,5 & 0,3 & 13,3 \\
\hline RxJ161 & 5,2 & 0,1 & 0,2 & 1,2 & 41,9 & 17,9 & 11,2 & 0,5 & 8,8 & 0,3 & 12,6 \\
\hline RxJ166 & 5,0 & 0,2 & 0,1 & 1,4 & 54,9 & 17,1 & 8,6 & 0,5 & 4,6 & 0,2 & 7,6 \\
\hline RxJ400 & 5,1 & 0,1 & 0,0 & 1,0 & 30,0 & 18,3 & 10,0 & 0,5 & 13,3 & 0,3 & 21,2 \\
\hline RxJ401 & 5,1 & 0,2 & 0,0 & 1,2 & 43,3 & 18,2 & 11,2 & 0,3 & 10,1 & 0,3 & 9,9 \\
\hline RxJ408 & 5,0 & 0,2 & 0,0 & 1,2 & 33,9 & 17,1 & 9,8 & 0,4 & 11,7 & 0,2 & 20,3 \\
\hline RxJ410 & 5,8 & 0,1 & 0,0 & 1,0 & 51,4 & 18,2 & 10,3 & 0,4 & 5,6 & 0,2 & 7,1 \\
\hline RxK160.1.1 & 5,2 & 0,2 & 0,0 & 1,0 & 48,3 & 16,8 & 11,6 & 0,3 & 6,9 & 0,2 & 9,3 \\
\hline RxMOL1 & 4,9 & 0,2 & 0,1 & 1,8 & 47,7 & 19,0 & 10,2 & 0,5 & 8,7 & 0,2 & 6,3 \\
\hline RxMOL2 & 4,8 & 0,6 & 0,0 & 2,7 & 65,2 & 8,6 & 6,3 & 1,2 & 5,6 & 0,7 & 4,2 \\
\hline RxMOY2 & 4,3 & 0,2 & 0,2 & 1,6 & 33,7 & 16,8 & 9,6 & 0,6 & 12,4 & 0,3 & 19,6 \\
\hline RxOLL1 & 4,8 & 0,1 & 0,0 & 1,1 & 48,0 & 17,7 & 10,7 & 0,4 & 8,9 & 0,2 & 7,9 \\
\hline RxR53 & 4,7 & 0,2 & 0,0 & 1,0 & 35,4 & 13,9 & 12,0 & 0,3 & 14,2 & 0,3 & 18,0 \\
\hline RxR99 & 5,2 & 0,2 & 0,0 & 1,2 & 51,8 & 16,6 & 10,6 & 0,3 & 7,8 & 0,2 & 6,0 \\
\hline
\end{tabular}


Tab. 3-12: Ergebnisse der GC-Analyse der Fettsäuremuster für die Samenproben aus dem Beobachtungsanbau der Testhybriden in Göttingen (Fortsetzung)

\begin{tabular}{llllllllllll}
\hline Genotyp & $\mathbf{1 6 : 0}$ & $\mathbf{1 6 : 1}$ & $\mathbf{1 6 : 2}$ & $\mathbf{1 8 : 0}$ & $\mathbf{1 8 : 1}$ & $\mathbf{1 8 : 2}$ & $\mathbf{1 8 : 3}$ & $\mathbf{2 0 : 0}$ & $\mathbf{2 0 : 1}$ & $\mathbf{2 2 : 0}$ & $\mathbf{2 2 : 1}$ \\
\hline RxRS10/7 & 5,2 & 0,2 & 0,0 & 0,9 & 49,3 & 18,0 & 11,5 & 0,3 & 5,1 & 0,3 & 9,4 \\
RxRS13/6 & 4,8 & 0,2 & 0,0 & 1,0 & 37,3 & 15,9 & 11,1 & 0,4 & 12,2 & 0,3 & 16,7 \\
RxRS4/2 & 5,0 & 0,1 & 0,0 & 1,1 & 53,1 & 17,4 & 11,0 & 0,4 & 5,5 & 0,2 & 6,2 \\
RxRS7/6 & 4,4 & 0,3 & 0,1 & 1,5 & 29,8 & 16,5 & 11,3 & 0,6 & 13,3 & 0,5 & 21,1 \\
RxRS8/6 & 4,9 & 0,2 & 0,1 & 1,4 & 45,2 & 18,6 & 11,7 & 0,5 & 8,4 & 0,5 & 8,0 \\
RxS108.1. & 4,7 & 0,3 & 0,3 & 1,6 & 52,2 & 16,2 & 11,4 & 0,5 & 6,2 & 0,3 & 5,9 \\
RxS13 & 5,3 & 0,3 & 0,2 & 1,1 & 27,6 & 15,8 & 12,1 & 0,5 & 14,2 & 0,6 & 21,1 \\
RxS237.20.1 & 5,3 & 0,3 & 0,1 & 1,5 & 55,2 & 19,2 & 11,3 & 0,5 & 2,9 & 0,3 & 3,0 \\
RxS45.2.2 & 5,0 & 0,4 & 0,3 & 1,5 & 45,8 & 18,2 & 12,1 & 0,5 & 7,5 & 0,4 & 8,0 \\
\hline Tester Syngenta & 4,7 & 0,3 & 0,2 & 1,4 & 57,0 & 19,8 & 10,4 & 0,5 & 2,6 & 0,2 & 2,3 \\
MSL007 & 4,6 & 0,3 & 0,2 & 1,6 & 60,4 & 19,1 & 10,1 & 0,5 & 2,0 & 0,1 & 0,7 \\
Visby & 4,8 & 0,3 & 0,2 & 1,4 & 59,3 & 21,3 & 10,4 & 0,5 & 1,2 & 0,2 & 0,2 \\
\hline LSD (p = 0,05) & 0,6 & 0,1 & 0,1 & 0,3 & 6,5 & 1,8 & 1,1 & 0,1 & 2,8 & 0,2 & 4,6 \\
Min. & 4,0 & 0,0 & 0,0 & 0,8 & 26,2 & 8,6 & 6,3 & 0,2 & 1,2 & 0,1 & 0,2 \\
Max. & 6,0 & 0,6 & 1,0 & 2,8 & 65,2 & 21,3 & 13,5 & 1,2 & 16,1 & 1,5 & 26,4 \\
MW Resynthesen & 4,9 & 0,2 & 0,1 & 1,3 & 41,2 & 17,6 & 10,6 & 0,5 & 9,8 & 0,3 & 13,1 \\
MW Standards & 4,7 & 0,3 & 0,2 & 1,5 & 58,9 & 20,1 & 10,3 & 0,5 & 1,9 & 0,2 & 1,1 \\
\hline & & & & & & & & & & & \\
MxJ166 ${ }^{1}$ & 6,7 & 0 & 0 & 1,39 & 34,1 & 22,5 & 11,2 & 0,5 & 8,6 & 0,3 & 14,6 \\
RxVIL1 ${ }^{1}$ & 4,6 & 0,2 & 0 & 1,49 & 47,6 & 20,0 & 10,1 & 0,5 & 7,7 & 0,21 & 7,1 \\
\hline
\end{tabular}

${ }^{1}$ Ergebnisse für diese Resynthesen stammen vom Standort Einbeck und wurden daher nicht zusammen mit den übrigen aufgeführten Resynthesen vom Standort Göttingen verrechnet.

Wie aus der Varianzanalyse (Tab.3-13) ersichtlich, gibt es für die einzelnen Fettsäuren hochsignifikante genotypische Variationen und auch die Heritabilitäten erreichen hohe bis sehr hohe Werte. Besonders große Spannbreiten lassen sich für die Merkmale Ölsäure (C 18:1), Linolsäure (C 18:2), Linolensäure (C 18:3), Icosensäure (C 20:1) und Erucasäure (C 22:1) beobachten. Der Ölsäuregehalt der Testhybriden reicht von 26,2\% (,MSL $007 \times \mathrm{J} 45^{\circ}$ ) bis 65,2\% (,RNX $4621 \times$ MOL $\left.2^{\prime}\right)$. Im Mittel liegt er bei $41,2 \%$. Bei den drei Standards liegt der mittlere Ölsäuregehalt bei 58,9\%. Der Linolsäuregehalt liegt bei den Testhybriden im Mittel bei 17,6\% und damit etwas niedriger als bei den Standards (20,1\%). Auffallend ist hier der Genotyp ,RNX $4621 \times$ MOL 2', der mit 8,6\% einen sehr geringen Gehalt aufweist. Auch beim Linolensäuregehalt weist diese Testhybride mit 6,3\% den geringsten Gehalt auf. Im Mittel liegt der Linolensäuregehalt bei den Testhybriden bei $10,6 \%$ und bei den Standards bei 10,3\%. Icosensäure und Erucasäure sind in den Standards nur in Spuren enthalten (1,9\% bzw. 1,2\% im Mittel). Bei den Testhybriden reicht die Variationsbreite für Icosensäure von 2,5\% 
(,MSL $007 \times$ G 50') bis 16,1\% (,MSL $007 \times$ S 13') und bei Erucasäure von 1,3\% (,MSL $007 \times$ G 50) bis 26,4\% (,MSL $\left.007 \times \mathrm{J} 45^{\circ}\right)$. Im Mittel liegt der Wert für Icosensäure bei den Testhybriden bei 9,8\% und der für Erucasäure bei 13,1\%.

Tab. 3-13: Ergebnisse der ANOVA für die GC-Analyse der Fettsäuren der Resynthesen vom Standort Göttingen. Gezeigt sind die Varianzkomponenten und die Heritabilität der einzelnen Merkmale

\begin{tabular}{lrcrr}
\hline Varianzursache $^{\text {a }}$ & Genotyp & Wdh. & GxW & $\mathbf{h}^{\mathbf{2}}$ \\
\hline 16:0 Palmitinsäure & $0,15^{\star *}$ & 0,00 & 0,09 & 0,78 \\
16:1 Palmitoleinsäure & $0,01^{* *}$ & 0,00 & 0,00 & 0,95 \\
16:2 & $0,03^{* *}$ & 0,00 & 0,00 & 0,98 \\
18:0 Stearinsäure & $0,13^{\star *}$ & 0,00 & 0,03 & 0,91 \\
18:1 Ölsäure & $72,63^{* *}$ & $0,89^{* *}$ & 10,77 & 0,93 \\
18:2 Linolsäure & $3,32^{* *}$ & $0,04^{*}$ & 0,82 & 0,89 \\
18:3 Linolensäure & $0,90^{* *}$ & $0,01^{*}$ & 0,30 & 0,86 \\
20:0 Arachinsäure & $0,02^{* *}$ & 0,00 & 0,00 & 0,91 \\
20:1 Icosensäure & $8,62^{* *}$ & $-0,02$ & 2,00 & 0,90 \\
22:0 Behensäure & $0,03^{* *}$ & $0,00^{+}$ & 0,01 & 0,91 \\
22:1 Erucasäure & $37,71^{* *}$ & $0,23^{*}$ & 5,45 & 0,93 \\
\hline
\end{tabular}

${ }^{\mathrm{a}}$ Wdh. $=$ Wiederholung, $\mathrm{GxW}=$ Interaktion zwischen Genotyp und Wiederholung, $\mathrm{h}^{2}=$ Heritabilität; $* *,{ }^{*},{ }^{+}$signifikant bei $p=0,01, p=0,05$ bzw. $p=0,1$

In den HPLC-Analysen der Glucosinolate der Testhybriden konnten, wie bei den Untersuchungen der Resynthesen, zwölf unterschiedliche Glucosinolate nachgewiesen werden. In der Varianzanalyse (Tab. 3-14) zeigte sich für alle einzelnen Glucosinolate sowie für den Gesamtglucosinolatgehalt eine hochsignifikante genotypische Variation. Der Gesamtglucosinolatgehalt und die Glucosinolatgehalte der Testhybriden sind in Abb. 3-6 für die MSL 007-Hybriden und in Abb. 3-7 für die RNX 4621-Hybriden graphisch dargestellt. Die genauen Einzelwerte sind aus Tabelle XIII im Anhang ersichtlich. Die Spannweite des Gesamtglucosinolatgehaltes der Testhybriden reicht von $29,1 \mu \mathrm{mol} / \mathrm{g}$ (,MSL $007 \times$ INY $1^{\prime}$ ) bis 142,4 $\mu \mathrm{mol} / \mathrm{g}$ (,MSL $007 \times$ MAY 1'). Im Mittel liegt er bei $61,8 \mu \mathrm{mol} / \mathrm{g}$. Teilt man die Testhybriden nach ihren Testern ein, so liegt der Mittelwert bei den ,RNX'-Hybriden mit 53,1 $\mu \mathrm{mol} / \mathrm{g}$ etwa $14 \mu \mathrm{mol}$ niedriger als der der ,MSL'-Hybriden. Die Standards weisen einen durchschnittlichen Glucosinolatgehalt von 22,5 $\mu \mathrm{mol} / \mathrm{g}$ auf. Die höchsten Glucosinolatgehalte werden mit wenigen Ausnahmen bei Testhybriden mit Wild-Resynthesen beobachtet. Betrachtet man die Glucosinolatmuster, so zeigt sich, dass das Hauptglucosinolat 
bei fast allen Testhybriden und den Standards Progoitrin (PRO) mit Anteilen von $30,8 \%$ bis $76,2 \%$ des Gesamtglucosinolatgehaltes ist.

Tab. 3-14: Ergebnisse der ANOVA für die HPLC-Analyse der Samenglucosinolatgehalte und -muster für die Testhybriden aus dem Beobachtungsanbau am Standort Göttingen. Gezeigt sind die Varianzkomponenten und die Heritabilität der einzelnen Merkmale

\begin{tabular}{lrrrr}
\hline Varianzursache $^{\text {a }}$ & Genotyp & Wdh. & GxW & $\mathbf{h}^{\mathbf{2}}$ \\
\hline Progoitrin (PRO) & $153,8497^{* *}$ & $1,5082^{*}$ & 30,5043 & 0,91 \\
Sinigrin (SIN) & $4,1887^{* *}$ & $-0,0096$ & 1,3277 & 0,86 \\
Gluconapoleiferin (GNL) & $1,0004^{* *}$ & $-0,0050$ & 0,5673 & 0,78 \\
Glucoraphanin (RAA) & $0,1192^{* *}$ & $-0,0001$ & 0,0897 & 0,73 \\
Glucoraphenin (RAE) & $0,4928^{* *}$ & $-0,0003$ & 0,0847 & 0,92 \\
Gluconapin (GNA) & $94,8322^{* *}$ & $0,3990^{+}$ & 16,6854 & 0,92 \\
4-Hydroxiglucobrassicin (4OH) & $1,1525^{* *}$ & $-0,0012$ & 0,7428 & 0,76 \\
Glucobrassicanapin (GBN) & $3,2675^{* *}$ & $-0,0062$ & 0,6392 & 0,91 \\
Glucobrassicin (GBC) & $0,0572^{* *}$ & 0,0000 & 0,0120 & 0,91 \\
Gluconasturtiin (NAS) & $0,1679^{* *}$ & 0,0001 & 0,0464 & 0,88 \\
4-Methoxyglucobrassicin (4ME) & $0,0024^{* *}$ & 0,0000 & 0,0028 & 0,63 \\
Neoglucobrassicin (NEO) & $0,0565^{* *}$ & 0,0000 & 0,0006 & 0,99 \\
GSL gesamt & $471,1816^{* *}$ & $3,7257^{*}$ & 79,0937 & 0,92 \\
\hline
\end{tabular}

${ }^{a}$ Wdh. $=$ Wiederholung, $\mathrm{GxW}=$ Interaktion zwischen Genotyp und Wiederholung, $\mathrm{h}^{2}=$ Heritabilität;

${ }^{* *},{ }^{*},{ }^{+}$signifikant bei $p=0,01, p=0,05$ bzw. $p=0,1$

Ausnahmen bilden die Testhybriden ,MSL 007 x OLY 2', ,MSL 007 x RS 7/6“, ,MSL 007 x VIL 1‘, ,RNX 4621 x INY 3“， ,RNX 4621 x J 400‘ und ,RNX 4621 x MOY 2' bei denen Gluconapin (GNA) das Hauptglucosinolat mit Anteilen zwischen $38,6 \%$ und $48,6 \%$ stellt. Auch eine ganze Reihe weiterer Testhybriden, insbesondere solche, die mit Wild-Resynthesen erstellt wurden, weisen hohe GNA-Gehalte auf. Insgesamt reicht die Spanne für GNA von 4,1\% (,RNX $4621 \times$ BOY 1') $\quad$ bis $\quad 48,6 \% \quad$ (,MSL $007 \times$ OLY 2'). Für 4Hydroxiglucobrassicin $(4 \mathrm{OH})$ reicht die Variationsbreite von $2,8 \%$ für ,RNX 4621 x MOY 2‘ bis 27,8\% für den Standard ,MSL 007‘. Der Mittelwert der Standards liegt hier mit 26,6\% deutlich über dem der Testhybriden (10,8\%). Die übrigen Glucosinolate treten nur in geringeren Prozentanteilen von < 10\% auf. Lediglich bei Glucobrassicanapin (GBN) lassen sich einige wenige Genotypen mit etwas höheren Anteilen beobachten. Bei diesen handelt es sich mit Ausnahme der ,MSL'- und der ,RNX‘-Kreuzung mit der Resynthese ,G 50‘ um Kreuzungen mit verschiedenen Wild-Resynthesen. 




$\square \mathrm{PRO} \square \mathrm{SIN} \square \mathrm{GNL} \square \mathrm{RAA} \square \mathrm{RAE} \square \mathrm{GNA} \square 4 \mathrm{OH} \square \mathrm{GBN} \square \mathrm{GBC} \square \mathrm{NAS} \square 4 \mathrm{ME} \square \mathrm{NEO}$

Abb. 3-6: Samenglucosinolatgehalt und -Muster der ,MSL'-Testhybriden des Beobachtungsanbaus am Standort Göttingen; ${ }^{*}=$ Standards, ${ }^{* *}=$ Samenproben vom Standort Einbeck 


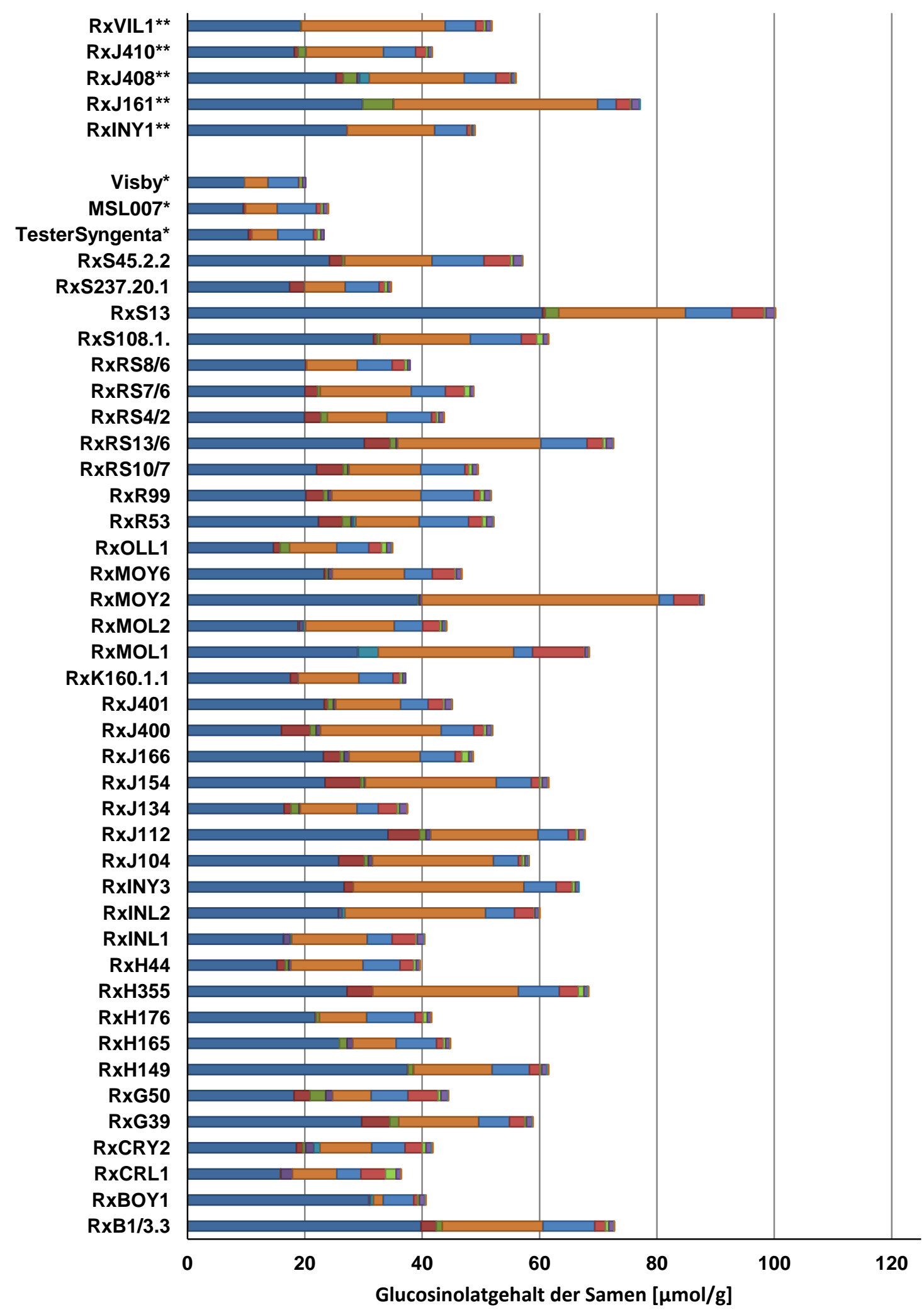

$\square$ PRO $\square$ SIN $\square$ GNL $\square$ RAA $\square$ RAE $\square$ GNA $\square$ 4OH $\square$ GBN $\square$ GBC $\square$ NAS $\square$ 4ME $\square$ NEO

Abb. 3-7: Samenglucosinolatgehalt und -Muster der ,RNX'-Testhybriden Standort Göttingen; * = Standards, ** $=$ Samenproben vom Standort Einbeck 


\subsubsection{Leistungsprüfungen}

Für 18 ,MSL'-Hybriden und 21 ,RNX'-Hybriden konnte zusammen mit drei Standards (insgesamt 42 Prüfglieder) eine 9-ortige Leistungsprüfung durchgeführt werden. Weitere $12, \mathrm{MSL}$ '-Hybriden und $13, \mathrm{RNX}$ '-Hybriden konnten nur an vier der neun Standorte geprüft werden, so dass an diesen vier Standorten insgesamt 67 Prüfglieder vorhanden waren. Eine Gegenüberstellung der Ergebnisse für die 4-ortigen und 9-ortigen Leistungsprüfungen bezüglich der Parameter Ertrag und Ölgehalt ist in Tabelle 3-15 zu finden.

Tab. 3-15: Ergebnisse der 4-ortigen und 9-ortigen Leistungsprüfungen der Testhybriden für die Parameter Ertrag und Ölgehalt

\begin{tabular}{|c|c|c|c|c|}
\hline \multirow[b]{2}{*}{ Genotypen } & \multicolumn{2}{|c|}{ Mittelwerte über 4 Orte } & \multicolumn{2}{|c|}{ Mittelwerte über 9 Orte } \\
\hline & Ertrag [dt/ha] & Ölgehalt [\%] & Ertrag [dt/ha] & Ölgehalt [\%] \\
\hline MxB1/3.3 & 38,6 & 44,1 & 40,5 & 43,8 \\
\hline MxBOY1 & 31,6 & 42,4 & - & - \\
\hline MxFS94.3 & 41,6 & 43,2 & 41,7 & 42,8 \\
\hline MxG39 & 37,8 & 42,2 & 37,9 & 42,4 \\
\hline MxG50 & 41,9 & 43,8 & 41,7 & 43,8 \\
\hline MxH149 & 45,0 & 45,5 & 46,6 & 45,1 \\
\hline MxH165 & 37,7 & 44,0 & 39,2 & 44,1 \\
\hline MxH176 & 47,1 & 45,6 & 49,5 & 45,4 \\
\hline MxH44 & 41,7 & 45,1 & 44,2 & 44,5 \\
\hline MxINL2 & 34,4 & 41,5 & - & - \\
\hline MxJ134 & 39,5 & 43,1 & - & - \\
\hline MxJ154 & 33,8 & 42,3 & 35,8 & 42,3 \\
\hline MxJ161 & 34,4 & 44,2 & 33,2 & 43,6 \\
\hline MxJ166 & 30,4 & 41,0 & - & - \\
\hline MxJ32 & 38,3 & 43,1 & 41,9 & 42,7 \\
\hline MxJ401 & 41,5 & 43,4 & - & - \\
\hline MxJ45 & 37,0 & 42,9 & - & - \\
\hline MxK199.16.2 & 36,2 & 43,7 & - & - \\
\hline MxMOL1 & 35,5 & 42,0 & 39,4 & 42,0 \\
\hline MxMOL2 & 38,8 & 40,4 & 44,9 & 40,7 \\
\hline MxMOY5 & 18,4 & 41,3 & - & - \\
\hline MxR53 & 39,1 & 45,1 & 43,2 & 45,3 \\
\hline MxR99 & 38,7 & 43,9 & 42,4 & 43,7 \\
\hline MxRS13/6 & 37,6 & 44,6 & - & - \\
\hline MxRS4/2 & 38,2 & 43,9 & - & - \\
\hline MxS108.1.1 & 45,3 & 43,8 & - & - \\
\hline MxS13 & 45,0 & 46,2 & 46,7 & 46,2 \\
\hline MxS228.8.1 & 37,8 & 44,1 & - & - \\
\hline MxS45.2.2 & 40,7 & 43,8 & 38,5 & 43,3 \\
\hline MxVIL1 & 40,1 & 42,7 & 39,4 & 42,4 \\
\hline
\end{tabular}


Tab. 3-15: Ergebnisse der 4-ortigen und 9-ortigen Leistungsprüfungen der Testhybriden für die Parameter Ertrag und Ölgehalt (Fortsetzung)

\begin{tabular}{|c|c|c|c|c|}
\hline \multirow[b]{2}{*}{ Genotypen } & \multicolumn{2}{|c|}{ Mittelwerte über 4 Orte } & \multicolumn{2}{|c|}{ Mittelwerte über 9 Orte } \\
\hline & Ertrag [dt/ha] & Ölgehalt [\%] & Ertrag [dt/ha] & Ölgehalt [\%] \\
\hline RxB1/3.3 & 39,6 & 42,9 & 39,6 & 42,5 \\
\hline RxBOY1 & 38,6 & 41,6 & - & - \\
\hline RxG39 & 38,7 & 41,9 & 40,4 & 42,0 \\
\hline RxG50 & 35,7 & 43,4 & 42,1 & 43,3 \\
\hline RxH149 & 42,6 & 43,7 & 46,2 & 43,9 \\
\hline RxH165 & 39,9 & 43,3 & 38,0 & 43,1 \\
\hline RxH176 & 42,7 & 43,9 & 47,1 & 43,8 \\
\hline RxH355 & 36,3 & 42,5 & - & - \\
\hline RxH44 & 42,6 & 45,0 & 44,3 & 44,5 \\
\hline RxINL1 & 42,7 & 41,5 & - & - \\
\hline RxINL2 & 38,9 & 41,7 & 40,7 & 41,6 \\
\hline RxJ112 & 38,6 & 42,9 & - & - \\
\hline RxJ134 & 38,4 & 42,5 & 41,5 & 42,6 \\
\hline RxJ154 & 39,5 & 42,9 & - & - \\
\hline RxJ161 & 37,2 & 42,9 & - & - \\
\hline RxJ166 & 36,1 & 41,7 & 40,7 & 42,6 \\
\hline RxJ401 & 37,7 & 42,2 & 41,5 & 41,7 \\
\hline RxJ408 & 36,6 & 42,2 & 39,7 & 42,2 \\
\hline RxJ410 & 42,9 & 42,3 & - & - \\
\hline RxJ45 & 38,5 & 43,3 & - & - \\
\hline RxMOY4 & 43,7 & 42,5 & - & - \\
\hline RxOLL1 & 36,9 & 41,5 & - & - \\
\hline RxR53 & 41,7 & 44,1 & 44,1 & 43,9 \\
\hline RxR99 & 44,1 & 43,2 & 46,6 & 43,1 \\
\hline RxRS10/7 & 43,7 & 43,7 & - & - \\
\hline RxRS13/6 & 38,9 & 44,0 & - & - \\
\hline RxRS4/2 & 43,6 & 43,5 & 45,3 & 43,0 \\
\hline RxRS7/6 & 41,5 & 43,3 & 42,2 & 43,4 \\
\hline RxRS8/6 & 42,0 & 43,2 & 44,0 & 43,0 \\
\hline RxRUY1 & 38,5 & 43,1 & - & - \\
\hline RxS108.1.1 & 42,3 & 41,9 & 44,3 & 42,1 \\
\hline RxS13 & 43,4 & 44,5 & 47,9 & 44,5 \\
\hline RxS39 & 44,5 & 42,0 & 44,8 & 42,1 \\
\hline RxS45.2.2 & 34,2 & 42,3 & 37,6 & 42,2 \\
\hline MSL007 & 35,8 & 45,4 & 37,8 & 45,2 \\
\hline Tester Syngenta & 33,7 & 42,1 & 38,7 & 42,0 \\
\hline Visby & 49,2 & 43,6 & 51,2 & 43,8 \\
\hline LSD $(p=0,05)$ & 6,3 & 1,2 & 4,9 & 0,7 \\
\hline Min. & 18,4 & 40,4 & 33,2 & 40,7 \\
\hline Max. & 49,2 & 46,2 & 51,2 & 46,2 \\
\hline MW Testhybriden & 39,2 & 43,1 & 42,2 & 43,2 \\
\hline MW Standards & 39,6 & 43,7 & 42,6 & 43,7 \\
\hline
\end{tabular}


Im Mittel über neun Umwelten liegen die Erträge der Testhybriden und auch der Standards etwa $3 \mathrm{dt} /$ ha höher als im Mittel über vier Umwelten. Der mittlere Ölgehalt der Testhybriden und auch der Standards ist sowohl über neun Umwelten wie auch über vier Umwelten annähernd konstant. Auffallend sind die niedrigen Kornerträge der beiden Standards ,MSL 007 (35,8 dt/ha bzw. 37,8 dt/ha) und ,Tester Syngenta' (33,7 dt/ha bzw. 38,7 dt/ha) während der Standard ,Visby' sowohl über vier Orte gemittelt wie auch über neun Orte gemittelt die höchsten Erträge (49,2 dt/ha bzw. 51,2 dt/ha) erbringt. Der niedrigste Ertrag über vier Orte findet sich bei der Testhybride ,MSL 007 x MOY 5' mit 18,6 dt/ha, der höchste bei der Testhybride ,MSL 007 x H 176'mit 47,1 dt/ha. Über neun Orte gemittelt lässt sich der niedrigste Kornertrag für die Kreuzung ,MSL $007 \times$ J 161" mit 33,2 dt/ha beobachten, der höchste für ,MSL $007 \times$ H 176' mit 49,5 dt/ha. Der niedrigste Ölgehalt ist bei den Testkreuzungen sowohl über vier wie auch über neun Orte gemittelt für den Genotyp ,MSL 007 x MOL 2' mit 40,4\% bzw. 40,7\% festzustellen. Den höchsten Ölgehalt insgesamt weist in beiden Fällen die Testhybride ,MSL $007 \times$ × $13^{\prime}$ mit jeweils $46,2 \%$ auf.

Die Ergebnisse der 4-ortigen Leistungsprüfung für den Kornertrag sowie für den Ölgehalt der einzelnen Testhybriden und der Standards sind in den Abbildungen 3-8 und 3-10 graphisch dargestellt.

Im Balkendiagramm für den Ertrag (Abb. 3-8) ist zu erkennen, das mit Ausnahme der beiden Genotypen ,MSL $007 \times$ MOY 5“ und ,MSL $007 \times \mathrm{J} 166^{\prime}$ alle Testhybriden auf oder über dem Ertragsniveau der beiden Tester ,MSL 007' und ,RNX 4621' liegen. Weiterhin ist zu beobachten, dass die meisten Testhybriden mit Wild-Resynthesen (in grün und hellgrün dargestellt) geringere Erträge erbracht haben als viele Testhybriden mit klassischen Resynthesen (in grau dargestellt). Ausnahmen sind hier die Genotypen ,MSL $007 \times$ VIL 1', ,MSL 007 x J 401', ,RNX 4621 x INL 1', ,RNX 4621 x J 410‘ und ,RNX 4621 x MOY 4‘, deren Erträge bei $>40 \mathrm{dt} /$ ha lagen. Besonders auffallend ist die Testhybride ,MSL $007 \times \mathrm{H} 176$, deren Ertragsniveau nah an das des Standards ,Visby' heranreicht.

Vergleicht man die Erträge für die 22 Tester/Resynthese-Kombinationen, die mit beiden Testern gelungen sind und in den Leistungsprüfungen geprüft werden konnten, so erhält man eine relativ niedrige signifikante Korrelation von 0,45 (Abb. 3-9). 


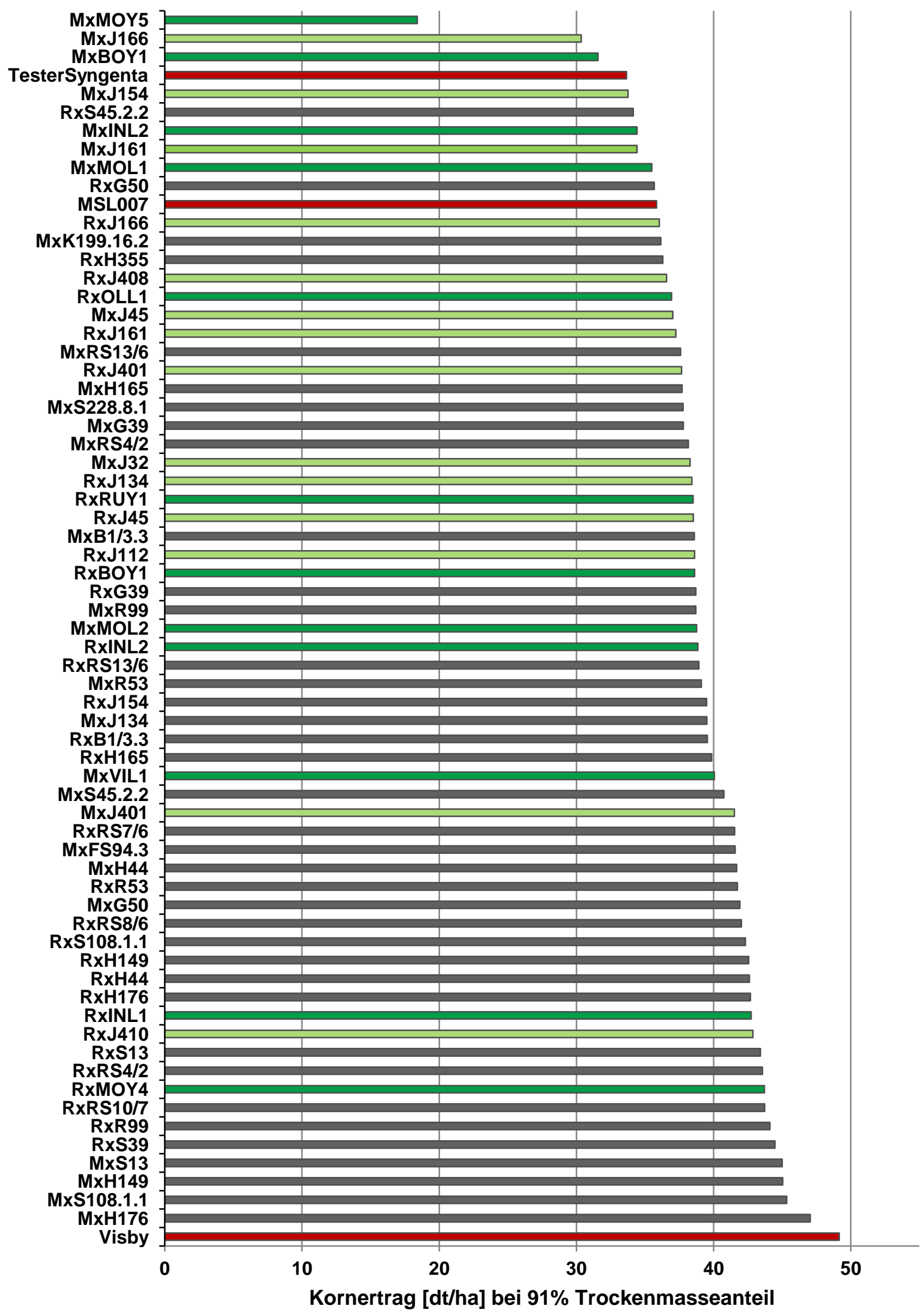

Abb. 3-8: Kornertrag der Testhybriden über 4 Standorte gemittelt: Hellgrün = Testhybriden mit Resynthesen, die das C-Genom einer B. oleracea-Wildform enthalten, grün = Testhybriden mit Resynthesen, die das C-Genom einer B. oleracea-Wildart enthalten, dunkelgrau $=$ Testhybriden mit klassischen Resynthesen, rot $=$ Standards 




Abb. 3-9: Korrelation der Kornerträge für Tester/Resynthese-Kombinationen, die mit beiden Testern gelungen sind. $(n=22) ;{ }^{*}=$ signifikant $(P=0,1)$

Bei den Ölgehalten (Abb. 3-8) weisen vor allem die mit Wild-Resynthesen (in Abb. 3-8 in grün und hellgrün dargestellt) erstellten Testhybriden niedrige Werte zwischen ungefähr $40 \%$ und $43 \%$ auf. Neben wenigen Hybriden mit klassischen Resynthesen (grau dargestellt) reiht sich hier auch der ,Tester Syngenta' mit knapp über $42 \%$ Ölanteil ein. Oberhalb von $43 \%$ Ölgehalt finden sich nur drei Testhybriden mit Wild-Resynthesen. Diese sind ,RNX $4621 \times \mathrm{J} \mathrm{45}$, ,MSL 007 x J 410، und ,MSL 007 x J 161', die mit knapp über 44\% Ölgehalt den höchsten Ölanteil unter den mit Wild-Resynthesen erstellten Testhybriden aufweist. Ölgehalte über $45 \%$ erreichen neben dem Standard/Tester ,MSL 007 nur die Hybriden ,RNX 4621 x H 44,, ,MSL $007 \times$ H 44،, ,MSL $007 \times$ R 53،, ,MSL $007 \times$ H 149' und ,MSL $007 \times$ H 176'. Ein Ölanteil von über $46 \%$ konnte nur für die Kreuzung ,MSL 007 x S 13‘ beobachtet werden. 




Abb. 3-10: Ölgehalt der Testhybriden über 4 Standorte gemittelt: Hellgrün = Testhybriden mit Resynthesen, die das C-Genom einer $B$. oleracea-Wildform enthalten, grün = Testhybriden mit Resynthesen, die das C-Genom einer $B$. oleracea-Wildart enthalten, dunkelgrau = Testhybriden mit klassischen Resynthesen, rot $=$ Standards 
Die für die weiteren agronomischen Merkmale ermittelten Ergebnisse werden im Folgenden nur für die 4-ortigen Leistungsprüfungen dargestellt (Tab. 3-17), da diese insgesamt mehr Genotypen umfassten. Die Ergebnisse der 9-ortigen Leistungsprüfungen sind den Tabellen XVI bis XIX im Anhang zu entnehmen.

Für die Phytosterole und Sinapoylverbindungen werden in Tabelle 3-17 nur die Gesamtgehalte aufgeführt. Die Werte für die einzelnen enthaltenen Phytosterole und Sinapoylverbindungen sind aus den Tabellen XIV und XV im Anhang ersichtlich.

In der Varianzanalyse der Ergebnisse (Tab. 3-16) zeigten sich für annähernd alle erfassten Merkmale hochsignifikante genotypische Variationen. Eine Ausnahme bildete das Merkmal Winterfestigkeit, für das keine signifikanten Variationen festgestellt werden konnten. Auch die errechneten Heritabilitäten sind in der Regel hoch $(\geq 0,75)$. Lediglich die durch Bonituren erfassten Merkmale Winterfestigkeit und Lager sowie das die durch Messung erfasste Wuchshöhe und der mittels NIRS erfasste Sinapinsäuregehalt weisen niedrigere Heritabilitäten auf.

Tab. 3-16: Ergebnisse der ANOVA für die 4-ortigen Leistungsprüfungen der Testhybriden, gezeigt sind die Varianzkomponenten und die Heritabilität der einzelnen Merkmale

\begin{tabular}{|c|c|c|c|c|c|}
\hline & Varianzursache $^{a}$ & Genotyp & Ort & GxO & $h^{2}$ \\
\hline & Kornertrag & $14,89^{* *}$ & $58,25^{\star *}$ & 20,19 & 0,75 \\
\hline & TKG & $0,08^{* *}$ & $0,15^{* *}$ & 0,04 & 0,86 \\
\hline & Wuchshöhe & $25,92^{\star *}$ & $95,84^{* *}$ & 59,89 & 0,63 \\
\hline & Blühbeginn & $7,31^{* *}$ & $118,52^{* *}$ & 4,84 & 0,82 \\
\hline & Winterfestigkeit & 0,06 & $0,35^{\star *}$ & 1,09 & 0,16 \\
\hline & Lager & $0,22^{* *}$ & $0,48^{* *}$ & 0,98 & 0,41 \\
\hline & ÖL & $1,26^{\star \star}$ & $2,23^{* *}$ & 0,71 & 0,88 \\
\hline & $\mathrm{C} 22: 1$ & $36,82^{* *}$ & $33,54^{* *}$ & 12,55 & 0,92 \\
\hline & Protein & $0,46^{* *}$ & $0,60^{* *}$ & 0,53 & 0,78 \\
\hline & Glucosinolate & $87,62^{* \star}$ & $1,37^{* *}$ & 21,84 & 0,94 \\
\hline \multirow{6}{*}{$\begin{array}{l}\frac{0}{0} \\
\frac{0}{d} \\
\frac{\Delta}{0} \\
\stackrel{0}{\frac{1}{\alpha}} \\
\frac{1}{\alpha}\end{array}$} & Brassicasterol & $315,25^{\star *}$ & $1027,16^{* *}$ & 191,9 & 0,83 \\
\hline & Camposterol & $4045,37^{* *}$ & $4362,20^{* *}$ & 2190,78 & 0,85 \\
\hline & Stigmasterol & $0,06^{* \star}$ & $0,10^{\star *}$ & 0,05 & 0,80 \\
\hline & Sitosterol & $5176,89^{* *}$ & $261,70^{\star *}$ & 1776,49 & 0,90 \\
\hline & Avenasterol & $56,49^{\star *}$ & $47,99^{* *}$ & 43,6 & 0,80 \\
\hline & Phytosterol gesamt & $24222,47^{\star *}$ & $4279,74^{\star *}$ & 9159,79 & 0,89 \\
\hline \multirow{4}{*}{ 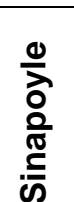 } & Sinapoylglucose & $0,24^{\star *}$ & $0,09^{* *}$ & 0,12 & 0,85 \\
\hline & Sinapin & $0,22^{* \star}$ & $0,06^{* *}$ & 0,18 & 0,79 \\
\hline & andere Sinapinsäureester & $0,04^{* *}$ & $0,02^{* *}$ & 0,03 & 0,82 \\
\hline & Sinapinsäure gesamt & $0,08^{* *}$ & $0,23^{* *}$ & 0,23 & 0,52 \\
\hline
\end{tabular}

${ }^{a} \mathrm{GxO}=$ Interaktion zwischen Genotyp und Ort, $\mathrm{h}^{2}=$ Heritabilität; ** signifikant bei $\mathrm{p}=0,01$ 
Tab. 3-17: Agronomische Merkmale der Testhybriden aus den 4-ortigen Leistungsprüfungen

\begin{tabular}{|c|c|c|c|c|c|c|c|c|c|c|c|c|}
\hline Genotyp & $\begin{array}{l}\text { Ertrag } \\
\text { [dt/ha] }\end{array}$ & $\begin{array}{c}\text { Öl } \\
{[\%]}\end{array}$ & $\begin{array}{c}\text { C22:1 } \\
{[\%]}\end{array}$ & $\begin{array}{c}\text { Protein } \\
{[\%]}\end{array}$ & $\begin{array}{c}\mathrm{GSL} \\
{[\mu \mathrm{mol} / \mathrm{g}]}\end{array}$ & $\begin{array}{c}\text { Phytosterol } \\
\text { gesamt [mg/kg] }\end{array}$ & $\begin{array}{c}\text { Sinapinsäure } \\
\text { gesamt }[\mathrm{mg} / \mathrm{g}]^{\mathrm{a}}\end{array}$ & $\begin{array}{c}\text { TKG } \\
{[g]}\end{array}$ & $\begin{array}{l}\text { Höhe } \\
{[\mathrm{cm}]}\end{array}$ & BB & WF & Lager \\
\hline MxB1/3.3 & 38,6 & 44,1 & 11,7 & 18,7 & 49,7 & 3527,4 & 6,9 & 4,2 & 163,8 & 116,3 & 2,5 & 2,0 \\
\hline MxBOY1 & 31,6 & 42,4 & 16,2 & 19,8 & 55,4 & 3566,8 & 7,3 & 4,7 & 152,5 & 117,0 & 3,5 & 3,0 \\
\hline MxFS94.3 & 41,6 & 43,2 & 3,1 & 18,4 & 34,3 & 3770,8 & 7,7 & 4,3 & 166,3 & 117,3 & 2,5 & 2,0 \\
\hline MxG39 & 37,8 & 42,2 & 11,7 & 20,0 & 51,7 & 3515,0 & 8,0 & 4,4 & 161,3 & 119,3 & 2,5 & 3,7 \\
\hline MxG50 & 41,9 & 43,8 & 1,7 & 18,6 & 38,3 & 3774,7 & 8,0 & 4,3 & 158,8 & 117,0 & 2,0 & 2,3 \\
\hline MxH149 & 45,0 & 45,5 & 24,5 & 17,8 & 44,6 & 3390,5 & 7,0 & 4,3 & 155,0 & 113,0 & 2,0 & 3,0 \\
\hline MxH165 & 37,7 & 44,0 & 13,2 & 19,2 & 37,8 & 3547,9 & 7,3 & 4,1 & 151,3 & 117,7 & 3,3 & 3,0 \\
\hline MxH176 & 47,1 & 45,6 & 16,1 & 18,1 & 27,7 & 3533,6 & 7,6 & 4,5 & 162,5 & 117,0 & 2,5 & 2,0 \\
\hline MxH44 & 41,7 & 45,1 & 24,9 & 19,6 & 32,9 & 3289,0 & 7,0 & 4,6 & 152,5 & 111,0 & 2,3 & 1,7 \\
\hline MxINL2 & 34,4 & 41,5 & 12,8 & 20,4 & 44,8 & 3473,3 & 7,3 & 4,9 & 155,0 & 115,7 & 2,3 & 2,3 \\
\hline MxJ134 & 39,5 & 43,1 & 11,1 & 19,0 & 32,8 & 3413,5 & 6,9 & 4,6 & 147,5 & 112,0 & 2,0 & 2,7 \\
\hline MxJ154 & 33,8 & 42,3 & 17,7 & 19,7 & 53,7 & 3483,5 & 7,0 & 5,2 & 148,8 & 108,3 & 3,0 & 2,3 \\
\hline MxJ161 & 34,4 & 44,2 & 19,3 & 18,2 & 38,2 & 3422,8 & 7,3 & 4,0 & 137,5 & 115,3 & 3,5 & 4,3 \\
\hline MxJ166 & 30,4 & 41,0 & 19,5 & 19,9 & 50,8 & 3423,5 & 7,4 & 4,9 & 145,0 & 114,0 & 3,5 & 4,7 \\
\hline MxJ32 & 38,3 & 43,1 & 10,7 & 18,8 & 35,5 & 3585,7 & 7,5 & 4,6 & 160,0 & 114,0 & 2,5 & 2,3 \\
\hline MxJ401 & 41,5 & 43,4 & 14,2 & 18,3 & 32,1 & 3533,0 & 7,2 & 4,9 & 157,5 & 114,0 & 2,5 & 2,3 \\
\hline MxJ45 & 37,0 & 42,9 & 17,5 & 18,9 & 40,2 & 3520,8 & 6,9 & 4,4 & 147,5 & 112,3 & 3,5 & 3,0 \\
\hline MxK199.16.2 & 36,2 & 43,7 & 19,9 & 19,4 & 43,4 & 3319,6 & 7,4 & 4,1 & 157,5 & 117,3 & 2,5 & 2,3 \\
\hline MxMOL1 & 35,5 & 42,0 & 13,3 & 19,8 & 53,3 & 3501,7 & 7,6 & 4,7 & 162,5 & 117,3 & 2,8 & 2,3 \\
\hline MxMOL2 & 38,8 & 40,4 & 10,7 & 21,0 & 55,9 & 3478,6 & 6,4 & 5,1 & 168,8 & 120,3 & 3,5 & 2,0 \\
\hline MxMOY5 & 18,4 & 41,3 & 16,4 & 20,7 & 55,8 & 3509,9 & 6,7 & 4,5 & 161,3 & 114,3 & 3,0 & 2,7 \\
\hline MxR53 & 39,1 & 45,1 & 21,6 & 19,3 & 35,7 & 3350,1 & 7,6 & 4,5 & 158,8 & 115,7 & 2,3 & 1,7 \\
\hline MxR99 & 38,7 & 43,9 & 7,3 & 18,7 & 30,1 & 3665,0 & 7,2 & 4,4 & 158,8 & 115,0 & 2,3 & 1,7 \\
\hline MxRS13/6 & 37,6 & 44,6 & 19,9 & 18,8 & 42,2 & 3312,3 & 7,0 & 4,7 & 151,3 & 106,7 & 2,8 & 2,7 \\
\hline MxRS4/2 & 38,2 & 43,9 & 19,7 & 19,1 & 39,7 & 3409,1 & 7,3 & 4,2 & 163,8 & 114,3 & 3,0 & 3,7 \\
\hline
\end{tabular}

${ }^{a}$ berechnet als Sinapinsäureäquivalente 
Tab. 3-17: Agronomische Merkmale der Testhybriden aus den 4-ortigen Leistungsprüfungen (Fortsetzung)

\begin{tabular}{|c|c|c|c|c|c|c|c|c|c|c|c|c|}
\hline Genotyp & $\begin{array}{l}\text { Ertrag } \\
\text { [dt/ha] }\end{array}$ & $\begin{array}{c}\text { Öl } \\
{[\%]}\end{array}$ & $\begin{array}{c}\text { C22:1 } \\
{[\%]}\end{array}$ & $\begin{array}{c}\text { Protein } \\
{[\%]}\end{array}$ & $\begin{array}{c}\text { GSL } \\
{[\mu \mathrm{mol} / \mathrm{g}]}\end{array}$ & $\begin{array}{c}\text { Phytosterol } \\
\text { gesamt }[\mathrm{mg} / \mathrm{kg}]\end{array}$ & $\begin{array}{c}\text { Sinapinsäure } \\
\text { gesamt }[\mathrm{mg} / \mathrm{g}]^{\mathrm{a}}\end{array}$ & $\begin{array}{c}\text { TKG } \\
{[g]}\end{array}$ & $\begin{array}{l}\text { Höhe } \\
\text { [cm] }\end{array}$ & BB & WF & Lager \\
\hline MxS108.1.1 & 45,3 & 43,8 & 5,3 & 18,0 & 35,5 & 3706,1 & 7,4 & 4,5 & 156,3 & 108,7 & 2,0 & 1,7 \\
\hline MxS13 & 45,0 & 46,2 & 25,1 & 18,2 & 60,2 & 3393,1 & 7,0 & 4,1 & 152,5 & 115,3 & 2,3 & 2,7 \\
\hline MxS228.8.1 & 37,8 & 44,1 & 15,5 & 18,9 & 39,4 & 3496,4 & 7,1 & 4,3 & 156,3 & 115,0 & 2,0 & 2,3 \\
\hline MxS45.2.2 & 40,7 & 43,8 & 16,1 & 19,5 & 41,3 & 3453,9 & 7,4 & 4,1 & 155,0 & 111,7 & 3,8 & 2,7 \\
\hline MxVIL1 & 40,1 & 42,7 & 12,4 & 19,2 & 40,3 & 3514,8 & 7,4 & 4,9 & 162,5 & 114,0 & 2,5 & 1,3 \\
\hline $\mathrm{RxB} 1 / 3.3$ & 39,6 & 42,9 & 11,2 & 18,9 & 49,4 & 3571,7 & 7,4 & 4,6 & 165,0 & 116,7 & 2,3 & 2,3 \\
\hline RxBOY1 & 38,6 & 41,6 & 16,1 & 19,2 & 52,7 & 3471,6 & 7,4 & 4,8 & 160,0 & 117,7 & 3,3 & 2,7 \\
\hline RxG39 & 38,7 & 41,9 & 7,2 & 19,0 & 42,6 & 3673,0 & 7,6 & 4,6 & 166,3 & 117,3 & 2,3 & 2,3 \\
\hline RxG50 & 35,7 & 43,4 & 1,8 & 17,8 & 35,5 & 3858,9 & 8,1 & 4,3 & 155,0 & 117,0 & 1,8 & 2,0 \\
\hline RxH149 & 42,6 & 43,7 & 23,3 & 18,4 & 46,0 & 3437,5 & 7,2 & 4,6 & 156,3 & 111,3 & 2,3 & 2,7 \\
\hline RxH165 & 39,9 & 43,3 & 12,7 & 19,0 & 34,9 & 3606,6 & 7,4 & 4,1 & 148,8 & 118,0 & 2,5 & 3,0 \\
\hline RxH176 & 42,7 & 43,9 & 12,5 & 18,0 & 27,7 & 3603,8 & 7,6 & 4,8 & 160,0 & 116,3 & 2,8 & 2,3 \\
\hline RxH355 & 36,3 & 42,5 & 16,6 & 19,5 & 46,7 & 3475,4 & 8,3 & 4,9 & 152,5 & 115,7 & 3,0 & 2,7 \\
\hline RxH44 & 42,6 & 45,0 & 21,3 & 18,5 & 29,8 & 3410,5 & 7,4 & 4,7 & 155,0 & 112,0 & 2,8 & 2,3 \\
\hline RxINL1 & 42,7 & 41,5 & 8,7 & 19,0 & 31,4 & 3727,3 & 7,9 & 5,2 & 165,0 & 117,0 & 2,8 & 2,3 \\
\hline RxINL2 & 38,9 & 41,7 & 11,3 & 19,4 & 42,8 & 3517,6 & 7,4 & 4,8 & 155,0 & 114,7 & 1,8 & 2,3 \\
\hline RxJ112 & 38,6 & 42,9 & 15,3 & 18,4 & 36,3 & 3629,8 & 7,8 & 4,6 & 147,5 & 113,7 & 3,0 & 3,3 \\
\hline RxJ134 & 38,4 & 42,5 & 11,0 & 18,3 & 30,2 & 3534,2 & 7,2 & 4,7 & 146,3 & 114,0 & 2,8 & 3,3 \\
\hline RxJ154 & 39,5 & 42,9 & 8,1 & 18,0 & 36,8 & 3839,4 & 7,6 & 4,8 & 147,5 & 108,3 & 2,5 & 2,3 \\
\hline RxJ161 & 37,2 & 42,9 & 11,1 & 17,7 & 25,5 & 3765,4 & 7,7 & 4,4 & 147,5 & 114,7 & 2,0 & 3,0 \\
\hline RxJ166 & 36,1 & 41,7 & 15,8 & 18,6 & 43,5 & 3604,9 & 7,4 & 4,7 & 150,0 & 113,3 & 4,5 & 4,7 \\
\hline RxJ401 & 37,7 & 42,2 & 11,0 & 18,5 & 34,0 & 3600,9 & 7,4 & 5,3 & 157,5 & 115,0 & 2,3 & 3,0 \\
\hline RxJ408 & 36,6 & 42,2 & 22,0 & 18,6 & 42,9 & 3500,8 & 7,8 & 4,4 & 150,0 & 112,7 & 3,8 & 5,0 \\
\hline RxJ410 & 42,9 & 42,3 & 14,5 & 18,5 & 36,1 & 3659,6 & 7,1 & 4,4 & 150,0 & 112,3 & 3,0 & 3,3 \\
\hline RxJ45 & 38,5 & 43,3 & 10,4 & 17,6 & 30,2 & 3764,1 & 7,2 & 4,4 & 152,5 & 116,3 & 3,0 & 3,0 \\
\hline
\end{tabular}

aberechnet als Sinapinsäureäquivalente 
Tab. 3-17: Agronomische Merkmale der Testhybriden aus den 4-ortigen Leistungsprüfungen (Fortsetzung)

\begin{tabular}{|c|c|c|c|c|c|c|c|c|c|c|c|c|}
\hline Genotyp & $\begin{array}{l}\text { Ertrag } \\
\text { [dt/ha] }\end{array}$ & $\begin{array}{c}\text { ÖI } \\
\text { [\%] }\end{array}$ & $\begin{array}{c}\text { C22:1 } \\
{[\%]}\end{array}$ & $\begin{array}{c}\text { Protein } \\
{[\%]}\end{array}$ & $\begin{array}{c}\mathrm{GSL} \\
{[\mu \mathrm{mol} / \mathrm{g}]}\end{array}$ & $\begin{array}{c}\text { Phytosterol } \\
\text { gesamt }[\mathrm{mg} / \mathrm{kg}]\end{array}$ & $\begin{array}{c}\text { Sinapinsäure } \\
\text { gesamt }[\mathrm{mg} / \mathrm{g}]^{\mathrm{a}}\end{array}$ & $\begin{array}{c}\text { TKG } \\
\text { [g] }\end{array}$ & $\begin{array}{l}\text { Höhe } \\
\text { [cm] }\end{array}$ & BB & WF & Lager \\
\hline RxMOY4 & 43,7 & 42,5 & 6,8 & 18,7 & 31,3 & 3872,6 & 6,9 & 4,5 & 157,5 & 116,0 & 2,5 & 2,0 \\
\hline RxOLL1 & 36,9 & 41,5 & 8,2 & 19,6 & 30,1 & 3586,4 & 8,5 & 5,4 & 152,5 & 114,7 & 3,0 & 3,7 \\
\hline RxR53 & 41,7 & 44,1 & 20,5 & 19,0 & 34,0 & 3361,4 & 7,4 & 4,7 & 155,0 & 116,7 & 1,8 & 2,3 \\
\hline RxR99 & 44,1 & 43,2 & 5,2 & 18,2 & 27,3 & 3745,3 & 7,0 & 4,4 & 156,3 & 115,7 & 2,3 & 2,0 \\
\hline RxRS10/7 & 43,7 & 43,7 & 11,4 & 18,4 & 40,9 & 3667,4 & 7,2 & 4,8 & 162,5 & 116,0 & 2,5 & 2,3 \\
\hline RxRS13/6 & 38,9 & 44,0 & 15,6 & 17,9 & 36,8 & 3550,6 & 7,5 & 4,5 & 160,0 & 107,7 & 1,8 & 2,0 \\
\hline RxRS4/2 & 43,6 & 43,5 & 11,5 & 18,4 & 30,8 & 3707,2 & 7,9 & 4,3 & 167,5 & 115,7 & 3,0 & 2,7 \\
\hline RxRS7/6 & 41,5 & 43,3 & 20,5 & 19,4 & 35,4 & 3408,8 & 7,6 & 4,9 & 156,3 & 111,3 & 2,0 & 2,3 \\
\hline RxRS8/6 & 42,0 & 43,2 & 11,7 & 19,1 & 33,0 & 3654,3 & 8,1 & 5,0 & 158,8 & 115,7 & 2,5 & 2,3 \\
\hline RxRUY1 & 38,5 & 43,1 & 5,4 & 18,2 & 28,7 & 3871,9 & 7,2 & 4,6 & 158,8 & 117,3 & 2,8 & 3,0 \\
\hline RxS108.1.1 & 42,3 & 41,9 & 7,6 & 19,0 & 35,5 & 3556,5 & 7,5 & 4,8 & 153,8 & 108,3 & 2,8 & 3,3 \\
\hline RxS13 & 43,4 & 44,5 & 20,2 & 17,5 & 48,3 & 3553,7 & 7,3 & 4,5 & 150,0 & 116,0 & 2,0 & 2,7 \\
\hline RxS39 & 44,5 & 42,0 & 0,9 & 18,0 & 18,7 & 3875,7 & 7,9 & 4,4 & 147,5 & 116,7 & 2,3 & 2,3 \\
\hline RxS45.2.2 & 34,2 & 42,3 & 8,4 & 19,2 & 32,6 & 3705,0 & 7,8 & 4,2 & 153,8 & 113,3 & 2,3 & 2,7 \\
\hline MSL007 & 35,8 & 45,4 & 1,3 & 17,9 & 16,9 & 3929,3 & 7,6 & 4,4 & 142,5 & 117,3 & 1,8 & 1,3 \\
\hline TesterSyngenta & 33,7 & 42,1 & 2,3 & 18,5 & 21,6 & 3792,7 & 6,5 & 4,7 & 150,0 & 121,4 & 2,3 & 3,0 \\
\hline Visby & 49,2 & 43,6 & 0,0 & 17,0 & 15,0 & 4078,1 & 7,9 & 4,8 & 157,5 & 117,0 & 2,0 & 1,7 \\
\hline $\operatorname{LSD}(p=0,05)$ & 6,3 & 1,2 & 4,9 & 1,0 & 6,5 & 154,6 & 0,8 & 0,3 & 10,8 & 3,6 & 1,5 & 1,6 \\
\hline Min. & 18,4 & 40,4 & 0,0 & 17,0 & 15,0 & 3289,0 & 6,4 & 4,0 & 137,5 & 106,7 & 1,8 & 1,3 \\
\hline Max. & 49,2 & 46,2 & 25,1 & 21,0 & 60,2 & 4078,1 & 8,5 & 5,4 & 168,8 & 121,4 & 4,5 & 5,0 \\
\hline MW Testhybriden & 39,2 & 43,1 & 13,5 & 18,8 & 38,9 & 3566,4 & 7,4 & 4,6 & 155,7 & 114,6 & 2,6 & 2,7 \\
\hline MW Standards & 39,6 & 43,7 & 1,2 & 17,8 & 17,8 & 3933,4 & 7,3 & 4,6 & 150,0 & 118,6 & 2,0 & 2,0 \\
\hline
\end{tabular}

aberechnet als Sinapinsäureäquivalente 
Neben den beschriebenen Variationen beim Ertragsniveau und beim Ölgehalt zeigen sich auch bei anderen Merkmalen große Variationsbreiten (Tab. 3-17).

Der Erucasäuregehalt (C 22:1) reicht bei den Testhybriden von 1,7\% (,MSL 007 x G 50‘) bis 25,1\% (,MSL 007 x S 13‘) und erreicht im Mittel 13,5\%. Die Standards weisen einen mittleren Anteil von 1,2\% Erucasäure auf und sind damit praktisch erucasäurefrei. Beim Proteingehalt liegt der Gehalt der Testhybriden mit im Mittel 18,8\% leicht höher als der der Standards (17,8\%). Die beobachtete Spanne reicht bei den Hybriden von 17,5\% (,RNX $4621 \times \mathrm{S} 13)$ bis $21 \%$ (,MSL $007 \times$ MOL 2'). Bei den Glucosinolaten ist die Variation zwischen den Genotypen besonders hoch. Sie reicht von $15 \mu \mathrm{mol} / \mathrm{g}$ für den Standard ,Visby“ bis $60,2 \mu \mathrm{mol} / \mathrm{g}$ für die Kreuzung ,MSL 007 x S 13‘. Der Mittelwert der Standards liegt bei $17,8 \mu \mathrm{mol} / \mathrm{g}$, der der Testhybriden im Mittel bei 38,9 $\mu \mathrm{mol} / \mathrm{g}$. Auch für den Phytosterolgehalt kann eine große Spannbreite festgestellt werden. Die Spanne reicht hier von $3289 \mathrm{mg} / \mathrm{kg}$ (,MSL $007 \times$ H44') bis $4078 \mathrm{mg} / \mathrm{kg}$ (,Visby'). Die höchsten Werte werden von den Standards erreicht. Der mittlere Phytosterolgehalt der Standards liegt mit $3933 \mathrm{mg} / \mathrm{kg}$ deutlich höher als der der Testhybriden (3566 mg/kg). Beim Sinapinsäuregehalt unterscheiden sich die Mittelwerte für Standards und Hybriden nicht signifikant, es gibt aber Variationen zwischen den Genotypen. Diese reichen von $6,4 \mathrm{mg} / \mathrm{g}$ bis $8,5 \mathrm{mg} / \mathrm{g}$. Den geringsten Gehalt weist ,MSL 007 x MOL 2‘ auf, den höchsten ,RNX 4621 x OLL 1‘.

Für das Merkmal Winterfestigkeit zeigen die meisten Testhybriden niedrige Werte und weisen somit eine relativ gute Winterfestigkeit auf. Der Mittelwert liegt hier bei 2,6. Der Mittelwert der Standards liegt bei 2,6 und unterscheidet sich damit nicht signifikant von dem der Testhybriden. Die höchsten Werte und damit die schlechteste Winterfestigkeit wurden für die Testhybriden ,RNX 4621 x J 161' mit 4,5 sowie ,MSL 007 x S 45.2.2‘ und ,RNX 4621 x J 408‘ mit jeweils 3,8 ermittelt.

Für das Merkmal Lager lassen sich im Mittel ebenfalls keine signifikanten Unterschiede zwischen den Testhybriden und den Standards beobachten. Einzelne Genotypen weisen jedoch hohe Neigung zum Lagern auf, wie z.B. der Genotyp ,RNX 4621 x J 104‘, der einen mittleren Boniturwert von 5 erreicht, oder die ,RNX'- und ,MSL'-Hybriden mit ,J 166', die beide mittlere Boniturwerte für das Merkmal Lager von 4,7 aufweisen. 


\section{Diskussion}

\subsection{Markeranalysen}

Bei den AFLP-Analysen konnten durch Nutzung von drei Primerkombinationen insgesamt 471 polymorphe Marker für die untersuchten Rapsgenotypen identifiziert werden. Diese Zahl erscheint im Vergleich zu anderen AFLP-Studien in Brassica napus sehr hoch. So konnten z.B. Yu et al. (2007) in ihrer Arbeit zur genetischen Diversität in gelbsamigem Raps unter Nutzung von 18 Primerkombinationen nur 242 polymorphe Marker generieren. Auch LOMBARD et al. (2000) benötigten 17 Primerkombinationen um 324 polymorphe Fragmente zu erhalten. Die deutlich höhere Anzahl Polymorphismen, die in der vorliegenden Arbeit gefunden werden konnten, lässt sich aber leicht erklären. Während Yu et al. (2007) und LOMBARD et al. (2000) ausschließlich Kulturformen vom Raps untersuchten, die insgesamt eine sehr enge genetische Basis aufweisen, wurden in der vorliegenden Studie neben 55 Brassica napus Zuchtformen auch 71 resynthetisierte Genotypen analysiert. Diese Resynthesen zeigen im Vergleich zum Zuchtmaterial eine deutlich größere genetische Variation ( $\mathrm{vgl}$. BECKER et al. 1995; GIRKE 2000). Auch SEYIS et al. (2003) erzielten daher in ihrer Untersuchung zur genetischen Diversität von resynthetisiertem Raps im Vergleich mit Sommerrapssorten eine vergleichbar hohe Anzahl von 467 polymorphen Banden unter Nutzung von drei Primerkombinationen.

Die angesprochene Enge der genetischen Basis im Rapszuchtmaterial konnte im Rahmen dieser Untersuchung bestätigt werden. Die genetische Distanz über das gesamte analysierte Zuchtmaterial lag im Mittel bei 0,35. Vergleichbare Distanzwerte wurden auch in den RFLP-Analysen von DIERS \& OSBORN (1993) und GIRKE (2000) sowie den Untersuchungen mittels SSR-Markern von HASAN et al. (2006) gefunden. Die engen Verwandtschaftsbeziehungen im Zuchtmaterial sind darauf zurückzuführen, dass Raps entwicklungsgeschichtlich eine relativ junge Art ist und in der Pflanzenzüchtung erst seit wenigen Jahrzehnten eine größere Bedeutung hat (BECKER et al. 1995). Ihre Entstehung geht, wie bereits METZGER (1833) erkannte, auf die spontane Hybridisierung von Rübsen (Brassica rapa) und Kohl (Brassica oleracea) zurück. Auch wenn angenommen werden muss, dass Brassica napus polyphyletischen Ursprungs ist (SONG \& OSBORN 1992; ALLENDER \& KING 2010), so ist doch davon auszugehen, dass das derzeitige 
Zuchtmaterial ursprünglich auf einigen wenigen interspezifischen Hybridpflanzen basiert (BECKER et al. 1995). Zu einer weiteren Einengung des Genpools kam es durch die Fokussierung der Züchtung auf spezielle Qualitätsmerkmale (SEYIS et al. 2003; HASAN et al. 2006).

Die Hauptkoordinatenanalyse und die Clusteranalyse erlaubten eine Einteilung des Zuchtmaterials in die drei klar abgrenzbaren Formenkreise Winter-, Sommerund chinesischer Raps. Die gefundenen Gruppierungen wurden so bereits in einer Reihe von Studien zur genetischen Diversität im Rapsmaterial unter Nutzung verschiedener Markertypen nachgewiesen und auch die in den Dendrogrammen dargestellte Abtrennung der Cluster voneinander erfolgt bei vergleichbaren Distanzwerten (vgl. Diers \& OsBORN 1994; BECKER et al. 1995; LOMBARD et al. 2000, Plieske \& Struss 2001; Girke 2002; HASAN et al. 2006). Die mittleren genetischen Distanzen innerhalb der drei Cluster stimmen ebenfalls relativ gut mit den in der Literatur veröffentlichten Werten überein. Im Vergleich mit GIRKE (2002), der in seiner Arbeit ein ähnlich umfangreiches Sortiment mit RFLPMarkern untersucht hat, liegen die beobachteten Werte im Allgemeinen etwas höher. So lag die mittlere genetische Distanz im Winterrapsmaterial in der vorliegenden Arbeit bei 0,29, innerhalb des Sommerrapses bei 0,28 und im chinesischen Material bei 0,37 . GIRKE (2002) beobachtete für die entsprechenden Formenkreise mittlere genetische Distanzen von 0,21, 0,23 bzw. 0,28. Zu berücksichtigen ist aber, dass die genetischen Distanzen für die RFLP-Analysen nach DICE (1945) und die in den AFLP-Analysen dieser Studie mit dem JaccardKoeffizienten (JACCARD 1908) geschätzt wurden, entsprechend den Empfehlungen für kodominante Marker bzw. dominante Marker (LINK et al. 1995).

Das untersuchte resynthetisierte Material wies eine große genetische Distanz zum Zuchtmaterial auf. Dies entspricht den Ergebnissen anderer Diversitätstudien unter Einbeziehung von Resynthesen (vgl. SONG \& OSBORN 1992; BECKER et al. 1995; Voss et al. 1998; GIRKE 2002). Während sich in den Untersuchungen von SONG \& Osborn (1992), Diers \& Osborn (1996); Voss et al. (1998) sowie SeYIS et al. (2003) nur wenige resynthetisierte Rapsformen finden, verglichen BECKER et al. (1995) in ihrer RFLP-Studie 17 Resynthesen mit 24 Kulturformen und konnten dabei eine mittlere genetische Distanz der Resynthesen zum Zuchtmaterial von 0,35 feststellen. Einen fast identischen Wert $(0,36)$ ermittelte GIRKE (2002) in seinen umfangreichen RFLP-Analysen, bei denen insgesamt 142 Resynthesen 
und 57 Kulturformen untersucht wurden. Die mittlere genetische Distanz der Resynthesen zum Zuchtmaterial lag in der vorliegenden Studie bei 0,58 und damit bedeutend höher als in den Untersuchungen von BECKER et al. (1995) und GIRKE (2002). Dies ist durch die Zusammensetzung des untersuchten Resynthesematerials zu erklären, welches einerseits aus 27 klassischen Resynthesen (Resynthesen, die mit Brassica oleracea-Kulturformen erstellt wurden) sowie 44 Wild-Resynthesen (Resynthesen, die mit Wildformen von Brassica oleracea oder anderen Brassica-Wildarten erstellt wurden) bestand. Bei der Auswahl der klassischen Resynthesen wurden neben neun Resynthesen aus der Justus-Liebig-Universität Gießen zudem vor allem solche ausgewählt, die in der Arbeit von GIRKE (2002) besonders hohe genetische Distanzen aufwiesen.

Betrachtet man nur die klassischen Resynthesen, so liegt ihre genetische Distanz zum Zuchtmaterial mit 0,52 niedriger als die des gesamten Resynthesematerials. Interessant ist auch, dass die mittlere genetische Distanz der klassischen Resynthesen zu den chinesischen Rapsformen mit 0,45 kleiner ist als zu den Winterrapssorten $(0,50)$ und den Sommerrapssorten $(0,53)$ und einen fast identischen Wert erbringt wie die mittlere genetische Distanz zwischen chinesischem Raps und Sommerraps $(0,46)$. Ein Grund hierfür ist möglicherweise, dass die meisten chinesischen Rapssorten zwar auf europäisches Material zurückgehen (BECKER et al. 1999, Hu et al. 2007), im Laufe ihrer züchterischen Bearbeitung aber wiederholt asiatische Brassica rapa-Gemüse und -Ölformen eingekreuzt wurden (SERNYNK 1999, QIAN et al 2006; Hu et al. 2007) und der größte Teil der klassischen Resynthesen in dieser Studie auf Kreuzungen von asiatischen Brassica rapa-Gemüseformen (spp. chinensis und ssp. pekinensis) zurückgeht.

Eindeutige größere Cluster lassen sich für die klassischen Resynthesen im Dendrogramm nicht finden und auch in der Hauptkoordinatenanalyse zeigen sie keine eindeutige Gruppierung, sondern streuen fast über den gesamten Bereich. Auch dies entspricht den Beobachtungen von GIRKE (2002). Dennoch sind im Dendrogramm zwei Gruppierungen zu beobachten, die fast ausschließlich klassische Resynthesen enthalten (Gruppierung ,RS a' und ,RS b', Abb. 3.3). Ausgehend von der großen Formenvielfalt der Eltern, die zur Erstellung der klassischen Resynthesen verwendet wurde, weisen die Resynthesen nicht nur zu 
den anderen Materialgruppen eine sehr große genetische Distanzen auf, sondern auch untereinander (mittlere $\mathrm{GD}=0,55$ ).

Drei der klassischen Resynthesen (,B 1/3.3', ,S 108.1.1' und ,S 13') zeigen eine auffällig geringe genetische Distanz zum Winterrapsmaterial und clustern im Dendrogramm sogar mit diesem zusammen. Dies bestätigt für den Genotyp ,S 13، die Ergebnisse aus den Analysen von BECKER et al. (1999) und GIRKE (2002), in denen diese Resynthese ebenfalls untersucht wurde. Eine mögliche Ursache für diese Ähnlichkeit zum Winterraps könnten Einkreuzungen bei der Vermehrung dieser Resynthesen im Feld sein, insbesondere, wenn die Resynthesen selber stark selbstinkompatibel sind (GIRKE 2002).

Die untersuchten Wild-Resynthesen stellen ein besonderes und in dieser Form bisher einmaliges Materialset dar. Sie zeigen die größten mittleren genetischen Distanzen zu allen untersuchten Materialgruppen (jeweils $>0,60$ ) und weisen auch untereinander eine sehr hohe genetische Variabilität auf (mittlere $G D=0,58$ ). Insgesamt konnten fünf Wild-Resynthesecluster gefunden werden, von denen die beiden, die dem Zuchtmaterial am nächsten stehen (Cluster ,WT a' und ,WT b', Trennung bei GD von 0,57) ausschließlich Resynthesen mit Brassica oleraceaWildformen enthalten. In den anderen drei Clustern sind hingegen mit Ausnahme zweier auf Brassica oleracea-Wildformen zurückgehender Resynthesen und fünf klassischer Resynthesen nur die Resynthesen mit anderen Brassica-Wildarten zu finden. Dabei lassen sich interessante Gruppierungen beobachten. So enthält das Cluster ,WS a' Wild-Resynthesen die mit dem Winterrübsen ,Largo' erstellt wurden, sowie zwei klassische Resynthesen, die ebenfalls auf Winterrübsenkreuzungen zurückgehen. Ein weiteres Cluster, das drei WildResynthesen mit der Rübsensorte ,Largo' enthält, ist das Cluster ,WS c'. Diese Genotypen haben ihr C-Genom jeweils von einer Brassica montana-Akzession erhalten. Sie weisen im Dendrogramm die größte Entfernung zu allen anderen Genotypen auf und trennen sich von diesen bei einer genetischen Distanz von $\sim 0,65$. Das größte Cluster ,WS b' enthält mit Ausnahme der klassischen Resynthese ,RS 4/6 und der Wild-Resynthese ,HIL $1^{\text {' }}$ ausschließlich WildResynthesen, die auf Kreuzungen mit der Rübsenform ,Yellow Sarson' (Brassica rapa ssp. trilocularis) zurückgehen. Auch die beiden in dem Cluster enthaltenen klassischen Resynthesen ,RS 10/7 und ,RS 239' entstammen Kreuzungen mit ,Yellow Sarson'. Eine mögliche Erklärung hierfür könnte sein, dass die 
Rübsenunterart ,trilocularis' eine Sonderstellung einnimmt und möglicherweise eine, zu anderen Rübsenformen divergente Entwicklung aufweist (SEYIS et al. 2001; vgl. u.a. SONG et al. 1990; McGRATH \& QUIROS 1992; DuHOON \& KOPAR 1998).

Eine eindeutige Clusterung der Wildresynthesen entsprechend ihrer C-GenomHerkünfte ist in den meisten Fällen nicht zu beobachten. Ausnahmen bilden hier zwei kleine Gruppen, die innerhalb des Clusters ,WS b' eigene Subcluster bilden. Dies sind auf der eine Seite drei Wild-Resynthesen (,HIY 1', ,HIY 2' und ,HIL 1') die auf Kreuzungen mit Brassica hilarionis zurückgehen, und auf der anderen Seite vier Wild-Resynthesen deren C-Genom aus Brassica incana-Akzessionen stammt (,INY $1^{\prime}$, ,INY $3^{\prime}$, ,INY $4^{\prime}$ und , INY $\left.5^{\prime}\right)$, von denen bekannt ist, dass sie allesamt ursprünglich aus Sizilien stammen.

Das Wild-Resynthesematerial spiegelt insgesamt die breite genetische Variation der Brassica-Wildarten aus der Brassica oleracea-Verwandtschaft wieder, welche z.B. in den Diversitätsstudien von LANNÉR et al. (1997), LÁZARO \& AGUINAGALDE (1998) und MEl et al. (2010) aufgezeigt werden konnte.

\subsection{Charakterisierung der Brassica-Wildarten}

Die untersuchten Brassica-Wildarten wiesen eine extrem hohe Variabilität sowohl in ihren Glucosinolatmustern als auch im Gesamtglucosinolatgehalt ihrer Blätter auf. Teilweise zeigten die Glucosinolatmuster innerhalb der untersuchten Arten gute Übereinstimmungen zwischen den einzelnen Akzessionen, Beispiele hierfür sind z.B. Brassica cretica und Brassica insularis (mit Ausnahme der Akzession (AZ) 1952). Bei anderen Arten zeigten sich hingegen auch innerhalb der Akzessionen einer Art große Unterschiede (z.B. Brassica incana). Diese Ergebnisse stimmen gut mit den Ergebnissen von MITHEN et al. (1987) überein, die in ihrer Studie ebenfalls große Unterschiede im Blattglucosinolatgehalt und muster der verschiedenen Brassica-Arten sowohl zwischen den Arten als auch innerhalb der Arten nachweisen konnten. Gute Übereinstimmungen gibt es auch zwischen den in der vorliegenden Studie gefundenen Glucosinolatmustern und den bei MiTHEN et al (1987) beschriebenen. So beobachten MITHEN et al (1987) für Brassica insularis zwei Mustertypen und begründen dies mit der unterschiedlichen geographischen Herkunft der Pflanzen. Pflanzen die von Sardinien (Italien) 
stammten, wiesen als Hauptglucosinolat Progoitrin auf und enthielten außerdem größere Anteile Gluconapin. Solche die aus Tunesien stammten enthielten fast ausschließlich Sinigrin. Das gleiche Phänomen zeigte sich in den vorliegenden Ergebnissen. Während die untersuchten Akzessionen sardischer und korsischer Herkunft vor allem die Glucosinolate Progoitrin und Gluconapin enthielten unterschied sich die AZ 1952 komplett von den übrigen Brassica insularisAkzessionen. Sie enthielt zu 97\% Sinigrin. Laut ECPGR Brassica Database (MeNTING \& BAS 2010) stammt diese Akzession aus der Türkei, wo die Art jedoch nicht einheimisch ist (vgl. LANNÉR et al. 1997). Vermutlich stammt diese Akzession daher ursprünglich aus Tunesien. Auch bei den anderen Arten lassen sich Unterschiede im Glucosinolatmuster ausmachen, die möglicherweise auf ihre geographische Herkunft zurückzuführen sind. So ähneln sich z.B. die drei Brassica oleracea-Akzessionen 6824, 7681 (beide aus Frankreich) und 7694 (Groß Britannien) in ihren Mustern, während die AZ 7660 aus Spanien ein deutlich abweichendes Muster aufweist. Sehr interessant sind auch die drei untersuchten Brassica villosa-Akzessionen. Sie weisen extrem unterschiedliche Glucosinolatmuster auf. Dies ist erstaunlich, da Brassica villosa endemisch auf Sizilien vorkommt (LANNÉR et al. 1997, GLADIS \& HAMmeR 2003). Da Wildkohlpopulationen teilweise stark isoliert voneinander wachsen (HORN \& VAUGHAN, 1983), könnte es sein, dass die untersuchten Pflanzen aus sehr isolierten Vorkommen (z.B. kleine und kleinste Inseln) stammen. Weitere Gründe könnten Einkreuzungen durch andere Brassica-Arten sein, da auf Sizilien noch weitere Brassica-Arten wild vorkommen und vermutlich auch Kulturformen angebaut werden. Außerdem bestünde ferner die Möglichkeit einer Vertauschung der Akzessionen bzw. der falschen Artbestimmung einer Akzession. Dies wäre z.B. für die Brassica villosa AZ 6581 und die Brassica rupestris AZ 6580, die annähernd identische Muster aufweisen, in Betracht zu ziehen.

Die beobachteten Variationen im Gesamtglucosinolatgehalt waren sehr groß. Während die Werte bei einigen Arten zwischen den Akzessionen vergleichbar hohe Werte aufwiesen (z.B. Brassica cretica $\sim 50 \mu \mathrm{mol} / \mathrm{g}$ TM bis $\sim 70 \mu \mathrm{mol}$, Brassica oleracea $\sim 30 \mu \mathrm{mol} / \mathrm{g}$ TM bis $\sim 40 \mu \mathrm{mol} / \mathrm{g} \mathrm{TM}$ ), gab es bei den Akzessionen anderer Arten große Unterschiede. Die größte Spanne war zwischen den Brassica montana-Akzessionen zu beobachten. Sie reichte von $\sim 10 \mu \mathrm{mol} / \mathrm{g}$ TM bis $\sim 120 \mu \mathrm{mol} / \mathrm{g}$ TM und deckt damit die gesamte beobachtete 
Variation im Blattglucosinolatgehalt ab. Ähnlich hohe Variationen finden sich auch für die von MITHEN et al (1987) untersuchten Wild-Arten. Die angegebenen Werte reichen von $\sim 2 \mu \mathrm{mol} / \mathrm{g}$ bis $\sim 12 \mu \mathrm{mol} / \mathrm{g}$. Sie beziehen sich allerdings auf die Frischmasse (FM), so dass in der Trockenmasse (TM) vergleichbar hohe Werte wie in den dargestellten Ergebnissen dieser Studie zu erwarten sind.

Von VELASCO \& BECKER (2000) wurden Samenglucosinolate auch bei drei in dieser Arbeit untersuchten Akzessionen (AZ BRA 1166, AZ BRA 1644 (= K 5457) und AZ 3821) analysiert. Dabei zeigte sich, dass sich die Blatt- und Samenglucosinolatmuster deutlich unterscheiden. Während die Samen der Brassica incana-AZ BRA 1166 67\% Sinigrin und 15\% Glucoiberin (VELASCO \& BECKER 2000) enthielten, wiesen die Blätter der gleichen Akzession als Hauptglucosinolat Glucobrassicanapin (48\%) auf. Daneben waren 25\% Progoitrin und 17\% Sinigrin vorhanden. Bei der Brassica montana-AZ BRA 1644 war das Hauptsamenglucosinolat mit 53\% ebenfalls Sinigrin, daneben kamen vor allem Glucoiberin und Progoitrin vor, wohingegen die Blätter als Hauptglucosinolate Glucobrassicin (30\%) und Glucoiberin (28\%) enthielten. Daneben waren außerdem Sinigrin (18\%) und Gluconasturtiin (13\%) zu beobachten. Bei der AZ 3821 (Brassica villosa ssp. bivoniana) wiesen VeLASCO \& BECKER (2000) im Samen 95\% Glucoibervirin und 3\% Glucoiberin nach, welches in den Blättern der Akzession gar nicht gefunden wurde. Stattdessen wurde hier 63\% 4-Methoxyglucobrassicin und 34\% Glucoiberin festgestellt. MITHEN et al. (1987) findet für die Blattprobe der gleichen Akzession (unter dem Namen B. drepanensis inzwischen in B. villosa umbenannt) hingegen $75 \%$ Glucoibeverin und 25\% Glucoiberin. Dies würde im Vergleich zu anderen Beobachtungen für die AZ 3821 eine erstaunlich gute Übereinstimmung von Samen- und Blattglugosinolatmuster bedeuten und lässt vermuten, dass es sich bei den 63\% 4-Methoxyglucobrassicin eigentlich um $63 \%$ Glucoibeverin handelt und somit an dieser Stelle vermutlich ein Zuordnungsfehler bei der Auswertung der HPLC-Chromatogramme aufgetreten ist. Dass die Glucosinolatmuster in verschiedenen Pflanzenteilen unabhängig voneinander variieren, wurde unter anderem bei ROSA et al (1997) und VELASCO et al (2007) beschrieben. Auch CLEeMPUt \& BECKER (2011) konnten derartige Unterschiede zwischen Blatt- uns Samenglucosinolatmustern feststellen.

Die in der vorliegenden Studie beobachteten Gesamtblattglucosinolatgehalte der Wildkohl-Akzessionen erscheinen im Vergleich mit der Studie von CLEEMPUT \& 
BECKER (2011), die an resynthetisiertem Raps durchgeführt wurde, sehr hoch, korrespondieren aber mit den bei MITHEN et al. (1987) beschriebenen Werten. Während CLEEMPUT \& BECKER (2011) Maximalwerte von 4,75 $\mu \mathrm{mol} / \mathrm{g}$ TM finden, liegen diese in der Studie von MitHEN et al. (1987) bei den Wildarten bei bis zu $12,26 \mu \mathrm{mol} / \mathrm{g} \mathrm{FM}$ und in den vorliegenden Untersuchungen bei bis zu $118 \mu \mathrm{mol} / \mathrm{g}$ TM. MitHEN et al. (1987) beschreibt aber auch, dass die Blattglucosinolatgehalte der meisten kultivierten Brassica-Formen deutlich unter denen der Wildarten liegen. So weisen die in der Arbeit von MiTHEN et al. (1987) untersuchten Brassica oleracea-Kulturformen, mit Ausnahme der Sorte ,J. King ( $8 \mu \mathrm{mol} / \mathrm{g} \mathrm{FM}$ ), Gehalte zwischen 0,47 $\mu \mathrm{mol} / \mathrm{g} \mathrm{FM}$ und 1,65 $\mu \mathrm{mol} / \mathrm{g}$ FM auf. Bei den untersuchten Brassica rapa-Formen werden für Wildformen zwischen $4,15 \mu \mathrm{mol} / \mathrm{g} \mathrm{FM}$ und 10,15 $\mu \mathrm{mol} / \mathrm{g}$ FM gefunden. Auch in diesem Fall liegen die Werte der Kulturformen mit einer Spanne von $0,07 \mu \mathrm{mol} / \mathrm{g} \mathrm{FM}$ bis 2,90 $\mu \mathrm{mol} / \mathrm{g} \mathrm{FM}$ deutlich niedriger als die der Wildformen. Hier könnte eine Erklärung für die niedrigen, von CLEEMPUT \& BECKER (2011) ermittelten Werte liegen, da alle in der Studie untersuchten Resynthesen auf Kreuzungen von Rübsen- und Kohlkulturformen zurückgehen. Ein weiterer Grund ist möglicherweise die Anzucht des verwendeten Probematerials. Während dies für die vorliegende Studie sowie für die Studie von MıTHEN et al. (1987) im Gewächshaus geschah, wurden die Proben für die Analysen von CLEEMPUT \& BECKER (2011) im Feld genommen. Zumindest für Samenglucosinolatgehalte wird berichtet, das diese bei Gewächshausanzucht der Pflanzen höher ausfallen, als im Feld (BAHRANı \& MCVETTY 2008).

Ein weiterer Aspekt sind die Interaktionen zwischen Glucosinolatgehalt und der Umwelt. So wiesen CARTEA et al. (2008) in ihrem zweiortigen Versuch mit 36 Brassica napus var. pabularia-Genotypen extreme Unterschiede im Blattglucosinolatgehalt der einzelnen Genotypen über die beiden Orte nach. Im Extremfall lag der Unterschied zwischen den beiden Orten für einen Genotyp bei fast $40 \mu \mathrm{mol} / \mathrm{g} \mathrm{TM}$, in vielen anderen Fällen bei gut $20 \mu \mathrm{mol} / \mathrm{g}$ TM.

Außerdem kann auch die Probenahme an sich zu Unterschieden im Glucosinolatgehalt führen. Die Proben für die vorliegende Studie konnten im Gewächshaus/Labor genommen werden und direkt nach der Probenahme in flüssigem Stickstoff tiefgefroren und später gefriergetrocknet werden, wodurch der bei Verletzung der Blätter einsetzen Abbau der Glucosinolate durch das Enzym 
Myrosinase schnell und wirkungsvoll unterbunden wird. Die Proben von CLEEMPUT \& BECKER (2011) hingegen mussten im Feld genommen werden. Sie wurden anschließend für die Dauer der Probenahme und des Transportes gekühlt und danach bei $60^{\circ} \mathrm{C}$ im Trockenschrank getrocknet. Bei dieser Methode muss mit einem Glucosinolatverlust um die 40\% gerechnet werden (STEPHANI 1985).

Neben den sehr großen Unterschieden in den Blattglucosinolatgehalten, fand sich in den Einzelkorn-GC-Analysen der Wild-Arten auch eine sehr große Variation in den Fettsäuremustern, sowohl innerhalb der Arten als auch zwischen den Arten.

So konnte unter anderem beobachtet werden, dass Brassica villosa- und Brassica rupestris-Akzessionen tendenziell die höchsten Erucasäuregehalte und die geringsten Palmitinsäuregehalte im Vergleich mit den anderen untersuchten Arten aufwiesen. Bei diesen beiden Arten dominierte außerdem häufig der Linol- und Linolensäuregehalt über den Ölsäuregehalt. Da diese Beobachtungen anhand der Untersuchungen von einzelnen Samen gemacht wurden, ist ihre Aussagekraft begrenzt. Hier müssten weitere Analysen mit mehr Samenmaterial folgen. Die erzielten Ergebnisse passen aber zu denen von VELASCO et al. (1998).

\subsection{Agronomische Eigenschaften der Resynthesen}

Die meisten Resynthesen, insbesondere die Wild-Resynthesen erwiesen sich als schwierig handhabbar. Zu Beginn des Projektes gab es von vielen der Resynthesen kein oder nur wenig Saatgut. Die Pflanzen, die über Embryo-Rescue aus Kreuzungen von Rübsen und verschiedenen Brassica-Wildarten erstellt wurden, waren zum Teil schwer vermehrbar. Viele zeigten eine hochgradige Selbstinkompatibilität, so dass sie in Handarbeit knospenbestäubt werden mussten, um die Selbstinkompatibilität zu brechen. Selbstinkompatibilität ist bei resynthetisiertem Raps, anders als beim auf Selbstfertilität selektiertem Rapszuchtmaterial, ein häufig zu beobachtendes Problem (vgl. AHMADI 1988), da seine Ausgangsformen in der Regel ebenfalls selbstinkompatibel sind. Eine Ausnahme hiervon bildet der Rübsentyp ,Yellow Sarson'. Ein weiteres Problem war, dass viele der Resynthesen noch amphihaploid waren und auf die Colchizinbehandlung zur Aufdoppelung ihrer Chromosomensätze nur bedingt ansprachen, so dass die Behandlung mehrfach wiederholt werden musste. In 
vielen Fällen konnte dabei die Bildung von Chimären-Pflanzen beobachtet werden, bei denen die Colchizinierung nur partiellen Erfolg zeigte.

Im Beobachtungsanbau der Resynthesen offenbarten sich weitere Probleme. Viele der geprüften Genotypen zeigten erwartungsgemäß eine nur unzureichende Winterhärte, da sie sowohl von der A-Genomseite als auch von der C-Genomseite auf Sommertypen zurückgehen. Besonders betroffen waren davon die mit dem Sommerrübsen ,Yellow Sarson' erstellten Formen. Wild-Resynthesen, die hingegen mit dem Winterrübsen ,Largo' erstellt wurden, zeigten eine deutlich bessere Winterfestigkeit, obwohl die auf der C-Genomseite verwendeten Wildkohlarten aufgrund ihrer meist mediterranen Herkunft (vgl. LANNÉR et al. 1997, GLADIS \& HAMMER 2003) keine oder eine nur sehr geringe Winterfestigkeit aufwiesen. Einige der Resynthesen neigten zudem zu erhöhter Krankheitsanfälligkeit (vgl. GIRKE 2002), insbesondere gegen Phoma lingua.

Die Anzahl der Genotypen im Beobachtungsanbau der Resynthesen schrumpfte aufgrund der hohen Auswinterungsverluste, die durch den kalten und langen Winter 2009/2010 noch verschärft wurden, an den in Deutschland gelegenen Versuchsstandorten stark zusammen. Lediglich an dem Standort Impington in Großbritannien überlebten alle dort angebauten Genotypen.

Die Ergebnisse der untersuchten agronomischen Merkmale, insbesondere aber die Ergebnisse der Samenglucosinolatanalysen der Resynthesen vom Standort Impington (GB) unterstreichen die extreme phänotypische Variationsbreite des untersuchten Resynthesematerials. Diese spiegelt sich ebenfalls in Form der genotypischen Variation in den Markeranalysen wieder.

Die Ergebnisse der Einzelkorn-GC, die an Gewächshausmaterial durchgeführt wurde, weisen starke Unterschiede zwischen den einzelnen Genotypen nach. Der Erucasäuregehalt liegt z.B. zwischen $\sim 1 \%$ und $\sim 62 \%$. Eine hohe Variationsbreite der Fettsäuremuster der Resynthesen konnte auch bei den GC-Analysen für den Standort Impington (GB) sowie den NIRS-Analysen der übrigen Standorte beobachtet werden. Die Werte für den Erucasäuregehalt liegen hier insgesamt niedriger. Dabei ist aber zu berücksichtigen, dass diese Untersuchungen an Samenmaterial von offen abgeblühten Pflanzen durchgeführt wurden und die Fettsäuremuster der Samen nicht nur maternal bedingt sind, sondern auch durch den Genotyp des bestäubenden Pollens beeinflusst werden (HOM 2004). Alternativ hätte eine Isolation der Blütenstände mittels Crispack-Tüten durchgeführt werden 
können, um die Pflanzen zu selbsten. Dies hätte aufgrund der teilweise hohen Selbstinkompatibilität der Resynthesen den Samenansatz stark verringert. Außerdem ist bei der Selbstung unter Crispack-Tüten ein negativer Effekt auf den Ölgehalt der Samen sowie auf die Gesundheit der unter den Tüten befindlichen Pflanzenteile zu beobachten.

Im Gegensatz zu den Resynthesen, weisen die Standards (angepasste Winterrapssorten) ziemlich einheitliche Fettsäuremuster auf. Ihr Ölgehalt liegt in der Regel jedoch signifikant höher, als der der Resynthesen. Diese Beobachtung deckt sich mit den Ergebnissen von GIRKE (2002) und ENGQVIST \& BECKER (1994). Beim Glucosinolatgehalt weisen die Resynthesen sehr viel höhere Werte als die Standards auf. Dies liegt vor allem an den in der Regel hohen Glucosinolatgehalten ihrer Elternarten (vgl. GLAND 1982; VELASCO \& BECKER 2000), wohingegen das heutige angepasste Zuchtmaterial durch Einkreuzung der alten glucosinolatarmen polnischen Sommerrapssorte "Bronowski ${ }^{i}$ und anschließende konsequente Selektion sehr niedrige Glucosinolatgehalte aufweist (RÖBbELEN \& RAKOW 1979). Die Glucosinolatmuster unterscheiden sich ebenfalls grundlegend von den denen der Standardsorten, die aufgrund der Selektion auf niedrige Glucosinolatgehalte einen deutlich niedrigeren prozentualen Anteil an Alkenylglucosinolaten und einen deutlich höheren Anteil an Indolglucosinolaten aufweisen. Dies erklärt sich dadurch, dass die gezielte Selektion auf niedrige Glucosinolatgehalte vorwiegend gegen die Alkenylglucosinolate gerichtet war (RUCKER \& RUDLOFF 1992), wohingegen der Indolglucosinolatgehalt konstant blieb (MITHEN 1992).

Auch untereinander zeigten die Resynthesen eine große Variation in ihren Glucosinolatmustern. Es fielen vor allem die Wildresynthesen auf, deren Hauptglucosinolat in der Regel Gluconapin war, wohingegen die meisten klassischen Resynthesen Progoitrin als Hauptglucosinolat enthielten. Diese Unterschiede können unter anderem an der Wahl der, für die Resyntheseerstellung genutzten Eltern liegen. So ist z.B. für Brassica rapa ssp. trilocularis, die in vielen Fällen als Mutter bei der Erstellung der Wild-Resynthesen diente, bekannt, dass sie Gluconapingehalte im Samen von > 90\% aufweisen kann (VELASCO \& BECKER 2000). Es gibt aber bei anderen Rübsen- und Kohlformen (sowohl Wild- als auch Kulturformen) sehr große Unterschiede in ihren Glucosinolatmustern (VELASCO \& BECKER 2000). Bei Resynthesen wurden 
außerdem in Bezug auf die Ausprägung ihrer Glucosinolatmuster große genomische Interaktionen beobachtet, so dass sie in ihren Mustern nicht zwangsläufig ihren Elternformen entsprechen müssen (GLAND 1982). Insgesamt unterscheiden sich die Resynthesen und ganz besonders die WildResynthesen in annähernd allen beobachteten und erfassten Merkmalen extrem vom angepassten Zuchtmaterial.

\subsection{Agronomische Eigenschaften der Testkreuzungen}

\subsubsection{Erstellung der Testkreuzungen}

Die Erstellung der Testkreuzungen mit den Resynthesen erfolgte bei den Züchtern NPZ und Syngenta, wobei es eine Reihe von Schwierigkeiten gab.

Durch die beschriebene Selbstinkompatibilität vieler Resynthesen standen für die Testkreuzungen in vielen Fällen nur eine geringe Anzahl Pflanzen je Resynthesen als Pollenspender zur Verfügung. Dies betraf vor allem die Wild-Resynthesen. Ein weiteres Problem ergab sich aus der geringen Winterfestigkeit der Resynthesen, die eine Anzucht der Resynthesen im Gewächshaus erforderlich machte. Die Resynthesen wurden anschließend im Frühjahr 2009 zwischen die bereits im Herbst 2008 im Feld ausgedrillten männlich sterilen Tester gepflanzt. Dies hatte zur Folge, dass die gedrillten Tester einen großen Wachstumsvorsprung hatten und damit einen großen Konkurrenzdruck gegenüber den in den meisten Fällen schwachwüchsigen resynthetisierten Rapsformen aufbauten. Auch die Blüte der Tester setze in vielen Fällen deutlich früher ein als die der Resynthesen, wodurch es erforderlich wurde, die Tester zum Teil mehrfach zurückzuschneiden, um so ihre Blütezeit zu verlängern. Durch diese unglücklichen Umstände kam es bei vielen Testkreuzungen zu nur geringen Bestäubungserfolgen und daraus resultierend zu geringen Erntemengen. Bei einigen der geplanten Testkreuzungen konnte bei den Züchtern gar kein Saatgut geerntet werden. Auch dieses Problem betraf vor allem die besonders unangepassten Wildresynthesen.

Des Weiteren musste bei einer Reihe von "Testkreuzungen“ mit dem Tester ,RNX 4621' festgestellt werden, dass ihre Samen keinen oder nur einen sehr geringen Erucasäure- und Glucosinolatgehalt aufwiesen. Da aber alle für die Testkreuzungen verwendeten Resynthesen, bis auf drei bekannte Ausnahmen, Erucasäure enthielten und außerdem hohe Glucosinolatgehalte aufwiesen, ist 
davon auszugehen, dass es sich bei den Genotypen ohne Erucasäure und mit niedrigem Glucosinolatgehalt nicht um Testkreuzungen handelt. Möglicherweise gehen diese Saatgutpartien auf Selbstungen der Tester (falls diese teilweise doch fertile Blüten bildeten) zurück oder es handelt sich um Kreuzungen der Tester mit anderen Genotypen, da die Isoliernetze nicht 100\%ig Pollendicht sind. Das Saatgut dieser „Kreuzungen“ konnte somit nicht in den Versuchen verwendet werden.

Bei der Erstellung der Testkreuzungen im Gewächshaus konnte gezeigt werden, dass es prinzipiell möglich gewesen wäre, alle geplanten Testkreuzungen herzustellen. Da die Testkreuzungsproduktion im Gewächshaus aber nur in sehr kleinem Umfang stattfinden konnte, konnten hier nur sehr geringe Saatgutmengen produziert werden, die für die Anlage größerer Feldversuche nicht ausreichend waren. Einige wenige Genotypen konnten aufgrund der Gewächshauskreuzungen allerdings zusätzlich mit in den Beobachtungsanbau der Testhybriden aufgenommen werde.

Als Konsequenz aus den Erfahrungen bei der Testkreuzungsproduktion sollte in Betracht gezogen werden, hier in Zukunft anders vorzugehen. Eine Möglichkeit wäre es, sowohl die Tester als auch die vorgesehenen Pollenspender im Herbst und Winter im Gewächshaus vorzuziehen und im Frühjahr gemeinsam ins Feld zu Pflanzen. Noch besser wäre es, experimentelle Testkreuzungen grundsätzlich im Gewächshaus zu erstellen, dieses würde jedoch einen größeren Arbeitsaufwand zur Folge haben.

\subsubsection{Beobachtungsanbau und Leistungsprüfungen der Testkreuzungen}

Im Vergleich mit den für ihre Erstellung verwendeten Resynthesen zeigten annähernd alle Testkreuzungen eine deutlich bessere Winterfestigkeit. Offenbar reichte der genetische Hintergrund der angepassten Tester aus, um eine gute Winterfestigkeit der Testhybriden zu gewährleisten. Die schlechtesten Werte für die Winterfestigkeit wurden bei Testhybriden mit Resynthesen beobachtet, welche aus Kreuzungen von ,Yellow Sarson' mit Brassica oleracea-Wildformen erstellt wurden. Testkreuzungen mit Wild-Resynthesen unter Beteiligung von ,Yellow Sarson' und anderen Brassica-Wildarten zeigten bessere Winterfestigkeit. Dies ist erstaunlich, da Brassica oleracea die am nördlichsten verbreitete Wildart ist (vgl. LANNÉR et al. 1997, GLADIS \& HAMMER 2003). Akzessionen dieser Art sind unter 
den für die Resyntheseerstellung verwendeten Brassica-Wildarten am ehesten in der Lage mitteleuropäische Winter zu überstehen. Die mediterranen Kohlarten müssen hingegen in der Lage sein in ihren Verbreitungsgebieten längere teils extreme Trockenphasen zu überstehen. Da bekannt ist, dass Froststress und Trockenstress bei Pflanzen gleiche bzw. ähnliche physiologische Reaktionen auslösen (BECK et al. 2007; SCHOPFER \& BRENNICKE 2010), könnte sich das Zusammenwirken der guten Frosttoleranz der Tester mit der vermutlich besseren Trockentoleranz der mit mediterranen Kohlarten erstellten Wild-Resynthesen positiv auf die Winterfestigkeit der Testkreuzungen ausgewirkt haben. Diese hypothetische Annahme müsste aber experimentell Untersucht werden.

Die Testkreuzungen zeigten im Bezug auf die erfassten agronomischen Merkmale, wie die Resynthesen auch, eine hohe Variabilität. Im Gegensatz zu den Resynthesen waren sie aber besser angepasst und in einigen Merkmalen den Standards ähnlicher, so z.B: für die bereits angesprochene Winterfestigkeit. Auch der Ölgehalt der Testkreuzungen lag für die Genotypen im Beobachtungsanbau im Schnitt nur 1,4\% unter dem der Standards. Für die Genotypen, die in den Leistungsprüfungen vertreten waren, betrug der Unterschied zu den Standards im Mittel nur noch $\sim 0,5 \%$ und war damit nicht mehr signifikant. Dennoch zeigten insbesondere Testkreuzungen unter Beteiligung von Wild-Resynthesen deutlich niedrigere Ölgehalte als die Standards. Zu berücksichtigen ist dabei außerdem, dass die weitaus meisten Testkreuzungen, im Gegensatz zu den Standards Allele für Erucasäure tragen, die einen positiven Effekt auf den Gesamtölgehalt haben (ECKE et al. 1995). Ohne diese Allele würden die Testkreuzungen vermutlich noch geringere Ölgehalte aufweisen.

In den Leistungsprüfungen zeigten nur drei aus ,MSL 007 und klassischen Resynthesen erstellte Genotypen höhere Ölgehalte als die als Standard verwendete fertile Form von ,MSL 007'. Der höchste Ölertrag war bei der Kreuzung mit der Resynthese , $S 13^{\prime}$ zu beobachten, die bei den Markeranalysen im Dendrogramm zusammen mit dem Winterraps clusterte, also eine geringe genetische Distanz zum Winterraps aufwies.

Bei den Glucosinolatanalysen der Samen zeigte sich, sowohl im Gesamtglucosinolatgehalt, als auch im Glucosinolatmuster eine große Variationsbreite. Während die Standards niedrige Glucosinolatgehalte ( 20 $\mu \mathrm{mol} / \mathrm{g})$ aufwiesen, reichte die Spanne bei den Testhybriden von $\sim 29 \mu \mathrm{mol} / \mathrm{g}$ bis $\sim 142 \mu \mathrm{mol} / \mathrm{g}$, wobei 
die höchsten Werte bei Testkreuzungen unter Beteiligung von Wildresynthesen zu beobachten waren. Weiterhin zeigte sich für Testhybriden, die mit ,RNX 4621“ erstellt wurden, ein im Mittel gut $14 \mu \mathrm{mol} / \mathrm{g}$ niedrigerer Glucosinolatgehalt als bei Testhybriden mit ,MSL 007، Dies liegt wahrscheinlich darin begründet, dass für die ,RNX 4621'-Testkreuzungsserie die Resynthese/Tester Kombinationen fehlten, die bei den 'MSL-007'-Hybriden die höchsten Gehalte aufwiesen. Bei den Glucosinolatmustern fiel auf, dass bei fast allen Testhybriden, mit wenigen Ausnahmen, Progoitrin das Hauptglucosinolat darstellte. Bei den Ausnahmen handelte es sich vorwiegend um Kreuzungen mit Wild-Resynthesen. Bei ihnen stellte Gluconapin das Glucosinolat mit dem größten prozentualen Anteil. Auch andere Testkreuzungen, vor allem solche unter Beteiligung von WildResynthesen, zeigten hohe Gluconapingehalte. Dies korreliert gut mit den Ergebnissen der Resynthesen. Die Testkreuzungen wiesen im Vergleich mit den Resynthesen einen deutlich erhöhten Anteil an Indolglucosinolaten auf. Bei den Resynthesen betrug dieser im Mittel 6\%; bei den Testkreuzungen lag er im Mittel bei $12 \%$ und damit annähernd doppelt so hoch. Bei den Standards lag der Anteil mit $\sim 30 \%$ noch deutlich höher. Der hohe Indolglucosinolatgehalt der Standards liegt, wie im Abschnitt 4.3 erläutert, in der züchterischen Bearbeitung des Glucosinolatgehaltes begründet (vgl. RUCKER \& RUDLOFF 1992, MITHEN 1992). Insgesamt unterscheiden sich die Glucosinolatmuster in den meisten Fällen deutlich von denen ihrer Ausgangseltern und zeigen zum Teil überraschend hohe Gesamtglucosinolatgehalte. Diese liegen bei den Testkreuzungen in vielen Fällen etwa genauso hoch wie die für die Resynthesen ermittelten Werte (sowohl wenn man die mit NIRS ermittelten Werte betrachtet, als auch bei den HPLC-Werten). In einigen Fällen liegen die Werte aber auch noch höher und nur in wenigen niedriger, obwohl die für die Testhybridproduktion verwendeten Tester beide nur geringe Glucosinolatgehalte aufweisen. Dies beruht höchstwahrscheinlich auf einer sehr großen Interaktion der Genome der beiden Kreuzungspartner, wie sie bei GLAND (1982) für Resynthesen beschrieben wurde.

Für den Ertrag zeigte sich in den Leistungsprüfungen, dass bis auf ganz wenige Ausnahmen alle Testkreuzungen mindestens das Ertragsniveau ihrer Mütter erreichten. Viele waren sogar deutlich besser, aber keine war besser als die als Standard verwendete Hybridsorte ,Visby‘. Die höchsten Erträge erbrachten 
Testkreuzungen mit klassischen Resynthesen, darunter auch die drei, die den höchsten Ölgehalt aufwiesen. Im Gegensatz dazu zeigten die meisten mit WildResynthesen Erträge, die in etwa auf Höhe der Erträge der Tester oder nur wenig darüber lagen. Nur sieben Testkreuzungen mit Wild-Resynthesen erreichten Erträge, die über dem Mittelwert der Erträge der Testhybriden von 39,2 dt/ha lagen. Für die Testkreuzungen, deren Erträge unterhalb der Erträge der Tester lagen, stellte sich heraus, dass dies mit mangelnder Winterhärte einherging. Betrachtet man die Erträge dieser Testhybriden, die an den einzelnen Versuchsstandorten erzielt wurden, so fällt auf, dass sie nur an einigen Standorten schlechte Ergebnisse erbrachten, an anderen aber deutlich über den Erträgen der Tester lagen. In Abbildung 4-1 ist diese Beobachtung exemplarisch für alle neun Leistungsprüfungsstandorte für den Genotyp ,MSL 007 x J 161`im Vergleich mit dem Tester ,MSL 007‘ dargestellt.



Abb. 4-1: Vergleich der Kornerträge des Testhybriden ,MSL $007 \times \mathrm{J} 161^{\prime}$ mit denen der als Standard verwendeten fertilen Form von ,MSL 007‘ über die einzelnen Versuchsstandorte.

Versucht man die für die einzelnen Testhybriden ermittelten Erträge in Beziehung zur genetischen Distanz ihrer Eltern zusetzten, so ist mit $r=-0,29$ eine leicht negative Korrelation zu beobachten (Abb. 4-2). 


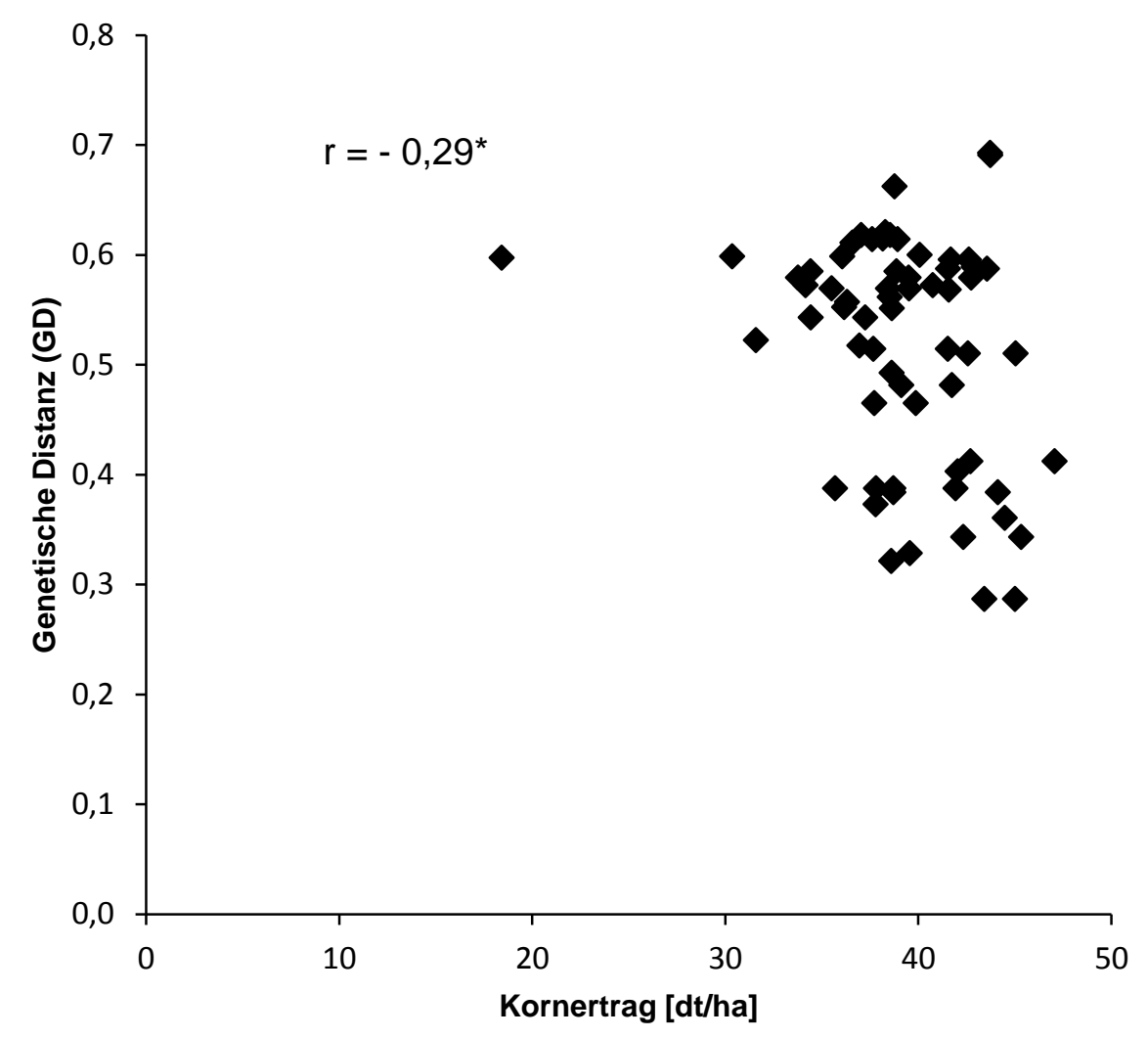

Abb. 4-2: Korrelation zwischen der genetischen Distanz (zwischen den Testern und den für die Testkreuzungen verwendeten Resynthesen) und dem Kornertrag der Testhybriden; * $=$ signifikant $(P=0,1)$

Ähnliche Beobachtungen machte auch GIRKE (2002). Es scheint so zu sein, dass die Resynthesen mit der höchsten genetischen Distanz auch die schlechteste Anpassung aufweisen. Dies würde auch den Erwartungen entsprechen, da die größten genetischen Distanzen vor allem bei Resynthesen, die aus der Sommerübsenform ,Yellow Sarson' und mediterranen Wildkohlarten entstanden sind, zu beobachten waren. Eine gute Anpassung an mitteleuropäische Umweltbedingungen ist für diese Resynthesen als eher unwahrscheinlich anzusehen. 


\subsection{Fazit und Ausblick}

Die untersuchten Resynthesen, insbesondere die, die mit Brassica-Wildarten erstellt wurden, stellen Aufgrund ihrer zum Teil sehr hohen genetischen Distanzen zum angepassten Zuchtmaterial ein sehr diverses und für die Rapszüchtung hoch interessantes Material dar.

Sie enthalten möglicherweise eine Reihe interessanter neuer Eigenschaften, wie z.B. Resistenzen gegen Schadorganismen, Anpassungen an Stressbedingungen oder auch ungewöhnliche Blattglucsosinolatmuster, die, wie Untersuchungen von EICKERMANN (2008) zeigten, Einfluss auf Schädlinge haben können.

Die großen genetischen Distanzen bedingen aber auch eine Reihe negativer Eigenschaften, die die positiven Eigenschaften überdecken können. Hier besteht daher weiterer Forschungsbedarf.

Um die Wildresynthesen für die Züchtung nutzbar zu machen, sollte in einem Folgeprojekt versucht werden, die Allele für die negativsten Eigenschaften der Resynthesen durch positive Allele aus dem angepassten Zuchtmaterial zu ersetzen. Beispielsweise müsste die Winterfestigkeit des Materials verbessert, die zum Teil vorhandenen Selbstinkompatibilitäten vermindert sowie die Anfälligkeit gegenüber Phoma verringert werden. Ferner wären der niedrige Ölgehalt, der Erucasäuregehalt und der hohe Glucosinolatgehalt im Samen als negative Eigenschaften zu nennen.

Um dieses Ziel zu erreichen könnten zum Beispiel Kreuzungen der Resynthesen mit einer angepassten Winterrapslinie durchgeführt werden, welche anschließend ein oder mehrfach mit dem Resyntheseelter rückgekreuzt werden könnten, um dann DH Populationen zu erstellen. In diesen könnte dann möglichst markergestützt gegen die unerwünschten Eigenschaften selektiert werden. Auf diese Weise wäre es möglich ein Material zu erhalten, welches einerseits noch zu einem hohen Prozentsatz die interessanten Allele der Resynthesen beinhalten würde, andererseits aber weniger negative Eigenschaften und eine verbesserte Anpassung aufweisen würde. 


\section{Zusammenfassung}

Die genetische Basis des für die Rapszüchtung zur Verfügung stehenden Rapsmaterials ist im Vergleich zu anderen Kulturarten, die schon seit sehr langer Zeit vom Menschen genutzt werden, eng begrenzt. Dies resultiert einerseits daraus, dass der Raps (Brassica napus) erst seit wenigen Jahrzehnten eine größere Rolle in der Züchtung spielt und andererseits eine entwicklungsgeschichtlich sehr junge Art ist. Um auf Dauer aber eine erfolgreiche Züchtung gewährleisten zu können, ist eine möglichst große genetische Diversität im Zuchtmaterial notwendig.

Da Raps eine amphidiploide Art ist, deren evolutionärer Ursprung in einer spontanen Kreuzung zwischen Rübsen (Brassica rapa; A-Genome) und Kohl (Brassica oleracea, C-Genom) liegt, lassen sich durch artifizielle Kreuzung dieser beiden Ursprungseltern neue „resynthetisierte“ Rapsformen erstellen. Derartige Resynthesen können genutzt werden, um neue züchterisch interessante Allele zu finden. Für die Erstellung von Resyntheseraps wurden als Brassica oleracea-Elter bisher fast ausschließlich Gemüseformen eingesetzt. Neben den Brassica oleracea-Gemüseformen gibt es aber vor allem im mediterranen Raum noch eine ganze Reihe von Brassica oleracea-Wildformen bzw. nah verwandten BrassicaArten die potentiell für die Erstellung von Resynthesen genutzt werden können. Diese Arten zeigen eine hohe genetische Diversität. Ihr züchterisches Potential ist bisher weitgehend ungenutzt.

Ziel dieser Arbeit war es, das Potential der Wildarten über ihre Verwendung als Elter zur Erstellung von resynthetisiertem Raps für die Pflanzenzüchtung verfügbar zu machen. Dabei gab es drei Fragestellungen:

(1) Zeigen Resynthesen, die mit Brassica-Wildarten erstellt wurden, eine größere genetische Distanz zum angepassten Zuchtmaterial als Resynthesen die mit Brassica oleracea-Kulturformen erstellt wurden? Stellen sie tatsächlich eine Erweiterung des für die Rapszüchtung nutzbaren Genpools dar?

(2) Welche agronomischen Eigenschaften weisen derartige Resynthesen auf?

(3) Wie gut ist die Kombinationseignung derartiger Resynthesen in Kreuzungen mit angepasstem Winterrapszuchtmaterial? 
Um die genetische Distanz der Resynthesen zum angepassten Zuchtmaterial zu ermitteln, wurden für insgesamt 126 Rapsgenotypen AFLP-Analysen durchgeführt. Die 126 untersuchten Genotypen setzten sich aus 44 verschiedenen Resynthesen, die mit elf verschiedenen das C-Genom tragenden BrassicaWildarten erstellt wurden (Wild-Resynthesen) sowie 27 klassischen Resynthesen (Resynthesen unter Einbeziehung von $B$. oleracea-Gemüseformen) und 55 Genotypen aus dem angepassten Zuchtmaterial zusammen. Das untersuchte Zuchtmaterial enthielt ein breitgefächertes Sortiment von Winter-, Sommer- und chinesischen Rapssorten sowie einigen Gemüseformen.

Zur Prüfung der agronomischen Eigenschaften wurde für 70 Resynthesen zusammen mit zehn Standards (angepasste Winterrapssorten) im Versuchsjahr 2009/2010 ein Beobachtungsanbau an insgesamt acht Standorten (sechs in Deutschland, zwei in Großbritannien) angelegt. die Erfassung der agronomischen Eigenschaften erfolgte sowohl im Feld, wie auch nach der Ernte durch verschiedene Qualitätsanalysen der Samen im Labor.

Des Weiteren wurden Kreuzungen von 65 Resynthesen, darunter die WildResynthesen, mit zwei unterschiedlichen männlich sterilen Testern aus dem angepassten Winterrapsmaterial durchgeführt. Die aus diesen Kreuzungen resultierenden Testhybriden wurden anschließend im Anbaujahr 2009/2010 in Leistungsprüfungen mit sieben Standorten in Deutschland, sowie jeweils einem Standort in Frankreich und Großbritannien geprüft. Außerdem wurde für weitere Testhybriden ein Beobachtungsanbau an den gleichen acht Standorten wie für die Resynthesen angelegt. Auch für diese Versuche wurden die agronomischen Eigenschaften erfasst.

In den AFLP-Analysen konnte die bereits gut untersuchte enge genetische Verwandtschaft des Zuchtmaterials aufgezeigt werden. Die mittlere genetische Distanz (GD) über das gesamte Zuchtmaterial betrug 0,35. Innerhalb der Gruppen des Zuchtmaterials lag sie mit 0,29 beim Winterraps und 0,28 im Sommerrapsmaterial noch niedriger. Lediglich chinesische Sorten sowie die in die Untersuchungen einbezogenen Rapsgemüseformen erreichten mit 0,37 bzw. 0,41 etwas höhere mittlere GD-Werte. Das Resynthesematerial hingegen hob sich deutlich vom Zuchtmaterial ab und zeigte hohe bis sehr hohe genetische Distanzen, sowohl zum Zuchtmaterial als auch innerhalb der beiden 
Resynthesegruppen (klassische Resynthesen, Wild-Resynthesen). Die mittlere GD zum Zuchtmaterial betrug bei den klassischen Resynthesen 0,52. Auch innerhalb der Gruppe der klassischen Resynthesen ließ sich eine hohe mittlere GD von 0,55 beobachten. Für die Wild-Resynthesen konnten erwartungsgemäß die höchsten genetischen Distanzen beobachtet werden. Die mittlere Distanz lag zu allen untersuchten Gruppen bei 0,61 bzw. 0,62 und innerhalb der Gruppe bei 0,59 . Bei Vergleichen zwischen zwei Genotypen unter Einbeziehung einer WildResynthese konnten im Extremfall genetische Distanzen $>0,75$ beobachtet werden.

Im Rahmen einer Bachelorarbeit wurden 40 verschiedene Wildkohl-Akzessionen aus 10 verschiedenen Arten (B. bourgeaui, B. cretica, B incana, B insularis, B. macrocarpa, B. montana, B. oleracea, B. rupestris, B taurica und B. villosa) hinsichtlich ihrer Blattglucosinolatmuster charakterisiert.

Dabei zeigte sich, dass es sowohl für den Blattglucosinolatgehalt wie auch für die Blattglucosinolatmustern eine sehr hohe Variationsbreite gibt. Die Höhe des festgestellten Blattglucosinolatgehaltes schwankte zwischen $\sim 10 \mu \mathrm{mol} / \mathrm{g}$ TM und $\sim 120 \mu \mathrm{mol} / \mathrm{g}$ TM. Bei den Blattglucosinolatmustern konnten insgesamt zwölf verschiedene Glucosinolate nachgewiesen werden, die in den untersuchten Akzessionen in ganz unterschiedlichen Musterzusammensetzungen vorkamen.

Auch die Resynthesen zeigten in phänotypischer Hinsicht eine breite Variation. Insbesondere bei den Samenglucosinolatanalysen konnten große Unterschiede sowohl im Gesamtgehalt als auch in den Glucosinolatmustern festgestellt werden. Besonders die Wildresynthesen zeigten hier auffällige Muster. In vielen Fällen enthielten sie zu mehr als $80 \%$ das Glucosinolat Gluconapin während die meisten anderen Resynthesen als Hauptglucosinolat Progoitrin mit in der Regel unter 60\% enthielten. Insgesamt konnten in den Samen 12 verschiedene Glucosinolate in sehr unterschiedlicher Menge und Zusammensetzung gefunden werden.

Aufgrund ihrer schlechten Anpassung an die Bedingungen im Feld zeigten die Resynthesen in vielen anderen agronomisch interessanten Merkmalen jedoch äußerst schlechte Leistungen. So wiesen sie in der Regel niedrige Ölgehalte auf und waren in den meisten Fällen schwachwüchsig. Das größte Defizit war aber 
ihre geringe Winterfestigkeit, da viele der Resynthesen auf nicht winterfeste Eltern zurückgehen.

Die Testkreuzungen aus den Resynthesen und zwei angepassten Testern zeigten hingegen erstaunlich gute Leistungen. Die meisten wiesen eine akzeptable Winterfestigkeit auf und erbrachten in den Leistungsprüfungen Erträge, die in den meisten Fällen mindestens genauso gut und in vielen Fällen auch deutlich höher als die der Tester ausfielen. Einige wenige erreichten annähernd die Ertragswerte der als Standard verwendeten Hybridsorte ,Visby“.

Insgesamt zeigen die Ergebnisse dieser Arbeit, dass es möglich ist die große Diversität der Brassica-Wildarten, die auch bei ihrer Charakterisierung in Bezug auf die Blattglucosinolate deutlich wurde, für die Rapszüchtung verfügbar zu machen. Resynthesen und insbesondere Resynthesen mit Wildarten können sehr interessant für den Einsatz in der Züchtung sein. Sie weisen teilweise sehr große genetische Distanzen zum angepassten Zuchtmaterial auf und stellen somit eine eindrucksvolle Erweiterung des Rapsgenpools dar. Es ist zu vermuten, dass sie eine Reihe züchterisch interessanter Allele für Eigenschaften, wie z.B. Stresstoleranzen oder Resistenzen gegen Schadorganismen in sich tragen. Aufgrund ihrer schlechten Eigenleistungen die möglicherweise die in ihnen enthaltenen positiven Eigenschaften überdecken, muss aber in Zukunft in die Verbesserung ihrer agronomischen Merkmale investiert werden. Insbesondere wäre hier die schlechte Winterfestigkeit zu nennen, aber auch andere Eigenschaften wie Ölgehalt, Samenqualität oder Krankheitsanfälligkeit sind verbesserungswürdig. 


\section{Literaturverzeichnis}

AHMADI, M.R. (1988): Charakterisierung der genetischen Variabilität vpn amphidiploiden resynthetischen Rapsformen und deren Ausgangseltern. Dissertation an der Georg-August-Universität Göttingen.

AlLENDER, C.J. \& KING, G.J. (2010): Origin of the amphiploid species Brassica napus $\mathrm{L}$. investigated by chloroplast and nuclear molecular markers. - BMY Plant Biology 10:54.

AMAR, S., BeCKER, H.C. \& MölleRS, C. (2009): Genetic variation in phytosterol content of winter rapeseed (Brassica napus L.) and development of NIRS calibration equations. - Plant Breeding 128, 78 - 83.

Backhaus, K., ERichson B., Plinke W. \& Weiber, R.. (1990): Multivariate Analysemethoden. - Springer Verlag, Berlin, 6. Aufl.: 115-160.

BAHRANI, J. \& McVETTY P.B.E. (2008): Relationship of seed quality traits for greenhouse-grown versus field-grown high erucic acid rapeseed: Is seed quality trait selection for greenhouse-grown seed worthwhile? - Canadian Journal of Plant Science 88: 419 - 423.

Beck, E.H., Fettig, S., Knake, C. Hartig, K. \& Bhattaral, T. (2007): Specific and unspecific responses of plants to cold and drought stress. - J. Biosci. 32 (3): $501-510$

Becker, H.C, Engqvist, G.M. \& KarLsson, B. (1995): Comparison of rapeseed cultivars and resynthesized lines based on allozyme and RFLP markers. Theor. Appl. Genet. 91: 62-67.

Becker, H.C., LÖPtIEN, H. \& RÖBbelen, G. (1999): Breeding: an overview. In: Gómez-CAMPO, C. (ed.) Biology of Brassica Coenospecies. - Elsevier Amsterdam: 413 - 460.

BECKER, H.C. (2001): Nutzung genetischer Ressourcen in der Pflanzenzüchtung. In: HammeR, K. \& Gladis, T. (Hrsg.): Schriften zu Genetischen Ressourcen, Band 16: 79 - 90

BMELV (2010): Ernte 2010: Mengen und Preise. - elektr. Veröffentlichung: URL: http://www.bv-agrar.de/bvagrar/agrarwelt/daten/ernte_getreide_2010.pdf

Cartea, M.E. Rodriguez V.M., de Haro, A., Velasco, P. \& Ordás A. (2008): Variation of glucosinolates and nutritional value in nabicol (Brassica napus pabularia group). - Euphytica 159: 111 - 112.

DICE L.R. (1945): Measures of the amount of ecological association between species. - Ecology 26: 297 - 302. 
DIEDERICHSEN, E. (1992): Kombination verschiedener Resistenzen gegenüber Plasmodiophora brassicae Wor. in resynthetisierten Formen von amphidiploiden Brassica-Arten. - Dissertation an der Freien Universität Berlin: $172 \mathrm{~S}$.

DUHOON, S.S. \& KOPAR M.N. (1998): Distribution, collection and conservation of biodiversityin cruciferous oilseeds in India. - Genetic Resources and Crop Evolution 45: 317-323.

ECKE, W., UZUNOVA, M., \& WEIBLEDER, K. (1995): Mapping the genome of rapeseed (Brassica napus L.). II. Localization of genes controlling erucic acid synthesis and seed oil content. - Theor. Appl. Genet. 91: 972 - 977.

ECKe, W., Clemens, R. Honsdorf, N. \& BeCKER H.C. (2010): Extent and structure of linkage disequilibrium in canola quality winter rapeseed (Brassica napus L.). - Theor. Appl. Genet. 120: 921 - 931.

EICKERMANN, M. (2009): Effect of Brassica genotype on the infestation by cabbage stem weevil Ceutorhynchus pallidactylus (Mrsh.) (Col.: Curculionidae) and the parasitism of stem weevil larvae. - Dissertation an der Georg-AugustUniversität Göttingen: 67 S. - elektr. Veröffentlichung:

URL: http://webdoc.sub.gwdg.de/diss/2010/eickermann/eickermann.pdf

ENGQVIST, G.M. \& BECKER H.C. (1994): What can resynthesized Brassica napus offer to plant breeding? Sveriges Utsädesförenings Tidskrift 104: 87 - 92.

FAO (2010): Food Outlook, November 2010: 117 S. - elektr. Veröffentlichung: URL: http://www.fao.org/giews/

FELSENSTEIN, J. (1985): Confidence limits on phylogenies: An approach using the bootstrap. - Evolution: international journal of organic evolution 39: 783 - 791 .

FRIEDT, W. \& LÜHS, W. (1994): Resynthese von neuen Rapsformen. - Vorträge für Pflanzenzüchtung 30: $98-115$.

GIRKE, A. (2002): Neue Genpools aus resynthetisiertem Raps (Brassica napus L.) für die Hybridzüchtung. - Dissertation an der Georg-August-Universität Göttingen: 99 S. - elektr. Veröffentlichung:

URL: http://webdoc.sub.gwdg.de/diss/2002/girke/girke.pdf.

Gladis, T. \& HAMmeR, K. (1990): Die Gaterslebener Brassica-Kollektion - eine Übersicht. - Kulturpflanzen 38, 121 - 156.

Gladis, T. \& HAMmeR, K. (2003): Die Brassica-oleracea-Gruppe. - Lennestadt, Selbstverlag des Vereins zur Erhaltung der Nutzpflanzenvielfalt.

GLAND, A. (1982) Gehalt und Muster der Glucosinolate in Samen von resynthetisierten Rapsformen. - Z. Pflanzenzüchtg. 88: 242 - 254. 
Hampl, V., PAVlíceK A. \& FLegR J. (2001): Construction and bootstrap analysis of DNA fingerprinting-based phylogenetic trees with a freeware program FreeTree: Application to trichomonad parasites. - Int. J. of Systematic and Evolutionary Microbiology 51: $731-735$.

HANELT, P. (2001): Mansfeld's Encyclopedia of Agricultural and Horticultural Crops. - Band 3, Springer Verlag Heidelberg.

Happstadius, I., LJungberg, A., Kristiansson, B. \& Dixelius, C. (2003): Identification of Brassica oleracea germplasm with improved resistance to Verticillium wilt. - Plant Breeding 122: 30 - 34

Hasan, M., Seyis, F., Badani A.G., Pons-Kühnemann, J., Friedt, W., Lühs, W. \& SNOWDON, R.J. (2006): Analysis of genetic diversity in the Brassica napus L. gene pool using SSR markers. - Genetic Resources and Crop Evolution 53: $793-802$.

HiLLIS, D.M. \& BULL, J.J. (1993): An Empirical Test of Bootstrapping as a Method fpr Assesing Confidence. - Systematic Biologists 42 (2): 182 - 92.

Hoffmann, W. \& Peters, R. (1958): Versuche zur Herstellung synthetischer und semisynthetischer Rapsformen. - Züchter 28: 40 - 51.

Hom, N.H. (2004): Pollen Genotype Effects on Seed Quality and Selection of Single Seeds by Near-Infrared Reflectance Spectroscopy (NIRS) in Winter Oilseed Rape. - Dissertation an der Universität Göttingen -elektr. Veröffentlichung: URL: http://webdoc.sub.gwdg.de/diss/2004/hom/hom.pdf

Hu, S., Yu, C., Zhao, H., Sun, G., Zhao, S., Vyvadilova, M. \& Kucera, V. (2007): Genetic diversity in Brassica napus L. Germplasm from China and Europe assessed by some agronomically important characters. - Euphytica 154: 9 16.

INOMATA, N. (1993): Crossability and cytology of hybrid progenies in the cross between Brassica campestris and three wild relatives of $B$. oleracea, $B$. bourgeaui, B. cretica and B. montana. - Euphytica 69: 7 - 17.

INOMATA, N. (2002): A cytogenetic study of the progenies of hybrids between Brassica napus and Brassica oleracea, Brassica bourgeaui, Brassica cretica and Brassica montana. - Plant Breeding 121: 174-176.

JACCARD, P. (1908): Nouvelles recherches sur la distribution florale.- Bull. Soc. Vaud. Sci. Nat. 44: 223 - 270.

KNAAK C. (1995): Schätzung genetischer Distanzen mittels RFLP zur Identifizierung von Genpools für die Hybridzüchtung bei Winterraps. Dissertation an der Universität Göttingen, Cuvillier Verlag: $130 \mathrm{~S}$.

LannéR, C., Bryngelsson, T. \& Gustaffson, M. (1997) Relationship of wild Brassica species with chromosome number $2 n=18$, based on RFLP studies. Genome 40: 302 - 308. 
LÁZARO, A. \& Aguinagalde, I. (1998): Genetic diversity in Brassica oleracea L. (Cruciferea) an Wild Relatives $(2 n=18)$ using Isozymes. - Annals of Botany $\mathbf{8 2}$ : $821-828$.

Link, W., Dixkens, C., Singh, M., SchWAlL, M. \& MelChingeR, A.E. (1995): Genetic diversity in European and Mediterranean faba bean germ plasm revealed by RAPD markers. - Theor. Appl. Genet. 90: 27 - 32.

Lombard, V., Baril, C.P., Dubreull, P., Blouet, F. \& Zhang, D. (2000): Genetic Relationships and Fingerprinting of Rapeseed Cultivars by AFLP: Consequences for Varietal Registration. - Crop Science 40: 1417 - 1425.

LÜHS, W. \& FRIEDT, W. (1994): Stand und Perspektiven der Züchtung von Raps (Brassica napus L.) mit einem maximalen Erucasäuregehalt im Öl für industrielle Nutzungszwecke. Fat. Sci. Technol. 96: 137 - 146

MoRINAGA (1934): Interspecific hybridisation in Brassica. VI. The cytology of $F_{1}$ hybrids between $B$. juncea and B. nigra. - Cytologia 6, 62 - 67 .

McGRATH, J.M. \& QUIROS, C.F. (1992): Genetic diversity at isozyme and RFLP loci in Brassica campestris as related to crop type and geographical origin. - Theor. Appl. Genet. 83: 783 - 790.

McFerson, J.R., LAMBOY, W.F. \& KRESOVICH (1996): Assessing user perceptions of genetic resource collection in crucifer crops. - Crop Science 36: 831 - 838.

Mel, J., Li, Q., YanG, X., Qian, L., Liu, L., Yin, J., Frauen, M., LI, J., \& Qian, W. (2010): Genomic relationship between wild and cultivated Brassica oleracea L. with emphasis on the origination of cultivated crops. - Gent. Resour. Crop. Evol. 57: $687-692$.

METZGER, J. (1833): Systematische Beschreibung der kultivierten Kohlarten. Heidelberg.

MITHEN, R.F. (1992): Leaf glucossinolate profiles and their relationship to pest and disease resistance in oilseed rape. - Euphytica 63: 71 - 83.

Mithen, R.F., LeWIS, B.G., HEANEY, R.K. \& FENWICK, G.R. (1987): Glucosinolates of wild and cultivated Brassica species. - Phytochemistry 26 (7): 1969 - 1973.

Mithen, R.F. \& MAGRATH, R. (1992): Glucosinolates and resistance to Leptoshaeria maculans in wild and cultivated Brassica species. - Plant Breeding 108: 60 68.

PAGE, R.D.M. (1996): TREEVIEW: An application to display phylogenetic trees on personal computers. - Computer Applications in the Biosciences 12: $357-358$.

Paulmann, W. \& Frauen, M. (1998): Erfahrungsbericht zur Entwicklung und Saatguterzeugung von restaurierten Winterraps-Hybridsorten. - Bericht über die 48. Tagung d. Arbeitsgem. d. Saatzuchtleiter. BAL Gumpenstein, 25-27. Nov. 1997. 
OLSson, G. (1960): Species crosses within the genus Brassica. II. Artificial Brassica napus L.. - Hereditas 45: 351 - 386.

OLSsON, G. (1983): Allopolyploids in Brassica. - in: Svalöf 1886 - 1986. Research and Results in Plant Breeding. LTs förlag, Stockholm: 114-119.

PLIESKE, J. \& StRUSS, D. (2001): Microsatellite markers for genome analysis in Brassica. I. development in Brassica napus and abundance in Brassicaceae species. - Theor. Appl. Genet. 102: 689 - 694.

REINHARD, TC (1992): Entwicklung und Anwendung von Nah-infrarotspektroskopischen Methoden für die Bestimmung von Öl-, Protein-, Glucosinolat-, Feuchte und Fettsäuregehalt in intakter Rapssaat. - Dissertation an der Georg-August-Universität Göttingen: 129 + IV S.

Renard, M., Delourme, R., Vallée \& Pierre, J. (1997): Hybrid rapeseed breeding and production. - Acta Hortculturae 459: 583 - 591.

RöBbelen, G. \& RAKOW, G. (1979): Eiweißsaat Raps: Züchterische Erfolge und Möglichkeiten. - Fette, Seifen; Anstrichmittel 81 (5): 197 - 200.

ROHLF, F. J. (2000): NTSYS-pc Numerical taxonomy and multivariate analysis system. Version2.1. - Setauket, New York: Exeter Publishing Co, Ltd.

Rosa, E.A.S., HeAney, R.K., Fenwick, G.R. \& PORTAS C.A.M. (1997): Glucosinolates in crop plants. - Horticultural Reviews 19: $99-215$.

RUCKER, B. \& RUDLOFF, E. (1992): Investigations on inheritance of the glucosinolate content in seeds of oilseed rape (Brassica napus). - Proceedings of the Eighth International Rapeseed Congress: 191 - 196.

RUDORF, W. (1951): Über die Erzeugung und die Eigenschaften synthetischer Rapsformen. - Z. Pflanzenzüchtetg. 29: $35-54$.

RUDORF, W. (1958): Experimentelle aus ihren Ursprungsarten hergestellte Rapsformen im Vergleich mit natürlichem Raps. - Fette, Seifen, Anstrichmittel 60: 635 - 673.

Rygulla, W., Snowdon, R.J., Eynck, C., KoOpmann, B., von Tiedemann, A., LÜHS, W. \& FrIEDT, W. (2007a): Broadening the Genetic Basis of Verticillium longisporum Resistance in Brassica napus by Intespecific Hybridization. Phytopathology 97 (11): $1391-1396$.

Rygulla, W., Snowdon, R.J., Eynck, C., Koopmann, B., von Tiedemann, A., LÜHS, W. \& FRIEDT, W. (2007b): Combination of resistance to Verticillium longisporum from zero erucic acid Brassica oleracea and oilseed Brassica rapa genotypes in resynthesized rapeseed (Brassica napus) lines. - Plant Breeding 126: 596 602. 
Rygulla, W., Snowdon, R.J., Friedt, W., Happstadius, I., Cheung, W.Y. \& Chen, D. (2008): Identification of Quantitative Trait Loci for Resistance Against Verticillium longisporum in Oilseed Rape (Brassica napus). - Phytopathology 98 (2): $215-221$.

SCHOPfER, P. \& BRENNICKE, A. (2010): Pflanzenphysiologie. - 7. Auflage, Spektrum Akademischer Verlag Heidelberg: 702 S.

SERNYK, J.L. (1999): Catalogue of oilseed rape cultivars: 1999 edition.

Seyis, F., SNOWdON, R.J., LÜHS, W. \& FRIED, W. (2003): Molecular characterization of novel resynthesized rapeseed (Brassica napus) lines and analysis of their genetic diversity in comparison with spring rapeseed cultivars. - Plant Breeding 122: $473-478$.

SEYIS, F., FRIEDT, W. \& LÜHS, W. (2001): Resynthese-Raps (Brassica napus L.) als genetische Ressource für die Qualitäts- und Ertragszüchtung. - In: HAMMER, K. \& GLADIS, T. (Hrsg.): Schriften zu Genetischen Ressourcen, Band 16: 91 - 112.

SeYIS, F., FrIEDT, W. \& LÜHS, W. (2005): Yield of Brassica napus L. hybrids developed using resynthesized rapeseed material sown at different locations. Fiel Crop Research 96: 176 - 180.

SNeATH, P. H. A. \& SoKAL, R. R. (1973): Numerical taxonomy. The principles and practice of numerical classification. - Freeman, San Francisco: 573 S.

Snogerup, S., Gustafsson, M., \& von Bothmer, R. (1990): Brassica sect. Brassica Brassicaceae) I. Taxonomy an variation. - Wildenowia 19: $271-365$.

SoNG, K. \& OsBoRN, T.C. (1992): Polyphentic origins of Brassica napus: new evidence based on organelle and nuclear RFLP analyses. - Genome 35: 992 1001.

SONG, K., OsboRn, T.C. \& WILLIAMS, P.H. (1990): Brassica taxonomy based on nuclear restriction fragment length polymorphisms (RFLPs). 3. Genome relationships in Brassica and related genera and the origin of $B$. oleracea and $B$. rapa (syn. campestris). - Theor. Appl. Genet. 79: 497-506.

StePHANI, V. (1985): Selektion auf Gehalt und Zusammensetzung der Glucosinolate in der Grünmasse von Raps (Brassica napus L.). - Dissertation an der Georg-August-Universität Göttingen: 109 S.

U, N. (1935): Genome analysis in Brassica with special reference to the experimental formation of $B$. napus and peculiar mode of fertilization. Japanese Journal of Botany 7: $389-452$.

UTZ, H.F. (2007): PLABSTAT (Version 2N): a computer program for the computation of variances and covariances. - Institut of Plant Breeding, Seed Science and Population Genetics, Universität Hohenheim, Stuttgart 
VeLASCO, L. \& BECKER, H.C. (2000): Variability for seed glucosinolates in a germplasm collection of the genus Brassica. - Genetic Resources and Crop Evolution 47: $231-238$.

Velasco, L., Goffman, F.D. \& BeCKER, H.C. (1998): Variability for the fatty acid composition of the seed oil in a germplasm collection of the genus Brassica. Genetic Resources and Crop Evolution 45: 371 - 382.

Vos, P., Hogers, R., Bleeker, M., Reijans, M., van de Lee, T., Hornes, M., Friters, A., Pot, J., PAleman, J., KUIPER, M. \& Zabeau, M. (1995): AFLP: a new technique for DNA fingerprinting. - Nucleic Acid Research 23: 4407 - 4414.

Voss, A., Friedt, W., Marjanovic-Jeromela, A. \& LüHS, W. (1998): Molecular genotyping of rapeseed including resynthesized Brassica napus lines. Cruciferae Newsletter 20: 27-28.

Yu, C., LeisovÁ, L., Kucera, V., VyVydilová, M., OVESNÁ, J., Dotlacil, L. \& Hu, S. (2007): Assessment of Genetic Diversity of Yellow-seeded Rapeseed (Brassica napus L.) Accessions by AFLP Markers. - Czech J. Genet. Plant Breeding 43 (3): $105-112$.

zum Felde, T., Baumert, A., Strack, D., Becker, H.C. \& Möllers, C. (2007): Genetic variation for sinapate ester content in winter rapeseed (Brassica napus L.) and development of NIRS calibration equations. Plant Breeding 126, 291 296.

Internetquellen:

Menting, F. \& BAS, N. (2010): The ECPGR Brassica Database. - Centre for Genetic Resources. The Netherlands (CGN):

URL: http://documents.plant.wur.nl/cgn/pgr/brasedb/ (Abfrage: 28.04.2011). 


\section{$7 \quad$ Anhang}

Tab. I: Adressen der Zuchtfirmen, Forschungsinstitute und Genbanken

\begin{tabular}{|c|c|}
\hline Abkürzung & Adresse \\
\hline AG Cda & $\begin{array}{l}\text { Agriculture and Agri-Food Canada, } \\
107 \text { Science Place, Saskatoon, Saskatchewan, S7N 0X2, Kanada }\end{array}$ \\
\hline Borries & $\begin{array}{l}\text { W. von Borries-Eckendorf GmbH \& Co.KG } \\
\text { Hovedisser Straße 92, } 33818 \text { Leopoldshöhe, Deutschland }\end{array}$ \\
\hline CAAS & $\begin{array}{l}\text { Oil Crops Research Institute, Chinese Academy of Agricultural Science, } \\
\text { No2 Xudong Second Road Wuhan, Hubei Province, P.R.China } 430062\end{array}$ \\
\hline CGN & $\begin{array}{l}\text { Centrum voor Genetische Bronnen Nederland (CGN) } \\
\text { Postbus } 9101,6700 \text { HB Wageningen, Niederlande }\end{array}$ \\
\hline DA & $\begin{array}{l}\text { Department of Agriculture, } \\
\text { Agriculture House, Kildare St., Dublin 2, Irland }\end{array}$ \\
\hline DSV & $\begin{array}{l}\text { Deutsche Saatveredelung AG, Weissenburger Straße 5, } 59557 \text { Lippstadt } \\
\text { Postfach 1407, } 59524 \text { Lippstadt, Deutschland }\end{array}$ \\
\hline ESP & $\begin{array}{l}\text { Banco de Germoplasma, Universidad Politécnica de Madrid. Escuela } \\
\text { Técnica Superior de Ingenieros Agrónomos., Madrid, Spanien }\end{array}$ \\
\hline FUB & $\begin{array}{l}\text { FU Berlin, Institut für Biologie, Angewandte Genetik, } \\
\text { Albrecht-Thaer-Weg 6, } 14195 \text { Berlin }\end{array}$ \\
\hline GAU & $\begin{array}{l}\text { Georg-August-Universität Göttingen, Department für } \\
\text { Nutzpflanzenwissenschaften, Abt. Pflanzenzüchtung, Von-Siebold- } \\
\text { Straße 8, } 37075 \text { Göttingen }\end{array}$ \\
\hline GBR & $\begin{array}{l}\text { Warwick Crop Centre, The University of Warwick, } \\
\text { WellesbourneWarwick, CV35 9EF, United Kingdom }\end{array}$ \\
\hline HAAS & $\begin{array}{l}\text { Hunan Agricultural University } \\
\text { Furong District, Changsha City, Hunan Province, P.R.China } 410128\end{array}$ \\
\hline HAU & $\begin{array}{l}\text { Huazhong Agricultural University, } \\
\text { No1, Shizishan Street, Hongshan District, Wuhan, Hubei Province, } \\
\text { P.R.China } 430070\end{array}$ \\
\hline IHAR & $\begin{array}{l}\text { Instytut Hodowli i Aklimatyzacji Roślin - Państwowy Instytut Badawczy } \\
\text { Radzików, 05-870 Błonie, Polen }\end{array}$ \\
\hline INRA & $\begin{array}{l}\text { INRA (Institute national de la recherché agronomique) } \\
147 \text { rue de l'université, } 75338 \text { Paris Cedex 07, Frankreich }\end{array}$ \\
\hline IPK & $\begin{array}{l}\text { Leibniz-Institut für Pflanzengenetik und Kulturpflanzenforschung (IPK) } \\
\text { Abt. Genbank, Corrensstraße 3, } 06466 \text { Gatersleben, Deutschland }\end{array}$ \\
\hline JAAS & $\begin{array}{l}\text { Jiangsu Academy of Agricutural Sciences, } \\
50 \text { Zhongling Street, Nanjing 210014, P.R.China, }\end{array}$ \\
\hline JLU & $\begin{array}{l}\text { Justus-Liebig-Universität Gießen, IFZ, Institut für Pflanzenbau und } \\
\text { Pflanzenzüchtung I, Heinrich-Buff-Ring 26, } 35392 \text { Gießen }\end{array}$ \\
\hline
\end{tabular}


Tab. I: Adressen der Zuchtfirmen, Forschungsinstitute und Genbanken (Fortsetzung)

\begin{tabular}{|c|c|}
\hline Abkürzung & Adresse \\
\hline Joordens & $\begin{array}{l}\text { Joordens Zaden B.V. } \\
\text { Postbus 7823, } 5995 \text { ZG Kessel, Niederlande }\end{array}$ \\
\hline KWS & $\begin{array}{l}\text { KWS SAAT AG, } \\
\text { Grimsehlstr. 31, Postfach 1463, } 37555 \text { Einbeck, Deutschland }\end{array}$ \\
\hline Limagrain & $\begin{array}{l}\text { Limagrain GmbH, } \\
\text { Griewenkamp 2, } 31234 \text { Edemissen, Deutschland }\end{array}$ \\
\hline Mansholt & $\begin{array}{l}\text { DR. R.J. MANSHOLT'S VEREDELINGSBEDRIJF B.V. } \\
\text { Westpolder } 8 \text { PB } 29975 \text { WJ Vierhuizen, Niederlande }\end{array}$ \\
\hline NPZ & $\begin{array}{l}\text { Norddeutsche Pflanzenzucht Hans-Georg Lembke KG, } \\
\text { Hohenlieth, } 24363 \text { Holtsee, Deutschland }\end{array}$ \\
\hline Petkus & siehe KWS \\
\hline Raps GbR & $\begin{array}{l}\text { Raps GbR Saatzucht Lundsgaard } \\
\text { Streichmühler Straße 8a, } 24977 \text { Grundhof, Deutschland }\end{array}$ \\
\hline Serasem & $\begin{array}{l}\text { Serasem, } \\
60 \text { rue Léon Beauchamp - BP 45, } 59933 \text { La Chapelle d'Armentières cedex } \\
\text { Frankreich }\end{array}$ \\
\hline $\begin{array}{l}\text { Svalöv } \\
\text { ( = SW Seed) }\end{array}$ & $\begin{array}{l}\text { Lantmännen SW Seed AB, } \\
26881 \text { Svalöv, Schweden }\end{array}$ \\
\hline Syngenta & $\begin{array}{l}\text { Syngenta Seeds GmbH, } \\
\text { Zum Knipkenbach 20, } 32107 \text { Bad Salzuflen, Deutschland }\end{array}$ \\
\hline U. of Man. & $\begin{array}{l}\text { Department of Plant Science, University of Manitoba, } \\
222 \text { Agriculture Building, } 66 \text { Dafoe Road ,Winnipeg, MB, Canada - R3T 2N2 }\end{array}$ \\
\hline VDLUFA & $\begin{array}{l}\text { VDLUFA Qualitätssicherung, } \\
\text { Am Versuchsfeld 13, } 34128 \text { Kassel }\end{array}$ \\
\hline WIAS & $\begin{array}{l}\text { Wanxian Institute of Agricultural Sciences of Sichuan Province, } \\
\text { Wanxian, P.R.China } 634006\end{array}$ \\
\hline ZAU & $\begin{array}{l}\text { ZheJiang Academy of Agriculteral Sciences, } \\
\text { Shiqiao Rd, Hangzhou. Zhejiang, P.R. China } 310021\end{array}$ \\
\hline ZNRio & nicht mehr existent, siehe IHAR \\
\hline
\end{tabular}




\section{Markeranalysen}



Abb. I: UPGMA Dendrogramm der Verwandtschaftsbeziehungen zwischen 55 Rapssorten und 71 Resynthesen mit Bootstrapwerten. Die Bootstrapwerte basieren auf einem Bootstrapping (FELSENSTEIN 1985) mit 10.000 Permutationen. Die Skala gibt die mittlere genetische Distanz nach Jaccard an. 


\section{Blattglucosinolatanalysen der Brassica-Wildarten}

Tab. II: Ergebnisse der HPLC-Analyse: Blattglucosinolatgehalt und Blattglucosinolatmuster der Brassica-Wildarten

\begin{tabular}{|c|c|c|c|c|c|c|c|c|c|c|c|c|c|}
\hline Genotyp & $\begin{array}{l}\text { IBE } \\
\text { [\%] }\end{array}$ & $\begin{array}{l}\text { PRO } \\
{[\%]}\end{array}$ & $\begin{array}{l}\text { SIN } \\
{[\%]}\end{array}$ & $\begin{array}{l}\text { RAA } \\
{[\%]}\end{array}$ & $\begin{array}{l}\text { GNL } \\
{[\%]}\end{array}$ & $\begin{array}{l}\text { GNA } \\
{[\%]}\end{array}$ & $\begin{array}{l}4 \mathrm{OH} \\
{[\%]}\end{array}$ & $\begin{array}{l}\text { GBN } \\
{[\%]}\end{array}$ & $\begin{array}{l}\text { GBC } \\
{[\%]}\end{array}$ & $\begin{array}{l}\text { NAS } \\
{[\%]}\end{array}$ & $\begin{array}{l}\text { 4ME } \\
{[\%]}\end{array}$ & $\begin{array}{l}\text { NEO } \\
{[\%]}\end{array}$ & $\begin{array}{l}\mathrm{GSL}_{\text {gesamt }} \\
{[\mu \mathrm{mol} / \mathrm{g}]}\end{array}$ \\
\hline BRA 2998 (B. bourgeauI) & 1,3 & 15,1 & 0,0 & 24,1 & 0,0 & 1,7 & 2,6 & 0,0 & 41,3 & 10,1 & 0,3 & 3,8 & 11,7 \\
\hline 5971 (B. cretica) & 0,0 & 1,6 & 0,3 & 0,0 & 0,0 & 94,9 & 0,1 & 0,0 & 2,2 & 0,9 & 0,0 & 0,0 & 55,9 \\
\hline BRA 2997 (B. cretica aegaea) & 0,0 & 1,2 & 0,0 & 9,8 & 0,0 & 85,7 & 0,1 & 0,4 & 1,8 & 0,8 & 0,0 & 0,0 & 71,0 \\
\hline 6021 (B. cretica aegaea) & 0,0 & 2,2 & 0,0 & 0,3 & 0,0 & 95,2 & 0,1 & 1,2 & 0,6 & 0,3 & 0,0 & 0,1 & 67,8 \\
\hline 6344 (B. cretica aegaea) & 0,1 & 2,6 & 29,0 & 0,0 & 0,0 & 64,3 & 0,1 & 0,1 & 1,4 & 1,0 & 0,0 & 1,4 & 53,4 \\
\hline 6346 (B. cretica aegaea) & 0,0 & 0,8 & 0,2 & 0,1 & 0,0 & 91,4 & 0,3 & 3,7 & 2,6 & 0,9 & 0,0 & 0,0 & 56,5 \\
\hline 3821 (B. villosa) & 34,2 & 0,0 & 0,4 & 0,1 & 0,4 & 0,4 & 62,8 & 0,0 & 1,2 & 0,7 & 0,0 & 0,0 & 22,3 \\
\hline BRA 1166 (B. incana) & 3,1 & 25,3 & 16,6 & 0,2 & 0,0 & 3,1 & 0,6 & 0,0 & 47,7 & 3,2 & 0,0 & 0,2 & 28,7 \\
\hline BRA 1262 (B. incana) & 51,7 & 0,7 & 21,0 & 1,3 & 0,0 & 1,9 & 0,5 & 0,0 & 21,7 & 1,1 & 0,0 & 0,1 & 19,6 \\
\hline 5974 (B. incana) & 55,4 & 2,4 & 13,2 & 12,3 & 0,0 & 0,7 & 0,2 & 0,0 & 15,2 & 0,7 & 0,0 & 0,0 & 36,6 \\
\hline 6558 (B. incana) & 0,0 & 1,4 & 0,2 & 21,4 & 0,0 & 57,3 & 14,5 & 0,0 & 4,7 & 0,5 & 0,0 & 0,0 & 63,3 \\
\hline 6560 (B. incana) & 4,0 & 3,0 & 6,5 & 18,8 & 0,0 & 43,9 & 11,1 & 0,0 & 11,6 & 1,2 & 0,0 & 0,0 & 21,0 \\
\hline 6563 (B. incana) & 0,0 & 1,6 & 0,0 & 58,0 & 1,0 & 12,3 & 3,1 & 0,0 & 22,9 & 1,1 & 0,0 & 0,0 & 22,5 \\
\hline 6564 (B. incana) & 0,0 & 1,7 & 0,0 & 32,7 & 0,0 & 40,6 & 10,3 & 0,0 & 12,5 & 2,3 & 0,0 & 0,0 & 26,3 \\
\hline 6570 (B. incana) & 0,3 & 2,0 & 0,2 & 0,4 & 0,2 & 61,1 & 15,4 & 0,0 & 18,0 & 1,1 & 0,0 & 1,3 & 17,4 \\
\hline 6572 (B. incana) & 1,7 & 2,0 & 0,2 & 0,1 & 0,2 & 71,6 & 18,0 & 0,0 & 5,7 & 0,4 & 0,1 & 0,0 & 47,5 \\
\hline HRIGRU 6691 (B. incana) & 0,0 & 4,0 & 0,0 & 35,5 & 0,0 & 27,0 & 0,4 & 0,0 & 31,2 & 2,0 & 0,0 & 0,0 & 32,8 \\
\hline CGN 18470 (B. incana) & 37,4 & 1,9 & 30,7 & 2,1 & 0,0 & 0,4 & 0,8 & 0,0 & 24,7 & 1,3 & 0,0 & 0,7 & 31,3 \\
\hline 1952 (B. insularis) & 0,3 & 0,2 & 97,1 & 0,0 & 0,0 & 0,3 & 0,1 & 0,0 & 0,1 & 0,3 & 0,0 & 1,7 & 56,5 \\
\hline BRA 2996 (B. insularis) & 0,2 & 48,8 & 0,1 & 0,1 & 0,0 & 27,1 & 0,1 & 0,9 & 0,6 & 21,1 & 0,0 & 1,0 & 64,9 \\
\hline BRA 3050 (B. insularis) & 0,0 & 7,4 & 0,2 & 0,0 & 0,0 & 90,4 & 0,1 & 0,0 & 0,3 & 1,7 & 0,0 & 0,0 & 41,8 \\
\hline BRA 3051 (B. insularis) & 0,4 & 42,8 & 0,3 & 0,0 & 0,0 & 46,1 & 0,1 & 0,6 & 0,5 & 8,4 & 0,0 & 0,9 & 59,9 \\
\hline 7346 (B. insularis) & 0,3 & 57,2 & 0,4 & 0,0 & 0,0 & 25,4 & 0,2 & 0,8 & 0,5 & 12,2 & 0,0 & 2,9 & 83,5 \\
\hline 7347 (B. insularis) & 0,4 & 50,8 & 0,2 & 0,1 & 0,3 & 34,1 & 0,0 & 1,0 & 0,6 & 11,9 & 0,0 & 0,8 & 51,8 \\
\hline
\end{tabular}


Tab. II: Ergebnisse der HPLC-Analyse: Blattglucosinolatgehalt und Blattglucosinolatmuster der Brassica-Wildarten (Fortsetzung)

\begin{tabular}{|c|c|c|c|c|c|c|c|c|c|c|c|c|c|}
\hline Genotyp & $\begin{array}{l}\text { IBE } \\
{[\%]}\end{array}$ & $\begin{array}{l}\text { PRO } \\
{[\%]}\end{array}$ & $\begin{array}{l}\text { SIN } \\
{[\%]}\end{array}$ & $\begin{array}{l}\text { RAA } \\
{[\%]}\end{array}$ & $\begin{array}{l}\text { GNL } \\
{[\%]}\end{array}$ & $\begin{array}{l}\text { GNA } \\
\text { [\%] }\end{array}$ & $\begin{array}{l}40 \mathrm{OH} \\
{[\%]}\end{array}$ & $\begin{array}{l}\text { GBN } \\
{[\%]}\end{array}$ & $\begin{array}{l}\text { GBC } \\
{[\%]}\end{array}$ & $\begin{array}{l}\text { NAS } \\
{[\%]}\end{array}$ & $\begin{array}{l}\text { 4ME } \\
{[\%]}\end{array}$ & $\begin{array}{l}\text { NEO } \\
{[\%]}\end{array}$ & $\begin{array}{l}\mathrm{GSL}_{\text {gesamt }} \\
{[\mu \mathrm{mol} / \mathrm{g}]}\end{array}$ \\
\hline 7356 (B. insularis) & 0,2 & 66,8 & 0,0 & 0,0 & 0,0 & 29,7 & 0,2 & 1,1 & 0,5 & 1,4 & 0,0 & 0,0 & 111,7 \\
\hline 3819 (B. macrocarpa) & 5,6 & 0,0 & 72,3 & 0,0 & 0,0 & 0,7 & 20,3 & 0,0 & 0,8 & 0,4 & 0,0 & 0,0 & 66,8 \\
\hline BRA 1644 (B. montana) & 28,3 & 4,5 & 17,6 & 2,7 & 0,0 & 0,2 & 1,4 & 0,0 & 30,3 & 12,8 & 0,0 & 2,4 & 16,0 \\
\hline BRA 2942 (B. montana) & 0,2 & 1,9 & 0,0 & 25,8 & 0,0 & 52,4 & 0,2 & 0,0 & 16,9 & 2,4 & 0,0 & 0,2 & 25,3 \\
\hline BRA 2993 (B. montana) & 0,0 & 2,3 & 0,0 & 3,1 & 0,0 & 76,7 & 1,2 & 0,0 & 9,7 & 5,8 & 0,0 & 1,6 & 10,1 \\
\hline BRA 3047(B. montana) & 0,0 & 2,7 & 0,3 & 0,1 & 0,0 & 82,0 & 0,5 & 0,1 & 12,9 & 0,7 & 0,0 & 0,7 & 35,3 \\
\hline 6816 (B. montana) & 0,0 & 1,1 & 0,2 & 0,1 & 0,1 & 96,4 & 0,1 & 1,3 & 0,6 & 0,3 & 0,0 & 0,0 & 117,5 \\
\hline CGN 18472 (B. montana) & 0,0 & 8,9 & 0,3 & 0,2 & 0,0 & 76,3 & 1,2 & 0,0 & 8,6 & 2,2 & 0,0 & 2,2 & 20,2 \\
\hline 6824 (B. oleracea) & 0,0 & 16,3 & 0,3 & 11,4 & 0,0 & 1,1 & 0,3 & 0,0 & 66,8 & 3,5 & 0,0 & 0,3 & 36,8 \\
\hline 7660 (B. oleracea) & 0,0 & 0,6 & 39,6 & 0,0 & 0,0 & 52,3 & 0,4 & 0,0 & 4,7 & 1,3 & 0,0 & 1,2 & 39,3 \\
\hline 7681 (B. oleracea) & 3,5 & 39,2 & 9,8 & 13,3 & 0,0 & 5,0 & 1,1 & 0,0 & 27,2 & 0,7 & 0,0 & 0,3 & 34,4 \\
\hline 7694 (B. oleracea) & 0,5 & 34,0 & 28,7 & 1,0 & 0,0 & 5,2 & 0,3 & 0,0 & 28,8 & 1,2 & 0,0 & 0,3 & 31,9 \\
\hline 6580 (B. rupestris hispida) & 0,7 & 0,0 & 0,0 & 97,4 & 0,1 & 0,0 & 0,4 & 0,0 & 1,3 & 0,0 & 0,0 & 0,0 & 22,7 \\
\hline BRA 2947 (B. taurica) & 27,1 & 1,2 & 10,7 & 13,9 & 0,0 & 0,0 & 1,5 & 0,0 & 39,6 & 5,5 & 0,0 & 0,7 & 10,8 \\
\hline 6581 (B. villosa bivoniana) & 0,7 & 0,0 & 0,0 & 97,0 & 0,0 & 0,0 & 0,3 & 0,0 & 1,2 & 0,8 & 0,0 & 0,0 & 31,0 \\
\hline HRIGRU 6848 (B. villosa) & 0,0 & 3,6 & 0,0 & 0,0 & 0,0 & 73,7 & 0,3 & 13,9 & 7,3 & 1,2 & 0,0 & 0,0 & 22,3 \\
\hline $\operatorname{LSD}(p=0,05)$ & 4,4 & 6,7 & 7,0 & 7,6 & 0,3 & 10,7 & 1,5 & 5,6 & 8,6 & 1,7 & 0,1 & 1,5 & 14,1 \\
\hline Mittelwert & 6,4 & 11,5 & 9,9 & 12,1 & 0,1 & 38,2 & 4,3 & 0,6 & 13,2 & 3,1 & 0,0 & 0,6 & 41,9 \\
\hline Min. & 0,0 & 0,0 & 0,0 & 0,0 & 0,0 & 0,0 & 0,0 & 0,0 & 0,1 & 0,0 & 0,0 & 0,0 & 10,1 \\
\hline Max. & 55,4 & 66,8 & 97,1 & 97,4 & 1,0 & 96,4 & 62,8 & 13,9 & 66,8 & 21,1 & 0,3 & 3,8 & 117,5 \\
\hline
\end{tabular}




\section{Beobachtungsanbau der Resynthesen}

Tab. III: Beobachtungsanbau der Resynthesen: Phytosterolgehalt und -Muster, gemittelt über sechs Standorte

\begin{tabular}{|c|c|c|c|c|c|c|}
\hline Genotyp & $\begin{array}{l}\text { Brassica } \\
\text {-sterol } \\
{[\mathrm{mg} / \mathrm{kg}]}\end{array}$ & $\begin{array}{l}\text { Campo } \\
\text {-sterol } \\
\text { [mg/kg] }\end{array}$ & $\begin{array}{l}\text { Stigma } \\
\text {-sterol } \\
{[\mathrm{mg} / \mathrm{kg}]}\end{array}$ & $\begin{array}{l}\text { Sito } \\
\text {-sterol } \\
\text { [mg/kg] }\end{array}$ & $\begin{array}{l}\text { Avena } \\
\text {-sterol } \\
\text { [mg/kg] }\end{array}$ & $\begin{array}{l}\text { Phytosterol } \\
\text { gesamt } \\
{[\mathrm{mg} / \mathrm{kg}]}\end{array}$ \\
\hline B1/3.3 & 310,9 & 1141,6 & 11,4 & 1879,8 & 61,5 & 3573,4 \\
\hline FS94.3 & 308,4 & 982,5 & 12,0 & 1803,9 & 34,6 & 3294,5 \\
\hline G39 & 328,6 & 918,6 & 12,7 & 1839,1 & 28,1 & 3291,0 \\
\hline G50 & 297,4 & 1171,6 & 11,4 & 1905,6 & 58,8 & 3553,4 \\
\hline H149 & 306,9 & 955,2 & 11,6 & 1694,5 & 45,9 & 3193,3 \\
\hline H165 & 310,9 & 898,0 & 12,2 & 1772,7 & 24,0 & 3207,2 \\
\hline H176 & 296,8 & 1098,7 & 10,9 & 1751,2 & 50,3 & 3354,2 \\
\hline H355 & 233,6 & 998,8 & 10,9 & 1696,5 & 41,0 & 3164,7 \\
\hline H44 & 335,2 & 949,8 & 12,1 & 1760,4 & 40,5 & 3228,8 \\
\hline INL2 & 305,2 & 1144,4 & 11,1 & 1830,3 & 59,1 & 3507,6 \\
\hline INY1 & 286,9 & 963,7 & 11,8 & 1768,5 & 29,8 & 3279,8 \\
\hline J134 & 332,0 & 1035,4 & 11,3 & 1734,7 & 57,2 & 3306,8 \\
\hline K160.1.1 & 286,3 & 1177,4 & 11,1 & 1868,7 & 51,4 & 3552,4 \\
\hline K199.16.2 & 259,8 & 1022,4 & 10,7 & 1648,9 & 38,2 & 3144,7 \\
\hline OLL1 & 310,9 & 1097,7 & 11,2 & 1821,9 & 55,5 & 3444,5 \\
\hline R53 & 275,1 & 1013,3 & 10,9 & 1666,7 & 36,3 & 3162,6 \\
\hline R99 & 271,0 & 1144,3 & 10,7 & 1768,5 & 44,2 & 3381,5 \\
\hline RS10/7 & 298,4 & 992,3 & 12,0 & 1806,7 & 33,1 & 3292,2 \\
\hline $\mathrm{RS} 7 / 6$ & 286,4 & 1013,5 & 11,5 & 1766,2 & 55,9 & 3288,6 \\
\hline RS8/6 & 291,3 & 1124,1 & 11,1 & 1820,4 & 42,8 & 3418,2 \\
\hline S108.1.1 & 297,9 & 1158,3 & 11,1 & 1869,5 & 46,5 & 3551,9 \\
\hline S13 & 227,6 & 985,4 & 10,9 & 1685,5 & 39,6 & 3142,8 \\
\hline S228.8.1 & 287,4 & 1064,5 & 11,6 & 1810,6 & 46,0 & 3396,5 \\
\hline Tester Syngenta & 325,8 & 1288,1 & 11,0 & 1998,3 & 64,2 & 3870,9 \\
\hline MSL 007 & 339,4 & 1382,1 & 10,4 & 1981,3 & 80,2 & 3984,3 \\
\hline Alesi & 332,1 & 1329,0 & 10,7 & 1993,7 & 79,8 & 3936,8 \\
\hline Elektra & 333,3 & 1411,1 & 10,4 & 2023,8 & 91,9 & 4067,7 \\
\hline Favorite & 337,5 & 1328,6 & 10,5 & 1948,7 & 82,6 & 3894,9 \\
\hline Ladoga & 332,8 & 1398,7 & 10,5 & 2049,5 & 98,5 & 4093,4 \\
\hline Lorenz & 357,8 & 1419,0 & 10,6 & 2075,3 & 100,7 & 4164,4 \\
\hline Oase & 328,6 & 1352,9 & 10,3 & 1948,6 & 88,5 & 3911,3 \\
\hline Trabant & 346,6 & 1381,0 & 10,5 & 2005,3 & 88,2 & 4022,5 \\
\hline Visby & 360,6 & 1403,8 & 10,8 & 2099,0 & 97,3 & 4178,1 \\
\hline $\operatorname{LSD}(p=0,05)$ & 20,4 & 87,03 & 0,38 & 74,28 & 12,05 & 181,2 \\
\hline Min. & 227,63 & 897,95 & 10,66 & 1648,88 & 23,97 & 3142,81 \\
\hline Max. & 335,16 & 1177,44 & 12,68 & 1905,64 & 61,45 & 3573,39 \\
\hline MW Resynthesen & 293,24 & 1045,71 & 11,39 & 1781,34 & 44,35 & 3336,11 \\
\hline MW Standards & 339,46 & 1369,43 & 10,58 & 2012,35 & 87,18 & 4012,42 \\
\hline
\end{tabular}

${ }^{a}$ Resynthesen, die nur am Standort Impington (GB) überlebt haben und daher nicht mit in die Gesamtauswertung eingeflossen sind 
Tab. III: Beobachtungsanbau der Resynthesen: Phytosterolgehalt und -Muster, gemittelt über sechs Standorte (Fortsetzung)

\begin{tabular}{lllllll}
\hline Genotyp & $\begin{array}{l}\text { Brassica } \\
\text {-sterol } \\
{[\mathbf{m g} / \mathbf{k g}]}\end{array}$ & $\begin{array}{l}\text { Campo } \\
\text {-sterol } \\
\text { [mg/kg] }\end{array}$ & $\begin{array}{l}\text { Stigma } \\
\text {-sterol } \\
\text { [mg/kg] }\end{array}$ & $\begin{array}{l}\text { Sito } \\
\text {-sterol } \\
{[\mathbf{m g} / \mathbf{k g}]}\end{array}$ & $\begin{array}{l}\text { Avena } \\
\text {-sterol } \\
{[\mathbf{m g} / \mathbf{k g}]}\end{array}$ & $\begin{array}{l}\text { Phytosterol } \\
\text { gesamt } \\
\text { [mg/kg] }\end{array}$ \\
\hline BOY1 $^{\text {a }}$ & 288,2 & 800,3 & 12,1 & 1628,5 & 27,7 & 2943,1 \\
CRL1 $^{\text {a }}$ & 310,6 & 977,0 & 12,7 & 1818,3 & 20,6 & 3316,9 \\
CRY1 $^{\text {a }}$ & 318,9 & 910,7 & 11,8 & 1703,1 & 38,5 & 3208,1 \\
HIY1 $^{\text {a }}$ & 281,5 & 909,5 & 11,9 & 1657,3 & 15,3 & 3067,5 \\
INY3 $^{\text {a }}$ & 335,8 & 903,8 & 12,9 & 1836,9 & 35,4 & 3389,8 \\
INY4 $^{\text {a }}$ & 313,7 & 826,4 & 12,4 & 1668,7 & 24,0 & 3053,3 \\
INY5 $^{\text {a }}$ & 214,2 & 1029,5 & 11,1 & 1713,9 & 18,1 & 3209,6 \\
MOY4 $^{\text {a }}$ & 230,0 & 990,1 & 11,4 & 1710,8 & 11,0 & 3177,0 \\
MOY5 $^{\text {a }}$ & 264,6 & 1039,0 & 11,6 & 1776,3 & 26,7 & 3350,3 \\
OLY2 $^{\text {a }}$ & 314,1 & 914,3 & 11,9 & 1720,6 & 13,1 & 3189,2 \\
RUY1 $^{\text {a }}$ & 289,9 & 922,1 & 12,1 & 1723,0 & 16,1 & 3207,2 \\
S237.20.1 $^{\text {a }}$ & 253,3 & 988,2 & 11,1 & 1676,3 & 9,3 & 3133,8 \\
S39 $^{\text {a }}$ & 310,9 & 1080,5 & 11,7 & 1858,3 & 39,7 & 3510,7 \\
S45.2.2 $^{\text {a }}$ & 342,5 & 1004,8 & 11,2 & 1709,2 & 59,8 & 3316,0 \\
\hline
\end{tabular}

${ }^{a}$ Resynthesen, die nur am Standort Impington (GB) überlebt haben und daher nicht mit in die Gesamtauswertung eingeflossen sind

Tab IV: Beobachtungsanbau der Resynthesen: NIRS-Ergebnisse für die Sinapoylver-bindungen, gemittelt über sechs Standorte

\begin{tabular}{|c|c|c|c|c|}
\hline Genotyp & $\begin{array}{c}\text { Sinapoylglucose } \\
{[\mathrm{mg} / \mathrm{g}]}\end{array}$ & $\begin{array}{c}\text { Sinapin } \\
{[\mathrm{mg} / \mathrm{g}]}\end{array}$ & $\begin{array}{c}\text { Sinapinsäure } \\
\text { gesamt }[\mathrm{mg} / \mathrm{g}]^{\mathrm{a}}\end{array}$ & $\begin{array}{c}{\text { andere } \mathrm{SE}^{\mathrm{b}}}^{[\mathrm{mg} / \mathrm{g}]^{\mathrm{a}}} \\
\end{array}$ \\
\hline B1/3.3 & 2,2 & 6,9 & 6,9 & 1,2 \\
\hline FS94.3 & 1,6 & 7,8 & 6,6 & 0,8 \\
\hline G39 & 2,1 & 6,9 & 6,1 & 0,9 \\
\hline G50 & 2,8 & 6,7 & 7,9 & 1,6 \\
\hline H149 & 2,3 & 6,7 & 6,2 & 0,9 \\
\hline H165 & 1,4 & 7,7 & 5,8 & 0,4 \\
\hline H176 & 2,9 & 6,4 & 7,3 & 1,6 \\
\hline H355 & 2,6 & 7,2 & 7,1 & 1,1 \\
\hline H44 & 2,1 & 7,0 & 6,6 & 1,0 \\
\hline INL2 & 2,6 & 7,6 & 7,9 & 1,4 \\
\hline INY1 & 1,7 & 7,6 & 6,0 & 0,7 \\
\hline J134 & 2,7 & 6,5 & 6,9 & 1,3 \\
\hline K160.1.1 & 2,2 & 5,9 & 6,3 & 1,2 \\
\hline K199.16.2 & 3,0 & 6,7 & 7,4 & 1,4 \\
\hline OLL1 & 2,7 & 6,7 & 7,3 & 1,4 \\
\hline R53 & 2,8 & 6,7 & 7,3 & 1,3 \\
\hline R99 & 2,4 & 6,5 & 6,9 & 1,3 \\
\hline
\end{tabular}

a berechnet als Sinapinsäureäquivalente, ${ }^{\mathrm{b}} \mathrm{SE}=$ Sinapinsäureester, ${ }^{\mathrm{C}}$ Resynthesen, die nur am Standort Impington (GB) überlebt haben und daher nicht mit in die Gesamtauswertung eingeflossen sind 
Tab IV: Beobachtungsanbau der Resynthesen: NIRS-Ergebnisse für die Sinapoylverbindungen, gemittelt über sechs Standorte (Fortsetzung)

\begin{tabular}{|c|c|c|c|c|}
\hline Genotyp & $\begin{array}{c}\text { Sinapoylglucose } \\
{[\mathrm{mg} / \mathrm{g}]}\end{array}$ & $\begin{array}{l}\text { Sinapin } \\
{[\mathrm{mg} / \mathrm{g}]}\end{array}$ & $\begin{array}{c}\text { Sinapinsäure } \\
\text { gesamt }[\mathrm{mg} / \mathrm{g}]^{\mathrm{a}}\end{array}$ & $\begin{array}{c}\text { andere SE }^{b} \\
{[\mathrm{mg} / \mathrm{g}]^{\mathrm{a}}}\end{array}$ \\
\hline RS10/7 & 2,8 & 7,3 & 6,9 & 1,0 \\
\hline $\mathrm{RS} 7 / 6$ & 1,6 & 7,9 & 6,9 & 0,9 \\
\hline RS8/6 & 2,8 & 7,7 & 8,0 & 1,3 \\
\hline S108.1.1 & 3,4 & 6,3 & 7,8 & 1,6 \\
\hline S13 & 2,4 & 7,5 & 7,1 & 1,0 \\
\hline S228.8.1 & 2,5 & 6,7 & 7,1 & 1,3 \\
\hline Tester Syngenta & 3,5 & 6,0 & 7,8 & 1,8 \\
\hline MSL 007 & 3,0 & 7,1 & 8,0 & 1,6 \\
\hline Alesi & 3,4 & 5,8 & 7,4 & 1,8 \\
\hline Elektra & 4,0 & 6,5 & 8,5 & 2,0 \\
\hline Favorite & 3,7 & 5,3 & 7,6 & 2,0 \\
\hline Ladoga & 4,3 & 5,9 & 8,3 & 2,0 \\
\hline Lorenz & 3,8 & 6,1 & 8,1 & 2,0 \\
\hline Oase & 3,7 & 6,6 & 8,5 & 1,9 \\
\hline Trabant & 3,5 & 6,4 & 8,3 & 1,9 \\
\hline Visby & 4,1 & 6,3 & 8,6 & 2,1 \\
\hline LSD $(p=0,05)$ & 0,46 & 0,53 & 0,62 & 0,24 \\
\hline Min. & 1,40 & 5,93 & 5,79 & 0,36 \\
\hline Max. & 3,43 & 7,93 & 8,01 & 1,62 \\
\hline MW Resynthesen & 2,42 & 6,99 & 6,96 & 1,14 \\
\hline MW Standards & 3,70 & 6,21 & 8,09 & 1,92 \\
\hline BOY ${ }^{c}$ & 2,1 & 6,8 & 5,9 & 0,6 \\
\hline $\mathrm{CRL1}^{\mathrm{C}}$ & 1,8 & 7,6 & 6,4 & 0,9 \\
\hline $\mathrm{CRY}^{\mathrm{C}}$ & 1,4 & 7,0 & 4,9 & 0,7 \\
\hline$H I Y 1^{c}$ & 0,5 & 8,2 & 5,2 & 0,2 \\
\hline INY3 $^{c}$ & 1,1 & 4,7 & 2,8 & 0,1 \\
\hline INY4 ${ }^{c}$ & 0,7 & 7,9 & 4,8 & 0,3 \\
\hline INY5 ${ }^{c}$ & 1,5 & 8,0 & 6,4 & 0,5 \\
\hline MOY4 $^{\mathrm{C}}$ & 1,0 & 8,0 & 6,4 & 0,7 \\
\hline MOY5 $^{\mathrm{C}}$ & 2,0 & 6,5 & 5,3 & 0,5 \\
\hline OLY2 $^{c}$ & 3,2 & 5,9 & 5,5 & 0,7 \\
\hline RUY1 $^{c}$ & 1,4 & 6,2 & 4,3 & 0,4 \\
\hline $\mathrm{S} 237.20 .1^{\mathrm{C}}$ & 2,3 & 5,9 & 5,6 & 0,8 \\
\hline $\mathrm{S} 39^{\mathrm{c}}$ & 3,3 & 6,1 & 6,4 & 0,8 \\
\hline$S 45.2 .2^{c}$ & 1,8 & 9,0 & 7,4 & 1,1 \\
\hline
\end{tabular}

${ }^{a}$ berechnet als Sinapinsäureäquivalente, ${ }^{b} \mathrm{SE}=$ Sinapinsäureester, ${ }^{\mathrm{C}}$ Resynthesen, die nur am Standort Impington (GB) überlebt haben und daher nicht mit in die Gesamtauswertung eingeflossen sind 
Tab. V: Ergebnisse der ANOVA für den Beobachtungsanbau der Resynthesen am Standort Impington (GB), gezeigt sind die Varianzkomponenten und die Heritabilität der einzelnen Merkmale

\begin{tabular}{|c|c|c|c|c|c|}
\hline & Varianzursache $^{a}$ & Genotyp & Wdh. & GxW & $h^{2}$ \\
\hline & TKG & $2,27^{* *}$ & 0,00 & 0,36 & 0,93 \\
\hline & ÖL & $8,17^{* *}$ & 0,02 & 1,53 & 0,96 \\
\hline & C18:3 & $0,53^{* *}$ & $0,02^{*}$ & 0,25 & 0,81 \\
\hline & C22:1 & $129,09^{* *}$ & 0,16 & 1,38 & 0,92 \\
\hline & Protein & $5,01^{* *}$ & $-0,01$ & 0,55 & 0,95 \\
\hline & Glucosinolate & $844,63^{* *}$ & $1,41^{+}$ & 33,98 & 0,98 \\
\hline \multirow{6}{*}{$\begin{array}{l}\frac{0}{0} \\
\frac{0}{0} \\
\frac{1}{0} \\
\stackrel{0}{\frac{1}{\alpha}} \\
\frac{1}{\square}\end{array}$} & Brassicasterol & $1328,24^{* *}$ & $16,06^{+}$ & 356,71 & 0,88 \\
\hline & Camposterol & $6747,47^{\star *}$ & $155,70^{+}$ & 620,42 & 0,96 \\
\hline & Stigmasterol & $0,53^{* *}$ & 0,00 & 0,13 & 0,89 \\
\hline & Sitosterol & $18115,81^{* *}$ & 51,41 & 1536,40 & 0,96 \\
\hline & Avenasterol & $580,09^{* *}$ & $-0,54$ & 66,51 & 0,96 \\
\hline & Phytosterol gesamt & $123670,78^{* *}$ & $1052,07^{* *}$ & 6014,81 & 0,98 \\
\hline \multirow{4}{*}{ 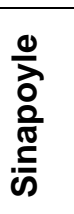 } & Sinapoylglucose & $0,87^{\star *}$ & $0,00^{* *}$ & 0,24 & 0,88 \\
\hline & Sinapin & $0,81^{* *}$ & $0,10^{* *}$ & 0,27 & 0,86 \\
\hline & andere $\mathrm{SE}^{\mathrm{c}}$ & $0,23^{* *}$ & $0,01^{* *}$ & 0,04 & 0,91 \\
\hline & Sinapinsäure gesamt & $1,22^{* *}$ & $0,09^{* *}$ & 0,40 & 0,86 \\
\hline
\end{tabular}

${ }^{+*},{ }^{* *}$ signifikant bei $p=0,1, p=, 05$ bzw. bei $p=0,01,{ }^{a}$ Wdh. $=$ Wiederholung, GxW = Interaktion zwischen Genotyp und Wiederholung, $h^{2}=$ Heritabilität; ${ }^{b}$ Fehler geschätzt aus 4 Orten mit je 2 Wiederholungen; ${ }^{c} \mathrm{SE}=$ Sinapinsäureester 
Tab. VI: Gesamtglucosinolatgehalt und Glucosinolatmuster der Resynthesen vom Standort Impington (GB)

\begin{tabular}{|c|c|c|c|c|c|c|c|c|c|c|c|c|c|}
\hline Genotyp & $\begin{array}{l}\text { PRO } \\
{[\%]}\end{array}$ & $\begin{array}{l}\text { SIN } \\
{[\%]}\end{array}$ & $\begin{array}{l}\text { GNL } \\
{[\%]}\end{array}$ & 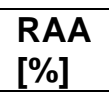 & $\begin{array}{l}\text { RAE } \\
{[\%]}\end{array}$ & $\begin{array}{l}\text { GNA } \\
\text { [\%] }\end{array}$ & $\begin{array}{l}4 \mathrm{OH} \\
{[\%]}\end{array}$ & $\begin{array}{l}\text { GBN } \\
{[\%]}\end{array}$ & $\begin{array}{l}\text { GBC } \\
{[\%]}\end{array}$ & $\begin{array}{l}\text { NAS } \\
{[\%]}\end{array}$ & $\begin{array}{l}\text { 4ME } \\
{[\%]}\end{array}$ & $\begin{array}{l}\text { NEO } \\
{[\%]}\end{array}$ & $\begin{array}{l}\text { GSL gesamt } \\
{[\mu \mathrm{mol} / \mathrm{g}]}\end{array}$ \\
\hline B1/3.3 & 53,2 & 1,2 & 6,7 & 0,0 & 0,0 & 19,3 & 14,5 & 1,4 & 1,7 & 1,6 & 0,2 & 0,1 & 57,2 \\
\hline BOY1 & 67,8 & 8,6 & 0,0 & 0,0 & 0,0 & 15,9 & 3,8 & 3,4 & 0,3 & 0,2 & 0,0 & 0,0 & 182,0 \\
\hline CRL1 & 3,0 & 0,0 & 0,2 & 0,2 & 4,8 & 67,1 & 3,6 & 18,3 & 0,2 & 2,5 & 0,0 & 0,0 & 97,0 \\
\hline CRY1 & 3,1 & 0,1 & 0,1 & 0,0 & 0,0 & 92,3 & 4,0 & 0,1 & 0,1 & 0,2 & 0,0 & 0,0 & 137,6 \\
\hline FS94.3 & 50,6 & 0,5 & 4,4 & 2,1 & 2,9 & 22,5 & 6,8 & 7,8 & 0,3 & 1,9 & 0,2 & 0,0 & 87,9 \\
\hline G39 & 53,0 & 0,1 & 24,2 & 2,4 & 0,2 & 12,2 & 4,7 & 2,3 & 0,2 & 0,6 & 0,1 & 0,0 & 113,5 \\
\hline G50 & 35,0 & 0,1 & 7,1 & 6,5 & 9,8 & 11,3 & 11,3 & 14,4 & 0,9 & 3,4 & 0,1 & 0,1 & 55,0 \\
\hline H149 & 67,0 & 2,3 & 0,0 & 3,0 & 1,8 & 14,3 & 5,1 & 4,3 & 0,1 & 1,8 & 0,2 & 0,0 & 72,7 \\
\hline H165 & 71,1 & 0,9 & 0,1 & 1,5 & 4,6 & 14,7 & 2,8 & 3,1 & 0,1 & 1,1 & 0,1 & 0,0 & 100,5 \\
\hline H176 & 56,6 & 0,4 & 0,0 & 1,8 & 1,4 & 21,9 & 11,5 & 4,1 & 0,7 & 1,2 & 0,3 & 0,0 & 53,4 \\
\hline H355 & 59,6 & 0,4 & 0,1 & 3,1 & 2,0 & 22,1 & 1,8 & 8,0 & 0,1 & 2,8 & 0,1 & 0,0 & 99,2 \\
\hline H44 & 35,6 & 0,0 & 4,7 & 1,8 & 7,4 & 31,0 & 7,4 & 8,5 & 0,6 & 3,0 & 0,1 & 0,0 & 55,3 \\
\hline HIY1 & 2,7 & 0,0 & 0,0 & 0,2 & 0,1 & 94,4 & 2,4 & 0,1 & 0,1 & 0,1 & 0,0 & 0,0 & 144,1 \\
\hline INL2 & 38,8 & 0,2 & 0,2 & 0,5 & 2,6 & 42,9 & 6,7 & 6,4 & 0,2 & 1,2 & 0,1 & 0,0 & 69,6 \\
\hline INY1 & 2,2 & 0,0 & 0,9 & 1,0 & 0,0 & 93,0 & 2,5 & 0,0 & 0,0 & 0,4 & 0,0 & 0,0 & 69,0 \\
\hline INY3 & 1,5 & 0,0 & 0,2 & 0,0 & 0,0 & 96,3 & 1,4 & 0,4 & 0,0 & 0,1 & 0,0 & 0,0 & 139,4 \\
\hline INY4 & 10,0 & 0,0 & 5,2 & 0,3 & 0,2 & 82,0 & 1,6 & 0,6 & 0,0 & 0,1 & 0,0 & 0,0 & 135,0 \\
\hline INY5 & 7,3 & 0,1 & 0,1 & 0,2 & 0,5 & 87,2 & 3,2 & 0,9 & 0,1 & 0,3 & 0,0 & 0,0 & 140,2 \\
\hline J134 & 39,0 & 0,1 & 5,7 & 1,6 & 5,1 & 27,4 & 8,7 & 9,2 & 0,5 & 2,5 & 0,1 & 0,1 & 54,9 \\
\hline K160.1.1 & 22,1 & 1,2 & 5,3 & 0,4 & 2,1 & 53,1 & 9,6 & 3,5 & 0,6 & 1,8 & 0,2 & 0,0 & 69,6 \\
\hline K199.16.2 & 43,6 & 0,0 & 11,4 & 0,4 & 7,1 & 14,7 & 12,6 & 5,2 & 1,4 & 3,3 & 0,2 & 0,1 & 61,9 \\
\hline MOY4 & 1,2 & 0,0 & 0,0 & 0,0 & 0,0 & 94,9 & 3,3 & 0,3 & 0,1 & 0,2 & 0,0 & 0,0 & 137,4 \\
\hline MOY5 & 1,0 & 0,0 & 0,0 & 0,0 & 0,1 & 94,2 & 4,5 & 0,2 & 0,1 & 0,2 & 0,0 & 0,0 & 100,6 \\
\hline OLL1 & 40,0 & 1,0 & 7,1 & 1,9 & 10,2 & 18,6 & 9,4 & 7,9 & 1,0 & 2,8 & 0,2 & 0,1 & 79,3 \\
\hline OLY2 & 7,6 & 38,6 & 37,2 & 0,0 & 0,0 & 10,4 & 5,8 & 0,0 & 0,1 & 0,3 & 0,0 & 0,0 & 43,9 \\
\hline R53 & 47,3 & 0,0 & 11,7 & 2,8 & 4,1 & 13,1 & 12,3 & 4,3 & 0,9 & 3,1 & 0,2 & 0,1 & 63,9 \\
\hline
\end{tabular}


Tab. VI: Gesamtglucosinolatgehalt und Glucosinolatmuster der Resynthesen vom Standort Impington (GB) (Fortsetzung)

\begin{tabular}{|c|c|c|c|c|c|c|c|c|c|c|c|c|c|}
\hline Genotyp & $\begin{array}{l}\text { PRO } \\
{[\%]}\end{array}$ & $\begin{array}{l}\text { SIN } \\
{[\%]}\end{array}$ & $\begin{array}{l}\text { GNL } \\
{[\%]}\end{array}$ & $\begin{array}{l}\text { RAA } \\
{[\%]}\end{array}$ & $\begin{array}{l}\text { RAE } \\
{[\%]}\end{array}$ & $\begin{array}{l}\text { GNA } \\
{[\%]}\end{array}$ & $\begin{array}{l}4 \mathrm{OH} \\
{[\%]}\end{array}$ & $\begin{array}{l}\text { GBN } \\
{[\%]}\end{array}$ & $\begin{array}{l}\text { GBC } \\
{[\%]}\end{array}$ & $\begin{array}{l}\text { NAS } \\
{[\%]}\end{array}$ & $\begin{array}{l}4 \mathrm{ME} \\
{[\%]}\end{array}$ & $\begin{array}{l}\text { NEO } \\
{[\%]}\end{array}$ & $\begin{array}{l}\text { GSL gesamt } \\
{[\mu \mathrm{mol} / \mathrm{g}]}\end{array}$ \\
\hline R99 & 28,5 & 0,0 & 11,4 & 0,3 & 2,0 & 40,8 & 12,3 & 1,5 & 0,9 & 2,0 & 0,2 & 0,1 & 60,8 \\
\hline RS10/7 & 50,2 & 0,0 & 24,5 & 1,6 & 0,6 & 13,3 & 6,5 & 2,1 & 0,1 & 0,9 & 0,1 & 0,0 & 114,2 \\
\hline $\mathrm{RS} 7 / 6$ & 59,8 & 0,1 & 8,0 & 1,0 & 0,3 & 21,1 & 6,7 & 1,4 & 0,3 & 1,1 & 0,2 & 0,0 & 103,2 \\
\hline RS8/6 & 60,3 & 1,4 & 4,5 & 1,2 & 2,1 & 19,4 & 6,4 & 3,3 & 0,1 & 1,0 & 0,2 & 0,0 & 75,0 \\
\hline RUY1 & 3,9 & 0,3 & 0,3 & 0,0 & 0,0 & 92,9 & 2,2 & 0,2 & 0,0 & 0,2 & 0,0 & 0,0 & 130,8 \\
\hline S108.1.1 & 61,1 & 0,0 & 7,4 & 1,0 & 0,1 & 18,9 & 7,4 & 2,0 & 0,7 & 1,1 & 0,2 & 0,1 & 70,9 \\
\hline S13 & 58,5 & 0,5 & 0,1 & 2,8 & 2,2 & 22,5 & 2,1 & 8,2 & 0,1 & 2,9 & 0,1 & 0,1 & 90,9 \\
\hline S228.8.1 & 64,1 & 2,3 & 0,5 & 1,1 & 1,6 & 18,3 & 8,8 & 1,9 & 0,3 & 0,8 & 0,3 & 0,1 & 74,8 \\
\hline S237.20.1 & 4,1 & 0,0 & 7,5 & 0,0 & 0,8 & 80,1 & 2,3 & 4,2 & 0,1 & 0,9 & 0,0 & 0,0 & 88,9 \\
\hline S39 & 53,9 & 0,3 & 21,2 & 2,2 & 1,1 & 11,6 & 5,0 & 3,6 & 0,2 & 0,7 & 0,2 & 0,1 & 111,0 \\
\hline S45.2.2 & 38,4 & 3,3 & 0,0 & 4,4 & 7,0 & 28,8 & 6,6 & 8,7 & 0,2 & 2,4 & 0,2 & 0,1 & 80,7 \\
\hline VIL1 & 4,7 & 0,0 & 0,2 & 0,0 & 0,0 & 91,9 & 2,1 & 0,8 & 0,1 & 0,2 & 0,0 & 0,0 & 129,7 \\
\hline Tester Syngenta & 52,3 & 0,0 & 1,0 & 0,0 & 0,0 & 20,5 & 18,5 & 4,7 & 1,6 & 1,0 & 0,3 & 0,2 & 26,7 \\
\hline MSL007 & 45,5 & 0,6 & 0,1 & 0,0 & 0,0 & 19,6 & 26,6 & 4,4 & 0,8 & 1,9 & 0,4 & 0,1 & 21,4 \\
\hline Alesi & 48,4 & 0,5 & 0,0 & 0,0 & 0,0 & 18,6 & 25,4 & 3,1 & 1,8 & 1,6 & 0,6 & 0,2 & 18,9 \\
\hline Elektra & 50,2 & 1,5 & 0,3 & 0,0 & 0,0 & 21,5 & 20,0 & 3,8 & 0,5 & 1,6 & 0,4 & 0,2 & 22,8 \\
\hline Favorite & 35,3 & 0,0 & 1,6 & 0,7 & 3,7 & 23,6 & 27,6 & 2,7 & 1,8 & 2,4 & 0,3 & 0,3 & 17,7 \\
\hline Ladoga & 37,4 & 1,4 & 0,5 & 1,5 & 6,8 & 21,1 & 25,0 & 1,1 & 1,7 & 2,2 & 0,6 & 0,9 & 19,8 \\
\hline Lorenz & 37,5 & 1,4 & 0,0 & 1,1 & 3,0 & 26,8 & 21,2 & 5,3 & 1,2 & 1,9 & 0,4 & 0,4 & 25,1 \\
\hline Oase & 46,5 & 1,7 & 0,1 & 0,0 & 0,0 & 20,0 & 24,7 & 2,3 & 1,2 & 2,8 & 0,4 & 0,3 & 19,5 \\
\hline Trabant & 46,9 & 0,3 & 0,4 & 1,3 & 1,9 & 19,6 & 21,4 & 4,7 & 1,0 & 1,9 & 0,3 & 0,4 & 24,6 \\
\hline Visby & 51,7 & 0,3 & 0,0 & 0,9 & 1,0 & 15,7 & 23,8 & 3,0 & 1,3 & 1,0 & 0,4 & 1,1 & 18,8 \\
\hline $\operatorname{LSD}(p=0.05)$ & 12,0 & 2,5 & 7,1 & 1,5 & 1,7 & 17,2 & 3,2 & 2,2 & 0,7 & 0,6 & 0,1 & 0,2 & 15,8 \\
\hline Min. & 1,0 & 0,0 & 0,0 & 0,0 & 0,0 & 10,4 & 1,4 & 0,0 & 0,0 & 0,1 & 0,0 & 0,0 & 17,7 \\
\hline Max: & 71,1 & 38,6 & 37,2 & 6,5 & 10,2 & 96,3 & 27,6 & 18,3 & 1,8 & 3,4 & 0,6 & 1,1 & 182,0 \\
\hline MW Resynthesen & 34,4 & 1,7 & 5,7 & 1,2 & 2,2 & 42,8 & 6,0 & 4,0 & 0,4 & 1,3 & 0,1 & 0,0 & 93,4 \\
\hline
\end{tabular}


Tab. VI: Gesamtglucosinolatgehalt und Glucosinolatmuster der Resynthesen vom Standort Impington (GB) (Fortsetzung)

\begin{tabular}{|c|c|c|c|c|c|c|c|c|c|c|c|c|c|}
\hline Genotyp & $\begin{array}{l}\text { PRO } \\
{[\%]}\end{array}$ & $\begin{array}{l}\text { SIN } \\
{[\%]}\end{array}$ & $\begin{array}{l}\text { GNL } \\
{[\%]}\end{array}$ & $\begin{array}{l}\text { RAA } \\
{[\%]}\end{array}$ & $\begin{array}{l}\text { RAE } \\
{[\%]}\end{array}$ & $\begin{array}{l}\text { GNA } \\
{[\%]}\end{array}$ & $\begin{array}{l}\mathbf{4 O H} \\
{[\%]}\end{array}$ & $\begin{array}{l}\text { GBN } \\
{[\%]}\end{array}$ & $\begin{array}{l}\text { GBC } \\
{[\%]}\end{array}$ & $\begin{array}{l}\text { NAS } \\
{[\%]}\end{array}$ & $\begin{array}{l}\mathrm{ME} \\
{[\%]}\end{array}$ & $\begin{array}{l}\text { NEO } \\
{[\%]}\end{array}$ & $\begin{array}{l}\text { GSL gesamt } \\
{[\mu \mathrm{mol} / \mathrm{g}]}\end{array}$ \\
\hline Min. & 1,0 & 0,0 & 0,0 & 0,0 & 0,0 & 10,4 & 1,4 & 0,0 & 0,0 & 0,1 & 0,0 & 0,0 & 17,7 \\
\hline MW Resynthesen & 34,4 & 1,7 & 5,7 & 1,2 & 2,2 & 42,8 & 6,0 & 4,0 & 0,4 & 1,3 & 0,1 & 0,0 & 93,4 \\
\hline MW Standards & 45,2 & 0,8 & 0,4 & 0,6 & 1,6 & 20,7 & 23,4 & 3,5 & 1,3 & 1,8 & 0,4 & 0,4 & 21,5 \\
\hline $\mathrm{J} 401^{1}$ & 24,2 & 4,9 & 0,1 & 0,0 & 0,3 & 57,0 & 0,0 & 9,6 & 0,2 & 3,9 & 0,0 & 0,0 & 40,6 \\
\hline
\end{tabular}

${ }^{1}$ Ergebnisse für diese Resynthesen stammen vom Standort Göttingen und wurden daher nicht zusammen mit den übrigen aufgeführten Resynthesen vom Standort Impington (UK)

verrechnet. 


\section{Beobachtungsanbau der Testhybriden}

Tab. VII: Beobachtungsanbau der Testhybriden: Phytosterolgehalt und -Muster, gemittelt über vier Standorte

\begin{tabular}{|c|c|c|c|c|c|c|}
\hline Genotyp & $\begin{array}{l}\text { Brassica } \\
\text {-sterol } \\
\text { [mg/kg] }\end{array}$ & $\begin{array}{l}\text { Campo } \\
\text {-sterol } \\
\text { [mg/kg] }\end{array}$ & $\begin{array}{l}\text { Stigma } \\
\text {-sterol } \\
\text { [mg/kg] }\end{array}$ & $\begin{array}{l}\text { Sito } \\
\text {-sterol } \\
\text { [mg/kg] }\end{array}$ & $\begin{array}{l}\text { Avena } \\
\text {-sterol } \\
\text { [mg/kg] }\end{array}$ & $\begin{array}{l}\text { Phytosterol } \\
\text { gesamt } \\
{[\mathrm{mg} / \mathrm{kg}]}\end{array}$ \\
\hline MxB1/3.3 & 295,2 & 1246,5 & 10,6 & 1880,3 & 67,2 & 3663,1 \\
\hline MxBOY1 & 275,7 & 1108,6 & 10,8 & 1743,3 & 44,5 & 3365,5 \\
\hline MxCRY1 & 273,0 & 1118,3 & 11,2 & 1819,6 & 45,3 & 3446,2 \\
\hline MxFS94.3 & 332,5 & 1330,7 & 10,6 & 1970,9 & 79,5 & 3885,7 \\
\hline MxG39 & 307,3 & 1253,5 & 10,7 & 1886,4 & 64,9 & 3697,7 \\
\hline MxG50 & 311,1 & 1412,8 & 10,3 & 2003,1 & 77,5 & 3976,8 \\
\hline MxH149 & 294,3 & 1169,5 & 10,3 & 1742,7 & 69,4 & 3456,1 \\
\hline MxH165 & 311,5 & 1238,0 & 10,4 & 1836,1 & 65,6 & 3640,4 \\
\hline MxH176 & 324,2 & 1262,0 & 10,2 & 1828,3 & 77,3 & 3651,1 \\
\hline MxH355 & 276,5 & 1107,6 & 10,5 & 1718,5 & 53,8 & 3336,2 \\
\hline MxH44 & 322,9 & 1118,4 & 10,7 & 1751,9 & 66,5 & 3427,5 \\
\hline MxHIY1 & 262,4 & 1094,4 & 10,9 & 1743,9 & 41,4 & 3326,6 \\
\hline MxINL1 & 339,2 & 1221,6 & 11,0 & 1870,6 & 65,5 & 3663,5 \\
\hline MxINL2 & 319,4 & 1187,0 & 11,0 & 1837,6 & 61,0 & 3569,3 \\
\hline MxINY1 & 283,3 & 1063,1 & 11,2 & 1772,2 & 29,6 & 3351,5 \\
\hline MxINY4 & 305,9 & 1066,5 & 11,7 & 1822,1 & 40,5 & 3437,4 \\
\hline MxINY6 & 289,2 & 1240,1 & 11,0 & 1896,2 & 49,6 & 3661,7 \\
\hline MxJ104 & 282,9 & 1093,3 & 11,2 & 1773,0 & 44,7 & 3368,9 \\
\hline MxJ112 & 330,3 & 1303,1 & 10,6 & 1938,6 & 68,2 & 3840,6 \\
\hline MxJ134 & 341,4 & 1185,1 & 11,0 & 1840,2 & 70,8 & 3590,0 \\
\hline MxJ154 & 309,3 & 1179,7 & 10,9 & 1850,4 & 65,9 & 3579,5 \\
\hline MxJ161 & 298,2 & 1112,0 & 10,8 & 1759,1 & 58,1 & 3378,7 \\
\hline MxJ166 & 267,7 & 1203,1 & 10,8 & 1821,6 & 50,2 & 3458,8 \\
\hline MxJ32 & 309,1 & 1238,9 & 10,7 & 1873,8 & 59,7 & 3657,7 \\
\hline MxJ400 & 283,5 & 1143,9 & 11,2 & 1823,6 & 50,4 & 3497,8 \\
\hline MxJ401 & 342,1 & 1210,4 & 10,8 & 1847,8 & 70,0 & 3643,5 \\
\hline MxJ408 & 299,8 & 1194,0 & 10,7 & 1826,0 & 58,9 & 3562,4 \\
\hline MxJ410 & 279,3 & 1138,8 & 10,8 & 1762,4 & 47,3 & 3407,6 \\
\hline MxJ45 & 275,5 & 1143,4 & 11,0 & 1798,3 & 50,0 & 3442,2 \\
\hline MxK199.16.2 & 297,2 & 1134,6 & 10,6 & 1744,6 & 59,5 & 3389,6 \\
\hline MxMOL1 & 275,5 & 1260,9 & 10,5 & 1876,3 & 52,3 & 3634,6 \\
\hline MxMOL2 & 312,9 & 1224,9 & 10,9 & 1905,6 & 60,9 & 3687,3 \\
\hline MxMOY2 & 306,3 & 1276,6 & 10,4 & 1877,7 & 63,9 & 3692,8 \\
\hline MxMOY4 & 302,4 & 1300,4 & 10,4 & 1916,1 & 74,7 & 3779,4 \\
\hline MxMOY5 & 297,0 & 1111,7 & 11,1 & 1795,7 & 44,3 & 3421,3 \\
\hline MxMOY6 & 288,3 & 1006,5 & 11,8 & 1789,7 & 13,4 & 3302,7 \\
\hline MxOLL1 & 332,6 & 1225,9 & 10,8 & 1862,5 & 63,6 & 3634,7 \\
\hline MxOLY2 & 309,7 & 1233,2 & 10,7 & 1874,1 & 61,0 & 3653,3 \\
\hline MxR53 & 288,5 & 1178,2 & 10,2 & 1731,4 & 60,8 & 3439,0 \\
\hline MxR99 & 321,1 & 1285,8 & 10,4 & 1893,4 & 70,8 & 3741,2 \\
\hline MxRS10/7 & 310,9 & 1140,2 & 10,8 & 1788,7 & 65,3 & 3496,9 \\
\hline
\end{tabular}


Tab. VII: Beobachtungsanbau der Testhybriden: Phytosterolgehalt und -Muster, gemittelt über vier Standorte (Fortsetzung)

\begin{tabular}{|c|c|c|c|c|c|c|}
\hline Genotyp & $\begin{array}{l}\text { Brassica } \\
\text {-sterol } \\
\text { [mg/kg] }\end{array}$ & $\begin{array}{l}\text { Campo } \\
\text {-sterol } \\
\text { [mg/kg] }\end{array}$ & $\begin{array}{l}\text { Stigma } \\
\text {-sterol } \\
\text { [mg/kg] }\end{array}$ & $\begin{array}{l}\text { Sito } \\
\text {-sterol } \\
\text { [mg/kg] }\end{array}$ & $\begin{array}{l}\text { Avena } \\
\text {-sterol } \\
\text { [mg/kg] }\end{array}$ & $\begin{array}{l}\text { Phytosterol } \\
\text { gesamt } \\
{[\mathrm{mg} / \mathrm{kg}]}\end{array}$ \\
\hline MxRS13/6 & 290,8 & 1148,3 & 10,5 & 1719,7 & 53,6 & 3327,9 \\
\hline MxRS4/2 & 293,4 & 1153,0 & 10,5 & 1752,0 & 53,8 & 3403,2 \\
\hline MxRS4/6 & 310,8 & 1167,2 & 10,6 & 1779,5 & 63,4 & 3481,0 \\
\hline MxRS7/6 & 320,2 & 1181,7 & 10,4 & 1790,3 & 76,9 & 3539,7 \\
\hline MxRS8/6 & 277,2 & 1165,9 & 10,2 & 1728,7 & 54,7 & 3380,2 \\
\hline MxRUY1 & 302,8 & 1143,2 & 11,1 & 1825,2 & 44,1 & 3539,4 \\
\hline MxS108.1.1 & 304,6 & 1247,5 & 10,6 & 1873,0 & 62,7 & 3669,9 \\
\hline MxS13 & 261,2 & 1164,2 & 10,2 & 1758,0 & 62,6 & 3444,0 \\
\hline MxS228.8.1 & 305,6 & 1214,9 & 10,6 & 1833,9 & 61,4 & 3605,6 \\
\hline MxS237.20.1 & 307,1 & 1155,7 & 10,8 & 1802,2 & 62,4 & 3488,0 \\
\hline MxS45.2.2 & 332,6 & 1211,5 & 10,7 & 1849,5 & 69,9 & 3648,1 \\
\hline MxVIL1 & 310,5 & 1254,7 & 10,7 & 1879,0 & 63,0 & 3681,4 \\
\hline $\mathrm{RxB1/3.3}$ & 300,4 & 1285,5 & 10,6 & 1928,3 & 74,3 & 3776,4 \\
\hline RxBOY1 & 296,4 & 1170,4 & 10,7 & 1792,4 & 56,5 & 3514,2 \\
\hline RxG39 & 319,4 & 1294,5 & 10,8 & 1949,8 & 72,5 & 3827,1 \\
\hline RxG50 & 312,6 & 1413,9 & 10,3 & 2019,8 & 84,5 & 4016,5 \\
\hline RxH149 & 303,7 & 1151,1 & 10,5 & 1769,9 & 72,6 & 3495,5 \\
\hline RxH165 & 316,0 & 1214,2 & 10,8 & 1879,3 & 63,5 & 3658,0 \\
\hline RxH176 & 319,0 & 1226,5 & 10,8 & 1895,7 & 64,2 & 3686,8 \\
\hline RxH355 & 294,8 & 1149,0 & 10,7 & 1808,2 & 54,1 & 3474,9 \\
\hline RxH44 & 321,5 & 1154,4 & 10,7 & 1808,6 & 65,8 & 3518,2 \\
\hline RxINL1 & 335,1 & 1241,7 & 11,2 & 1931,3 & 65,6 & 3754,9 \\
\hline RxINL2 & 318,6 & 1232,2 & 10,9 & 1893,3 & 65,2 & 3667,9 \\
\hline RxINY1 & 309,3 & 1300,9 & 10,6 & 1939,2 & 72,6 & 3820,9 \\
\hline RxJ104 & 288,0 & 1268,4 & 11,0 & 1910,5 & 54,9 & 3728,3 \\
\hline RxJ112 & 289,4 & 1098,4 & 11,1 & 1790,2 & 51,9 & 3381,2 \\
\hline RxJ134 & 337,7 & 1217,0 & 10,9 & 1872,5 & 76,1 & 3656,8 \\
\hline RxJ154 & 314,6 & 1189,5 & 11,0 & 1873,3 & 62,4 & 3615,4 \\
\hline RxJ161 & 299,7 & 1111,4 & 11,1 & 1833,3 & 49,4 & 3393,6 \\
\hline RxJ166 & 285,4 & 1187,6 & 11,0 & 1855,3 & 45,3 & 3563,9 \\
\hline RxJ32 & 288,2 & 1144,1 & 11,2 & 1853,6 & 58,0 & 3512,6 \\
\hline RxJ400 & 336,3 & 1194,0 & 10,9 & 1856,4 & 68,6 & 3614,4 \\
\hline RxJ408 & 290,0 & 1149,8 & 11,0 & 1814,2 & 48,5 & 3481,2 \\
\hline RxJ410 & 290,6 & 1235,4 & 10,7 & 1880,4 & 61,7 & 3652,8 \\
\hline RxJ45 & 318,3 & 1346,7 & 10,7 & 1959,8 & 70,2 & 3945,0 \\
\hline RxK160.1.1 & 309,3 & 1269,6 & 10,6 & 1917,5 & 67,3 & 3743,9 \\
\hline RxMAY1 & 299,1 & 1277,0 & 10,8 & 1984,9 & 79,6 & 3850,4 \\
\hline RxMOL1 & 281,3 & 1302,1 & 10,7 & 1934,1 & 52,5 & 3748,9 \\
\hline RxMOL2 & 314,8 & 1255,9 & 11,0 & 1964,7 & 59,4 & 3789,4 \\
\hline RxMOY5 & 295,8 & 1280,4 & 10,4 & 1897,1 & 73,2 & 3740,0 \\
\hline RxOLL1 & 334,5 & 1214,3 & 10,9 & 1883,3 & 65,7 & 3643,4 \\
\hline RxR53 & 286,8 & 1148,7 & 10,4 & 1754,5 & 54,8 & 3419,1 \\
\hline
\end{tabular}


Tab. VII: Beobachtungsanbau der Testhybriden: Phytosterolgehalt und -Muster, gemittelt über vier Standorte (Fortsetzung)

\begin{tabular}{lllllll}
\hline Genotyp & $\begin{array}{l}\text { Brassica } \\
\text {-sterol } \\
\text { [mg/kg] }\end{array}$ & $\begin{array}{l}\text { Campo } \\
\text {-sterol } \\
\text { [mg/kg] }\end{array}$ & $\begin{array}{l}\text { Stigma } \\
\text {-sterol } \\
{[\mathbf{m g} / \mathbf{k g}]}\end{array}$ & $\begin{array}{l}\text { Sito } \\
\text {-sterol } \\
{[\mathbf{m g} / \mathbf{k g}]}\end{array}$ & $\begin{array}{l}\text { Avena } \\
\text {-sterol } \\
{[\mathbf{m g} / \mathbf{k g}]}\end{array}$ & $\begin{array}{l}\text { Phytosterol } \\
\text { gesamt } \\
\text { [mg/kg] }\end{array}$ \\
\hline RxR76 & 320,8 & 1173,1 & 11,1 & 1873,1 & 61,5 & 3601,8 \\
RxR99 & 306,8 & 1325,9 & 10,4 & 1946,3 & 76,6 & 3847,9 \\
RxRS10/7 & 314,7 & 1224,1 & 10,8 & 1896,2 & 71,9 & 3709,9 \\
RxRS13/6 & 290,9 & 1179,8 & 10,6 & 1806,1 & 53,2 & 3495,1 \\
RxRS4/2 & 298,8 & 1256,8 & 10,6 & 1892,4 & 68,3 & 3685,5 \\
RxRS7/6 & 310,5 & 1203,0 & 10,6 & 1843,5 & 68,9 & 3596,0 \\
RxRS8/6 & 302,0 & 1322,2 & 10,6 & 1955,2 & 67,1 & 3826,6 \\
RxS108.1.1 & 314,2 & 1257,0 & 10,8 & 1935,3 & 65,5 & 3762,5 \\
RxS13 & 256,7 & 1208,8 & 10,3 & 1832,1 & 69,5 & 3571,9 \\
RxS45.2.2 & 334,5 & 1228,7 & 10,9 & 1902,6 & 69,4 & 3700,7 \\
RxVIL1 & 322,9 & 1322,5 & 10,7 & 1991,8 & 72,4 & 3894,5 \\
\hline MSL 007 & 338,3 & 1396,7 & 10,3 & 1991,9 & 80,3 & 3990,1 \\
TesterSyngenta & 323,0 & 1349,4 & 10,7 & 2022,1 & 72,6 & 3974,5 \\
Visby & 357,9 & 1435,9 & 10,7 & 2108,9 & 98,1 & 4219,3 \\
\hline LSD (p = 0,05) & 18,4 & 67,8 & 0,3 & 61,3 & 11,5 & 149,7 \\
Min. & 256,7 & 1006,5 & 10,2 & 1718,5 & 13,4 & 3302,7 \\
Max. & 357,9 & 1435,9 & 11,8 & 2108,9 & 98,1 & 4219,3 \\
MW Testhybriden & 304,1 & 1206,4 & 10,7 & 1851,2 & 61,4 & 3600,5 \\
MW Standards & 339,7 & 1394,0 & 10,6 & 2041,0 & 83,7 & 4061,3 \\
\hline
\end{tabular}

Tab. VIII: Beobachtungsanbau der Testhybriden: NIRS-Ergebnisse für die Sinapoylverbindungen, gemittelt über vier Standorte

\begin{tabular}{lcccc}
\hline Genotyp & $\begin{array}{c}\text { Sinapoylglucose } \\
{[\mathbf{m g} / \mathbf{g}]}\end{array}$ & $\begin{array}{c}\text { Sinapin } \\
{[\mathbf{m g} / \mathbf{g}]}\end{array}$ & $\begin{array}{c}\text { Sinapinsäure } \\
\text { gesamt [mg/g] }^{\mathrm{a}}\end{array}$ & $\begin{array}{c}\text { andere SE }^{\mathbf{b}} \\
{[\mathbf{m g} / \mathbf{g}]^{\mathbf{a}}}\end{array}$ \\
\hline MxB1/3.3 & 2,4 & 7,6 & 7,6 & 1,3 \\
MxBOY1 & 2,7 & 7,3 & 7,5 & 1,3 \\
MxCRY1 & 1,6 & 8,7 & 7,2 & 1,1 \\
MxFS94.3 & 3,2 & 6,9 & 7,9 & 1,6 \\
MxG39 & 3,1 & 6,9 & 7,6 & 1,4 \\
MxG50 & 3,5 & 7,4 & 8,6 & 1,8 \\
MxH149 & 2,6 & 6,7 & 7,1 & 1,3 \\
MxH165 & 3,0 & 7,3 & 7,9 & 1,5 \\
MxH176 & 3,4 & 6,8 & 8,1 & 1,7 \\
MxH355 & 2,5 & 8,2 & 8,0 & 1,4 \\
MxH44 & 2,1 & 7,2 & 7,1 & 1,4 \\
MxHIY1 & 1,7 & 8,1 & 7,0 & 0,9 \\
MxINL1 & 3,2 & 7,1 & 7,9 & 1,7 \\
MxINL2 & 2,5 & 7,5 & 7,7 & 1,4 \\
MxINY1 & 2,2 & 7,6 & 6,3 & 0,7 \\
\hline
\end{tabular}

${ }^{a}$ berechnet als Sinapinsäureäquivalente, ${ }^{b}$ SE = Sinapinsäureester 
Tab. VIII: Beobachtungsanbau der Testhybriden: NIRS-Ergebnisse für die Sinapoylverbindungen, gemittelt über vier Standorte (Fortsetzung)

\begin{tabular}{|c|c|c|c|c|}
\hline Genotyp & $\begin{array}{c}\text { Sinapoylglucose } \\
{[\mathrm{mg} / \mathrm{g}]}\end{array}$ & $\begin{array}{c}\text { Sinapin } \\
{[\mathrm{mg} / \mathrm{g}]}\end{array}$ & $\begin{array}{l}\text { Sinapinsäure } \\
\text { gesamt }[\mathrm{mg} / \mathrm{g}]^{\mathrm{a}}\end{array}$ & $\begin{array}{c}\text { andere SE }^{\mathrm{b}} \\
{[\mathrm{mg} / \mathrm{g}]^{\mathrm{a}}}\end{array}$ \\
\hline MxINY4 & 2,2 & 8,4 & 7,5 & 1,3 \\
\hline MxINY6 & 3,5 & 6,8 & 7,8 & 1,5 \\
\hline MxJ104 & 3,6 & 6,1 & 7,5 & 1,7 \\
\hline MxJ112 & 2,9 & 7,0 & 7,8 & 1,7 \\
\hline MxJ134 & 3,0 & 6,6 & 7,4 & 1,5 \\
\hline MxJ154 & 2,6 & 7,6 & 7,6 & 1,3 \\
\hline MxJ161 & 3,1 & 7,1 & 7,9 & 1,7 \\
\hline MxJ166 & 3,7 & 6,4 & 7,9 & 1,8 \\
\hline MxJ32 & 3,3 & 6,7 & 7,8 & 1,6 \\
\hline MxJ400 & 3,5 & 6,2 & 7,8 & 1,8 \\
\hline MxJ401 & 3,4 & 6,4 & 7,7 & 1,7 \\
\hline MxJ408 & 3,3 & 6,5 & 7,6 & 1,7 \\
\hline MxJ410 & 3,7 & 6,3 & 7,8 & 1,8 \\
\hline MxJ45 & 3,6 & 6,1 & 7,6 & 1,7 \\
\hline MxK199.16.2 & 2,7 & 7,7 & 7,7 & 1,3 \\
\hline MxMOL1 & 3,1 & 7,6 & 8,0 & 1,4 \\
\hline MxMOL2 & 2,3 & 7,5 & 7,2 & 1,1 \\
\hline MxMOY2 & 3,1 & 6,7 & 7,8 & 1,6 \\
\hline MxMOY4 & 3,4 & 6,6 & 7,8 & 1,6 \\
\hline MxMOY5 & 2,0 & 7,1 & 6,8 & 1,2 \\
\hline MxMOY6 & 1,9 & 7,8 & 6,5 & 0,7 \\
\hline MxOLL1 & 3,4 & 6,8 & 8,1 & 1,7 \\
\hline MxOLY2 & 3,6 & 7,0 & 7,3 & 1,4 \\
\hline MxR53 & 2,8 & 7,5 & 7,8 & 1,5 \\
\hline MxR99 & 2,8 & 6,9 & 7,7 & 1,6 \\
\hline MxRS10/7 & 2,0 & 7,6 & 7,4 & 1,4 \\
\hline MxRS13/6 & 2,5 & 6,9 & 7,2 & 1,3 \\
\hline MxRS4/2 & 2,7 & 7,9 & 7,7 & 1,4 \\
\hline MxRS4/6 & 2,3 & 7,1 & 7,1 & 1,2 \\
\hline MxRS7/6 & 2,5 & 7,0 & 7,3 & 1,5 \\
\hline MxRS8/6 & 3,0 & 7,1 & 7,9 & 1,5 \\
\hline MxRUY1 & 2,2 & 7,6 & 6,9 & 1,0 \\
\hline MxS108.1.1 & 3,4 & 6,6 & 7,9 & 1,7 \\
\hline MxS13 & 2,6 & 7,3 & 7,5 & 1,3 \\
\hline MxS228.8.1 & 3,0 & 6,9 & 7,7 & 1,6 \\
\hline MxS237.20.1 & 2,9 & 7,8 & 8,1 & 1,5 \\
\hline MxS45.2.2 & 2,8 & 8,2 & 8,1 & 1,4 \\
\hline MxVIL1 & 3,3 & 7,0 & 8,0 & 1,6 \\
\hline RxB1/3.3 & 3,3 & 6,9 & 7,9 & 1,6 \\
\hline RxBOY1 & 3,1 & 6,5 & 7,4 & 1,5 \\
\hline RxG39 & 4,2 & 6,4 & 8,6 & 2,0 \\
\hline RxG50 & 4,0 & 6,8 & 8,7 & 2,1 \\
\hline
\end{tabular}

${ }^{a}$ berechnet als Sinapinsäureäquivalente, ${ }^{b} \mathrm{SE}=$ Sinapinsäureester 
Tab. VIII: Beobachtungsanbau der Testhybriden: NIRS-Ergebnisse für die Sinapoylverbindungen, gemittelt über vier Standorte (Fortsetzung)

\begin{tabular}{|c|c|c|c|c|}
\hline Genotyp & $\begin{array}{c}\text { Sinapoylglucose } \\
{[\mathrm{mg} / \mathrm{g}]}\end{array}$ & $\begin{array}{c}\text { Sinapin } \\
{[\mathrm{mg} / \mathrm{g}]}\end{array}$ & $\begin{array}{c}\text { Sinapinsäure } \\
\text { gesamt }[\mathrm{mg} / \mathrm{g}]^{\mathrm{a}}\end{array}$ & $\begin{array}{c}\text { andere SE }^{\mathrm{b}} \\
{[\mathrm{mg} / \mathrm{g}]^{\mathrm{a}}}\end{array}$ \\
\hline RxH149 & 3,2 & 6,6 & 7,5 & 1,5 \\
\hline RxH165 & 3,5 & 6,2 & 7,5 & 1,5 \\
\hline RxH176 & 3,5 & 5,8 & 7,2 & 1,6 \\
\hline RxH355 & 3,3 & 7,3 & 8,3 & 1,6 \\
\hline RxH44 & 2,7 & 6,5 & 7,2 & 1,5 \\
\hline RxINL1 & 3,4 & 6,2 & 7,6 & 1,7 \\
\hline RxINL2 & 3,2 & 7,2 & 8,1 & 1,6 \\
\hline RxINY1 & 3,9 & 5,9 & 7,8 & 1,8 \\
\hline RxJ104 & 4,5 & 5,4 & 8,1 & 2,1 \\
\hline RxJ112 & 3,6 & 6,5 & 7,8 & 1,7 \\
\hline RxJ134 & 3,7 & 6,4 & 7,9 & 1,8 \\
\hline RxJ154 & 3,6 & 6,9 & 8,1 & 1,6 \\
\hline RxJ161 & 3,6 & 6,1 & 7,7 & 1,7 \\
\hline RxJ166 & 4,2 & 6,0 & 8,0 & 1,9 \\
\hline RxJ32 & 4,6 & 5,8 & 8,2 & 2,1 \\
\hline RxJ400 & 4,1 & 5,9 & 7,9 & 1,9 \\
\hline RxJ408 & 4,0 & 5,8 & 7,8 & 1,9 \\
\hline RxJ410 & 4,1 & 5,8 & 8,0 & 2,0 \\
\hline RxJ45 & 3,9 & 5,9 & 8,0 & 2,0 \\
\hline RxK160.1.1 & 3,7 & 6,6 & 8,2 & 1,8 \\
\hline RxMAY1 & 3,0 & 6,8 & 7,9 & 1,7 \\
\hline RxMOL1 & 3,9 & 6,6 & 8,3 & 1,8 \\
\hline RxMOL2 & 3,2 & 6,9 & 7,5 & 1,4 \\
\hline RxMOY5 & 4,0 & 6,9 & 8,6 & 1,8 \\
\hline RxOLL1 & 4,2 & 6,5 & 8,4 & 1,9 \\
\hline RxR53 & 3,6 & 6,5 & 7,9 & 1,7 \\
\hline RxR76 & 3,4 & 6,3 & 7,1 & 1,5 \\
\hline RxR99 & 3,6 & 6,1 & 7,8 & 1,8 \\
\hline RxRS10/7 & 3,3 & 6,7 & 7,7 & 1,6 \\
\hline RxRS13/6 & 3,0 & 6,8 & 7,6 & 1,5 \\
\hline RxRS4/2 & 3,7 & 6,5 & 7,8 & 1,6 \\
\hline RxRS7/6 & 3,2 & 6,3 & 7,5 & 1,6 \\
\hline RxRS8/6 & 4,0 & 6,7 & 8,6 & 1,8 \\
\hline RxS108.1.1 & 3,8 & 6,0 & 7,9 & 1,9 \\
\hline RxS13 & 3,5 & 6,5 & 7,6 & 1,6 \\
\hline RxS45.2.2 & 3,5 & 6,6 & 7,8 & 1,7 \\
\hline RxVIL1 & 3,8 & 6,1 & 7,9 & 1,9 \\
\hline MSL 007 & 3,2 & 6,8 & 7,8 & 1,6 \\
\hline TesterSyngenta & 3,6 & 5,8 & 7,7 & 1,8 \\
\hline Visby & 4,0 & 6,1 & 8,3 & 2,1 \\
\hline
\end{tabular}

${ }^{a}$ berechnet als Sinapinsäureäquivalente, ${ }^{b} \mathrm{SE}=$ Sinapinsäureester 
Tab. VIII: Beobachtungsanbau der Testhybriden: NIRS-Ergebnisse für die Sinapoylverbindungen, gemittelt über vier Standorte (Fortsetzung)

\begin{tabular}{|c|c|c|c|c|}
\hline Genotyp & $\begin{array}{c}\text { Sinapoylglucose } \\
{[\mathrm{mg} / \mathrm{g}]}\end{array}$ & $\begin{array}{c}\text { Sinapin } \\
{[\mathrm{mg} / \mathrm{g}]}\end{array}$ & $\begin{array}{c}\text { Sinapinsäure } \\
\text { gesamt }[\mathrm{mg} / \mathrm{g}]^{\mathrm{a}}\end{array}$ & $\begin{array}{c}\text { andere SE }^{\mathrm{b}} \\
{\left[\mathrm{mg}^{\mathrm{m} / \mathrm{g}}\right]^{\mathrm{a}}}\end{array}$ \\
\hline $\operatorname{LSD}(p=0,05)$ & 0,5 & 0,5 & 0,5 & 0,2 \\
\hline Min. & 1,6 & 5,4 & 6,3 & 0,7 \\
\hline Max. & 4,6 & 8,7 & 8,7 & 2,1 \\
\hline MW Testhybriden & 3,2 & 6,8 & 7,7 & 1,6 \\
\hline MW Standards & 3,6 & 6,2 & 7,9 & 1,8 \\
\hline
\end{tabular}

Tab. IX: Beobachtungsanbau der Testhybriden: Agronomische Merkmale, gemittelt über sechs Standorte

\begin{tabular}{|c|c|c|c|c|c|c|c|c|c|}
\hline Genotyp & $\begin{array}{l}\text { ÖI } \\
\text { [\%] }\end{array}$ & $\begin{array}{l}\text { C22:1 } \\
{[\%]}\end{array}$ & $\begin{array}{l}\text { Protein } \\
\text { [\%] }\end{array}$ & $\begin{array}{l}\text { GSL } \\
{[\mu \mathrm{mol} / \mathrm{g}]}\end{array}$ & $\begin{array}{l}\text { TKG } \\
\text { [g] }\end{array}$ & $\begin{array}{l}\text { Höhe } \\
\text { [cm] }\end{array}$ & BoF & WF & Lager \\
\hline MxB1/3.3 & 43,8 & 7,1 & 19,2 & 60,9 & 5,1 & 160,6 & 1,6 & 118,0 & 1,7 \\
\hline MxFS94.3 & 42,4 & 1,6 & 19,4 & 40,6 & 5,4 & 170,0 & 2,4 & 117,7 & 1,7 \\
\hline MxG39 & 41,7 & 8,1 & 20,5 & 58,0 & 4,9 & 166,6 & 4,3 & 119,6 & 3,3 \\
\hline MxG50 & 43,5 & 0,6 & 19,0 & 42,5 & 5,1 & 150,0 & 1,6 & 118,7 & 2,0 \\
\hline MxH149 & 44,4 & 19,8 & 19,0 & 52,3 & 5,0 & 157,5 & 2,3 & 113,2 & 2,0 \\
\hline MxH165 & 43,1 & 11,8 & 20,1 & 43,0 & 5,0 & 139,3 & 2,7 & 118,6 & 2,0 \\
\hline MxH176 & 45,7 & 13,7 & 18,0 & 28,0 & 5,4 & 152,5 & 1,6 & 117,8 & 1,7 \\
\hline MxH355 & 44,3 & 18,8 & 20,8 & 54,2 & 5,2 & 141,7 & 3,1 & 117,4 & 2,1 \\
\hline MxH44 & 45,3 & 19,4 & 19,2 & 38,4 & 5,4 & 143,8 & 1,4 & 113,2 & 1,7 \\
\hline MxHIY1 & 41,1 & 17,8 & 21,7 & 78,3 & 7,4 & 145,6 & 4,6 & 116,6 & 1,8 \\
\hline MxINL1 & 41,6 & 10,2 & 20,3 & 40,5 & 6,1 & 155,6 & 1,5 & 118,2 & 1,7 \\
\hline MxINL2 & 41,2 & 10,6 & 21,0 & 52,0 & 5,3 & 155,0 & 3,2 & 115,7 & 2,3 \\
\hline MxJ134 & 42,6 & 9,4 & 19,3 & 34,1 & 5,4 & 140,9 & 3,1 & 116,2 & 1,8 \\
\hline MxJ154 & 41,9 & 11,1 & 20,2 & 53,9 & 5,8 & 139,5 & 3,5 & 113,6 & 1,7 \\
\hline MxJ161 & 42,3 & 18,9 & 20,4 & 56,7 & 5,1 & 137,9 & 5,5 & 119,9 & 1,4 \\
\hline MxJ166 & 40,9 & 17,5 & 21,1 & 58,4 & 5,8 & 142,4 & 6,0 & 115,3 & 2,0 \\
\hline MxJ32 & 41,7 & 8,8 & 20,2 & 46,7 & 5,6 & 147,5 & 4,8 & 117,8 & 1,7 \\
\hline MxJ400 & 41,4 & 14,5 & 19,7 & 47,1 & 5,5 & 139,9 & 6,1 & 118,3 & 1,8 \\
\hline MxJ401 & 42,6 & 10,2 & 19,5 & 41,0 & 5,7 & 153,1 & 3,2 & 116,5 & 2,0 \\
\hline MxJ408 & 43,1 & 15,1 & 19,1 & 45,9 & 5,2 & 146,4 & 2,8 & 115,7 & 1,9 \\
\hline MxJ45 & 42,2 & 14,8 & 19,3 & 48,8 & 5,0 & 147,3 & 4,7 & 117,8 & 1,8 \\
\hline MxK199.16.2 & 43,6 & 18,4 & 20,4 & 55,4 & 5,2 & 152,5 & 3,2 & 119,0 & 2,0 \\
\hline MxMOL1 & 42,4 & 10,5 & 19,8 & 59,8 & 5,5 & 151,9 & 1,3 & 116,8 & 1,7 \\
\hline MxMOL2 & 41,0 & 7,7 & 21,0 & 63,2 & 5,8 & 166,9 & 0,4 & 118,3 & 1,3 \\
\hline MxMOY4 & 44,2 & 5,4 & 18,2 & 37,9 & 5,6 & 151,9 & 2,0 & 116,4 & 1,8 \\
\hline MxR53 & 45,0 & 19,4 & 19,7 & 39,9 & 5,3 & 151,1 & 2,5 & 117,2 & 1,7 \\
\hline MxR99 & 44,3 & 8,6 & 19,1 & 33,8 & 4,9 & 152,4 & 1,8 & 116,4 & 1,3 \\
\hline MxRS13/6 & 43,9 & 16,3 & 19,8 & 51,0 & 5,7 & 144,1 & 3,0 & 108,8 & 1,8 \\
\hline MxRS4/2 & 44,2 & 17,3 & 19,4 & 45,7 & 5,2 & 156,3 & 4,0 & 118,2 & 2,0 \\
\hline MxRS4/6 & 43,8 & 13,8 & 20,5 & 43,2 & 5,2 & 154,4 & 2,6 & 116,0 & 2,0 \\
\hline MxRS7/6 & 45,4 & 15,6 & 18,8 & 35,6 & 5,4 & 148,1 & 2,1 & 114,3 & 1,7 \\
\hline
\end{tabular}


Tab. IX: Beobachtungsanbau der Testhybriden: Agronomische Merkmale, gemittelt über sechs Standorte (Fortsetzung)

\begin{tabular}{|c|c|c|c|c|c|c|c|c|c|}
\hline Genotyp & $\begin{array}{l}\text { ÖI } \\
\text { [\%] }\end{array}$ & $\begin{array}{l}\text { C22:1 } \\
{[\%]}\end{array}$ & $\begin{array}{l}\text { Protein } \\
\text { [\%] }\end{array}$ & $\begin{array}{l}\text { GSL } \\
{[\mu \mathrm{mol} / \mathrm{g}]}\end{array}$ & $\begin{array}{l}\text { TKG } \\
\text { [g] }\end{array}$ & $\begin{array}{l}\text { Höhe } \\
\text { [cm] }\end{array}$ & BoF & WF & Lager \\
\hline MxS108.1.1 & 42,7 & 6,2 & 19,5 & 41,2 & 5,4 & 147,4 & 2,6 & 112,3 & 1,7 \\
\hline MxS13 & 45,4 & 21,5 & 19,0 & 64,1 & 5,1 & 151,3 & 0,8 & 116,5 & 1,7 \\
\hline MxS228.8.1 & 43,3 & 10,8 & 19,8 & 48,3 & 5,1 & 153,4 & 3,0 & 116,9 & 1,8 \\
\hline MxS45.2.2 & 42,7 & 11,0 & 20,7 & 47,8 & 5,0 & 142,5 & 3,6 & 115,0 & 2,0 \\
\hline MxVIL1 & 42,2 & 7,6 & 19,9 & 45,0 & 6,0 & 151,9 & 2,0 & 117,5 & 1,7 \\
\hline RxB1/3.3 & 42,9 & 5,9 & 18,9 & 51,3 & 5,5 & 157,6 & 2,0 & 117,3 & 2,0 \\
\hline RxG50 & 44,0 & 0,9 & 17,5 & 38,0 & 5,0 & 152,5 & 1,5 & 118,7 & 1,3 \\
\hline RxH149 & 43,7 & 18,2 & 18,5 & 47,7 & 5,0 & 155,6 & 2,2 & 114,5 & 2,3 \\
\hline RxH165 & 42,5 & 11,2 & 19,6 & 37,0 & 4,6 & 142,5 & 3,3 & 118,7 & 2,3 \\
\hline RxH176 & 43,2 & 11,5 & 19,1 & 33,3 & 5,7 & 149,4 & 1,2 & 117,5 & 1,7 \\
\hline RxH355 & 42,0 & 13,8 & 20,2 & 47,5 & 5,4 & 149,4 & 3,0 & 117,8 & 2,0 \\
\hline RxH44 & 44,7 & 18,4 & 19,2 & 32,7 & 5,6 & 149,9 & 0,8 & 114,1 & 1,8 \\
\hline RxINL1 & 40,7 & 7,5 & 20,2 & 38,2 & 6,1 & 171,9 & 2,3 & 117,5 & 1,7 \\
\hline RxINL2 & 41,6 & 7,4 & 20,0 & 47,2 & 5,6 & 158,1 & 2,6 & 115,7 & 1,3 \\
\hline RxJ112 & 40,8 & 17,2 & 20,2 & 57,1 & 6,0 & 144,0 & 4,6 & 118,6 & 1,8 \\
\hline RxJ134 & 42,4 & 8,2 & 18,9 & 32,7 & 5,3 & 136,3 & 3,5 & 117,0 & 2,3 \\
\hline RxJ154 & 42,5 & 10,6 & 19,0 & 47,9 & 6,2 & 147,4 & 2,6 & 114,3 & 1,8 \\
\hline RxJ161 & 41,0 & 14,5 & 20,3 & 46,3 & 4,8 & 133,9 & 2,5 & 118,6 & 2,3 \\
\hline RxJ166 & 40,1 & 9,2 & 20,8 & 47,4 & 5,9 & 140,1 & 5,0 & 117,1 & 3,0 \\
\hline RxJ32 & 42,1 & 16,1 & 18,2 & 45,5 & 5,2 & 143,8 & 2,8 & 118,6 & 2,1 \\
\hline RxJ400 & 41,7 & 10,9 & 19,1 & 39,8 & 5,9 & 147,5 & 4,5 & 117,8 & 2,0 \\
\hline RxJ408 & 40,3 & 13,7 & 20,6 & 46,3 & 5,2 & 136,0 & 3,9 & 115,8 & 2,0 \\
\hline RxJ410 & 42,1 & 13,4 & 18,8 & 45,2 & 5,3 & 138,3 & 4,4 & 117,6 & 1,8 \\
\hline RxJ45 & 42,7 & 13,6 & 18,4 & 45,9 & 4,9 & 149,9 & 2,8 & 118,3 & 1,8 \\
\hline RxMOL1 & 41,6 & 4,1 & 19,8 & 47,5 & 5,4 & 162,1 & 2,0 & 117,6 & 1,1 \\
\hline RxOLL1 & 41,7 & 8,0 & 19,7 & 35,2 & 6,1 & 157,5 & 3,2 & 115,7 & 2,3 \\
\hline RxR53 & 43,5 & 19,4 & 19,9 & 40,9 & 5,4 & 152,5 & 2,0 & 118,0 & 1,3 \\
\hline RxR99 & 44,1 & 4,2 & 17,6 & 31,3 & 5,0 & 153,8 & 1,7 & 117,2 & 1,7 \\
\hline RxRS10/7 & 42,7 & 11,9 & 19,6 & 55,4 & 5,8 & 149,4 & 2,6 & 117,7 & 1,7 \\
\hline RxRS13/6 & 41,9 & 12,7 & 20,1 & 45,9 & 5,8 & 147,5 & 3,3 & 116,7 & 2,3 \\
\hline RxRS4/2 & 44,0 & 12,4 & 18,1 & 38,7 & 5,0 & 164,8 & 1,2 & 117,1 & 2,0 \\
\hline RxRS7/6 & 44,1 & 17,0 & 19,0 & 38,5 & 5,7 & 150,0 & 2,1 & 114,2 & 2,3 \\
\hline RxRS8/6 & 42,8 & 7,8 & 19,1 & 36,0 & 5,7 & 161,4 & 1,2 & 117,6 & 1,7 \\
\hline RxS108.1.1 & 42,5 & 4,8 & 19,0 & 42,2 & 5,5 & 144,4 & 1,6 & 110,7 & 2,3 \\
\hline RxS13 & 44,9 & 19,4 & 17,5 & 60,0 & 5,2 & 151,9 & 1,1 & 117,0 & 1,7 \\
\hline RxS45.2.2 & 42,3 & 8,0 & 19,9 & 39,4 & 5,0 & 141,6 & 1,8 & 117,3 & 1,8 \\
\hline MSL 007 & 44,6 & 0,0 & 18,8 & 22,8 & 5,3 & 143,1 & 1,1 & 118,3 & 1,7 \\
\hline Tester Syngenta & 43,2 & 0,5 & 18,5 & 23,6 & 5,8 & 146,9 & 1,4 & 122,6 & 2,7 \\
\hline Visby & 43,6 & 0,0 & 17,7 & 19,0 & 5,8 & 146,9 & 0,6 & 117,5 & 1,3 \\
\hline LSD $(p=0,05)$ & 1,4 & 3,8 & 1,2 & 7,5 & 0,5 & 11,8 & 1,9 & 2,4 & 1,1 \\
\hline Min. & 40,1 & 0,0 & 17,5 & 19,0 & 4,6 & 133,9 & 0,4 & 108,8 & 1,1 \\
\hline Max. & 45,7 & 21,5 & 21,7 & 78,3 & 7,4 & 171,9 & 6,1 & 122,6 & 3,3 \\
\hline MW Testhybriden & 42,8 & 12,0 & 19,5 & 45,8 & 5,4 & 150,0 & 2,7 & 116,7 & 1,9 \\
\hline MW Standards & 43,8 & 0,2 & 18,3 & 21,8 & 5,6 & 145,6 & 1,0 & 119,5 & 1,9 \\
\hline
\end{tabular}


Tab. X: Beobachtungsanbau der Testhybriden: Phytosterolgehalt und -Muster, gemittelt über sechs Standorte

\begin{tabular}{|c|c|c|c|c|c|c|}
\hline Genotyp & $\begin{array}{l}\text { Brassica } \\
\text {-sterol } \\
\text { [mg/kg] }\end{array}$ & $\begin{array}{l}\text { Campo } \\
\text {-sterol } \\
{[\mathrm{mg} / \mathrm{kg}]}\end{array}$ & $\begin{array}{l}\text { Stigma } \\
\text {-sterol } \\
\text { [mg/kg] }\end{array}$ & $\begin{array}{l}\text { Sito } \\
\text {-sterol } \\
\text { [mg/kg] }\end{array}$ & $\begin{array}{l}\text { Avena } \\
\text {-sterol } \\
{[\mathrm{mg} / \mathrm{kg}]}\end{array}$ & $\begin{array}{l}\text { Phytosterol } \\
\text { gesamt } \\
{[\mathrm{mg} / \mathrm{kg}]}\end{array}$ \\
\hline MxB1/3.3 & 301,1 & 1248,7 & 10,5 & 1881,6 & 75,4 & 3669,7 \\
\hline MxFS94.3 & 340,0 & 1310,5 & 10,8 & 1981,8 & 78,6 & 3887,2 \\
\hline MxG39 & 322,3 & 1202,0 & 10,8 & 1881,6 & 63,6 & 3646,0 \\
\hline MxG50 & 316,3 & 1386,1 & 10,3 & 1983,3 & 79,7 & 3935,6 \\
\hline MxH149 & 299,3 & 1156,8 & 10,3 & 1736,5 & 71,4 & 3445,3 \\
\hline MxH165 & 322,8 & 1199,1 & 10,5 & 1836,4 & 64,1 & 3608,7 \\
\hline MxH176 & 319,5 & 1247,7 & 10,2 & 1815,9 & 78,9 & 3611,2 \\
\hline MxH355 & 281,6 & 1148,8 & 10,4 & 1753,1 & 64,1 & 3417,7 \\
\hline MxH44 & 323,4 & 1111,0 & 10,6 & 1750,0 & 73,4 & 3414,8 \\
\hline MxHIY1 & 275,0 & 1110,7 & 10,9 & 1766,5 & 49,5 & 3382,5 \\
\hline MxINL1 & 342,8 & 1212,6 & 11,0 & 1875,8 & 70,8 & 3674,3 \\
\hline MxINL2 & 325,0 & 1164,4 & 11,1 & 1844,2 & 63,8 & 3558,8 \\
\hline MxJ134 & 347,5 & 1159,0 & 11,0 & 1833,6 & 72,8 & 3561,0 \\
\hline MxJ154 & 316,5 & 1181,6 & 11,1 & 1873,3 & 66,0 & 3614,7 \\
\hline MxJ161 & 302,9 & 1071,5 & 11,0 & 1758,5 & 58,2 & 3341,6 \\
\hline MxJ166 & 277,4 & 1111,6 & 11,2 & 1794,0 & 43,1 & 3375,2 \\
\hline MxJ32 & 322,6 & 1221,7 & 10,9 & 1878,4 & 62,6 & 3664,5 \\
\hline MxJ400 & 295,2 & 1154,8 & 11,1 & 1840,6 & 58,7 & 3538,5 \\
\hline MxJ401 & 346,9 & 1172,4 & 10,9 & 1824,0 & 72,0 & 3577,3 \\
\hline MxJ408 & 304,7 & 1211,1 & 10,7 & 1846,5 & 64,9 & 3615,7 \\
\hline MxJ45 & 286,1 & 1163,0 & 11,0 & 1825,4 & 56,2 & 3509,2 \\
\hline MxK199.16.2 & 306,8 & 1134,8 & 10,6 & 1760,2 & 63,7 & 3419,1 \\
\hline MxMOL1 & 284,3 & 1254,8 & 10,5 & 1873,4 & 60,2 & 3633,3 \\
\hline MxMOL2 & 323,3 & 1222,2 & 10,8 & 1914,6 & 65,9 & 3702,4 \\
\hline MxMOY4 & 310,6 & 1294,5 & 10,4 & 1917,6 & 78,9 & 3787,1 \\
\hline MxR53 & 295,5 & 1166,0 & 10,2 & 1727,5 & 63,5 & 3424,3 \\
\hline MxR99 & 320,6 & 1256,3 & 10,5 & 1865,4 & 70,1 & 3679,7 \\
\hline MxRS13/6 & 293,8 & 1141,8 & 10,5 & 1730,6 & 57,3 & 3343,6 \\
\hline MxRS4/2 & 296,2 & 1158,8 & 10,4 & 1752,5 & 60,5 & 3408,4 \\
\hline MxRS4/6 & 317,7 & 1168,6 & 10,7 & 1799,3 & 64,8 & 3509,7 \\
\hline MxRS7/6 & 323,0 & 1169,6 & 10,4 & 1795,3 & 80,1 & 3530,8 \\
\hline MxS108.1.1 & 310,0 & 1245,8 & 10,6 & 1876,3 & 68,0 & 3673,8 \\
\hline MxS13 & 260,9 & 1157,9 & 10,2 & 1756,6 & 66,8 & 3431,9 \\
\hline MxS228.8.1 & 308,8 & 1211,6 & 10,6 & 1838,1 & 66,5 & 3607,4 \\
\hline MxS45.2.2 & 343,5 & 1192,9 & 10,8 & 1843,3 & 71,8 & 3638,9 \\
\hline MxVIL1 & 321,3 & 1238,8 & 10,8 & 1892,3 & 65,6 & 3691,4 \\
\hline $\mathrm{R} \times \mathrm{B} 1 / 3.3$ & 305,8 & 1251,4 & 10,7 & 1927,7 & 75,2 & 3732,2 \\
\hline RxG50 & 316,3 & 1389,5 & 10,3 & 2011,6 & 86,7 & 3982,4 \\
\hline RxH149 & 304,3 & 1130,2 & 10,6 & 1770,8 & 74,6 & 3460,1 \\
\hline RxH165 & 322,2 & 1175,9 & 10,9 & 1870,1 & 61,8 & 3604,0 \\
\hline RxH176 & 325,7 & 1207,2 & 10,9 & 1897,7 & 67,6 & 3662,7 \\
\hline RxH355 & 305,1 & 1170,4 & 10,8 & 1847,3 & 57,1 & 3552,5 \\
\hline
\end{tabular}


Tab. X: Beobachtungsanbau der Testhybriden: Phytosterolgehalt und -Muster, gemittelt über sechs Standorte (Fortsetzung)

\begin{tabular}{|c|c|c|c|c|c|c|}
\hline Genotyp & $\begin{array}{l}\text { Brassica } \\
\text {-sterol } \\
{[\mathrm{mg} / \mathrm{kg}]}\end{array}$ & $\begin{array}{l}\text { Campo } \\
\text {-sterol } \\
{[\mathrm{mg} / \mathrm{kg}]}\end{array}$ & $\begin{array}{l}\text { Stigma } \\
\text {-sterol } \\
{[\mathrm{mg} / \mathrm{kg}]}\end{array}$ & $\begin{array}{l}\text { Sito } \\
\text {-sterol } \\
{[\mathrm{mg} / \mathrm{kg}]}\end{array}$ & $\begin{array}{l}\text { Avena } \\
\text {-sterol } \\
\text { [mg/kg] }\end{array}$ & $\begin{array}{l}\text { Phytosterol } \\
\text { gesamt } \\
{[\mathrm{mg} / \mathrm{kg}]}\end{array}$ \\
\hline RxH44 & 325,8 & 1134,6 & 10,8 & 1804,2 & 70,6 & 3496,4 \\
\hline RxINL1 & 340,6 & 1209,3 & 11,3 & 1931,2 & 65,3 & 3727,3 \\
\hline RxINL2 & 324,5 & 1221,1 & 11,0 & 1899,3 & 69,6 & 3665,9 \\
\hline RxJ112 & 299,6 & 1076,4 & 11,2 & 1793,3 & 53,1 & 3366,8 \\
\hline RxJ134 & 342,2 & 1191,1 & 11,1 & 1891,3 & 74,0 & 3650,9 \\
\hline RxJ154 & 316,3 & 1175,1 & 10,9 & 1895,0 & 70,5 & 3684,9 \\
\hline RxJ161 & 311,0 & 1109,3 & 11,2 & 1854,3 & 52,3 & 3522,9 \\
\hline RxJ166 & 303,9 & 1189,4 & 11,2 & 1896,4 & 49,0 & 3626,1 \\
\hline RxJ32 & 295,4 & 1152,7 & 11,1 & 1860,1 & 68,1 & 3542,0 \\
\hline RxJ400 & 349,0 & 1169,1 & 11,0 & 1853,2 & 71,3 & 3600,1 \\
\hline RxJ408 & 299,8 & 1136,9 & 11,3 & 1846,5 & 48,0 & 3520,0 \\
\hline RxJ410 & 298,3 & 1213,0 & 10,9 & 1883,6 & 63,2 & 3639,9 \\
\hline RxJ45 & 320,5 & 1299,9 & 10,8 & 1949,2 & 72,6 & 3867,1 \\
\hline RxMOL1 & 293,7 & 1302,6 & 10,7 & 1945,9 & 59,9 & 3776,5 \\
\hline RxOLL1 & 342,3 & 1185,2 & 11,0 & 1868,0 & 68,7 & 3604,4 \\
\hline RxR53 & 292,2 & 1129,0 & 10,5 & 1750,9 & 55,7 & 3394,3 \\
\hline RxR99 & 313,5 & 1322,6 & 10,5 & 1961,4 & 79,6 & 3861,9 \\
\hline RxRS10/7 & 319,9 & 1199,6 & 10,8 & 1886,3 & 71,6 & 3670,5 \\
\hline RxRS13/6 & 307,9 & 1173,4 & 10,8 & 1841,3 & 55,9 & 3544,9 \\
\hline RxRS4/2 & 304,0 & 1247,1 & 10,5 & 1882,1 & 72,6 & 3663,6 \\
\hline RxRS7/6 & 316,8 & 1171,1 & 10,8 & 1840,3 & 71,5 & 3557,8 \\
\hline RxRS8/6 & 309,2 & 1289,5 & 10,7 & 1937,5 & 68,5 & 3766,5 \\
\hline RxS108.1.1 & 316,5 & 1269,7 & 10,7 & 1941,2 & 71,9 & 3789,5 \\
\hline RxS13 & 264,4 & 1185,5 & 10,4 & 1825,3 & 72,9 & 3536,5 \\
\hline RxS45.2.2 & 341,3 & 1199,0 & 11,0 & 1894,6 & 72,5 & 3669,2 \\
\hline MŚL 007 & 340,6 & 1382,4 & 10,4 & 1981,0 & 83,6 & 3966,3 \\
\hline Tester_Syngenta & 334,1 & 1329,2 & 10,9 & 2031,4 & 77,3 & 3962,4 \\
\hline Visby & 360,6 & 1396,4 & 10,9 & 2083,6 & 94,9 & 4145,7 \\
\hline $\operatorname{LSD}(p=0,05)$ & 15,2 & 61,3 & 0,3 & 53,5 & 10,6 & 128,8 \\
\hline Min. & 260,9 & 1071,5 & 10,2 & 1727,5 & 43,1 & 3341,6 \\
\hline Max. & 360,6 & 1396,4 & 11,3 & 2083,6 & 94,9 & 4145,7 \\
\hline MW Testhybriden & 312,1 & 1197,6 & 10,8 & 1853,5 & 66,6 & 3601,1 \\
\hline MW Standards & 345,1 & 1369,3 & 10,7 & 2032,0 & 85,3 & 4024,8 \\
\hline
\end{tabular}


Tab. XI: Beobachtungsanbau der Testhybriden: NIRS-Ergebnisse für die Sinapoylverbindungen, gemittelt über sechs Standorte

\begin{tabular}{|c|c|c|c|c|}
\hline Genotyp & $\begin{array}{c}\text { Sinapoylglucose } \\
{[\mathrm{mg} / \mathrm{g}]}\end{array}$ & $\begin{array}{c}\text { Sinapin } \\
{[\mathrm{mg} / \mathrm{g}]}\end{array}$ & $\begin{array}{c}\text { Sinapinsäure } \\
\text { gesamt }[\mathrm{mg} / \mathrm{g}]^{\mathrm{a}}\end{array}$ & $\begin{array}{c}\text { andere SE }^{\mathrm{b}} \\
{[\mathrm{mg} / \mathrm{g}]^{\mathrm{a}}}\end{array}$ \\
\hline MxB1/3.3 & 2,6 & 7,6 & 7,7 & 1,3 \\
\hline MxFS94.3 & 3,1 & 6,7 & 8,0 & 1,7 \\
\hline MxG39 & 3,1 & 6,7 & 7,6 & 1,5 \\
\hline MxG50 & 3,4 & 7,3 & 8,5 & 1,8 \\
\hline MxH149 & 2,6 & 6,7 & 7,0 & 1,3 \\
\hline MxH165 & 2,8 & 7,2 & 7,8 & 1,5 \\
\hline MxH176 & 3,4 & 6,8 & 8,1 & 1,8 \\
\hline MxH355 & 2,7 & 7,9 & 8,0 & 1,5 \\
\hline MxH44 & 2,1 & 7,3 & 7,2 & 1,4 \\
\hline MxHIY1 & 1,7 & 7,9 & 7,0 & 1,0 \\
\hline MxINL1 & 3,1 & 7,2 & 8,0 & 1,7 \\
\hline MxINL2 & 2,5 & 7,7 & 7,9 & 1,4 \\
\hline MxJ134 & 3,0 & 6,6 & 7,5 & 1,6 \\
\hline MxJ154 & 2,7 & 7,4 & 7,6 & 1,3 \\
\hline MxJ161 & 2,9 & 7,4 & 7,9 & 1,6 \\
\hline MxJ166 & 3,7 & 6,7 & 7,6 & 1,8 \\
\hline MxJ32 & 3,1 & 6,5 & 7,6 & 1,6 \\
\hline MxJ400 & 3,5 & 6,2 & 7,8 & 1,9 \\
\hline MxJ401 & 3,2 & 6,4 & 7,5 & 1,6 \\
\hline MxJ408 & 3,3 & 6,4 & 7,7 & 1,7 \\
\hline MxJ45 & 3,6 & 6,0 & 7,6 & 1,8 \\
\hline MxK199.16.2 & 2,5 & 7,6 & 7,6 & 1,3 \\
\hline MxMOL1 & 3,1 & 7,5 & 8,1 & 1,5 \\
\hline MxMOL2 & 2,2 & 7,5 & 7,2 & 1,1 \\
\hline MxMOY4 & 3,2 & 6,7 & 7,8 & 1,6 \\
\hline MxR53 & 2,9 & 7,3 & 7,9 & 1,5 \\
\hline MxR99 & 2,7 & 6,9 & 7,6 & 1,6 \\
\hline MxRS13/6 & 2,5 & 6,9 & 7,3 & 1,3 \\
\hline MxRS4/2 & 2,9 & 7,7 & 7,9 & 1,5 \\
\hline MxRS4/6 & 2,3 & 7,0 & 7,2 & 1,3 \\
\hline MxRS7/6 & 2,6 & 7,1 & 7,5 & 1,5 \\
\hline MxS108.1.1 & 3,3 & 6,6 & 8,0 & 1,7 \\
\hline MxS13 & 2,6 & 7,2 & 7,4 & 1,3 \\
\hline MxS228.8.1 & 3,0 & 6,9 & 7,8 & 1,6 \\
\hline MxS45.2.2 & 2,8 & 7,8 & 7,9 & 1,4 \\
\hline MxVIL1 & 3,3 & 6,8 & 8,0 & 1,7 \\
\hline RxB1/3.3 & 3,3 & 7,0 & 8,1 & 1,7 \\
\hline RxG50 & 3,9 & 6,7 & 8,5 & 2,1 \\
\hline RxH149 & 3,1 & 6,5 & 7,4 & 1,5 \\
\hline RxH165 & 3,3 & 6,0 & 7,3 & 1,5 \\
\hline RxH176 & 3,5 & 6,0 & 7,5 & 1,7 \\
\hline RxH355 & 3,3 & 7,1 & 8,3 & 1,7 \\
\hline
\end{tabular}

${ }^{a}$ berechnet als Sinapinsäureäquivalente, ${ }^{b} \mathrm{SE}=$ Sinapinsäureester 
Tab. XI: Beobachtungsanbau der Testhybriden: NIRS-Ergebnisse für die Sinapoylverbindungen, gemittelt über sechs Standorte (Fortsetzung)

\begin{tabular}{|c|c|c|c|c|}
\hline Genotyp & $\begin{array}{c}\text { Sinapoylglucose } \\
{[\mathrm{mg} / \mathrm{g}]}\end{array}$ & $\begin{array}{c}\text { Sinapin } \\
{[\mathrm{mg} / \mathrm{g}]}\end{array}$ & $\begin{array}{c}\text { Sinapinsäure } \\
\text { gesamt }[\mathrm{mg} / \mathrm{g}]^{\mathrm{a}}\end{array}$ & $\begin{array}{c}\text { andere SE } \\
{[\mathrm{mg} / \mathrm{g}]^{\mathrm{a}}}\end{array}$ \\
\hline RxH44 & 2,6 & 6,5 & 7,3 & 1,5 \\
\hline RxINL1 & 3,4 & 6,2 & 7,7 & 1,8 \\
\hline RxINL2 & 3,2 & 7,1 & 8,1 & 1,7 \\
\hline RxJ112 & 3,5 & 6,4 & 7,8 & 1,8 \\
\hline RxJ134 & 3,6 & 6,4 & 8,0 & 1,8 \\
\hline RxJ154 & 3,7 & 6,7 & 8,1 & 1,7 \\
\hline RxJ161 & 3,4 & 6,2 & 7,7 & 1,7 \\
\hline RxJ166 & 4,0 & 6,0 & 7,9 & 1,8 \\
\hline RxJ32 & 4,6 & 5,9 & 8,5 & 2,1 \\
\hline RxJ400 & 3,8 & 5,9 & 7,7 & 1,9 \\
\hline RxJ408 & 4,0 & 6,0 & 7,6 & 2,0 \\
\hline RxJ410 & 4,1 & 5,8 & 8,0 & 2,0 \\
\hline RxJ45 & 3,9 & 5,9 & 8,1 & 2,0 \\
\hline RxMOL1 & 4,0 & 6,3 & 8,3 & 1,9 \\
\hline RxOLL1 & 4,0 & 6,6 & 8,5 & 2,0 \\
\hline RxR53 & 3,6 & 6,6 & 8,1 & 1,8 \\
\hline RxR99 & 3,6 & 6,1 & 7,9 & 1,9 \\
\hline RxRS10/7 & 3,0 & 6,8 & 7,6 & 1,4 \\
\hline RxRS13/6 & 3,0 & 6,5 & 7,6 & 1,6 \\
\hline RxRS4/2 & 3,6 & 6,6 & 7,9 & 1,7 \\
\hline RxRS7/6 & 3,2 & 6,5 & 7,7 & 1,7 \\
\hline RxRS8/6 & 3,9 & 6,6 & 8,6 & 1,9 \\
\hline RxS108.1.1 & 3,9 & 6,2 & 8,1 & 1,8 \\
\hline RxS13 & 3,4 & 6,7 & 7,7 & 1,6 \\
\hline RxS45.2.2 & 3,5 & 6,8 & 7,9 & 1,8 \\
\hline MSL 007 & 3,2 & 6,9 & 7,9 & 1,6 \\
\hline Tester_Syngenta & 3,8 & 5,8 & 7,9 & 2,0 \\
\hline Visby & 3,9 & 6,3 & 8,4 & 2,1 \\
\hline $\operatorname{LSD}(p=0,05)$ & 0,4 & 0,5 & 0,5 & 0,2 \\
\hline Min. & 1,7 & 5,8 & 7,0 & 1,0 \\
\hline Max. & 4,6 & 7,9 & 8,6 & 2,1 \\
\hline MW Testhybriden & 3,2 & 6,7 & 7,8 & 1,6 \\
\hline MW Standards & 3,6 & 6,3 & 8,0 & 1,9 \\
\hline
\end{tabular}

${ }^{a}$ berechnet als Sinapinsäureäquivalente, ${ }^{b} \mathrm{SE}=$ Sinapinsäureester 
Tab. XII: Ergebnisse der ANOVA für den 6-ortigen Beobachtungsanbau der Testhybriden, gezeigt sind die Varianzkomponenten und die Heritabilität der einzelnen Merkmale

\begin{tabular}{|c|c|c|c|c|c|c|}
\hline & Varianzursache $^{\mathrm{a}}$ & Genotyp & Ort & GxO & Fehler $^{\text {b }}$ & $\mathrm{h}^{2}$ \\
\hline & TKG & $0,16^{\star *}$ & $0,44^{* *}$ & $0,17^{* *}$ & 0,09 & 0,85 \\
\hline & Wuchshöhe & $48,43^{\star \star}$ & $58,74^{* *}$ & $71,62^{* *}$ & 33,28 & 0,73 \\
\hline & Blühbeginn & $3,73^{* *}$ & $1,07^{* *}$ & $2,28^{* *}$ & 0,81 & 0,83 \\
\hline & Winterfestigkeit & $1,21^{\star *}$ & $1,60^{* *}$ & $2,33^{* *}$ & 0,58 & 0,72 \\
\hline & öL & $1,53^{\star *}$ & $3,78^{\star *}$ & $1,41^{* *}$ & 0,58 & 0,87 \\
\hline & C18:3 & $0,15^{\star *}$ & $0,68^{* *}$ & $0,15^{\star *}$ & 0,10 & 0,86 \\
\hline & C22:1 & $28,81^{* *}$ & $1,07^{* *}$ & $10,96^{* *}$ & 4,73 & 0,94 \\
\hline & Protein & $0,65^{\star *}$ & 3,49 ** & $1,10^{* *}$ & 0,50 & 0,78 \\
\hline & Glucosinolate & $99,27^{\star \star}$ & $39,39^{* *}$ & $43,35^{\star *}$ & 18,99 & 0,93 \\
\hline \multirow{6}{*}{  } & Brassicasterol & $387,92^{* *}$ & $525,07^{* *}$ & $177,82^{* *}$ & 119,61 & 0,93 \\
\hline & Camposterol & $4788,83^{* \star}$ & $3897,67^{\star *}$ & $2907,25^{\star *}$ & 1558,15 & 0,91 \\
\hline & Stigmasterol & $0,07^{\star *}$ & $0,18^{* *}$ & $0,07^{\star *}$ & 0,02 & 0,86 \\
\hline & Sitosterol & $5247,09^{\star \star}$ & $257,88^{\star *}$ & $2217,38^{* *}$ & 1296,42 & 0,93 \\
\hline & Avenasterol & $73,20^{\star *}$ & $138,15^{\star *}$ & $87,69^{* *}$ & 37,06 & 0,83 \\
\hline & Phytosterol gesamt & $25392,83^{* *}$ & $4715,22^{\star *}$ & $12856,83^{\star *}$ & 7600,75 & 0,92 \\
\hline \multirow{4}{*}{$\begin{array}{l}\frac{0}{\frac{0}{0}} \\
\frac{0}{\frac{0}{\pi}} \\
\frac{\stackrel{5}{\omega}}{2}\end{array}$} & Sinapoylglucose & $0,27^{* *}$ & $0,10^{* *}$ & $0,13^{* *}$ & 0,09 & 0,93 \\
\hline & Sinapin & $0,27^{\star *}$ & $0,14^{* *}$ & $0,17^{* *}$ & 0,12 & 0,91 \\
\hline & andere SE & $0,05^{\star *}$ & $0,02^{* *}$ & $0,03^{\star *}$ & 0,02 & 0,91 \\
\hline & Sinapinsäure gesamt & $0,10^{* *}$ & $0,02^{* *}$ & $0,18^{* *}$ & 0,13 & 0,77 \\
\hline
\end{tabular}

${ }^{a} \mathrm{GxO}=$ Interaktion zwischen Genotyp und Ort, $\mathrm{h}^{2}=$ Heritabilität; ${ }^{\mathrm{b}}$ Fehler geschätzt aus 4 Orten mit je 2 Wiederholungen; ${ }^{+},{ }^{*},{ }^{*}$ signifikant bei $p=0,1, p=0,05$ bzw. bei $p=0,01$ 
Tab. XIII: Gesamtglucosinolatgehalt und Glucosinolatmuster der Testhybriden aus dem Beobachtungsanbau am Standort Göttingen

\begin{tabular}{|c|c|c|c|c|c|c|c|c|c|c|c|c|c|}
\hline Genotyp & $\begin{array}{l}\text { PRO } \\
{[\%]}\end{array}$ & $\begin{array}{l}\text { SIN } \\
{[\%]}\end{array}$ & $\begin{array}{l}\text { GNL } \\
{[\%]}\end{array}$ & $\begin{array}{l}\text { RAA } \\
{[\%]}\end{array}$ & $\begin{array}{l}\text { RAE } \\
{[\%]}\end{array}$ & $\begin{array}{l}\text { GNA } \\
{[\%]}\end{array}$ & $\begin{array}{l}\mathrm{OH} \\
{[\%]}\end{array}$ & $\begin{array}{l}\text { GBN } \\
{[\%]}\end{array}$ & $\begin{array}{l}\text { GBC } \\
{[\%]}\end{array}$ & $\begin{array}{l}\text { NAS } \\
{[\%]}\end{array}$ & $\begin{array}{l}\text { 4ME } \\
{[\%]}\end{array}$ & $\begin{array}{l}\text { NEO } \\
{[\%]}\end{array}$ & $\begin{array}{l}\text { GSL gesamt } \\
{[\mu \mathrm{mol} / \mathrm{g}]}\end{array}$ \\
\hline MxB1/3.3 & 63,2 & 0,5 & 1,5 & 0,8 & 0,6 & 20,1 & 8,9 & 2,0 & 0,5 & 1,8 & 0,2 & 0,1 & 80,6 \\
\hline MxBOY1 & 66,0 & 0,0 & 0,0 & 0,0 & 0,0 & 23,3 & 7,3 & 2,2 & 0,5 & 0,6 & 0,1 & 0,0 & 90,5 \\
\hline MxCRL1 & 37,9 & 6,7 & 3,3 & 0,0 & 0,0 & 23,9 & 10,2 & 14,4 & 0,7 & 2,8 & 0,1 & 0,0 & 68,4 \\
\hline MxCRY2 & 51,5 & 0,2 & 0,0 & 0,0 & 0,0 & 38,3 & 4,4 & 5,1 & 0,1 & 0,3 & 0,1 & 0,0 & 128,3 \\
\hline MxFS94.3 & 47,2 & 1,8 & 2,8 & 1,1 & 2,3 & 21,4 & 12,7 & 7,3 & 0,5 & 2,7 & 0,1 & 0,0 & 46,5 \\
\hline MxG39 & 51,6 & 8,7 & 2,3 & 0,0 & 0,0 & 22,0 & 8,9 & 4,4 & 0,4 & 1,7 & 0,1 & 0,1 & 72,4 \\
\hline MxG50 & 45,9 & 4,0 & 2,3 & 0,0 & 0,0 & 20,0 & 12,3 & 11,3 & 0,7 & 3,3 & 0,1 & 0,0 & 50,0 \\
\hline MxH149 & 63,9 & 0,3 & 0,8 & 1,1 & 0,1 & 19,3 & 8,4 & 3,4 & 0,4 & 2,1 & 0,2 & 0,0 & 59,7 \\
\hline MxH165 & 65,2 & 0,8 & 1,1 & 0,0 & 0,0 & 18,3 & 9,5 & 3,4 & 0,5 & 1,1 & 0,1 & 0,0 & 54,1 \\
\hline MxH176 & 56,0 & 0,4 & 0,0 & 0,0 & 0,0 & 19,1 & 18,9 & 2,8 & 1,0 & 1,6 & 0,2 & 0,1 & 34,2 \\
\hline MxH355 & 39,6 & 0,7 & 4,7 & 0,4 & 1,7 & 36,8 & 8,9 & 4,5 & 0,7 & 1,6 & 0,2 & 0,0 & 77,6 \\
\hline MxH44 & 41,1 & 4,0 & 0,0 & 0,0 & 0,0 & 35,4 & 12,5 & 4,5 & 1,0 & 1,3 & 0,1 & 0,2 & 44,5 \\
\hline MxHIY1 & 53,8 & 0,0 & 0,0 & 0,0 & 0,0 & 35,3 & 7,3 & 2,9 & 0,2 & 0,3 & 0,2 & 0,0 & 126,5 \\
\hline MxINL1 & 33,9 & 5,1 & 1,6 & 0,0 & 0,0 & 34,9 & 12,1 & 9,1 & 0,5 & 2,7 & 0,0 & 0,1 & 48,7 \\
\hline MxINL2 & 48,2 & 0,7 & 0,0 & 0,0 & 0,0 & 34,6 & 9,1 & 5,7 & 0,5 & 1,0 & 0,1 & 0,0 & 64,2 \\
\hline MxINY1 & 42,8 & 0,0 & 0,0 & 0,0 & 0,0 & 35,1 & 18,1 & 0,0 & 1,5 & 2,1 & 0,3 & 0,1 & 29,1 \\
\hline MxINY3 & 43,7 & 0,5 & 0,0 & 0,0 & 0,0 & 42,6 & 7,3 & 4,2 & 0,5 & 1,0 & 0,1 & 0,0 & 90,2 \\
\hline MxINY6 & 62,6 & 0,1 & 0,0 & 0,0 & 0,0 & 20,4 & 10,4 & 3,9 & 0,8 & 1,5 & 0,1 & 0,1 & 55,3 \\
\hline MxISY1 & 47,4 & 2,3 & 0,0 & 0,0 & 0,0 & 40,8 & 5,2 & 3,5 & 0,2 & 0,3 & 0,3 & 0,1 & 98,3 \\
\hline MxJ104 & 44,3 & 6,5 & 0,6 & 0,0 & 0,0 & 35,6 & 9,9 & 1,2 & 0,6 & 1,1 & 0,1 & 0,1 & 65,2 \\
\hline MxJ134 & 43,7 & 4,8 & 0,0 & 0,0 & 0,0 & 23,8 & 11,8 & 10,8 & 1,1 & 3,8 & 0,1 & 0,1 & 37,3 \\
\hline MxJ154 & 52,2 & 7,2 & 0,0 & 0,0 & 0,0 & 31,2 & 6,2 & 1,8 & 0,3 & 0,9 & 0,1 & 0,1 & 72,2 \\
\hline MxJ161 & 57,3 & 3,3 & 0,5 & 0,0 & 0,0 & 29,3 & 7,4 & 0,6 & 0,5 & 0,9 & 0,1 & 0,1 & 65,2 \\
\hline MxJ166 & 58,1 & 0,0 & 0,0 & 0,0 & 0,0 & 27,3 & 7,4 & 3,2 & 0,2 & 0,6 & 0,2 & 3,0 & 80,7 \\
\hline MxJ32 & 42,1 & 1,8 & 0,0 & 0,0 & 0,0 & 39,3 & 12,8 & 2,4 & 0,4 & 1,1 & 0,1 & 0,0 & 53,2 \\
\hline
\end{tabular}


Tab. XIII: Gesamtglucosinolatgehalt und Glucosinolatmuster der Testhybriden aus dem Beobachtungsanbau am Standort Göttingen (Fortsetzung)

\begin{tabular}{|c|c|c|c|c|c|c|c|c|c|c|c|c|c|}
\hline Genotyp & $\begin{array}{l}\text { PRO } \\
{[\%]}\end{array}$ & $\begin{array}{l}\text { SIN } \\
{[\%]}\end{array}$ & $\begin{array}{l}\text { GNL } \\
{[\%]}\end{array}$ & $\begin{array}{l}\text { RAA } \\
{[\%]}\end{array}$ & $\begin{array}{l}\text { RAE } \\
{[\%]}\end{array}$ & $\begin{array}{l}\text { GNA } \\
{[\%]}\end{array}$ & $\begin{array}{l}4 \mathrm{OH} \\
{[\%]}\end{array}$ & $\begin{array}{l}\text { GBN } \\
{[\%]}\end{array}$ & $\begin{array}{l}\text { GBC } \\
{[\%]}\end{array}$ & $\begin{array}{l}\text { NAS } \\
{[\%]}\end{array}$ & $\begin{array}{l}\text { 4ME } \\
{[\%]}\end{array}$ & $\begin{array}{l}\text { NEO } \\
{[\%]}\end{array}$ & $\begin{array}{l}\text { GSL gesamt } \\
{[\mu \mathrm{mol} / \mathrm{g}]}\end{array}$ \\
\hline MxJ400 & 46,1 & 9,2 & 1,6 & 0,0 & 0,0 & 31,0 & 7,4 & 2,5 & 0,5 & 1,5 & 0,1 & 0,1 & 86,0 \\
\hline MxJ401 & 46,5 & 8,3 & 2,8 & 0,0 & 0,0 & 23,1 & 10,5 & 5,5 & 0,7 & 2,5 & 0,1 & 0,1 & 47,2 \\
\hline MxJ408 & 42,8 & 6,8 & 2,2 & 0,0 & 0,0 & 30,9 & 8,6 & 5,6 & 0,7 & 2,1 & 0,2 & 0,1 & 62,5 \\
\hline MxJ410 & 47,4 & 8,3 & 1,5 & 0,0 & 0,0 & 29,2 & 7,1 & 3,9 & 0,3 & 2,2 & 0,1 & 0,0 & 76,8 \\
\hline MxJ45 & 52,2 & 9,3 & 0,7 & 0,0 & 0,0 & 26,9 & 7,5 & 2,0 & 0,4 & 0,8 & 0,1 & 0,1 & 94,6 \\
\hline MxK160.1.1 & 40,8 & 0,8 & 4,2 & 0,5 & 2,3 & 35,5 & 10,8 & 2,5 & 0,6 & 1,9 & 0,1 & 0,0 & 61,3 \\
\hline MxK199.16.2 & 44,6 & 1,1 & 6,3 & 0,0 & 0,0 & 35,8 & 7,8 & 2,2 & 0,5 & 1,6 & 0,1 & 0,0 & 60,2 \\
\hline MxMAY1 & 49,9 & 8,0 & 0,0 & 0,0 & 0,0 & 32,2 & 4,8 & 3,9 & 0,1 & 0,9 & 0,1 & 0,1 & 142,4 \\
\hline MxMOL1 & 44,5 & 2,4 & 2,1 & 0,9 & 1,6 & 27,2 & 5,4 & 13,1 & 0,3 & 2,3 & 0,2 & 0,0 & 72,8 \\
\hline MxMOL2 & 36,3 & 2,9 & 1,8 & 0,0 & 0,0 & 40,5 & 8,1 & 8,3 & 0,1 & 1,9 & 0,1 & 0,0 & 68,5 \\
\hline MxMOY1 & 49,0 & 0,2 & 0,0 & 0,0 & 0,0 & 41,2 & 5,7 & 3,0 & 0,2 & 0,5 & 0,1 & 0,0 & 110,5 \\
\hline MxMOY4 & 41,9 & 0,3 & 0,0 & 0,0 & 0,0 & 38,6 & 13,5 & 3,7 & 0,8 & 1,0 & 0,1 & 0,1 & 46,2 \\
\hline MxMOY5 & 45,8 & 1,3 & 0,0 & 0,0 & 0,0 & 37,1 & 11,4 & 3,0 & 0,4 & 1,0 & 0,1 & 0,1 & 56,2 \\
\hline MxMOY6 & 39,3 & 0,3 & 0,0 & 0,0 & 0,0 & 42,9 & 13,2 & 1,6 & 1,0 & 1,5 & 0,1 & 0,1 & 55,4 \\
\hline MxOLL1 & 44,2 & 0,4 & 0,0 & 0,0 & 0,0 & 20,6 & 21,3 & 8,5 & 2,0 & 2,5 & 0,2 & 0,2 & 30,8 \\
\hline MxOLY1 & 45,9 & 0,6 & 1,2 & 0,0 & 0,0 & 44,3 & 4,9 & 2,3 & 0,1 & 0,6 & 0,0 & 0,0 & 110,1 \\
\hline MxOLY2 & 31,4 & 1,8 & 0,9 & 0,0 & 0,0 & 48,6 & 8,3 & 7,4 & 0,3 & 1,4 & 0,1 & 0,0 & 67,7 \\
\hline MxR53 & 48,7 & 4,5 & 3,5 & 0,1 & 0,1 & 19,1 & 17,2 & 3,2 & 1,2 & 2,5 & 0,2 & 0,0 & 37,6 \\
\hline MxR76 & 53,3 & 0,3 & 0,5 & 2,6 & 5,0 & 16,7 & 7,8 & 9,0 & 0,4 & 4,2 & 0,0 & 0,0 & 77,5 \\
\hline MxR99 & 46,4 & 1,0 & 0,0 & 0,0 & 0,0 & 25,5 & 22,7 & 1,5 & 1,4 & 1,4 & 0,2 & 0,0 & 36,0 \\
\hline MxRS10/7 & 59,0 & 1,2 & 3,6 & 0,0 & 0,0 & 26,3 & 7,2 & 1,5 & 0,3 & 0,9 & 0,1 & 0,0 & 78,6 \\
\hline MxRS13/6 & 46,5 & 6,2 & 1,6 & 0,0 & 0,0 & 31,8 & 7,6 & 4,2 & 0,3 & 1,6 & 0,1 & 0,0 & 82,9 \\
\hline MxRS4/2 & 57,5 & 4,4 & 3,0 & 0,0 & 0,0 & 17,6 & 11,6 & 3,5 & 0,7 & 1,4 & 0,2 & 0,1 & 50,1 \\
\hline MxRS4/6 & 51,1 & 2,4 & 1,1 & 0,0 & 0,0 & 26,8 & 14,6 & 1,5 & 0,7 & 1,8 & 0,1 & 0,0 & 46,3 \\
\hline MxRS7/6 & 37,4 & 1,7 & 2,7 & 0,4 & 2,2 & 38,6 & 10,3 & 4,2 & 1,0 & 1,2 & 0,1 & 0,0 & 55,8 \\
\hline
\end{tabular}


Tab. XIII: Gesamtglucosinolatgehalt und Glucosinolatmuster der Testhybriden aus dem Beobachtungsanbau am Standort Göttingen (Fortsetzung)

\begin{tabular}{|c|c|c|c|c|c|c|c|c|c|c|c|c|c|}
\hline Genotyp & $\begin{array}{l}\text { PRO } \\
\text { [\%] }\end{array}$ & $\begin{array}{l}\text { SIN } \\
{[\%]}\end{array}$ & $\begin{array}{l}\text { GNL } \\
{[\%]}\end{array}$ & $\begin{array}{l}\text { RAA } \\
\text { [\%] }\end{array}$ & $\begin{array}{l}\text { RAE } \\
\text { [\%] }\end{array}$ & $\begin{array}{l}\text { GNA } \\
{[\%]}\end{array}$ & $\begin{array}{l}4 \mathrm{OH} \\
{[\%]}\end{array}$ & $\begin{array}{l}\text { GBN } \\
{[\%]}\end{array}$ & $\begin{array}{l}\text { GBC } \\
{[\%]}\end{array}$ & $\begin{array}{l}\text { NAS } \\
{[\%]}\end{array}$ & $\begin{array}{l}\text { 4ME } \\
{[\%]}\end{array}$ & $\begin{array}{l}\text { NEO } \\
{[\%]}\end{array}$ & $\begin{array}{l}\text { GSL gesamt } \\
{[\mu \mathrm{mol} / \mathrm{g}]}\end{array}$ \\
\hline MxRS8/6 & 50,2 & 2,3 & 0,9 & 0,9 & 1,9 & 28,5 & 9,8 & 3,3 & 0,6 & 1,4 & 0,1 & 0,0 & 61,1 \\
\hline MxS108.1.1 & 47,9 & 0,2 & 3,6 & 1,1 & 1,7 & 28,6 & 11,7 & 2,2 & 0,9 & 2,1 & 0,1 & 0,1 & 57,9 \\
\hline MxS13 & 56,2 & 2,7 & 1,5 & 0,0 & 0,0 & 24,9 & 6,7 & 5,5 & 0,3 & 1,9 & 0,1 & 0,0 & 82,9 \\
\hline MxS228.8.1 & 50,5 & 0,4 & 1,5 & 0,0 & 0,0 & 29,7 & 12,4 & 3,1 & 0,5 & 1,9 & 0,2 & 0,0 & 56,7 \\
\hline MxS237.20.1 & 53,9 & 0,0 & 10,4 & 0,0 & 0,0 & 22,9 & 9,5 & 1,3 & 0,7 & 1,2 & 0,1 & 0,0 & 69,5 \\
\hline MxS39 & 52,1 & 0,0 & 7,4 & 0,3 & 3,1 & 22,4 & 8,1 & 4,2 & 0,4 & 1,8 & 0,2 & 0,0 & 68,5 \\
\hline MxS45.2.2 & 36,0 & 1,6 & 0,8 & 0,5 & 6,9 & 32,6 & 11,5 & 5,8 & 0,5 & 3,5 & 0,2 & 0,1 & 56,0 \\
\hline MxVIL1 & 38,4 & 0,4 & 0,0 & 0,0 & 0,0 & 47,1 & 9,6 & 3,4 & 0,3 & 0,8 & 0,0 & 0,0 & 57,8 \\
\hline RxB1/3.3 & 54,7 & 3,6 & 1,4 & 0,0 & 0,0 & 23,6 & 12,1 & 2,5 & 0,9 & 1,1 & 0,1 & 0,1 & 72,7 \\
\hline RxBOY1 & 76,2 & 0,1 & 0,0 & 0,5 & 1,3 & 4,1 & 12,8 & 1,7 & 0,8 & 2,1 & 0,5 & 0,2 & 40,6 \\
\hline RxCRL1 & 43,7 & 0,1 & 0,1 & 5,4 & 0,1 & 20,8 & 11,3 & 11,6 & 5,0 & 2,1 & 0,2 & 0,1 & 36,3 \\
\hline RxCRY2 & 44,4 & 2,5 & 1,2 & 3,3 & 2,6 & 21,0 & 13,6 & 6,9 & 1,6 & 2,1 & 0,5 & 0,2 & 41,8 \\
\hline RxG39 & 50,5 & 8,1 & 2,6 & 0,0 & 0,0 & 23,1 & 8,9 & 4,4 & 0,5 & 1,6 & 0,2 & 0,1 & 58,9 \\
\hline RxG50 & 40,9 & 6,0 & 6,0 & 2,6 & 0,0 & 14,8 & 14,1 & 11,4 & 1,3 & 2,6 & 0,3 & 0,0 & 44,5 \\
\hline RxH149 & 61,0 & 0,2 & 1,5 & 0,0 & 0,0 & 21,7 & 10,3 & 2,9 & 0,5 & 1,3 & 0,5 & 0,1 & 61,5 \\
\hline RxH165 & 57,9 & 0,0 & 2,8 & 2,2 & 0,0 & 16,5 & 15,4 & 2,5 & 1,0 & 1,4 & 0,2 & 0,1 & 44,8 \\
\hline RxH176 & 52,5 & 0,3 & 1,4 & 0,0 & 0,0 & 19,4 & 19,8 & 3,2 & 1,8 & 1,4 & 0,2 & 0,0 & 41,6 \\
\hline RxH355 & 39,7 & 6,4 & 0,0 & 0,0 & 0,0 & 36,3 & 10,1 & 4,7 & 1,4 & 0,9 & 0,2 & 0,1 & 68,4 \\
\hline RxH44 & 38,5 & 3,5 & 1,5 & 1,0 & 0,0 & 31,1 & 16,0 & 5,7 & 1,3 & 1,2 & 0,2 & 0,1 & 39,6 \\
\hline RxINL1 & 40,5 & 0,0 & 0,0 & 2,6 & 0,8 & 31,8 & 10,5 & 9,9 & 0,8 & 2,6 & 0,4 & 0,1 & 40,4 \\
\hline RxINL2 & 42,9 & 0,0 & 0,0 & 1,0 & 0,8 & 39,9 & 8,2 & 5,5 & 0,3 & 1,0 & 0,2 & 0,1 & 60,0 \\
\hline RxINY3 & 40,0 & 2,4 & 0,0 & 0,0 & 0,0 & 43,5 & 8,3 & 4,1 & 0,8 & 0,9 & 0,1 & 0,0 & 66,7 \\
\hline RxJ104 & 44,3 & 7,4 & 1,3 & 1,2 & 0,0 & 35,4 & 7,3 & 1,1 & 0,8 & 0,9 & 0,3 & 0,1 & 58,2 \\
\hline RxJ112 & 50,4 & 7,9 & 1,6 & 1,1 & 0,1 & 27,0 & 7,6 & 1,9 & 0,8 & 1,2 & 0,3 & 0,1 & 67,8 \\
\hline RxJ134 & 43,9 & 3,1 & 3,7 & 0,6 & 0,0 & 25,7 & 9,7 & 8,5 & 1,1 & 3,4 & 0,2 & 0,1 & 37,5 \\
\hline
\end{tabular}


Tab. XIII: Gesamtglucosinolatgehalt und Glucosinolatmuster der Testhybriden aus dem Beobachtungsanbau am Standort Göttingen (Fortsetzung)

\begin{tabular}{|c|c|c|c|c|c|c|c|c|c|c|c|c|c|}
\hline Genotyp & $\begin{array}{l}\text { PRO } \\
{[\%]}\end{array}$ & $\begin{array}{l}\text { SIN } \\
{[\%]}\end{array}$ & $\begin{array}{l}\text { GNL } \\
{[\%]}\end{array}$ & $\begin{array}{l}\text { RAA } \\
{[\%]}\end{array}$ & $\begin{array}{l}\text { RAE } \\
{[\%]}\end{array}$ & $\begin{array}{l}\text { GNA } \\
{[\%]}\end{array}$ & $\begin{array}{l}4 \mathrm{OH} \\
{[\%]}\end{array}$ & $\begin{array}{l}\text { GBN } \\
{[\%]}\end{array}$ & $\begin{array}{l}\text { GBC } \\
{[\%]}\end{array}$ & $\begin{array}{l}\text { NAS } \\
{[\%]}\end{array}$ & $\begin{array}{l}\text { 4ME } \\
{[\%]}\end{array}$ & $\begin{array}{l}\text { NEO } \\
{[\%]}\end{array}$ & $\begin{array}{l}\text { GSL gesamt } \\
{[\mu \mathrm{mol} / \mathrm{g}]}\end{array}$ \\
\hline RxJ154 & 38,1 & 9,8 & 1,0 & 0,3 & 0,0 & 36,3 & 9,7 & 2,3 & 0,8 & 1,4 & 0,2 & 0,1 & 61,6 \\
\hline RxJ166 & 47,7 & 5,7 & 1,5 & 1,8 & 0,0 & 24,8 & 12,2 & 2,3 & 2,4 & 1,2 & 0,3 & 0,1 & 48,7 \\
\hline RxJ400 & 30,8 & 9,4 & 2,0 & 1,5 & 0,0 & 39,6 & 10,6 & 3,2 & 1,0 & 1,5 & 0,3 & 0,2 & 52,0 \\
\hline RxJ401 & 51,7 & 1,3 & 2,2 & 0,9 & 0,0 & 24,5 & 10,4 & 5,7 & 0,8 & 2,4 & 0,2 & 0,1 & 45,1 \\
\hline RxK160.1.1 & 47,3 & 3,4 & 0,1 & 0,1 & 0,1 & 27,9 & 15,6 & 3,2 & 1,3 & 1,4 & 0,0 & 0,0 & 37,1 \\
\hline RxMOL1 & 42,4 & 0,1 & 0,0 & 0,1 & 5,0 & 33,7 & 4,7 & 12,9 & 0,2 & 0,8 & 0,1 & 0,0 & 68,4 \\
\hline RxMOL2 & 42,7 & 0,4 & 0,0 & 1,6 & 0,9 & 34,3 & 11,0 & 6,6 & 0,8 & 1,2 & 0,4 & 0,1 & 44,1 \\
\hline RxMOY2 & 44,6 & 0,0 & 0,3 & 0,5 & 0,0 & 45,9 & 2,8 & 4,9 & 0,1 & 0,7 & 0,1 & 0,0 & 88,0 \\
\hline RxMOY6 & 49,9 & 0,6 & 0,9 & 1,4 & 0,0 & 26,3 & 10,1 & 8,1 & 0,7 & 1,6 & 0,3 & 0,1 & 46,7 \\
\hline RxOLL1 & 42,0 & 3,3 & 4,5 & 0,0 & 0,0 & 23,1 & 15,6 & 6,2 & 2,6 & 2,2 & 0,5 & 0,1 & 34,9 \\
\hline RxR53 & 42,8 & 7,8 & 2,9 & 0,7 & 0,9 & 20,6 & 16,1 & 4,4 & 1,5 & 1,9 & 0,3 & 0,1 & 52,2 \\
\hline RxR99 & 39,0 & 5,8 & 1,6 & 1,2 & 0,0 & 29,4 & 17,5 & 2,0 & 1,5 & 1,9 & 0,2 & 0,1 & 51,7 \\
\hline RxRS10/7 & 44,5 & 9,1 & 1,6 & 0,5 & 0,0 & 24,6 & 15,2 & 1,2 & 1,4 & 1,6 & 0,2 & 0,1 & 49,5 \\
\hline RxRS13/6 & 41,5 & 6,0 & 1,4 & 0,3 & 0,0 & 33,7 & 10,8 & 3,7 & 0,7 & 1,6 & 0,1 & 0,0 & 72,6 \\
\hline RxRS4/2 & 45,6 & 6,3 & 2,5 & 0,0 & 0,0 & 23,2 & 17,4 & 1,9 & 1,0 & 1,7 & 0,2 & 0,1 & 43,8 \\
\hline RxRS7/6 & 41,0 & 4,4 & 1,1 & 0,0 & 0,0 & 31,7 & 11,9 & 6,6 & 2,0 & 1,1 & 0,0 & 0,1 & 48,8 \\
\hline RxRS8/6 & 53,2 & 0,4 & 0,0 & 0,0 & 0,0 & 22,8 & 15,7 & 5,5 & 1,5 & 0,9 & 0,0 & 0,0 & 37,9 \\
\hline RxS108.1. & 51,5 & 1,0 & 0,7 & 0,0 & 0,0 & 25,1 & 14,1 & 4,2 & 1,9 & 1,3 & 0,1 & 0,0 & 61,5 \\
\hline RxS13 & 60,4 & 0,5 & 2,3 & 0,0 & 0,0 & 21,5 & 7,9 & 5,4 & 0,4 & 1,4 & 0,1 & 0,0 & 100,2 \\
\hline RxS237.20.1 & 50,2 & 7,2 & 0,1 & 0,1 & 0,1 & 20,0 & 16,7 & 2,5 & 1,6 & 1,6 & 0,0 & 0,2 & 34,6 \\
\hline $\mathrm{RxS} 45.2 .2$ & 42,4 & 3,8 & 0,7 & 0,0 & 0,0 & 26,1 & 15,5 & 7,8 & 1,0 & 2,5 & 0,1 & 0,0 & 57,1 \\
\hline TesterSyngenta & 44,7 & 2,5 & 0,0 & 0,0 & 0,0 & 19,1 & 26,2 & 2,6 & 2,8 & 2,2 & 0,0 & 0,0 & 23,3 \\
\hline MSL007 & 39,7 & 1,5 & 0,0 & 0,0 & 0,0 & 22,6 & 27,8 & 3,1 & 1,8 & 3,0 & 0,4 & 0,1 & 24,0 \\
\hline Visby & 48,2 & 0,0 & 0,0 & 0,0 & 0,0 & 20,0 & 25,9 & 1,0 & 2,1 & 2,7 & 0,0 & 0,0 & 20,1 \\
\hline
\end{tabular}


Tab. XIII: Gesamtglucosinolatgehalt und Glucosinolatmuster der Testhybriden aus dem Beobachtungsanbau am Standort Göttingen (Fortsetzung)

\begin{tabular}{|c|c|c|c|c|c|c|c|c|c|c|c|c|c|}
\hline Genotyp & $\begin{array}{l}\text { PRO } \\
{[\%]}\end{array}$ & $\begin{array}{l}\text { SIN } \\
{[\%]}\end{array}$ & $\begin{array}{l}\text { GNL } \\
{[\%]}\end{array}$ & $\begin{array}{l}\text { RAA } \\
\text { [\%] }\end{array}$ & $\begin{array}{l}\text { RAE } \\
{[\%]}\end{array}$ & $\begin{array}{l}\text { GNA } \\
{[\%]}\end{array}$ & $\begin{array}{l}40 \mathrm{H} \\
{[\%]}\end{array}$ & $\begin{array}{l}\text { GBN } \\
{[\%]}\end{array}$ & $\begin{array}{l}\text { GBC } \\
{[\%]}\end{array}$ & $\begin{array}{l}\text { NAS } \\
{[\%]}\end{array}$ & $\begin{array}{l}\text { 4ME } \\
{[\%]}\end{array}$ & $\begin{array}{l}\text { NEO } \\
{[\%]}\end{array}$ & $\begin{array}{l}\text { GSL gesamt } \\
{[\mu \mathrm{mol} / \mathrm{g}]}\end{array}$ \\
\hline $\operatorname{LSD}(p=0,05)$ & 11,1 & 3,7 & 2,3 & 1,2 & 0,8 & 7,8 & 3,3 & 2,4 & 0,5 & 0,8 & 0,2 & 0,1 & 17,7 \\
\hline Min & 30,8 & 0,0 & 0,0 & 0,0 & 0,0 & 4,1 & 2,8 & 0,0 & 0,1 & 0,3 & 0,0 & 0,0 & 20,1 \\
\hline Max & 76,2 & 9,8 & 10,4 & 5,4 & 6,9 & 48,6 & 27,8 & 14,4 & 5,0 & 4,2 & 0,5 & 3,0 & 142,4 \\
\hline MW Testhybriden & 47,5 & 3,0 & 1,5 & 0,5 & 0,4 & 29,0 & 10,8 & 4,6 & 0,8 & 1,6 & 0,2 & 0,1 & 61,8 \\
\hline MW Standards & 44,2 & 1,3 & 0,0 & 0,0 & 0,0 & 20,6 & 26,6 & 2,2 & 2,3 & 2,6 & 0,1 & 0,0 & 22,5 \\
\hline MxINY4 ${ }^{1}$ & 53,7 & 0,0 & 0,0 & 0,0 & 0,0 & 33,6 & 7,7 & 3,4 & 0,3 & 1,3 & 0,1 & 0,1 & 41,8 \\
\hline MxRS8/6 $6^{1}$ & 59,9 & 2,5 & 0,0 & 0,9 & 2,1 & 25,1 & 5,7 & 2,7 & 0,2 & 0,9 & 0,1 & 0,0 & 62,0 \\
\hline RxINY1 ${ }^{1}$ & 55,7 & 0,0 & 0,0 & 0,0 & 0,0 & 30,5 & 11,2 & 1,3 & 0,5 & 0,8 & 0,1 & 0,2 & 48,9 \\
\hline RxJ161 ${ }^{1}$ & 38,7 & 0,1 & 6,7 & 0,0 & 0,1 & 45,0 & 4,1 & 3,1 & 0,3 & 1,7 & 0,2 & 0,0 & 77,2 \\
\hline RxJ408 ${ }^{1}$ & 45,3 & 2,3 & 4,1 & 0,8 & 3,0 & 28,9 & 9,6 & 4,3 & 0,4 & 1,0 & 0,2 & 0,3 & 55,9 \\
\hline RxJ410 & 43,6 & 1,6 & 3,0 & 0,1 & 0,1 & 31,6 & 13,1 & 4,2 & 1,0 & 1,3 & 0,2 & 0,1 & 41,8 \\
\hline RxVIL1 $^{1}$ & 37,2 & 0,0 & 0,1 & 0,1 & 0,1 & 47,2 & 10,0 & 2,5 & 0,9 & 1,6 & 0,2 & 0,2 & 51,9 \\
\hline
\end{tabular}

${ }^{1}$ Ergebnisse für diese Resynthesen stammen vom Standort Einbeck und wurden daher nicht zusammen mit den übrigen aufgeführten Resynthesen vom Standort Göttingen verrechnet. 


\section{Leistungsprüfungen der Testhybriden}

Tab. XIV: Leistungsprüfungen der Testhybriden: Phytosterolgehalt und -Muster, gemittelt über vier Standorte

\begin{tabular}{|c|c|c|c|c|c|c|}
\hline Genotyp & $\begin{array}{l}\text { Brassica } \\
\text {-sterol } \\
\text { [mg/kg] }\end{array}$ & $\begin{array}{l}\text { Campo } \\
\text {-sterol } \\
\text { [mg/kg] }\end{array}$ & $\begin{array}{l}\text { Stigma } \\
\text {-sterol } \\
\text { [mg/kg] }\end{array}$ & $\begin{array}{l}\text { Sito } \\
\text {-sterol } \\
\text { [mg/kg] }\end{array}$ & $\begin{array}{l}\text { Avena } \\
\text {-sterol } \\
\text { [mg/kg] }\end{array}$ & $\begin{array}{l}\text { Phytosterol } \\
\text { gesamt } \\
{[\mathrm{mg} / \mathrm{kg}]}\end{array}$ \\
\hline MSL007xB1/3.3 & 295,1 & 1190,5 & 10,5 & 1811,2 & 67,2 & 3527,4 \\
\hline MSL007xBOY1 & 319,8 & 1179,1 & 10,7 & 1838,5 & 63,3 & 3566,8 \\
\hline MSL007xFS94.3 & 327,6 & 1282,2 & 10,7 & 1928,5 & 76,1 & 3770,8 \\
\hline MSL007xG39 & 317,3 & 1161,9 & 10,8 & 1811,8 & 59,4 & 3515,0 \\
\hline MSL007xG50 & 286,9 & 1338,8 & 10,5 & 1917,2 & 68,8 & 3774,7 \\
\hline MSL007xH149 & 284,5 & 1140,2 & 10,2 & 1712,6 & 72,5 & 3390,5 \\
\hline MSL007xH165 & 311,3 & 1198,2 & 10,4 & 1808,9 & 69,0 & 3547,9 \\
\hline MSL007xH176 & 314,9 & 1211,7 & 10,2 & 1792,6 & 73,1 & 3533,6 \\
\hline MSL007xH44 & 317,5 & 1053,3 & 10,8 & 1709,2 & 61,5 & 3289,0 \\
\hline MSL007xINL2 & 299,9 & 1152,0 & 11,0 & 1819,3 & 57,4 & 3473,3 \\
\hline MSL007xJ134 & 330,9 & 1112,9 & 11,0 & 1778,8 & 69,5 & 3413,5 \\
\hline MSL007xJ154 & 297,3 & 1134,9 & 11,1 & 1829,1 & 60,9 & 3483,5 \\
\hline MSL007xJ161 & 309,5 & 1124,7 & 10,7 & 1768,4 & 66,0 & 3422,8 \\
\hline MSL007xJ166 & 281,2 & 1112,9 & 11,2 & 1813,2 & 44,0 & 3423,5 \\
\hline MSL007xJ32 & 314,2 & 1204,3 & 10,7 & 1847,4 & 62,7 & 3585,7 \\
\hline MSL007xJ401 & 325,0 & 1163,5 & 10,7 & 1784,6 & 70,9 & 3533,0 \\
\hline MSL007xJ45 & 297,4 & 1156,9 & 11,0 & 1831,9 & 56,5 & 3520,8 \\
\hline MSL007xK199.16.2 & 287,6 & 1108,9 & 10,6 & 1712,0 & 57,4 & 3319,6 \\
\hline MSL007xMOL1 & 281,2 & 1184,7 & 10,7 & 1827,7 & 47,8 & 3501,7 \\
\hline MSL007xMOL2 & 315,4 & 1110,3 & 11,3 & 1840,4 & 49,6 & 3478,6 \\
\hline MSL007xMOY5 & 301,3 & 1129,4 & 11,2 & 1825,1 & 54,9 & 3509,9 \\
\hline MSL007xR53 & 285,0 & 1141,4 & 10,2 & 1714,6 & 54,0 & 3350,1 \\
\hline MSL007xR99 & 314,2 & 1254,7 & 10,5 & 1871,4 & 66,5 & 3665,0 \\
\hline MSL007xRS13/6 & 278,7 & 1112,5 & 10,3 & 1709,6 & 57,5 & 3312,3 \\
\hline MSL007xRS4/2 & 304,0 & 1125,8 & 10,7 & 1770,6 & 58,8 & 3409,1 \\
\hline MSL007xS108.1.1 & 288,9 & 1276,7 & 10,4 & 1890,3 & 69,4 & 3706,1 \\
\hline MSL007xS13 & 249,8 & 1156,6 & 10,0 & 1723,5 & 66,4 & 3393,1 \\
\hline MSL007xS228.8.1 & 301,7 & 1168,9 & 10,6 & 1800,0 & 60,1 & 3496,4 \\
\hline MSL007xS45.2.2 & 327,4 & 1132,1 & 10,8 & 1763,6 & 66,4 & 3453,9 \\
\hline MSL007xVIL1 & 292,9 & 1177,0 & 10,8 & 1818,4 & 60,5 & 3514,8 \\
\hline RNX4621 XB1/3.3 & 302,2 & 1180,9 & 10,8 & 1858,4 & 67,4 & 3571,7 \\
\hline RNX4621XBOY1 & 322,0 & 1178,6 & 11,1 & 1879,9 & 63,8 & 3471,6 \\
\hline RNX4621xG39 & 314,4 & 1214,9 & 11,1 & 1907,9 & 64,4 & 3673,0 \\
\hline RNX4621xG50 & 313,5 & 1330,2 & 10,5 & 1965,5 & 76,9 & 3858,9 \\
\hline RNX4621xH149 & 299,4 & 1130,7 & 10,5 & 1742,4 & 71,5 & 3437,5 \\
\hline RNX4621xH165 & 309,7 & 1200,6 & 10,6 & 1841,0 & 65,0 & 3606,6 \\
\hline RNX4621 xH176 & 326,5 & 1193,1 & 10,8 & 1851,8 & 63,9 & 3603,8 \\
\hline RNX4621 xH355 & 290,0 & 1135,8 & 10,9 & 1816,7 & 52,6 & 3475,4 \\
\hline RNX4621xH44 & 323,7 & 1098,6 & 10,9 & 1776,1 & 63,3 & 3410,5 \\
\hline RNX4621 XINL1 & 333,1 & 1224,2 & 11,1 & 1929,4 & 70,8 & 3727,3 \\
\hline RNX4621xINL2 & 319,6 & 1137,9 & 11,2 & 1855,1 & 61,0 & 3517,6 \\
\hline
\end{tabular}


Tab. XIV: Leistungsprüfungen der Testhybriden: Phytosterolgehalt und -Muster, gemittelt über vier Standorte (Fortsetzung)

\begin{tabular}{|c|c|c|c|c|c|c|}
\hline Genotyp & $\begin{array}{l}\text { Brassica } \\
\text {-sterol } \\
\text { [mg/kg] }\end{array}$ & $\begin{array}{l}\text { Campo } \\
\text {-sterol } \\
\text { [mg/kg] }\end{array}$ & $\begin{array}{l}\text { Stigma } \\
\text {-sterol } \\
{[\mathrm{mg} / \mathrm{kg}]}\end{array}$ & $\begin{array}{l}\text { Sito } \\
\text {-sterol } \\
\text { [mg/kg] }\end{array}$ & $\begin{array}{l}\text { Avena } \\
\text {-sterol } \\
\text { [mg/kg] }\end{array}$ & $\begin{array}{l}\text { Phytosterol } \\
\text { gesamt } \\
{[\mathrm{mg} / \mathrm{kg}]}\end{array}$ \\
\hline RNX4621xJ112 & 303,8 & 1210,1 & 10,7 & 1869,1 & 69,0 & 3629,8 \\
\hline RNX4621xJ134 & 335,0 & 1150,3 & 11,0 & 1841,3 & 70,3 & 3534,2 \\
\hline RNX4621XJ154 & 326,8 & 1284,5 & 10,7 & 1956,5 & 79,4 & 3839,4 \\
\hline RNX4621XJ161 & 333,2 & 1248,5 & 10,9 & 1927,1 & 68,5 & 3765,4 \\
\hline RNX4621XJ166 & 289,8 & 1183,2 & 11,0 & 1890,3 & 57,0 & 3604,9 \\
\hline RNX4621xJ401 & 341,8 & 1198,3 & 10,9 & 1844,0 & 68,0 & 3600,9 \\
\hline RNX4621xJ408 & 285,5 & 1161,7 & 10,8 & 1815,4 & 58,1 & 3500,8 \\
\hline RNX4621XJ410 & 299,2 & 1217,5 & 10,9 & 1887,6 & 63,4 & 3659,6 \\
\hline RNX4621xJ45 & 314,6 & 1263,3 & 10,8 & 1932,5 & 71,1 & 3764,1 \\
\hline RNX4621xMOY4 & 323,5 & 1307,2 & 10,7 & 1971,7 & 73,2 & 3872,6 \\
\hline RNX4621xOLL1 & 328,7 & 1189,5 & 10,9 & 1864,8 & 66,8 & 3586,4 \\
\hline RNX4621 XR53 & 275,4 & 1134,1 & 10,4 & 1740,2 & 52,3 & 3361,4 \\
\hline RNX4621xR99 & 314,3 & 1262,4 & 10,7 & 1912,9 & 68,6 & 3745,3 \\
\hline RNX4621xRS10/7 & 307,2 & 1222,5 & 10,7 & 1858,4 & 71,3 & 3667,4 \\
\hline RNX4621xRS13/6 & 281,2 & 1208,7 & 10,4 & 1820,6 & 64,5 & 3550,6 \\
\hline RNX4621xRS4/2 & 316,6 & 1259,0 & 10,5 & 1892,1 & 70,6 & 3707,2 \\
\hline RNX4621xRS7/6 & 319,0 & 1089,6 & 11,1 & 1794,0 & 54,6 & 3408,8 \\
\hline RNX4621xRS8/6 & 300,7 & 1249,4 & 10,6 & 1877,7 & 61,5 & 3654,3 \\
\hline RNX4621xRUY1 & 327,4 & 1304,3 & 10,7 & 1960,6 & 74,1 & 3871,9 \\
\hline RNX4621XS108.1.1 & 309,7 & 1162,9 & 10,9 & 1847,3 & 58,1 & 3556,5 \\
\hline RNX4621xS13 & 277,0 & 1185,5 & 10,5 & 1823,1 & 69,1 & 3553,7 \\
\hline RNX4621xS39 & 325,4 & 1291,3 & 11,0 & 1992,1 & 71,1 & 3875,7 \\
\hline RNX4621xS45.2.2 & 321,5 & 1220,6 & 11,1 & 1916,9 & 63,1 & 3705,0 \\
\hline MSLOO7 & 331,7 & 1379,6 & 10,1 & 1944,8 & 86,4 & 3929,3 \\
\hline TesterSyngenta & 321,9 & 1261,0 & 10,9 & 1942,8 & 63,6 & 3792,7 \\
\hline Visby & 362,7 & 1351,4 & 10,9 & 2068,5 & 93,6 & 4078,1 \\
\hline $\operatorname{LSD}(p=0,05)$ & 22,38 & 75,60 & 0,34 & 68,07 & 10,66 & 154,59 \\
\hline Min. & 22,4 & 75,6 & 0,3 & 68,1 & 10,7 & 154,6 \\
\hline Max. & 362,7 & 1379,6 & 11,3 & 2068,5 & 93,6 & 4078,1 \\
\hline MW Testhybriden & 307,3 & 1187,9 & 10,7 & 1839,5 & 64,2 & 3566,4 \\
\hline MW Standards & 338,8 & 1330,7 & 10,6 & 1985,4 & 81,2 & 3933,4 \\
\hline
\end{tabular}


Tab XV: Leistungsprüfungen der Testhybriden: NIRS-Ergebnisse für die Sinapoylverbindungen, gemittelt über vier Standorte

\begin{tabular}{|c|c|c|c|c|}
\hline Genotyp & $\begin{array}{c}\text { Sinapoylglucose } \\
{[\mathrm{mg} / \mathrm{g}]}\end{array}$ & $\begin{array}{c}\text { Sinapin } \\
{[\mathrm{mg} / \mathrm{g}]}\end{array}$ & $\begin{array}{c}\text { Sinapinsäure } \\
{\text { gesamt }[\mathrm{mg} / \mathrm{g}]^{\mathrm{a}}}^{\text {a }}\end{array}$ & $\begin{array}{c}{ }^{\text {andere SE}}{ }^{\mathrm{b}} \\
{[\mathrm{mg} / \mathrm{g}]^{\mathrm{a}}}\end{array}$ \\
\hline MSL007xB1/3.3 & 2,4 & 7,1 & 6,9 & 1,0 \\
\hline MSL007xBOY1 & 2,8 & 6,9 & 7,3 & 1,4 \\
\hline MSL007xFS94.3 & 3,3 & 6,4 & 7,7 & 1,7 \\
\hline MSL007xG39 & 3,2 & 6,9 & 8,0 & 1,6 \\
\hline MSL007xG50 & 3,5 & 6,7 & 8,0 & 1,7 \\
\hline MSL007xH149 & 2,8 & 6,5 & 7,0 & 1,3 \\
\hline MSL007xH165 & 3,1 & 6,8 & 7,3 & 1,3 \\
\hline MSL007xH176 & 3,1 & 6,6 & 7,6 & 1,6 \\
\hline MSL007xH44 & 2,3 & 7,1 & 7,0 & 1,3 \\
\hline MSL007xINL2 & 3,1 & 7,0 & 7,3 & 1,2 \\
\hline MSL007xJ134 & 2,8 & 6,5 & 6,9 & 1,3 \\
\hline MSL007xJ154 & 2,7 & 6,9 & 7,0 & 1,2 \\
\hline MSL007xJ161 & 3,2 & 6,2 & 7,3 & 1,5 \\
\hline MSL007xJ166 & 3,3 & 5,9 & 7,4 & 1,6 \\
\hline MSL007xJ32 & 3,0 & 6,7 & 7,5 & 1,6 \\
\hline MSL007xJ401 & 3,3 & 6,2 & 7,2 & 1,6 \\
\hline MSL007xJ45 & 3,1 & 5,9 & 6,9 & 1,6 \\
\hline MSL007xK199.16.2 & 2,8 & 7,2 & 7,4 & 1,5 \\
\hline MSL007xMOL1 & 3,4 & 6,6 & 7,6 & 1,4 \\
\hline MSL007xMOL2 & 1,9 & 7,0 & 6,4 & 1,0 \\
\hline MSL007xMOY5 & 2,8 & 6,5 & 6,7 & 1,1 \\
\hline MSL007xR53 & 3,2 & 7,0 & 7,6 & 1,5 \\
\hline MSL007xR99 & 2,8 & 6,5 & 7,2 & 1,4 \\
\hline MSL007xRS13/6 & 2,1 & 6,9 & 7,0 & 1,3 \\
\hline MSL007xRS4/2 & 3,0 & 7,0 & 7,3 & 1,4 \\
\hline MSL007xS108.1.1 & 3,3 & 6,1 & 7,4 & 1,6 \\
\hline MSL007xS13 & 2,7 & 7,2 & 7,0 & 1,1 \\
\hline MSL007xS228.8.1 & 2,8 & 6,5 & 7,1 & 1,4 \\
\hline MSL007xS45.2.2 & 3,0 & 7,0 & 7,4 & 1,4 \\
\hline MSL007xVIL1 & 3,5 & 6,3 & 7,4 & 1,5 \\
\hline RNX4621 XB1/3.3 & 3,2 & 6,7 & 7,4 & 1,4 \\
\hline RNX4621XBOY1 & 3,8 & 5,8 & 7,4 & 1,6 \\
\hline RNX4621xG39 & 3,7 & 6,1 & 7,6 & 1,7 \\
\hline RNX4621XG50 & 4,1 & 6,1 & 8,1 & 1,9 \\
\hline RNX4621xH149 & 3,4 & 6,1 & 7,2 & 1,5 \\
\hline RNX4621xH165 & 3,6 & 5,9 & 7,4 & 1,6 \\
\hline RNX4621xH176 & 3,9 & 5,6 & 7,6 & 1,8 \\
\hline RNX4621xH355 & 4,1 & 6,6 & 8,3 & 1,7 \\
\hline RNX4621xH44 & 2,7 & 6,8 & 7,4 & 1,5 \\
\hline RNX4621xINL1 & 4,0 & 6,0 & 7,9 & 1,8 \\
\hline RNX4621xINL2 & 3,5 & 6,5 & 7,4 & 1,5 \\
\hline RNX4621XJ112 & 3,8 & 5,8 & 7,8 & 1,9 \\
\hline
\end{tabular}

${ }^{a}$ berechnet als Sinapinsäureäquivalente, ${ }^{b} \mathrm{SE}=$ Sinapinsäureester 
Tab XV: Leistungsprüfungen der Testhybriden: NIRS-Ergebnisse für die Sinapoylverbindungen, gemittelt über vier Standorte (Fortsetzung)

\begin{tabular}{|c|c|c|c|c|}
\hline Genotyp & $\begin{array}{c}\text { Sinapoylglucose } \\
{[\mathrm{mg} / \mathrm{g}]}\end{array}$ & $\begin{array}{c}\text { Sinapin } \\
{[\mathrm{mg} / \mathrm{g}]}\end{array}$ & $\begin{array}{c}\text { Sinapinsäure } \\
\text { gesamt }[\mathrm{mg} / \mathrm{g}]^{\mathrm{a}}\end{array}$ & $\begin{array}{c}\text { andere SE }^{\mathrm{b}} \\
{[\mathrm{mg} / \mathrm{g}]^{\mathrm{a}}}\end{array}$ \\
\hline RNX4621xJ134 & 3,4 & 5,9 & 7,2 & 1,6 \\
\hline RNX4621XJ154 & 3,7 & 6,1 & 7,6 & 1,7 \\
\hline RNX4621XJ161 & 4,1 & 5,5 & 7,7 & 1,8 \\
\hline RNX4621xJ166 & 3,9 & 5,4 & 7,4 & 1,8 \\
\hline RNX4621xJ401 & 3,6 & 6,1 & 7,4 & 1,7 \\
\hline RNX4621XJ408 & 4,1 & 5,8 & 7,8 & 2,0 \\
\hline RNX4621XJ410 & 4,1 & 5,1 & 7,1 & 1,8 \\
\hline RNX4621xJ45 & 3,8 & 5,5 & 7,2 & 1,7 \\
\hline RNX4621xMOY4 & 3,6 & 5,5 & 6,9 & 1,6 \\
\hline RNX4621xOLL1 & 4,3 & 6,2 & 8,5 & 2,0 \\
\hline RNX4621xR53 & 3,5 & 6,1 & 7,4 & 1,6 \\
\hline RNX4621xR99 & 3,3 & 5,7 & 7,0 & 1,6 \\
\hline RNX4621xRS10/7 & 3,2 & 6,1 & 7,2 & 1,6 \\
\hline RNX4621xRS13/6 & 3,8 & 5,8 & 7,5 & 1,7 \\
\hline RNX4621xRS4/2 & 3,9 & 6,0 & 7,9 & 1,8 \\
\hline RNX4621xRS7/6 & 3,0 & 6,8 & 7,6 & 1,5 \\
\hline RNX4621xRS8/6 & 3,8 & 6,1 & 8,1 & 1,7 \\
\hline RNX4621XRUY1 & 3,4 & 5,9 & 7,2 & 1,7 \\
\hline RNX4621XS108.1.1 & 3,6 & 5,8 & 7,5 & 1,7 \\
\hline RNX4621xS13 & 3,6 & 6,3 & 7,3 & 1,5 \\
\hline RNX4621xS39 & 4,0 & 5,7 & 7,9 & 1,9 \\
\hline RNX4621xS45.2.2 & 3,7 & 6,2 & 7,8 & 1,8 \\
\hline MSL007 & 3,2 & 6,6 & 7,6 & 1,6 \\
\hline TesterSyngenta & 3,5 & 5,0 & 6,5 & 1,6 \\
\hline Visby & 4,4 & 5,5 & 7,9 & 2,0 \\
\hline LSD $(p=0,05)$ & 0,57 & 0,67 & 0,77 & 0,27 \\
\hline Min. & 0,6 & 0,7 & 0,8 & 0,3 \\
\hline Max. & 4,4 & 7,2 & 8,5 & 2,0 \\
\hline MW Testhybriden & 3,3 & 6,3 & 7,4 & 1,6 \\
\hline MW Standards & 3,7 & 5,7 & 7,3 & 1,7 \\
\hline
\end{tabular}

${ }^{a}$ berechnet als Sinapinsäureäquivalente, ${ }^{b}$ SE = Sinapinsäureester 
Tab. XVI: Leistungsprüfungen der Teshybriden: Ertrags-, NIRS- und Boniturdaten, gemittelt über neun Standorte

\begin{tabular}{|c|c|c|c|c|c|c|c|c|c|c|}
\hline Genotyp & $\begin{array}{l}\text { Ertrag } \\
\text { [dt/ha] }\end{array}$ & $\begin{array}{l}\text { Öl } \\
{[\%]}\end{array}$ & $\begin{array}{l}\text { C 22:1 } \\
\text { [\%] }\end{array}$ & $\begin{array}{l}\text { Protein } \\
{[\%]}\end{array}$ & $\begin{array}{l}\text { GSL } \\
{[\mu \mathrm{mol} / \mathrm{g}]}\end{array}$ & $\begin{array}{l}\text { TKG } \\
\text { [g] }\end{array}$ & $\begin{array}{l}\text { Höhe } \\
\text { [cm] }\end{array}$ & BoF & WF & Lager \\
\hline MxB1/3.3 & 40,5 & 43,8 & 11,2 & 19,2 & 50,8 & 4,4 & 175,0 & 117,0 & 3,3 & 2,0 \\
\hline MxFS94.3 & 41,7 & 42,8 & 3,1 & 18,9 & 34,2 & 4,4 & 172,5 & 118,3 & 3,1 & 2,6 \\
\hline MxG39 & 37,9 & 42,4 & 10,4 & 20,0 & 51,7 & 4,4 & 166,3 & 120,0 & 3,3 & 3,7 \\
\hline MxG50 & 41,7 & 43,8 & 1,0 & 18,5 & 37,5 & 4,3 & 163,8 & 117,8 & 2,9 & 1,9 \\
\hline MxH149 & 46,6 & 45,1 & 22,8 & 18,3 & 44,8 & 4,3 & 165,6 & 114,3 & 2,6 & 3,1 \\
\hline MxH165 & 39,2 & 44,1 & 13,8 & 19,3 & 38,5 & 4,1 & 156,3 & 118,5 & 3,6 & 2,3 \\
\hline MxH176 & 49,5 & 45,4 & 15,4 & 18,2 & 26,9 & 4,6 & 165,6 & 118,2 & 3,0 & 1,9 \\
\hline MxH44 & 44,2 & 44,5 & 22,8 & 19,7 & 33,5 & 4,7 & 157,5 & 113,0 & 2,9 & 1,9 \\
\hline MxJ154 & 35,8 & 42,3 & 15,0 & 19,8 & 49,8 & 5,1 & 154,4 & 110,3 & 3,9 & 2,3 \\
\hline MxJ161 & 33,2 & 43,6 & 17,0 & 18,8 & 36,9 & 4,1 & 145,6 & 116,7 & 4,5 & 3,6 \\
\hline MxJ401 & 41,9 & 42,7 & 12,4 & 19,1 & 31,9 & 4,9 & 162,5 & 115,0 & 3,5 & 2,4 \\
\hline MxMOL1 & 39,4 & 42,0 & 11,3 & 19,9 & 53,8 & 4,6 & 163,1 & 118,5 & 3,3 & 2,4 \\
\hline MxMOL2 & 44,9 & 40,7 & 10,4 & 21,0 & 55,9 & 5,0 & 171,3 & 120,2 & 3,0 & 1,9 \\
\hline MxR53 & 43,2 & 45,3 & 21,3 & 19,2 & 34,7 & 4,6 & 161,3 & 116,7 & 2,1 & 2,0 \\
\hline MxR99 & 42,4 & 43,7 & 7,1 & 19,1 & 30,6 & 4,3 & 166,3 & 115,7 & 2,9 & 1,7 \\
\hline MxS13 & 46,7 & 46,2 & 23,9 & 18,2 & 58,0 & 4,2 & 156,9 & 116,5 & 2,4 & 2,6 \\
\hline MxS45.2.2 & 38,5 & 43,3 & 14,7 & 19,9 & 40,6 & 4,2 & 155,0 & 113,3 & 3,9 & 2,3 \\
\hline MxVIL1 & 39,4 & 42,4 & 11,5 & 19,6 & 38,8 & 4,9 & 168,6 & 115,8 & 3,1 & 1,9 \\
\hline $\mathrm{R} \times \mathrm{B} 1 / \mathbf{3} .3$ & 39,6 & 42,5 & 10,8 & 19,4 & 50,2 & 4,6 & 173,8 & 118,0 & 3,0 & 2,1 \\
\hline RxG39 & 40,4 & 42,0 & 6,1 & 19,0 & 38,9 & 4,7 & 173,8 & 119,0 & 2,6 & 2,0 \\
\hline RxG50 & 42,1 & 43,3 & 0,9 & 18,0 & 35,5 & 4,4 & 164,4 & 118,0 & 2,3 & 2,1 \\
\hline RxH149 & 46,2 & 43,9 & 21,1 & 18,4 & 44,0 & 4,6 & 160,0 & 113,2 & 2,1 & 3,6 \\
\hline RxH165 & 38,0 & 43,1 & 12,9 & 19,3 & 34,5 & 4,1 & 156,3 & 119,5 & 3,1 & 2,4 \\
\hline RxH176 & 47,1 & 43,8 & 12,4 & 18,2 & 27,3 & 4,8 & 164,4 & 117,7 & 2,8 & 2,1 \\
\hline RxH44 & 44,3 & 44,5 & 20,2 & 19,0 & 30,1 & 4,8 & 163,1 & 113,8 & 2,9 & 2,0 \\
\hline RxINL2 & 40,7 & 41,6 & 8,6 & 19,5 & 41,8 & 4,9 & 163,1 & 115,8 & 2,3 & 2,1 \\
\hline
\end{tabular}


Tab. XVI: Leistungsprüfungen der Teshybriden: Ertrags-, NIRS- und Boniturdaten, gemittelt über neun Standorte (Fortsetzung)

\begin{tabular}{|c|c|c|c|c|c|c|c|c|c|c|}
\hline Genotyp & $\begin{array}{l}\text { Ertrag } \\
\text { [dt/ha] }\end{array}$ & $\begin{array}{l}\text { ÖL } \\
\text { [\%] }\end{array}$ & $\begin{array}{l}\text { C 22:1 } \\
{[\%]}\end{array}$ & $\begin{array}{l}\text { Protein } \\
\text { [\%] }\end{array}$ & $\begin{array}{l}\text { GSL } \\
{[\mu \mathrm{mol} / \mathrm{g}]}\end{array}$ & $\begin{array}{l}\text { TKG } \\
\text { [g] }\end{array}$ & $\begin{array}{l}\text { Höhe } \\
\text { [cm] }\end{array}$ & BoF & WF & Lageı \\
\hline RxJ134 & 41,5 & 42,6 & 10,1 & 18,6 & 30,8 & 4,8 & 154,4 & 115,0 & 3,1 & 2,9 \\
\hline RxJ161 & 40,7 & 42,6 & 10,6 & 18,3 & 28,5 & 4,3 & 152,5 & 116,2 & 2,8 & 2,9 \\
\hline RxJ401 & 41,5 & 41,7 & 10,0 & 18,9 & 32,5 & 5,3 & 165,0 & 115,7 & 2,6 & 2,6 \\
\hline RxJ408 & 39,7 & 42,2 & 17,8 & 18,8 & 42,4 & 4,3 & 153,8 & 113,5 & 4,4 & 2,7 \\
\hline RxR53 & 44,1 & 43,9 & 19,4 & 19,2 & 34,1 & 4,8 & 163,1 & 117,2 & 2,5 & 2,0 \\
\hline RxR99 & 46,6 & 43,1 & 4,7 & 18,5 & 28,8 & 4,4 & 161,9 & 116,8 & 2,3 & 2,4 \\
\hline RxRS4/2 & 45,3 & 43,0 & 10,3 & 18,9 & 30,9 & 4,4 & 171,3 & 117,2 & 3,0 & 2,4 \\
\hline RxRS7/6 & 42,2 & 43,4 & 19,6 & 19,6 & 37,5 & 4,9 & 161,3 & 112,7 & 2,5 & 2,4 \\
\hline RxRS8/6 & 44,0 & 43,0 & 8,7 & 18,9 & 31,7 & 5,0 & 163,1 & 117,2 & 2,5 & 2,1 \\
\hline RxS108.1.1 & 44,3 & 42,1 & 7,9 & 19,1 & 35,1 & 4,8 & 156,9 & 110,2 & 2,9 & 3,3 \\
\hline RxS13 & 47,9 & 44,5 & 22,4 & 17,8 & 52,4 & 4,5 & 158,1 & 117,2 & 2,4 & 3,3 \\
\hline RxS39 & 44,8 & 42,1 & 0,4 & 18,0 & 18,1 & 4,5 & 154,4 & 117,8 & 2,5 & 2,6 \\
\hline RxS45.2.2 & 37,6 & 42,2 & 7,2 & 19,4 & 32,0 & 4,4 & 161,9 & 115,2 & 2,5 & 2,3 \\
\hline MSL 007 & 37,8 & 45,2 & 1,4 & 18,3 & 17,7 & 4,5 & 148,8 & 118,2 & 2,0 & 1,7 \\
\hline Tester Syngenta & 38,7 & 42,0 & 1,7 & 18,8 & 21,8 & 4,7 & 156,9 & 124,7 & 2,6 & 2,9 \\
\hline Visby & 51,2 & 43,8 & 0,0 & 17,0 & 15,3 & 4,8 & 161,3 & 117,8 & 1,9 & 1,9 \\
\hline LSD $(p=0,05)$ & 4,9 & 0,7 & 2,4 & 0,6 & 3,1 & 0,2 & 6,9 & 1,8 & 1,0 & 0,9 \\
\hline Min. & 33,2 & 40,7 & 0,0 & 17,0 & 15,3 & 4,1 & 145,6 & 110,2 & 1,9 & 1,7 \\
\hline Max. & 51,2 & 46,2 & 23,9 & 21,0 & 58,0 & 5,3 & 175,0 & 124,7 & 4,5 & 3,7 \\
\hline MW Testhybriden & 42,2 & 43,2 & 12,5 & 19,0 & 38,1 & 4,6 & 162,1 & 116,2 & 2,9 & 2,4 \\
\hline MW Standards & 42,6 & 43,7 & 1,1 & 18,0 & 18,3 & 4,6 & 155,6 & 120,2 & 2,2 & 2,1 \\
\hline
\end{tabular}


Tab. XVII: Leistungsprüfungen der Testhybriden: NIRS-Ergebnisse für Phytosterolgehalt und -Muster, gemittelt über neun Standorte

\begin{tabular}{|c|c|c|c|c|c|c|}
\hline Genotyp & $\begin{array}{l}\text { Brassica } \\
\text {-sterol } \\
\text { [mg/kg] }\end{array}$ & $\begin{array}{l}\text { Campo } \\
\text {-sterol } \\
\text { [mg/kg] }\end{array}$ & $\begin{array}{l}\text { Stigma } \\
\text {-sterol } \\
\text { [mg/kg] }\end{array}$ & $\begin{array}{l}\text { Sito } \\
\text {-sterol } \\
\text { [mg/kg] }\end{array}$ & $\begin{array}{l}\text { Avena } \\
\text {-sterol } \\
\text { [mg/kg] }\end{array}$ & $\begin{array}{l}\text { Phytosterol } \\
\text { gesamt } \\
\text { [mg/kg] }\end{array}$ \\
\hline MxB1/3.3 & 298,3 & 1182,8 & 10,5 & 1806,6 & 68,7 & 3514,0 \\
\hline MxFS94.3 & 327,9 & 1273,0 & 10,7 & 1922,5 & 75,8 & 3764,9 \\
\hline MxG39 & 310,9 & 1178,5 & 10,7 & 1820,3 & 63,8 & 3539,8 \\
\hline MxG50 & 297,1 & 1339,7 & 10,3 & 1926,8 & 74,2 & 3791,0 \\
\hline MxH149 & 288,0 & 1126,8 & 10,2 & 1699,0 & 70,9 & 3358,4 \\
\hline MxH165 & 312,9 & 1191,5 & 10,3 & 1788,9 & 70,5 & 3526,0 \\
\hline MxH176 & 313,0 & 1201,2 & 10,2 & 1779,7 & 74,8 & 3505,0 \\
\hline MxH44 & 318,7 & 1064,2 & 10,7 & 1718,8 & 64,3 & 3315,4 \\
\hline MxJ154 & 314,4 & 1157,7 & 11,0 & 1841,6 & 65,5 & 3535,4 \\
\hline MxJ161 & 311,5 & 1126,7 & 10,7 & 1770,8 & 66,0 & 3419,5 \\
\hline MxJ401 & 332,9 & 1147,2 & 10,8 & 1783,8 & 70,3 & 3513,8 \\
\hline MxMOL1 & 283,3 & 1191,8 & 10,6 & 1830,9 & 52,9 & 3506,3 \\
\hline MxMOL2 & 318,5 & 1145,8 & 11,1 & 1853,2 & 57,2 & 3535,9 \\
\hline MxR53 & 286,4 & 1143,1 & 10,1 & 1698,6 & 59,3 & 3339,1 \\
\hline MxR99 & 313,5 & 1240,9 & 10,4 & 1849,8 & 66,7 & 3626,6 \\
\hline MxS13 & 256,3 & 1154,6 & 10,0 & 1718,1 & 69,7 & 3384,4 \\
\hline MxS45.2.2 & 332,3 & 1130,3 & 10,7 & 1767,5 & 69,6 & 3460,9 \\
\hline MxVIL1 & 306,7 & 1158,2 & 10,9 & 1813,3 & 60,6 & 3498,4 \\
\hline RxB1/3.3 & 306,5 & 1166,2 & 10,9 & 1852,0 & 66,5 & 3549,3 \\
\hline RxG39 & 321,7 & 1230,2 & 11,0 & 1919,6 & 69,8 & 3708,7 \\
\hline RxG50 & 310,3 & 1348,3 & 10,5 & 1983,3 & 78,8 & 3888,6 \\
\hline RxH149 & 300,1 & 1135,5 & 10,5 & 1748,4 & 72,5 & 3437,2 \\
\hline RxH165 & 319,2 & 1184,2 & 10,7 & 1834,9 & 62,8 & 3622,1 \\
\hline RxH176 & 322,9 & 1194,7 & 10,7 & 1847,5 & 67,5 & 3591,9 \\
\hline RxH44 & 319,5 & 1097,1 & 10,8 & 1770,0 & 63,6 & 3399,1 \\
\hline RxINL2 & 322,5 & 1173,0 & 11,1 & 1880,9 & 66,3 & 3590,3 \\
\hline RxJ134 & 335,2 & 1151,4 & 11,0 & 1839,7 & 72,0 & 3533,3 \\
\hline RxJ161 & 323,4 & 1209,4 & 10,9 & 1885,7 & 67,4 & 3661,8 \\
\hline RxJ401 & 343,0 & 1166,6 & 11,0 & 1832,2 & 71,6 & 3556,5 \\
\hline RxJ408 & 294,2 & 1157,7 & 10,8 & 1817,8 & 61,7 & 3501,4 \\
\hline RxR53 & 283,5 & 1129,0 & 10,4 & 1736,2 & 55,3 & 3366,3 \\
\hline RxR99 & 316,7 & 1264,4 & 10,7 & 1920,7 & 70,8 & 3747,4 \\
\hline RxRS4/2 & 318,0 & 1222,9 & 10,7 & 1876,9 & 67,6 & 3650,1 \\
\hline RxRS7/6 & 310,9 & 1098,0 & 10,9 & 1781,7 & 58,8 & 3403,0 \\
\hline RxRS8/6 & 305,8 & 1254,0 & 10,6 & 1890,4 & 67,2 & 3672,7 \\
\hline RxS108.1.1 & 310,3 & 1172,1 & 10,8 & 1847,3 & 62,5 & 3570,0 \\
\hline RxS13 & 273,3 & 1160,0 & 10,4 & 1765,7 & 69,1 & 3439,2 \\
\hline RxS39 & 332,5 & 1289,6 & 10,9 & 1986,0 & 74,1 & 3866,9 \\
\hline RxS45.2.2 & 327,6 & 1208,0 & 11,0 & 1904,2 & 67,0 & 3681,3 \\
\hline MSL 007 & 334,8 & 1352,5 & 10,1 & 1917,3 & 85,4 & 3868,9 \\
\hline Tester Syngenta & 326,8 & 1264,6 & 11,0 & 1949,3 & 65,4 & 3809,1 \\
\hline Visby & 359,7 & 1368,5 & 10,7 & 2051,8 & 97,7 & 4080,7 \\
\hline
\end{tabular}


Tab. XVII: Leistungsprüfungen der Testhybriden: NIRS-Ergebnisse für Phytosterolgehalt und -Muster, gemittelt über neun Standorte (Fortsetzung)

\begin{tabular}{lllllll}
\hline Genotyp & $\begin{array}{l}\text { Brassica } \\
\text {-sterol } \\
{[\mathbf{m g} / \mathbf{k g}]}\end{array}$ & $\begin{array}{l}\text { Campo } \\
\text {-sterol } \\
{[\mathbf{m g} / \mathbf{k g}]}\end{array}$ & $\begin{array}{l}\text { Stigma } \\
\text {-sterol } \\
{[\mathbf{m g} / \mathbf{k g}]}\end{array}$ & $\begin{array}{l}\text { Sito } \\
\text {-sterol } \\
{[\mathbf{m g} / \mathbf{k g}]}\end{array}$ & $\begin{array}{l}\text { Avena } \\
\text {-sterol } \\
{[\mathbf{m g} / \mathbf{k g}]}\end{array}$ & $\begin{array}{l}\text { Phytosterol } \\
\mathbf{g e s a m t} \\
{[\mathbf{m g} / \mathbf{k g}]}\end{array}$ \\
\hline LSD (p=0,05) & 12,3 & 37,7 & 0,2 & 34,1 & 5,8 & 75,7 \\
Min. & 256,3 & 1064,2 & 10,0 & 1698,6 & 52,9 & 3315,4 \\
Max. & 359,7 & 1368,5 & 11,1 & 2051,8 & 97,7 & 4080,7 \\
MW Testhybriden & 310,8 & 1183,7 & 10,7 & 1828,5 & 67,0 & 3553,1 \\
MW Standards & 340,4 & 1328,5 & 10,6 & 1972,8 & 82,8 & 3919,6 \\
\hline
\end{tabular}

Tab. XVIII: Leistungsprüfungen der Testhybriden: NIRS-Ergebnisse für die Sinapoylverbindungen, gemittelt über neun Standorte

\begin{tabular}{|c|c|c|c|c|}
\hline Genotyp & $\begin{array}{c}\text { Sinapoylglucose } \\
{[\mathrm{mg} / \mathrm{g}]}\end{array}$ & $\begin{array}{c}\text { Sinapin } \\
{[\mathrm{mg} / \mathrm{g}]}\end{array}$ & $\begin{array}{c}\text { Sinapinsäure } \\
{\text { gesamt }[\mathrm{mg} / \mathrm{g}]^{\mathrm{a}}}^{\text {a }}\end{array}$ & $\begin{array}{c}\text { andere SE }^{\mathrm{b}} \\
{\left[^{\mathrm{mg} / \mathrm{g}]^{\mathrm{a}}}\right.}\end{array}$ \\
\hline $\mathrm{MxB1/3.3}$ & 2,4 & 7,5 & 7,4 & 1,2 \\
\hline MxFS94.3 & 3,3 & 6,5 & 7,9 & 1,7 \\
\hline MxG39 & 3,2 & 7,0 & 8,0 & 1,7 \\
\hline MxG50 & 3,4 & 6,8 & 8,1 & 1,8 \\
\hline MxH149 & 2,6 & 6,7 & 6,9 & 1,3 \\
\hline MxH165 & 3,0 & 7,1 & 7,7 & 1,5 \\
\hline MxH176 & 3,0 & 6,7 & 7,7 & 1,6 \\
\hline MxH44 & 2,3 & 7,4 & 7,3 & 1,3 \\
\hline MxJ154 & 2,9 & 7,1 & 7,5 & 1,3 \\
\hline MxJ161 & 3,2 & 6,4 & 7,5 & 1,6 \\
\hline MxJ401 & 3,1 & 6,4 & 7,3 & 1,6 \\
\hline MxMOL1 & 3,3 & 6,9 & 7,8 & 1,5 \\
\hline MxMOL2 & 2,2 & 7,3 & 6,8 & 1,0 \\
\hline MxR53 & 3,1 & 7,0 & 7,7 & 1,5 \\
\hline MxR99 & 2,8 & 6,6 & 7,3 & 1,5 \\
\hline MxS13 & 2,6 & 7,3 & 7,2 & 1,2 \\
\hline MxS45.2.2 & 2,8 & 7,6 & 7,8 & 1,4 \\
\hline MxVIL1 & 3,2 & 6,5 & 7,5 & 1,6 \\
\hline RxB1/3.3 & 3,3 & 6,9 & 7,8 & 1,5 \\
\hline RxG39 & 3,8 & 6,2 & 7,9 & 1,8 \\
\hline RxG50 & 4,1 & 6,3 & 8,3 & 1,9 \\
\hline RxH149 & 3,1 & 6,2 & 7,1 & 1,5 \\
\hline RxH165 & 3,5 & 6,3 & 7,8 & 1,6 \\
\hline RxH176 & 3,8 & 5,8 & 7,6 & 1,8 \\
\hline RxH44 & 3,1 & 6,8 & 7,7 & 1,6 \\
\hline RxINL2 & 3,6 & 6,7 & 7,9 & 1,7 \\
\hline RxJ134 & 3,4 & 6,1 & 7,5 & 1,7 \\
\hline RxJ161 & 4,1 & 5,8 & 7,8 & 1,8 \\
\hline RxJ401 & 3,5 & 6,2 & 7,5 & 1,7 \\
\hline
\end{tabular}

\footnotetext{
${ }^{a}$ berechnet als Sinapinsäureäquivalente, ${ }^{b}$ SE = Sinapinsäureester
} 
Tab. XVIII: Leistungsprüfungen der Testhybriden: NIRS-Ergebnisse für die Sinapoylverbindungen, gemittelt über neun Standorte (Fortsetzung)

\begin{tabular}{|c|c|c|c|c|}
\hline Genotyp & $\begin{array}{c}\text { Sinapoylglucose } \\
{[\mathrm{mg} / \mathrm{g}]}\end{array}$ & $\begin{array}{c}\text { Sinapin } \\
{[\mathrm{mg} / \mathrm{g}]}\end{array}$ & $\begin{array}{c}\text { Sinapinsäure } \\
\text { gesamt }[\mathrm{mg} / \mathrm{g}]^{\mathrm{a}}\end{array}$ & $\begin{array}{c}\text { andere SE } \\
{[\mathrm{mg} / \mathrm{g}]^{\mathrm{a}}}\end{array}$ \\
\hline RxJ408 & 4,0 & 6,0 & 7,9 & 1,9 \\
\hline RxR53 & 3,6 & 6,3 & 7,7 & 1,6 \\
\hline RxR99 & 3,3 & 5,9 & 7,3 & 1,7 \\
\hline RxRS4/2 & 3,7 & 6,3 & 7,8 & 1,7 \\
\hline RxRS7/6 & 3,0 & 6,9 & 7,6 & 1,4 \\
\hline RxRS8/6 & 3,8 & 6,3 & 8,2 & 1,8 \\
\hline RxS108.1.1 & 3,7 & 6,1 & 7,7 & 1,7 \\
\hline RxS13 & 3,5 & 6,4 & 7,4 & 1,5 \\
\hline RxS39 & 4,1 & 6,0 & 8,2 & 2,0 \\
\hline RxS45.2.2 & 3,7 & 6,4 & 7,9 & 1,8 \\
\hline TesterNPZ & 3,2 & 6,9 & 7,9 & 1,7 \\
\hline TesterSyngenta & 3,7 & 5,3 & 7,3 & 1,8 \\
\hline Visby & 4,1 & 6,0 & 8,1 & 2,0 \\
\hline $\operatorname{LSD}(p=0,05)$ & 0,4 & 0,4 & 0,4 & 0,1 \\
\hline Min. & 2,2 & 5,3 & 6,8 & 1,0 \\
\hline Max. & 4,1 & 7,6 & 8,3 & 2,0 \\
\hline MW Testhybriden & 3,3 & 6,6 & 7,6 & 1,6 \\
\hline MW Standards & 3,6 & 6,0 & 7,7 & 1,8 \\
\hline
\end{tabular}

${ }^{a}$ berechnet als Sinapinsäureäquivalente, ${ }^{b}$ SE = Sinapinsäureester 
Tab. XIX: Ergebnisse der ANOVA für die 9-ortigen Leistungsprüfungen der Testhybriden, gezeigt sind die Varianzkomponenten und die Heritabilität der einzelnen Merkmale

\begin{tabular}{|c|c|c|c|c|c|}
\hline & Varianzursache $^{a}$ & Genotyp & Ort & GxO & $h^{2}$ \\
\hline & Kornertrag & $11,12^{* *}$ & $37,89^{\star \star}$ & 28,09 & 0,78 \\
\hline & TKG & $0,08^{* *}$ & $0,16^{* *}$ & 0,04 & 0,94 \\
\hline & Wuchshöhe & $39,45^{\star *}$ & $106,97^{* *}$ & 49,24 & 0,87 \\
\hline & Blühbeginn & $6,75^{\star *}$ & $59,62^{* *}$ & 2,56 & 0,94 \\
\hline & Winterfestigkeit & $0,21^{* *}$ & $1,51^{\star *}$ & 1,06 & 0,62 \\
\hline & Lager & $0,17^{* *}$ & $0,29^{* *}$ & 0,74 & 0,62 \\
\hline & ÖL & $1,35^{\star *}$ & $2,37^{\star *}$ & 0,62 & 0,95 \\
\hline & C 18:3 & $0,14^{\star *}$ & $0,45^{\star \star}$ & 0,14 & 0,90 \\
\hline & C 22:1 & $46,21^{\star *}$ & $9,46^{\star \star}$ & 6,68 & 0,98 \\
\hline & Protein & $0,47^{\star *}$ & $0,83^{\star *}$ & 0,42 & 0,91 \\
\hline & Glucosinolate & $104,01^{* *}$ & $3,74^{\star *}$ & 11,45 & 0,99 \\
\hline \multirow{6}{*}{$\begin{array}{l}\frac{0}{0} \\
\frac{0}{d} \\
\frac{5}{0} \\
\stackrel{0}{Z} \\
\frac{1}{\alpha}\end{array}$} & Brassicasterol & $356,28^{\star \star}$ & $601,03^{* *}$ & 156,03 & 0,95 \\
\hline & Camposterol & $4915,04^{* *}$ & $2994,01^{* *}$ & 1468,32 & 0,96 \\
\hline & Stigmasterol & $0,08^{\star *}$ & $0,12^{* *}$ & 0,04 & 0,94 \\
\hline & Sitosterol & $6408,44^{\star \star}$ & $199,54^{\star \star}$ & 1198,86 & 0,98 \\
\hline & Avenasterol & $55,69^{\star *}$ & $40,26^{\star *}$ & 34,87 & 0,93 \\
\hline & Phytosterole gesamt & $27853,73^{\star \star}$ & $2887,39^{\star \star}$ & 5920,97 & 0,97 \\
\hline \multirow{4}{*}{$\begin{array}{l}\frac{0}{2} \\
\frac{0}{\pi} \\
\frac{5}{\infty}\end{array}$} & Sinapoylglucose & $0,23^{* *}$ & $0,08^{* \star}$ & 0,12 & 0,94 \\
\hline & Sinapin & $0,25^{\star *}$ & $0,16^{\star *}$ & 0,14 & 0,94 \\
\hline & andere Sinapinsäureester & $0,04^{* *}$ & $0,02^{* *}$ & 0,02 & 0,94 \\
\hline & Sinapinsäure gesamt & $0,09^{\star *}$ & $0,33^{\star *}$ & 0,19 & 0,80 \\
\hline
\end{tabular}

${ }^{a} \mathrm{GxO}=$ Interaktion zwischen Genotyp und Ort, $\mathrm{h}^{2}=$ Heritabilität; ** signifikant bei $\mathrm{p}=0,01$ 


\section{Danksagung}

Mein herzlicher Dank gilt Herrn Prof. Dr. Heiko Becker für die freundliche Überlassung des Themas sowie für die stets gute Betreuung und die kritische und schnelle Durchsicht meiner Manuskripte.

Herrn PD Dr. Rod Snowdon danke ich für die Übernahme des Koreferats.

Ganz besonders möchte ich mich bei Birgit Olberg für die gute Zusammenarbeit und die großartige Unterstützung bedanken. Ohne sie hätte dieses Projekt so nicht durchgeführt werden können.

Bedanken möchte ich mich auch bei Gunda Asselmeyer, Uwe Ammermann, Andreas Henn und all den Anderen die mich auf dem Feld, im Labor und im Gewächshaus so tatkräftig unterstützt haben.

Weiterhin bedanke ich mich für die hervorragende Zusammenarbeit und die Unterstützung bei allen Beteiligten der Saatzuchtunternehmen Deutsche Saatveredelung AG (Thüle), KWS Saat AG (Einbeck), Limagrain GmbH (Rosenthal), NPZ-Lembke KG (Hohenlieth) und Syngenta Seeds GmbH (Bad Salzuflen) sowie bei der GFP für die Koordination und beim BMELV für die Finanzierung des Projektes.

Bei meiner Schwester Alexandra, ihrem Mann Timo und meinem guten Freund Thorsten möchte ich mich ganz herzlich für das Korrekturlesen dieses umfangreichen Werkes bedanken.

Meinen lieben Freunden und Kollegen, die ich an dieser Stelle leider nicht alle namentlich aufzählen kann, gebührt ein besonders herzlicher Dank für fröhliche gemeinsame Stunden, interessante Ausflüge und Exkursionen und ihre Unterstützung in vielerlei Hinsicht.

Mein größter Dank gilt schließlich meiner Familie. 


\section{Lebenslauf}

\section{Persönliche Daten}

Name Tobias Jesske

Geburtstag 12. April. 1979

Geburtsort Wolfenbüttel

\section{Beruflicher Werdegang}

2008 - 2011 wissenschaftlicher Mitarbeiter / Doktorand am Department für Nutzpflanzenwissenschaften (DPNW) - Abt. Pflanzenzüchtung der Georg-August-Universität Göttingen

Studium

2008 - $2011 \quad$ Promotionsstudiengang Agrarwissenschaften an der Georg-August-Universität Göttingen

2006

Diplom im Studiengang Biologie

Thema der Diplomarbeit:

„Untersuchungen zur Ökologie und zur genetischen

Variabilität von Eryngium campestre“

1999 - $2006 \quad$ Studium der Biologie an der Technischen Universität

Carolo-Wilhelmina zu Braunschweig

Zivildienst

1998-1999 Amt für Jugendarbeit der ev.-luth. Landeskirche in Braunschweig

\section{Schulbildung}

1995 - $1998 \quad$ Lessinggymnasium Braunschweig

Abschluss: Abitur

1991 - $1995 \quad$ Leibniz-Realschule Wolfenbüttel

1989 - $1991 \quad$ Orientierungsstufe Cranachstraße/Wolfenbüttel

1985 - 1989 Grundschule Groß Denkte 